\title{
A Life Cycle Assessment of Medium Density Houses in New Zealand
}

\author{
By
}

\section{Sanjeev Ganda}

A thesis submitted to the Victoria University of Wellington in fulfilment of the requirements for the degree of Masters of Building Science

Victoria University of Wellington 



\section{Acknowledgements}

Throughout the writing of this dissertation, I have received a great deal of support and assistance.

Firstly, I would like to express my deep gratitude to my research supervisor, Dr Michael Donn, for your patient guidance, enthusiastic encouragement and useful critiques of this dissertation.

Thank you to Dr Dave Dowdell and Brian Berg for your guidance and input before and during this research.

I would like to acknowledge that this work would not be possible without financial assistance from the Building Research Levy and Victoria University of Wellington.

Thank you to Daniel Chegwidden, Linda Lee, Junia Mavo and Sandi Sirikhanchai for your valuable discussions and feedback.

Thank you to Priyanka Bisht, for your encouragement and unwavering support.

A special thank you to my mother, Prabha, and my sisters Pravina and Bhavika, your unconditional support throughout this research has been tremendous and will always be appreciated.

And to my father, Bharat, thank you. 
A Life Cycle Assessment of Medium Density Houses in New Zealand 


\begin{abstract}
This study develops an analysis method that designers can use to undertake a Life Cycle Assessment (LCA) on multiple building designs to inform design decisions and trials this on Medium Density Housing (MDH).

Measuring the environmental impact of a building is a time and resource-intensive process requiring multiple analysis tools, numerous inputs and quality assurance steps. Together with a lack of knowledge from designers, this makes it an unattractive task. Therefore, a method was needed to remove these barriers so that an LCA could be integrated into a designer's workflow to inform design decisions. To simulate issues designers would face in the early design stages when undertaking an LCA, an LCA was performed on three MDH houses using selected designers' Building Information Modelling (BIM) models in a warm and cool climate (Auckland and Christchurch). The LCA impact of changes to the insulation levels above the New Zealand Building Code minimum was examined to test the utility of the process.

Unique in the literature, this study includes multiple LCA indices: material impacts, resultant operational energy use, change in materials, multiple environmental indicators, the rationale behind the selected buildings, quality assurance of the results, presentation of model inputs and all results in sufficient detail for the methodology to be tested and replicated.

The case study research methodology developed three MDH houses that were representative of a broad range of MDH houses currently for sale in New Zealand. The goal was to evaluate whether the research method can identify differences between buildings that might inform design choices.

In theory, a single BIM model eliminates the need to have three building models: the designer's construction model; the LCA analysis model; and the energy performance model saving time and complexity for the designer. This methodology identified that it was not possible to have a single BIM model in Revit and use this for both an energy simulation and LCA using LCAQuick. Each house was recreated in OpenStudio for simulation in EnergyPlus to generate the energy performance of each house.
\end{abstract}


A database of inputs for the energy models was created, which was quality assured for use by designers. A visual assessment diagram was created to allow designers to interpret the output to help inform design decisions.

The case study analysis determined that the design of the houses had a more significant effect on reducing environmental impact compared to increasing insulation levels above the minimum required by the building code. Changes to the buildings' insulation levels resulted in an average change in environmental impact across the seven environmental indicators ranging from -1 to $7 \%$ in Auckland and -2 to $2 \%$ in Christchurch, whereas differences in the design resulted in a change in environmental impact of 21 to $22 \%$ in Auckland and 22 to $23 \%$ in Christchurch.

The research has demonstrated that LCA can be integrated into a designer's workflow. Designers can assess the environmental impact of multiple houses and construction changes in different climates and with multiple construction changes to each. However, the process requires further refinement. There is still a need to develop the Computer-Aided Design (CAD) modelling methods and their integration with the analytical tools. 
Abstract 
A Life Cycle Assessment of Medium Density Houses in New Zealand 


\section{Contents}

\section{Chapter 1 Introduction}

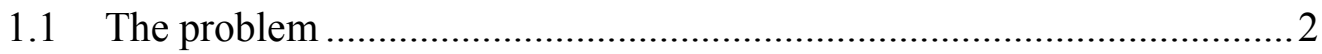

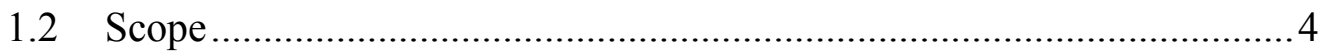

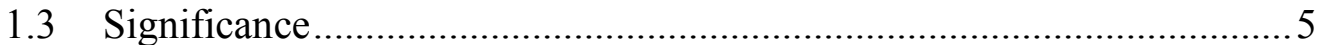

1.4 Life Cycle Assessment - What is it? ..............................................

1.5 Medium Density Housing - A definition.............................................. 10

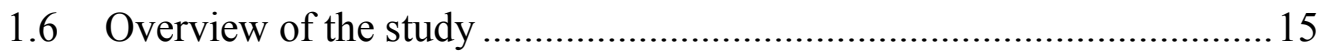

\section{Chapter 2 Literature Review ..........................17}

2.1 The systematic literature review question........................................ 18

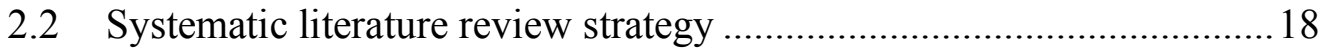

2.3 Quality assessment of relevant literature ..........................................27

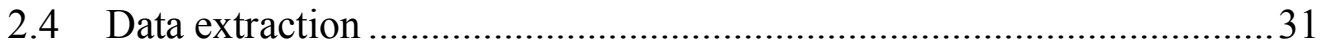

2.5 Review of this studies research question ........................................ 40

\section{Chapter 3 Medium Density Housing .................43}

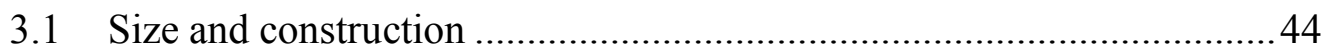

3.2 Thermal performance of Medium Density Housing ............................ 45

3.3 Medium Density Housing internal layout ......................................... 49

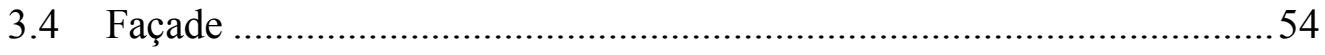

3.5 Medium Density Houses selected for inclusion ....................................66

\section{Chapter 4 Modelling Methodology .....................71}

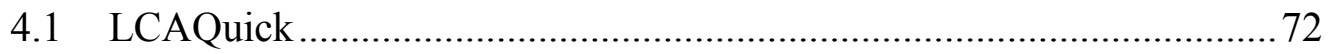


4.2 What software is appropriate for energy modelling?......................... 74

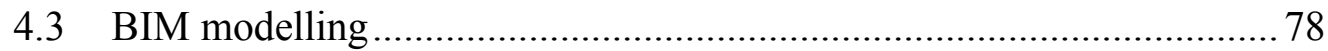

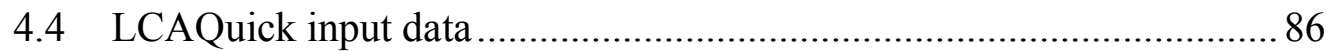

4.5 Energy modelling quality assurance measures ................................. 87

4.6 Comparison to reference buildings ................................................... 106

4.7 Heating energy breakdown between units ....................................... 110

4.8 Energy use operation - quality assurance....................................... 112

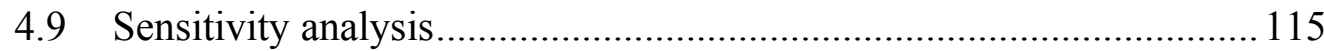

4.10 Quality assurance process summary ......................................... 119

\section{Chapter 5 Findings ....................................... 121}

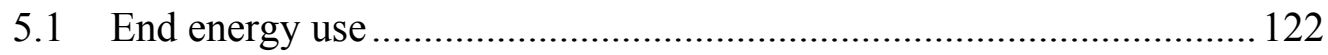

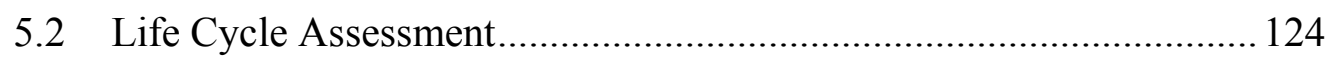

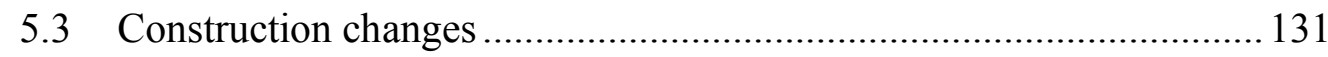

5.4 Comparison between Gross Floor Area and absolute results .............. 143

5.5 Another climate - Christchurch........................................................ 146

5.6 Green Star innovation challenge …................................................... 158

5.7 Summary of results .......................................................................... 160

\section{Chapter 6 Discussion and Conclusions ............ 163}

6.1 Building Information Modelling process............................................ 164

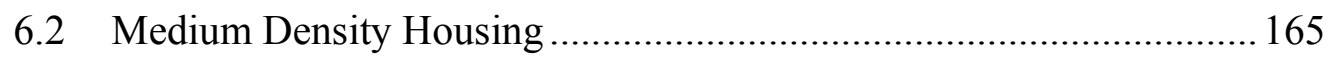

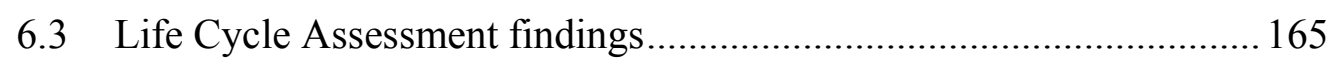

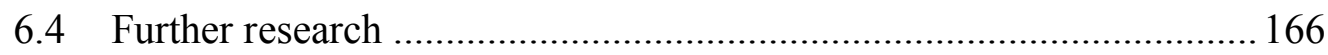

Reference List................................................ 169 
A.1 Quality assessment questions A-1

Appendix B House Drawings

B.1 House H.................................................................................

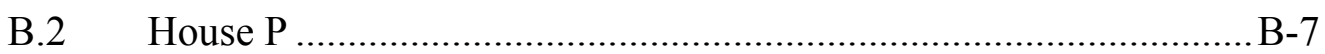

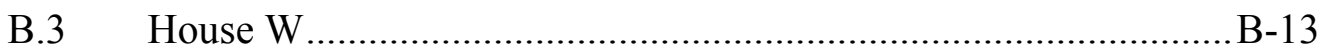

Appendix C Energy model conventions ............ C-1

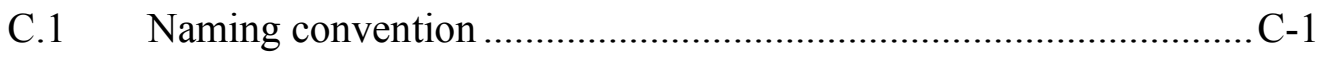

Appendix D BIM Model Inputs........................ D-1

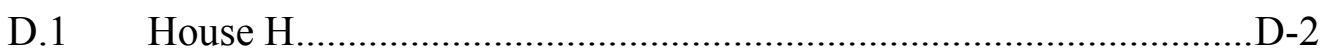

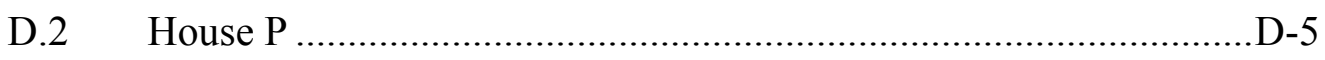

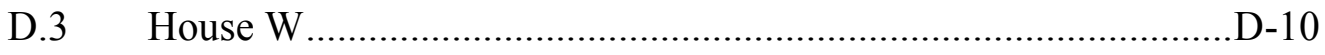

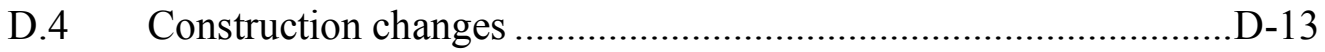


A Life Cycle Assessment of Medium Density Houses in New Zealand 


\section{List of Figures}

Figure 1 BRANZ MDH categories (Bryson \& Allen, 2017) ................................... 11

Figure 2 All dwellings national consents actual and forecast (MBIE, 2017) ............ 12

Figure 3 MDH regional consents actual and forecast (Page, 2017) ........................ 13

Figure 4 All dwellings Auckland consents actual and forecast (Page, 2017)............ 13

Figure 5 MDH national consents actual and forecast (Page, 2017) ......................... 15

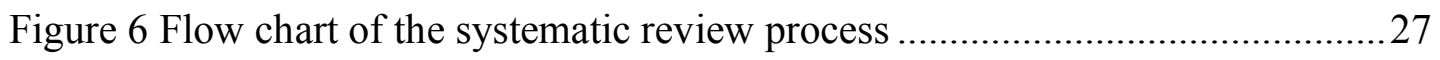

Figure 7 Quality assessment of included literature ….............................................30

Figure 8 Average percentage of residential constructions (Brunsdon \& Morgan, 2018)

Figure 9 Heat loss to adjoining units and exterior .................................................46

Figure 10 Type-A house - floor plan (Donn et al., 2015)...................................... 47

Figure 11 Type-A house - energy model (Donn et al., 2015) .................................4 47

Figure 12 Type B house - floor plan (Donn et al., 2015) ....................................... 48

Figure 13 Type B house - energy model (Donn et al., 2015) ..................................48

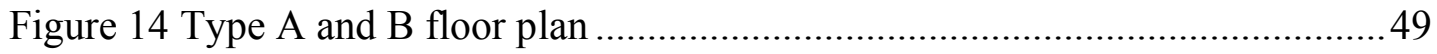

Figure 15 Estimated conditioned floor area for the $20 \mathrm{MDH}$ units surveyed............51

Figure 16 Zone layouts for the twenty units - not to scale .....................................52

Figure 17 Example of a randomly selected units' façade ........................................54

Figure 18 Percentage of façade area - all units.....................................................55

Figure 19 Average façade area of for a two-storey unit .........................................56

Figure 20 Average façade area of for a three-storey unit........................................57

Figure 21 Selected units living zones - not to scale ….........................................58

Figure 22 Average façade area of a two-storey unit - revised...................................60

Figure 23 Average façade area of a three-storey unit - revised ................................61

Figure 24 Selected units zones - not to scale-revised .............................................62

Figure 25 Percentage of façade area - all units - revised........................................64

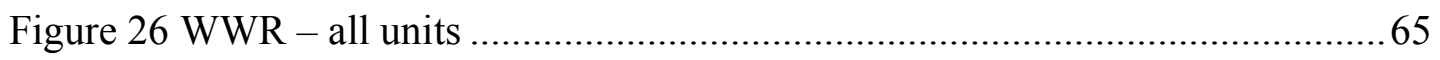

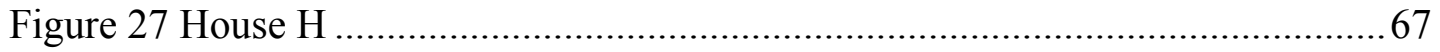

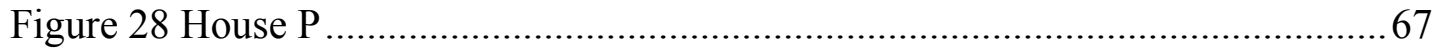

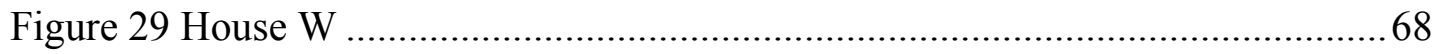


Figure 30 Example of selected Revit element and LOD .......................................73

Figure 31 Example SoQ output from Revit ............................................................ 73

Figure 32 Alignment of geometry centres in Revit for GBS .................................. 76

Figure 33 Example of complex geometry in Revit for GBS ................................. 77

Figure 34 Average percentage of timber in the external envelope (as a percentage of

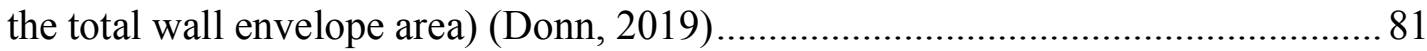

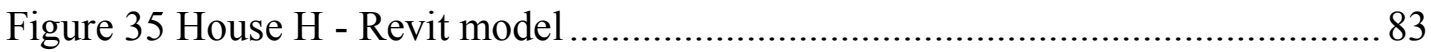

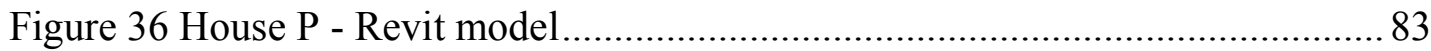

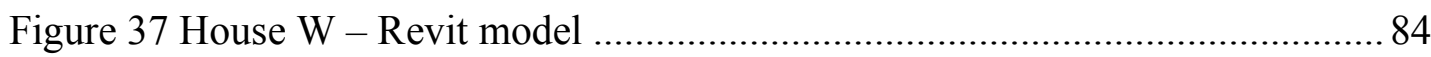

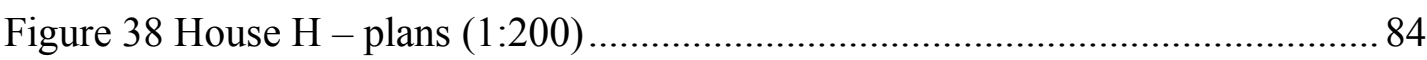

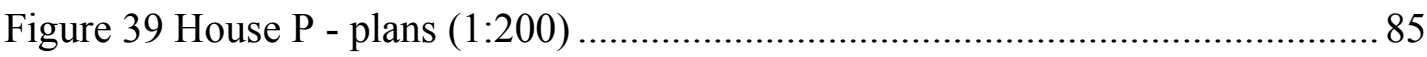

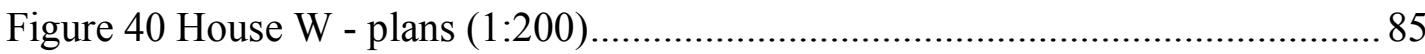

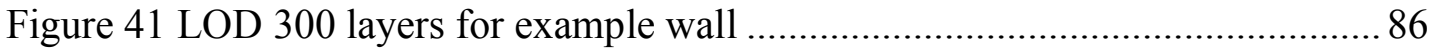

Figure 42 LOD 300 layers for example floor ......................................................... 86

Figure 43 LCAQuick input data interface (BRANZ, 2019a) ................................. 87

Figure 44 House $\mathrm{H}$ - energy model geometry - Openstudio .................................... 89

Figure 45 House P - energy model geometry - Openstudio .................................... 89

Figure 46 House W - energy model geometry - Openstudio ...................................8 89

Figure 47 Selected thermal zone and window for window opening quality assurance 102

Figure 48 Indoor and outdoor environmental conditions for the selected zone....... 103

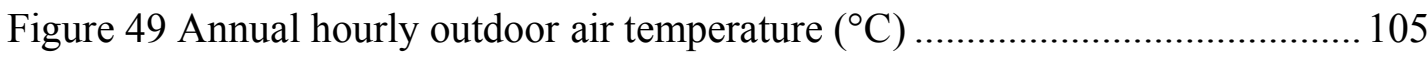

Figure 50 Annual hourly indoor air temperature (passive) $\left({ }^{\circ} \mathrm{C}\right)$.............................. 105

Figure 51 Now Home floor plan (Pathway, 2008) ............................................... 107

Figure 52 Annual hourly cooling energy (J) for the living area of House H........... 112

Figure 53 Annual hourly heating energy (J) for the living area of House H ........... 113

Figure 54 Annual hourly indoor air temperature $\left({ }^{\circ} \mathrm{C}\right)$ for the living area of House $\mathrm{H}$

Figure 55 Annual hourly outdoor air temperature $\left({ }^{\circ} \mathrm{C}\right)$ for the living area of House $\mathrm{H}$

Figure 56 Annual hourly window opening factor (\%) for the selected zone ........... 115

Figure 57 Diagram of modelled and estimated units in a block of eight ................. 124 
Figure 58 Percentage of environmental impact per environmental indicator for each house 126

Figure 59 Percentage of environmental impact per environmental indicator for each house - top five materials 128

Figure 60 Breakdown of life cycle stages environmental impact for Global Warming (100 years) of Building Code minimum buildings 130

Figure 61 Annual heating and cooling energy use for all houses and changes Auckland

Figure 62 Difference in heating/cooling energy use from Building Code minimum Auckland .....

Figure 63 Environmental impact for each environmental indicator - Auckland..... 140 Figure 64 Environmental impact for each environmental indicator - Auckland Raw (Absolute values) 144

Figure 65 Annual heating energy use for all houses and changes - Auckland and Christchurch

Figure 66 Annual cooling and fan energy use for all houses and changes - Auckland and Christchurch 148

Figure 67 Environmental impact for each environmental indicator - Auckland..... 152

Figure 68 Environmental impact for each environmental indicator - Christchurch 154

Figure B-1 House $\mathrm{H}$ first floor plan 1:100

Figure B-2 House H second floor plan 1:100 B-2

Figure B-3 House H north elevation 1:100 B-3

Figure B-4 House H south elevation 1:100 B-4

Figure B-5 House H short section 1:100. B-5

Figure B-6 House $\mathrm{H}$ long section 1:100 B-6

Figure B-7 House P ground floor plan 1:100. B-7

Figure B-8 House P first floor plan 1:100. B-8

Figure B-9 House P north elevation 1:100.. B-9

Figure B-10 House P south elevation 1:100 B-10

Figure B-11 House P short section 1:100 B-11

Figure B-12 House P long section 1:100 B-12 
Figure B-13 House W ground floor plan 1:100 ….......................................... B-13

Figure B-14 House W first floor plan 1:100 ................................................... B-14

Figure B-15 House W north elevation 1:100 ................................................... B-15

Figure B-16 House W south elevation 1:100 ............................................... B-16

Figure B-17 House W short section 1:100 .................................................. B-17

Figure B-18 House W long section 1:100 .................................................... B-18 


\section{List of Tables}

Table 1 Life cycle stages of a building (Dowdell, 2014) ..........................................6

Table 2 WBWL environmental indicators (Dowdell, 2014) .................................... 8

Table 3 Who, what, how and where keywords ...................................................... 19

Table 4 Summary of literature databases ............................................................220

Table 5 Revised who, what, how and where keywords .........................................2 21

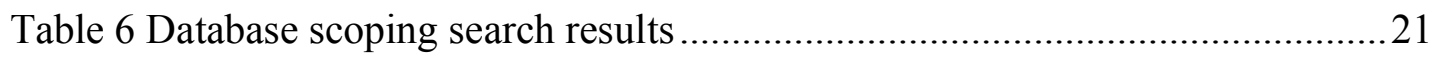

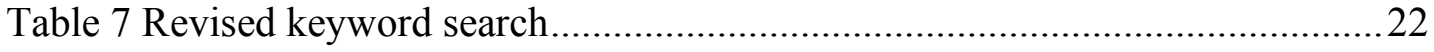

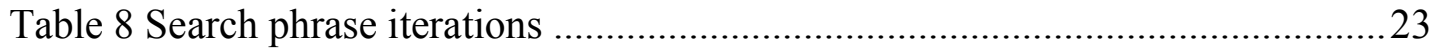

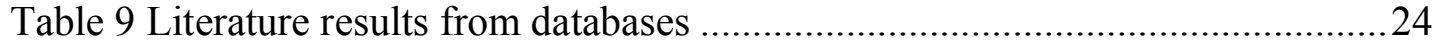

Table 10 Inclusion and exclusion keywords .......................................................2 24

Table 11 Final who, what, how and where keywords ...........................................25

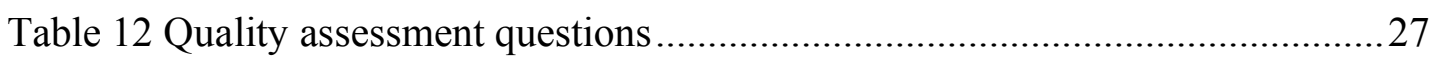

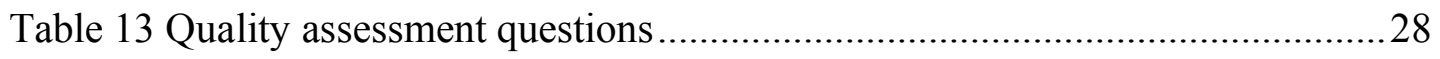

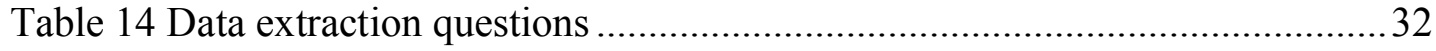

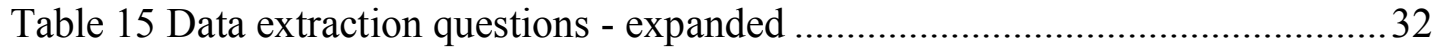

Table 16 Insulation materials examined in the 20 studies identified in the systematic literature review process

Table 17 Average floor area of consented dwellings - 2008 - 2017 (Statistics NZ,

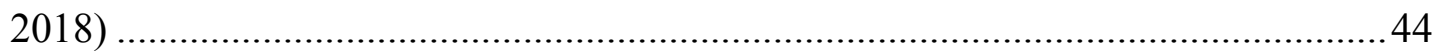

Table 18 List of Medium Density Housing characteristics.....................................65

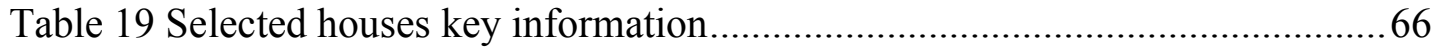

Table 20 LCAQuick environmental indicators (BRANZ, 2019a) ............................72

Table 21 Pros and cons of energy simulation software...........................................78

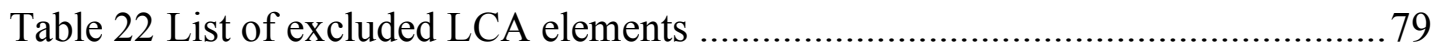

Table 23 BIM Modelling specifications provided $(\mathrm{Y}=$ specified, $\mathrm{N}=$ Not specified)

Table 24 Factors that affect timber-insulation ratios in walls................................. 82

Table 25 Estimated percentage of timber in building elements ............................... 82

Table 26 Energy modelling material inputs (Standards New Zealand, 2006) ...........91

Table 27 Energy modelling no mass material inputs ..............................................92 
Table 28 Energy modelling air gap material inputs .............................................. 92

Table 29 Energy modelling window material inputs .............................................. 92

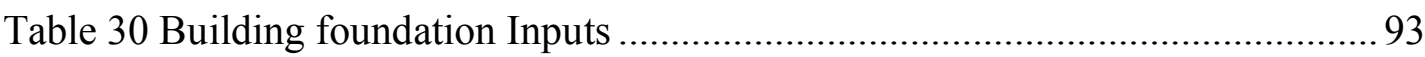

Table 31 Internal load schedule - the percentage of maximum power density (Burgess,

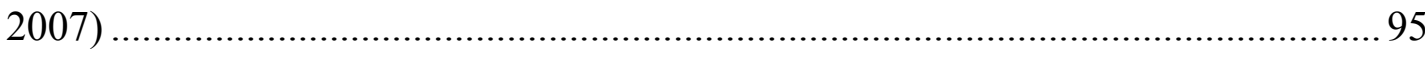

Table 32 Calculation of Effective Leakage Area for each house ............................98

Table 33 Proportion of households heating bedrooms (White \& Jones, 2017) .........99

Table 34 Energy difference for different timesteps ............................................. 101

Table 35 Quality assurance of selected thermal zone and window ........................ 102

Table 36 Percentage breakdown of annual end energy use between reference homes

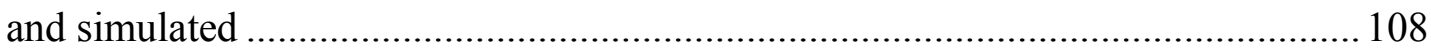

Table 37 Percentage breakdown of annual end energy use between reference homes

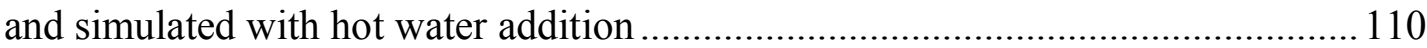

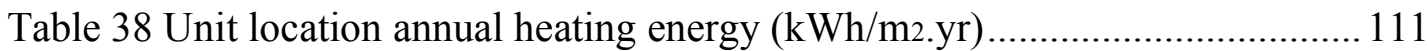

Table 39 Unit location annual cooling energy $(\mathrm{kWh} / \mathrm{m} 2 . y r)$................................. 111

Table 40 Input variables for sensitivity analysis (Westphal \& Lamberts, 2005)..... 115

Table 41 House $\mathrm{H}$ annual breakdown of end energy use for each sensitivity analysis

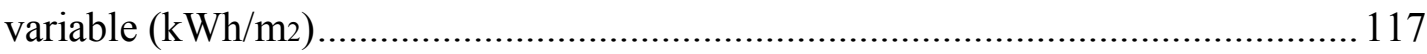

Table 42 House $\mathrm{P}$ annual breakdown of end energy use for each sensitivity analysis variable $(\mathrm{kWh} / \mathrm{m} 2)$

Table 43 House W annual breakdown of end energy use for each sensitivity analysis

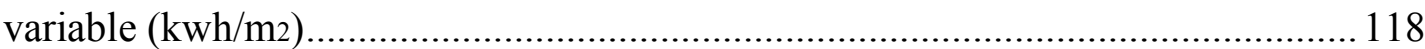

Table 44 Percentage breakdown of annual end energy use between houses ........... 122

Table 45 Average annual heating/cooling energy (kWh/m2.yr) - Auckland ........... 123

Table 46 Unit location annual heating/cooling energy (kWh/m2.yr) - Auckland .... 123

Table 47 Environmental impacts per $\mathrm{m} 2$ of GFA per house per environmental indicator

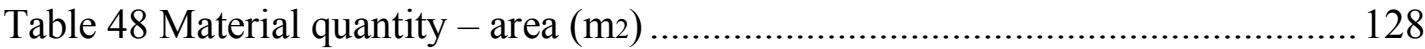

Table 49 Material quantity - volume (m3) ......................................................... 129

Table 50 Construction changes to the thermal envelope ....................................... 132

Table 51 Construction changes to windows ……................................................. 133 
Table 52 Environmental impact of construction changes for each environmental indicator and house per m2 of GFA - Auckland (Percentage increase/decrease in comparison to Building Code minimum)

Table 53 Average difference of all seven environmental indicators from Building Code minimum - Auckland.

Table 54 Average difference of all seven environmental indicators from House $\mathrm{H}$ Auckland

Table 55 Comparison of per $\mathrm{m} 2$ of GFA and absolute analysis....

Table 56 Percentage breakdown of annual end energy use between houses - Auckland and Christchurch

Table 57 Difference in heating/cooling energy use from Building Code minimum All climates 148

Table 58 Difference in heating/cooling energy use from House H - All climates .. 149 Table 59 Average difference of all seven environmental indicators from Building Code minimum - All climates 150

Table 60 Average difference of all seven environmental indicators from House $\mathrm{H}-$ All climates

Table 61 Environmental impact of construction changes for each environmental indicator and house per $\mathrm{m}_{2}$ of GFA - Christchurch (Percentage increase/decrease in comparison to Building Code minimum) 156

Table 62 Point awarded using NZGBC compared to Building Code minimum Auckland (points awarded (cumulative reduction \% - a negative percentage shows an environmental increase)).

Table 63 Point awarded using NZGBC compared to Building Code minimum Christchurch (points awarded (cumulative reduction \% - a negative percentage shows an environmental increase)) 159

Table 64 Point awarded using NZGBC compared to House $\mathrm{H}$ - Auckland.

Table 65 Point awarded using NZGBC compared to House $\mathrm{H}-$ Christchurch.

Table A-1 Quality assessment questions answer criteria A-1

Table A-2 Quality assessment questions answers....

Table C-1 Thermal zone naming convention. C-1 


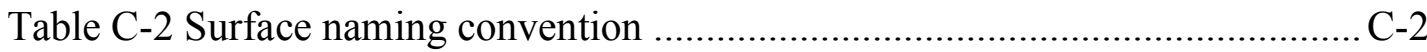

Table D-1 Standard BIM modelling inputs for all houses .................................... D-1

Table D-2 House H unique BIM modelling inputs.............................................. D-2

Table D-3 House P unique BIM modelling inputs ............................................. D-5

Table D-4 House W unique BIM modelling inputs .......................................... D-10

Table D-5 Construction changes BIM modelling inputs - ceiling ........................D-13

Table D-6 Construction changes BIM modelling inputs - wall ...........................D-13 


\section{List of Acronyms and Abbreviations}

\begin{tabular}{|c|c|}
\hline $\begin{array}{l}\text { Acronym/ } \\
\text { Abbreviation }\end{array}$ & Expanded \\
\hline $\mathrm{ACH}$ & Air Change per Hour \\
\hline $\mathrm{ADE}$ & Abiotic Depletion - Elements (kg Sb eq.) \\
\hline ADFF & Abiotic Depletion - Fossil Fuels (MJ) \\
\hline AFN & Airflow Network \\
\hline ANZ & Australia and New Zealand \\
\hline AP & Acidification (Land and Water) ( $\mathrm{kg} \mathrm{SO}_{2}$ eq.) \\
\hline AS & Australian Standard \\
\hline ASHRAE & American Society of Heating, Refrigerating, and Air-Conditioning Engineers \\
\hline ASTM & American Standard \\
\hline BIM & Building Information Modelling \\
\hline BMT & Base Metal Thickness \\
\hline BPI & Building Performance Index \\
\hline BRANZ & Building Research Association of New Zealand \\
\hline $\mathrm{C}_{2} \mathrm{H}_{4}$ & Ethylene \\
\hline $\mathrm{CC}$ & Climate Change - Global Warming \\
\hline CAD & Computer-Aided Design \\
\hline CFC-11 & Trichlorofluoromethane \\
\hline CIBSE & Chartered Institution of Building Services Engineers \\
\hline $\mathrm{CO}_{2}$ & Carbon dioxide \\
\hline DHW & Domestic Hot Water \\
\hline DOE & Department of Energy \\
\hline ELA & Effective Leakage Area \\
\hline $\mathrm{Eu}$ & Eutrophication (kg PO43-eq.) \\
\hline EPD & Environmental Product Declarations \\
\hline ETICS & Exterior Thermal Insulation Composite System \\
\hline
\end{tabular}




\begin{tabular}{|c|c|}
\hline GBS & Green Building Studio \\
\hline GFA & Gross Floor Area \\
\hline GW & Global Warming (100 year) (kg CO 2 eq.) \\
\hline HEEP & Household Energy End-Use Project \\
\hline HSS & High Standard of Sustainability \\
\hline HVAC & Heating, Ventilation, and Air Conditioning \\
\hline HWC & Hot Water Cylinder \\
\hline IBPSA & International Building Performance Simulation Association \\
\hline IECC & International Energy Conservation Code \\
\hline IEEE & Institute of Electrical and Electronics Engineers \\
\hline IEQ & Indoor Environmental Quality \\
\hline $\mathrm{kWh}$ & Kilowatt-hour \\
\hline LCA & Life Cycle Assessment \\
\hline LOD & Level of Development \\
\hline LVL & Laminated Veneer Lumber \\
\hline MBIE & Ministry of Business, Innovation and Employment \\
\hline MCDA & Multiple-Criteria Decision Analysis \\
\hline $\mathrm{MDH}$ & Medium Density Housing \\
\hline MJ & Megajoule \\
\hline NIWA & National Institute of Water and Atmospheric Research \\
\hline NLA & Net Lettable Area \\
\hline NZBC & New Zealand Building Code \\
\hline NZGBC & New Zealand Green Building Council \\
\hline NZS & New Zealand Standard \\
\hline $\mathrm{OP}$ & Openable \\
\hline OS & OpenStudio \\
\hline $\mathrm{PE}$ & Polyethylene \\
\hline PHI & Passive House Institute \\
\hline
\end{tabular}




\begin{tabular}{ll}
\hline PO43- & Phosphate \\
$\mathrm{PV}$ & Photovoltaic \\
$\mathrm{Sb}$ & Antimony \\
$\mathrm{SHGC}$ & Solar Heat Gain Coefficient \\
$\mathrm{SO}_{2}$ & Sulfur Dioxide \\
$\mathrm{SOD}$ & Stratospheric Ozone Depletion $(\mathrm{kg} \mathrm{CFC} \mathrm{11} \mathrm{eq.)}$ \\
$\mathrm{SR}$ & Study Report \\
\hline TMY & Typical Meteorological Year \\
$\mathrm{TOF}$ & Tropospheric Ozone Formation $(\mathrm{kg} \mathrm{C} 2 \mathrm{H} 4 \mathrm{eq})$. \\
\hline UV & Ultraviolet \\
\hline WBWL & Whole Building Whole of Life \\
\hline WWR & Window-to-Wall Ratio \\
\hline
\end{tabular}


A Life Cycle Assessment of Medium Density Houses in New Zealand 


\section{Chapter 1 \\ Introduction}

Measuring the environmental impact of a building is a time and resource-intensive process requiring numerous inputs and quality assurance steps, making it an unattractive task for designers. This study develops an analysis method to undertake a Life Cycle Assessment (LCA) on multiple building designs and trials this on Medium Density Housing (MDH).

This study aims to demonstrate whether it is feasible to incorporate LCA into a designer's workflow to routinely assess the environmental impact of buildings using a range of environmental indicators. An LCA of a building is a method of assessment that allows for the environmental impacts of a building's entire life cycle from cradle to grave to be assessed, including the building's materials and operational energy use. To demonstrate whether this is feasible, the level of insulation in the thermal envelope of MDH houses will be varied, and a method created to assess the results. The number of MDH units is predicted to increase in New Zealand, which makes it a suitable case study to develop this method (Page, 2017). 


\subsection{The problem}

LCA can be used to evaluate a buildings' design and inform design decisions on a whole (Dowdell \& Berg, 2016). In Europe, there are energy certification requirements for new buildings, but these only consider the operational energy not embodied energy of a building. This is an issue as identified in Zabalza Bribián, Aranda Usón, and Scarpellini (2009), where a simulated buildings insulation thickness and R-value was increased to reduce heating and cooling energy. A point was found where more $\mathrm{CO}_{2}$ was released from the additional building materials than was saved by the reduction in operational energy use. This finding demonstrates that an LCA can play an important role in finding an optimum design for a building, considering energy and materials and their environmental impact. However, to do so is difficult and timeconsuming (Meex, Hollberg, Knapen, Hildebrand, \& Verbeeck, 2018). The cause of this is due to the high level of unknown information throughout the design process and the inefficient modelling process. The lack of knowledge amongst the design team, particularly the architects who are making decisions about the amount and type of building materials to be used further complicates this process (Meex et al., 2018). Implementing LCA in New Zealand, raises a question, what are the barriers to implementation and how to eliminate these?

Meex et al. (2018) create a framework of requirements, from a qualitative study of architects, which need to be addressed to create a more appealing LCA process. These requirements were from Flemish architects, but Meex et al. (2018) state that "these findings are believed to be valid for many European countries" because of similarities that are faced by architects in European countries (Meex et al., 2018).

The first requirements for the input stage of an LCA suggest that a library of input data is required with default values if the final design is unknown. That way, an LCA can be performed in the early stages of the design without the need for the designer to spend time and energy on finding these values. This database would need to be context-specific. For LCA in New Zealand, this would require representative New Zealand values. During the input stage, it is important for architects not to exert energy in learning new software, so an integrated process with a commonly used 3D CAD (Computer-Aided Design) software is equally important. 
During the calculation stage of the environmental impact, Meex et al. (2018) suggest it is important that there is transparency of the predefined calculation settings, description of assumptions and inclusion of energy performance and environmental impact in the calculations.

Meex et al. (2018) suggest that the output stage is where architects have the most trouble due to the lack of knowledge on how to interpret the output. The architects suggest that having easy to interpret clear outputs, as well as supportive information for design decisions, would help improve this process (Meex et al., 2018). This interpretation would be made through visual output instead of extensive reports with visualisation of the output relative to benchmarks. Visualisations allow non-LCA experts to make design decisions and allow the decisions to be used by architects to help inform clients.

The architects from Meex et al. (2018) are reported to require that the LCA process be readily usable in the design process, including the ability to easily change the design either manually or through parametric control and have the results automatically generated without the need for extensive technical input from the designer. However, once the different designs are simulated, there is a need for comparing the designs again through visualisations to inform design decisions. A clear visual indication of the problem areas of the building is required, which could be with a 3D CAD model.

Attempts at resolving some of these issues have been made by (Hollberg \& Ruth, 2016). Parametric design was used in Rhino with Grasshopper3D to create LCA models and run LCA analyses. The result was that a simplified model could be made in Rhino with LCA results automatically generated with little user input. The output results of this process were then simplified for the architects. A noteworthy point of this study is that when changes were made to the design in a designer's software of choice, these changes were not be reflected in the LCA as the model needs to be remodelled adding to the time-intensive process. This process does allow for designs to be modelled simultaneously with results generated automatically, but the input and output for the process do not meet the architect's requirements.

Studies like Hollberg and Ruth (2016) which consider one environmental indicator like carbon, make a comparison between building designs easy as there is only one environmental indicator. However, once more indicators are added to the 
LCA, this creates more difficulty in the assessment phase due to the high number of results from a range of indicators and building designs. A process is needed that can allow for easy assessment of the number of results as well as the process of generating these results.

A process is needed, which resolves the input and output requirements to reduce the difficulty and increase efficiency to help make the analysis method more attractive for architects. This study aims to answer the question "How can an LCA be integrated into a designer's workflow to inform design decisions?" An LCA was performed to answer this question using a designer's models and construction changes made to determine how to resolve the issues presented by designers. This was with a 3D CAD model with a visual analysis of the results. The definitions of "designers" in this study includes anyone involved in the design of a building including architects, engineers and LCA practitioners.

\subsection{Scope}

This study focuses on testing whether an analysis method can be developed that allows an LCA to be conducted by designers. It does not aim to gather the environmental impact data relating to materials/energy across the life-cycle stages. This is because the data is sourced externally from the Building Research Association of New Zealand (BRANZ) LCA tool "LCAQuick" (BRANZ, 2019a).

The environmental indicators used will be based on the LCAQuick material database. This study will not attempt to define what indicators are most important or most relevant.

The study will not attempt to answer what designs/materials are the best at reducing the environmental impact but create the process for designers to do this.

Medium Density Housing (MDH) will be used as a case study to test the method, but the method developed will be able to be used on a range of building types.

The houses will be modelled in a New Zealand context as the LCAQuick database is for New Zealand (BRANZ, 2019a).

The above aspects are essential to making informed design decisions from an LCA but are all outside the scope of this study as the research method developed will be able to be applied using a range of different datasets. 


\subsection{Significance}

A study like this one which includes multiple building designs, several environmental indicators and presents the analysis method and results in thorough detail where it can be replicated, has not been performed before in New Zealand.

The goal is to demonstrate that replication is feasible to provide reassurance for designers wishing to perform an LCA that the analysis method has been tested and works. The LCA process produces many results; an incorrect assessment of these can lead to wrong decisions being made. A measure of the success of this study is that the analysis method should help prevent this from occurring by developing an analysis method which assesses the results holistically. For designers, this analysis method should help develop an understanding of the level of detail required in an LCA and the reasoning for each detail. Overall the goal is to make LCA more accessible to designers, creating for a more environmentally friendly future building stock.

\subsection{Life Cycle Assessment - What is it?}

An LCA of a building considers the energy use of the building and the quantities of materials to calculate a buildings potential environmental impact. An LCA can help designers to make informed decisions about replacing materials or elements in the building at any stage of the design process. An LCA can be used to determine potential impacts from several environmental indicators leading to informed decisions which reduce the risk of making a design choice relating to one environmental indicator that causes another indicator to inadvertently and adversely increase.

There are several resources that have been developed to facilitate LCA of buildings in a New Zealand context which this thesis is influenced by. These resources are:

- BS EN 15978:2011 Sustainability of construction works. Assessment of environmental performance of buildings. Calculation method;

- BS EN 15804:2012+A2:2019 Sustainability of construction works. Environmental product declarations. Core rules for the product category of construction products; 
- BRANZ Whole Building Whole of Life Framework (which includes default environmental data and requirements for modelling energy use;

- LCAQuick, a tool that embeds the BRANZ Whole Building Whole of Life Framework default data;

- BRANZ SR350 New Zealand Whole Building Whole of Life Framework: Development of reference office buildings for use in early design.

\subsubsection{Why use Life Cycle Assessment?}

An LCA requires consideration of a building's whole life cycle and produces a comprehensive understanding of the building's potential impact, identifying impacts from the production stage to the end-of-life stage. These stages and the intermediate stages are listed in Table 1.

Table 1 Life cycle stages of a building (Dowdell, 2014)

\begin{tabular}{llll}
\hline Product Stage & Construction Stage & Use Stage & End-of-life stage \\
\hline $\begin{array}{l}\text { A1 Raw material } \\
\text { supply }\end{array}$ & A4 Transport & $\begin{array}{l}\text { B1 Installed products } \\
\text { in use }\end{array}$ & $\begin{array}{l}\text { C1 Deconstruction/ } \\
\text { demolition }\end{array}$ \\
A2 Transport & $\begin{array}{l}\text { A5 Construction/ } \\
\text { installation process }\end{array}$ & B2 Maintenance & C2 Transport \\
A3 Manufacturing & B3 Repair & C3 Waste processing \\
& B4 Replacement & C4 Disposal \\
& B5 Refurbishment & \\
& B6 Operational & \\
& Energy & \\
& B7 Operational Water & \\
& & & \\
& &
\end{tabular}

Studies that focus on a single stage of the life cycle like the construction stage risk making decisions that lead to low impact in the construction stage but inadvertently and adversely cause an increased impact elsewhere in the life cycle. Whereas a "cradle 
to grave" approach of the entire life cycle reduces the possibility of this occurring because each stage's potential impact can be calculated.

An LCA approach can allow impact from different design options to be performed relatively quickly if the necessary data can be extracted out of a BIM model. At the simplest level, material quantities of the building can be exported from a BIM model and then the impact from those material quantities calculated. When a change is made to the BIM model, a new material schedule of quantities can be exported, and the new designs potential impact calculated.

An LCA considers not only the materials and their impacts but also the end energy use for heating, cooling, lighting and plug loads depending on the detail of the LCA. When materials and designs are changed, the new energy demand needs to be calculated, as well as the schedule of materials - allowing for decisions that cause problem shifts to be mitigated. For example, if the thermal envelope of the building were to change drastically from having low thermal resistance to high thermal resistance, this would decrease the operational energy demand to heat the building. Therefore, decreasing the impact of the building from energy but possibly increasing the impact of the building from additional materials in the building's envelope.

LCA datasets that are location specific are of high importance because of different processing and manufacturing practices around the world but also because impacts from transporting materials in the product and construction stages are calculated.

\subsubsection{Limitations of a Life Cycle Assessment}

LCA data collection can be time and resource-intensive due to the large scale of data required. Large data requirements can lead to a lot of assumptions and missing data inputs, which can reduce the quality of an LCA. In addition to this, New Zealand specific LCA data is not widely accessible or available, which adds to the reduction of quality of an LCA.

The source and type of data available influence an LCA. Generic data can be appropriate in early-stage design when there are a lot of unknowns, and accurate results are not necessary, whereas, in the detailed design stage, generic data will not be appropriate. Currently, in New Zealand, Environmental Product Declarations 
(EPDs) registered with EPD Australasia, and BRANZ $\mathrm{CO}_{2} \mathrm{NSTRUCT}$ are available for use for LCA (BRANZ, 2019a).

There are many environmental indicators that can be included in an LCA. To include a large portion of these indicators can be resource-intensive as it creates a lot of information about the building, which can be overwhelming for the user. Not enough indicators and this can be too little information for designers. Designers can also be in a scenario where the design of a certain building reduces one impact while another design option reduces a different impact. In this situation, the designer is in a difficult position on which design to select. By providing all indicators, a designer can assign them with an equal weighting of 1 . Or if the designer chooses, they could focus on a specific indicator and assign this a weighting of 1 and the remaining indicators 0 .

\subsubsection{Which environmental indicators for a Life Cycle Assessment?}

ISO 21929-1:2011 Sustainability in building construction - Part 1: Framework for the development of indicators and a core set of indicators for buildings, establish a core set of indicators to be used in an LCA for new or existing buildings (International Organization for Standardization, 2011). From this set of indicators BRANZ's Whole Building Whole of Life (WBWL) Framework, whose purpose is to provide information and resources to facilitate more consistent calculation of potential environmental impacts of New Zealand Buildings, provides a list of indicators that should be used in a New Zealand context (Dowdell, 2014). These seven indicators are listed in Table 2.

Table 2 WBWL environmental indicators (Dowdell, 2014)

\begin{tabular}{ll}
\hline Indicator Name & Unit \\
\hline Acidification (Land and Water) & $\mathrm{kg} \mathrm{SO}$ eq. \\
Global Warming (100 year) & $\mathrm{kg} \mathrm{CO}$ eq.(100 year) \\
Eutrophication & $\mathrm{kg} \mathrm{PO} 43$-eq. \\
Abiotic Depletion - Fossil Fuels & $\mathrm{MJ}$ (Net Calorific Value - NVC) \\
Abiotic Depletion - Elements & $\mathrm{kg} \mathrm{Sb}$ eq. \\
\hline
\end{tabular}


Stratospheric Ozone Depletion

Tropospheric Ozone Formation $\mathrm{kg}$ CFC 11 eq.

$\mathrm{kg} \mathrm{C}_{2} \mathrm{H}_{4}$ eq.

\section{What do the environmental indicators mean?}

The summary of each indicator below is quoted from BRANZ Bulletin 596 An Introduction to Life Cycle Assessment (LCA) and SR 2932014 (BRANZ, 2016; Dowdell, 2014).

\section{Acidification (Land and Water)}

"When emitted to the atmosphere, acidifying pollutants such as sulphur dioxide, nitrogen oxides and ammonia may remain in the air for days and can be dispersed and carried over long distances by winds. They can cause damaging effects far from the source of emission. Acidification can occur when the capacity of the soil or water bodies to neutralise acidifying atmospheric deposition declines. The effects include acidification of freshwater systems resulting in the loss of fisheries, impoverishment of soils, damage to forests and vegetation and corrosion of buildings, cultural monuments and materials."

\section{Global Warming (100 years)}

"Human society's part in climate change is caused by the emission of greenhouse gases and other activities influencing their atmospheric concentration. Greenhouse gases absorb infrared radiation from the earth."

\section{Eutrophication}

"This impact category addresses impacts due to the addition of nitrogen and phosphorus in bio-available forms in aquatic ecosystems primarily."

\section{Abiotic Depletion}

"This provides a measure of resource scarcity by considering resources based on availability. Methods for defining availability vary and are normally considered at a global level, not taking into account differences that may arise locally." 


\section{Stratospheric Ozone Depletion}

"Stratospheric ozone is vital for life because it hinders harmful solar ultraviolet UV-B radiation from penetrating to the lower levels of the atmosphere. Stratospheric ozone depletion occurs if the rate of ozone destruction is increased due to emissions of ozone-depleting substances, which persist in the atmosphere. This can lead to higher UV-B radiation reaching the surface of the earth, increasing the risk of skin cancer, cataracts, premature ageing and suppression of the immune system."

\section{Tropospheric Ozone Formation}

"This addresses the potential impacts from formation of ground-level ozone and other reactive oxygen compounds as a result of emissions of volatile organic compounds (VOCs) and carbon monoxide, for example. Health effects may include irritation of the respiratory system, reduced lung function, aggravation of asthma and inflammation and damage to the lung lining."

\subsection{Medium Density Housing - A definition}

Current definitions of MDH focus on the type of house or density of dwellings and some include limits for site size, building height and number of units per site (Bryson \& Allen, 2017). With no standard definition of MDH in New Zealand, this study does not try to create a definition. Instead, it uses the definition provided by BRANZ (Bryson \& Allen, 2017). This MDH definition is defined as multi-unit dwellings (up to six storeys) excluding stand-alone and infill buildings. The definition is further divided into three categories with different housing types, including 1-storey units and 1-2-storey duplexes or triplexes, 2-4-storey terraced houses, and 3-6-storey apartments (Figure 1). 

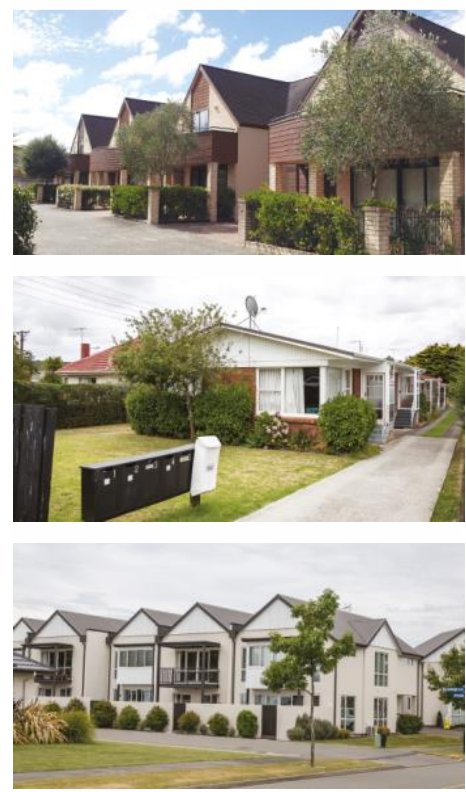

Category 1
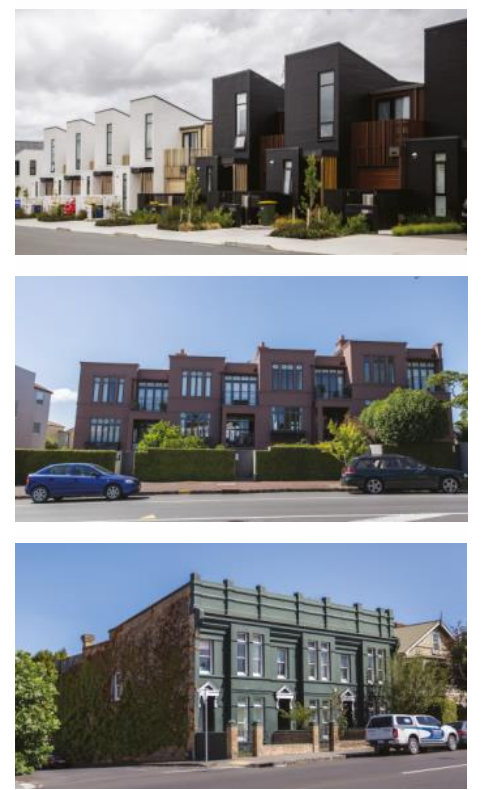

Category 2
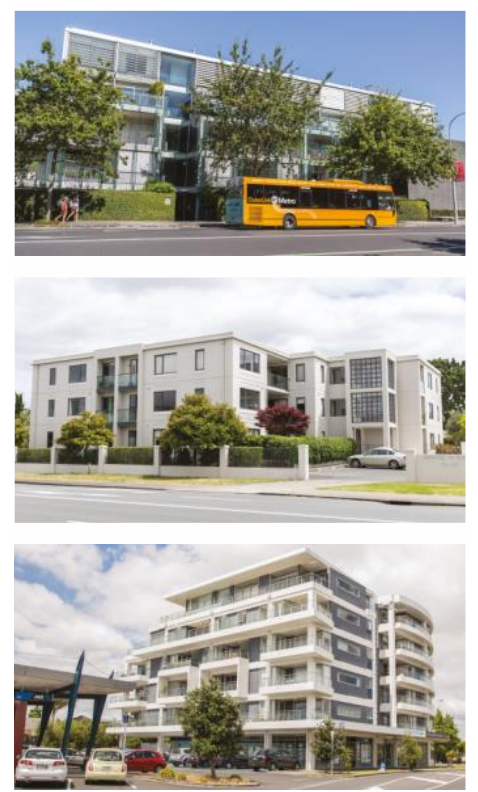

Category 3

Figure 1 BRANZ MDH categories (Bryson \& Allen, 2017)

\subsubsection{Why Medium Density Housing?}

A 2017 Ministry of Business, Innovation and Employment (MBIE) report forecast that dwelling consents nationally will rise to a peak of 34,500 dwellings annually in 2019 and 2020, higher than the highest previous peak in 2004 of 31,000 units (Figure 2) (MBIE, 2017). Over the period 2017 - 2020 it is predicted that Auckland will sustain an increase in construction for a longer period than other regions. It is predicted that Auckland will have 73,900 consents over the period 2017 - 2022 equating to $38 \%$ of the nationally predicted consents. This total is considerably more than the other regions, with the next highest growth in Waikato/Bay of Plenty with 40,800 consents (21\% of the total). All regions reach a peak in 2020 and then decline following that period. The region with the least amount of total consents is Wellington, followed by Canterbury (MBIE, 2017). It is forecast that 34\% $(67,600)$ of the new consents will be multi-unit dwellings and 51\% $(34,700)$ of these multi-unit dwellings will be built in Auckland. 


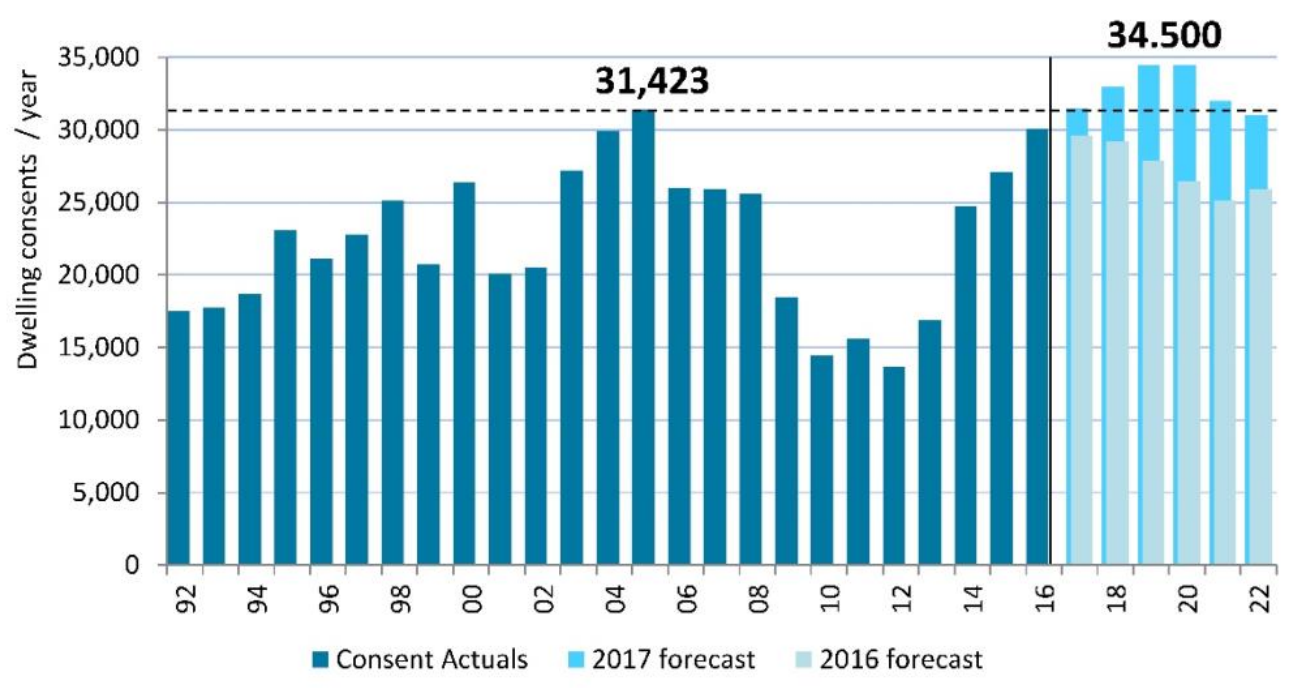

Figure 2 All dwellings national consents actual and forecast (MBIE, 2017)

Regionally, Auckland is forecast over the 2016 - 2025 period to have $49 \%$ of new MDH units with Canterbury having the second largest number at 19\% shown in Figure 4 (MBIE, 2017). MDH in this forecast is defined as "separate occupancy dwelling with either a wall, ceiling or floor in common with another building, including all retirement village units whether attached or not" (MBIE, 2017). This definition includes a wide variety of housing types when compared to Bryson et al. (2017). Therefore, it cannot be used directly for forecasting $\mathrm{MDH}$ in the future but instead used as an indication. This forecast shows that Auckland is expected to have a significantly larger number of both detached and $\mathrm{MDH}$ units over the period shown (Page, 2017). 


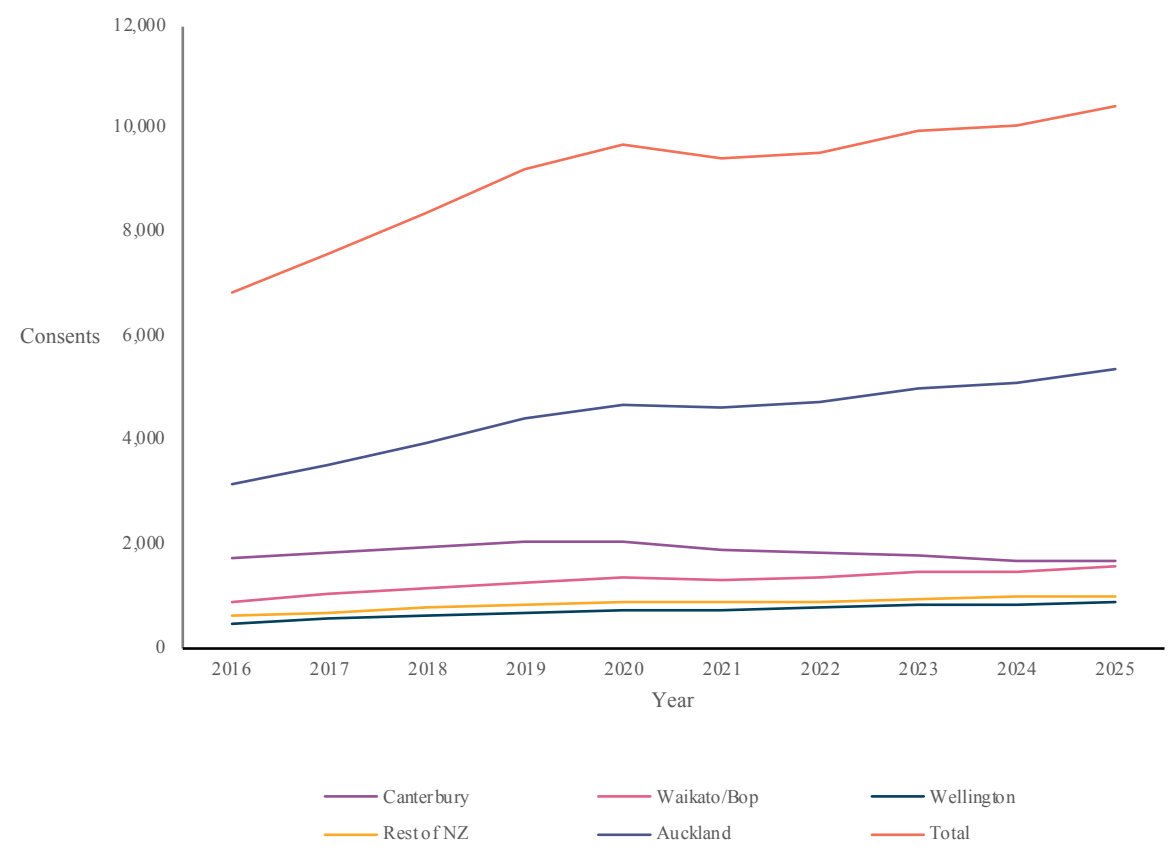

Figure 3 MDH regional consents actual and forecast (Page, 2017)

In Auckland, in 2016, new MDH accounted for $46 \%$ of the national total and is forecast to increase to $51 \%$ by 2025 with the total new MDH annually increasing by $71 \%$ by 2025 shown in Figure 4.

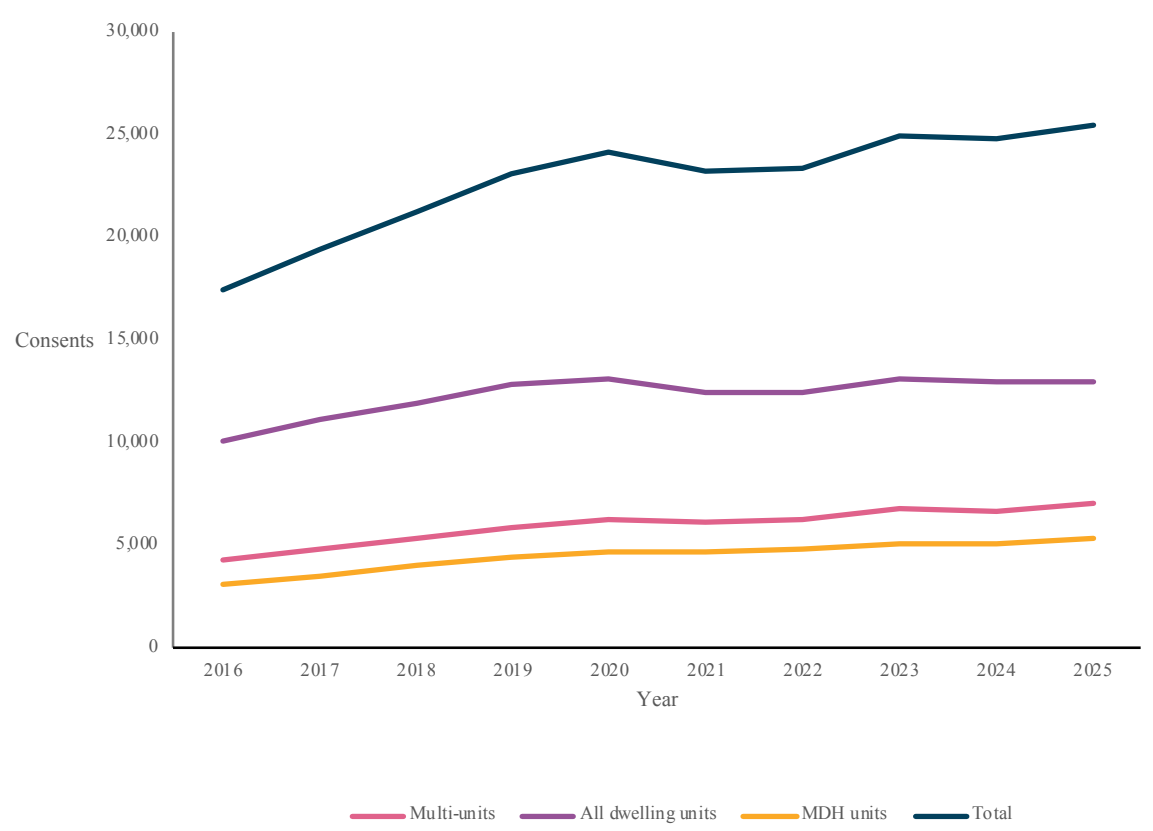

Figure 4 All dwellings Auckland consents actual and forecast (Page, 2017) 


\subsubsection{KiwiBuild - What is it?}

KiwiBuild is a government programme that aims to deliver 100,000 affordable, quality homes in New Zealand over the next ten years to help with housing shortages in New Zealand. The number of houses available from KiwiBuild is expected to be 1,000 in the first year growing to 12,000 from 2022 till 2028. It is not known what proportion of these will be MDH, but together with forecasts from (MBIE, 2017), this gives a prediction of the future housing in New Zealand.

\subsubsection{Medium Density Housing Construction}

MDH typologies can be broken down into two separate categories, horizontally attached or vertically attached. Horizontally attached units are attached side by side sharing an interior partition wall typically up to three stories high. Vertically attached units have residences one to two-storey high stacked on top of one another. From 2014 - 2015, horizontally attached units consented totalled 68\% of new MDH units and vertically attached, $32 \%$. From $2016-2025$, it is predicted that horizontally attached units will make up 74\% of MDH and vertical 26\% (Figure 5) (MBIE, 2017).

The difference in unit height and attachments also often means a difference in construction systems. Typically, horizontally attached units are constructed from light timber or steel framing. The interior partition wall is either a concrete panel or double stud wall. Vertically attached units are often constructed from concrete or structural steel framing with concrete floors. Vertically attached units are typically townhouses, apartments, plus retirement village units (Statistics NZ, 2018). Horizontally attached units are typically flats/terraced housing plus a percentage of retirement village units as above. They have the same occupancy on all levels up to three storeys and do not have an attachment to other units vertically. 


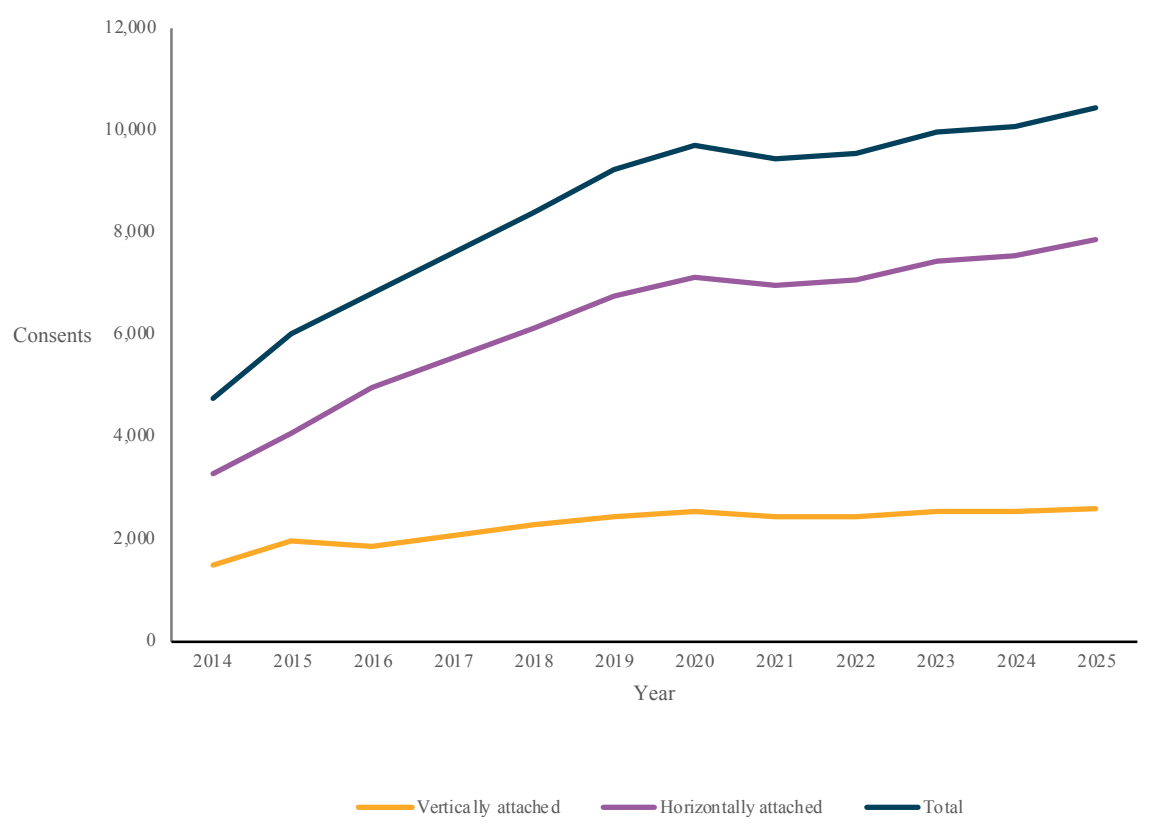

Figure 5 MDH national consents actual and forecast (Page, 2017)

The forecasts for the future housing of New Zealand indicate that MDH horizontally attached will increase significantly in Auckland over the next six years. Meaning that these houses will be contributing to the future environmental impact of New Zealand's housing stock.

\subsection{Overview of the study}

After the background and context of the study, a systematic literature review (Chapter 2) is conducted to find relevant literature to the study. Chapter 2 will identify the knowledge gap that the study will use as a basis for the methodology. Following this, the research method of developing a selection system for the Medium Density Housing (MDH) case study methodology is presented in Chapter 3. Chapter 4, Modelling methodology, examines the issues of conducting an LCA from the perspective of modelling the selected houses. Inputs to the LCA are presented with the rationale behind each decision. Chapter 5, Findings, outlines the findings of the LCA of each MDH case study and design in different climates. The process of assessing these results is shown and critical findings of the process presented. Finally, Chapter 6 presents the conclusions and evaluation of the process. 
A Life Cycle Assessment of Medium Density Houses in New Zealand 


\section{Chapter 2 \\ Literature Review}

A systematic literature review is selected for this study to identify relevant literature surrounding the review question using Boland, Dickson, and Gemma (2014) process. The systematic literature review aims to identify literature which has performed an LCA and the process used to make design decisions based on the LCA results. The aim is to understand what is required for a trustworthy LCA and the process required to achieve this. 


\subsection{The systematic literature review question}

In addition to this study's research question "How can an LCA be integrated into a designer's workflow to inform design decisions? " a secondary research question was created specifically for the systematic literature review which is "Can residential thermal envelopes meet indoor environmental quality requirements and have a low environmental impact?" The reasoning behind this second question is that an issue identified by designers in Meex et al. (2018) was that a 3D Computer-Aided Design (CAD) model is required to improve the implementation of an LCA. This means that the model used needs to generate material quantities and simulate the operational heating and cooling energy use as this has a large impact on the results in an LCA.

Therefore, literature that focuses on operational heating and cooling energy use and the thermal envelope were selected, and their methodology assessed. Keywords in the systematic literature review process were then used to identify literature which also performs an LCA, together with construction changes that affect operational heating and cooling energy use. This research question helped inform the methodology of this study and how to resolve the barrier faced by designers (Meex et al., 2018).

\subsection{Systematic literature review strategy}

The systematic process locates, appraises and synthesises available evidence relating to the review question in a process that clearly defines the question, identifies and critically assesses the literature, synthesises the findings and draws relevant conclusions (Boland et al., 2014). This process will mitigate the risk of potential bias throughout the entire review with clear assessment criteria and analysis processes. The review is broken into eight steps listed below;

- Step 1 - Perform scoping searches, identifying the review question and protocol,

- Step 2 - Literature searching,

- Step 4 - Obtaining papers,

- Step 5 - Selecting full-text papers,

- Step 6 - Quality assessment, 
- Step 7 - Data extraction,

- $\quad$ Step 8 - Analysis and synthesis.

This systematic process begins with outlining the initial research question then creates a search strategy, identifies relevant databases, identifies search keywords, performs scoping searches, reports on the extent of the scoping searches and identifies additional search keywords.

\subsubsection{Search strategy and the research problem}

To develop inclusion criteria and search strategy for the systematic process a "who, what, how and where" table was created (Table 3). This table defines the different components of the review question breaking this down into manageable categories. From here, the search strategy and search keywords were defined that can be used in databases to find relevant literature.

Table 3 Who, what, how and where keywords

\begin{tabular}{|c|c|c|c|c|}
\hline $\begin{array}{l}\text { Research } \\
\text { question }\end{array}$ & Who & What & How & Where \\
\hline $\begin{array}{l}\text { Can residential } \\
\text { thermal } \\
\text { envelopes meet } \\
\text { indoor } \\
\text { environmental } \\
\text { quality } \\
\text { requirements and } \\
\text { have a low } \\
\text { environmental } \\
\text { impact? }\end{array}$ & $\begin{array}{l}\text { Residential } \\
\text { occupants }\end{array}$ & $\begin{array}{l}\text { Thermal } \\
\text { envelopes/building } \\
\text { materials, Indoor } \\
\text { Environmental } \\
\text { Quality (IEQ), } \\
\text { environmental } \\
\text { impact }\end{array}$ & $\begin{array}{l}\text { Life Cycle } \\
\text { Assessment } \\
\text { (LCA) }\end{array}$ & $\begin{array}{l}\text { Residential } \\
\text { homes }\end{array}$ \\
\hline
\end{tabular}

Fifteen databases were identified that host literature in the form of books, journals and conference proceedings. The databases selected for the search had a specific focus on science, architecture and engineering. Table 4 summarises these databases. Google scholar was also included because of its ability to search for grey literature. 
Table 4 Summary of literature databases

\begin{tabular}{|c|c|}
\hline Database & Summary \\
\hline $\begin{array}{l}\text { Australian Building } \\
\text { Construction and } \\
\text { Engineering Database } \\
\text { (BUILD) }\end{array}$ & $\begin{array}{l}\text { Includes published and unpublished work on building, construction, } \\
\text { and engineering. It contains information on the economics, } \\
\text { administration, management and information technology. }\end{array}$ \\
\hline Birkhauser & $\begin{array}{l}\text { Multidisciplinary database of mostly eBooks from a wide range of } \\
\text { subjects including but not limited to history, sciences, economics and } \\
\text { architecture. }\end{array}$ \\
\hline EBSCOhost & $\begin{array}{l}\text { Multidisciplinary source of scholarly, reference and general material in } \\
\text { the fields of business, social science, health sciences, humanities and } \\
\text { the arts. }\end{array}$ \\
\hline Emerald & $\begin{array}{l}\text { Academic journal articles, often with a practical emphasis, covering } \\
\text { business, information science, and engineering. }\end{array}$ \\
\hline $\begin{array}{l}\text { Gale Infotrac } \\
\text { PowerSearch }\end{array}$ & $\begin{array}{l}\text { A multidisciplinary collection of articles and books from a range of } \\
\text { online resources. Includes but not limited to, the material on science, } \\
\text { fine arts, health, and business. }\end{array}$ \\
\hline Google Scholar & $\begin{array}{l}\text { An extensive search of scholarly literature from a wide range of } \\
\text { databases. }\end{array}$ \\
\hline IEEE Explore & $\begin{array}{l}\text { Includes journal articles and conference proceedings within the } \\
\text { engineering, specifically electrical, electronic and computer science } \\
\text { field. }\end{array}$ \\
\hline ProQuest & $\begin{array}{l}\text { A multidisciplinary source of scholarly, reference and general material } \\
\text { in the fields of business, social science, health sciences, humanities and } \\
\text { the arts. The ANZ Newstream includes newspaper articles and } \\
\text { information focused on New Zealand and Australia. }\end{array}$ \\
\hline $\begin{array}{l}\text { Sage Premier Journal } \\
\text { Collection }\end{array}$ & $\begin{array}{l}\text { Includes academic journals in the social sciences, humanities, business, } \\
\text { medicine, engineering, technology and physical and life sciences. }\end{array}$ \\
\hline $\begin{array}{l}\text { Sage: Science and } \\
\text { Geography Education }\end{array}$ & $\begin{array}{l}\text { Includes information on agriculture, archaeology, astronomy, biology, } \\
\text { chemistry, environmental science, ethics, geography, natural history, } \\
\text { physics, sustainability and zoology. }\end{array}$ \\
\hline Science Direct & $\begin{array}{l}\text { Includes books, journals and conference proceedings in science, } \\
\text { technology, social sciences, and humanities. }\end{array}$ \\
\hline Scopus & $\begin{array}{l}\text { Includes books, journals and conference proceedings in science, } \\
\text { technology, social sciences, and arts and humanities. }\end{array}$ \\
\hline SpringerLink & Science and social science research database. \\
\hline Tayler and Francis & Includes resources on arts and humanities, social sciences and sciences. \\
\hline Wiley & $\begin{array}{l}\text { Multidisciplinary databases containing resources in the sciences, arts } \\
\text { and humanities, business and architecture. }\end{array}$ \\
\hline
\end{tabular}




\section{Keywords and search terms}

From the "who, what, how and where" table in Table 3, keywords were generated for each criterion in relation to the review question. These keywords are shown in Table 5 and were used to perform scoping searches to determine the amount of relevant literature available.

Table 5 Revised who, what, how and where keywords

\begin{tabular}{|c|c|c|c|c|c|}
\hline $\begin{array}{l}\text { Research } \\
\text { question }\end{array}$ & Who & What & How & Where & $\begin{array}{l}\text { Exclusion } \\
\text { criteria }\end{array}$ \\
\hline $\begin{array}{l}\text { Can residential } \\
\text { thermal } \\
\text { envelopes meet } \\
\text { indoor } \\
\text { environmental } \\
\text { quality } \\
\text { requirements } \\
\text { and have a low } \\
\text { environmental } \\
\text { impact? }\end{array}$ & Residential & $\begin{array}{l}\text { "Thermal } \\
\text { envelope OR } \\
\text { insulation." }\end{array}$ & $\begin{array}{l}\text { "Life Cycle } \\
\text { Assessment" } \\
\text { OR LCA }\end{array}$ & Residential & Office \\
\hline
\end{tabular}

Using the keywords in Table 5 returned as little as zero results for some databases and up to 6,000 in others (Google Scholar) (Table 6). There are large gaps in the number of results between databases with the second-highest number of results being returned from Science Direct, which had 5,376 fewer results than Google Scholar. Because of the disparity between the number of results, it is unclear whether the results are relevant to the review question. To ensure that only relevant results are found, a developed search criterion was required.

Table 6 Database scoping search results

\begin{tabular}{llll}
\hline Database & $\begin{array}{l}\text { Number } \\
\text { of } \\
\text { results }\end{array}$ & Database & $\begin{array}{l}\text { Number } \\
\text { of } \\
\text { results }\end{array}$ \\
\hline $\begin{array}{l}\text { Australian Building Construction } \\
\text { and Engineering Database: } \\
\text { BUILD }\end{array}$ & 0 & Sage Premier Journal Collection & 16 \\
$\begin{array}{l}\text { Birkhauser } \\
\text { EBSCOhost }\end{array}$ & 0 & $\begin{array}{l}\text { Sage: Science and Geography } \\
\text { Education }\end{array}$ & \\
\hline & 112 & Science Direct & 624 \\
\hline
\end{tabular}




\begin{tabular}{llll}
\hline Emerald & 10 & Scopus & 50 \\
Gale Infotrac PowerSearch & 37 & SpringerLink & 137 \\
Google Scholar & 6,000 & Tayler and Francis & 70 \\
IEEE Explore & 2 & Wiley & 73 \\
ProQuest & 116 & & \\
\hline
\end{tabular}

Equivalent or similar terms and words were identified from the terms and words in the initial search phrase (Table 5). These are shown in Table 7 and are based off reading the titles from the first pages of results in the initial searches as well as discussions with colleagues.

Table 7 Revised keyword search

\begin{tabular}{ll}
\hline Initial scoping term & Refined scoping term \\
\hline Thermal envelope & Building envelope \\
Insulation & Materials \\
& Thermal resistance \\
& R-value \\
& U-value \\
& Indoor Environmental Quality \\
& IEQ \\
& Performance \\
& Low energy \\
& LCA \\
Life Cycle Assessment & Environmental impact \\
& House \\
Residential & Home \\
\hline
\end{tabular}

These additional search terms and words were added to the initial search phrase one at a time and searched in each database. This was performed to see how each additional term or word affected the number of relevant results found. This process was performed twice with the key difference being the set of search phrases used. 
"Life Cycle Assessment" was used in the first search term and "environmental impact" in the second shown in Table 8. The reason for this was to establish if there was a large difference in results between the two different terms.

Table 8 Search phrase iterations

\begin{tabular}{|c|c|}
\hline Life Cycle Assessment & Environmental impact \\
\hline $\begin{array}{l}\text { ("Thermal envelope" OR Insulation) AND } \\
\text { ("Life Cycle Assessment" OR LCA) AND } \\
\text { residential NOT office }\end{array}$ & $\begin{array}{l}\text { ("Thermal envelope" OR Insulation) AND } \\
\text { "environmental impact" AND residential NOT } \\
\text { office }\end{array}$ \\
\hline $\begin{array}{l}\text { ("Thermal envelope" OR Insulation) AND } \\
\text { ("Life Cycle Assessment" OR LCA) AND } \\
\text { (residential OR house) NOT office }\end{array}$ & $\begin{array}{l}\text { ("Thermal envelope" OR Insulation) AND } \\
\text { ("environmental impact") AND (residential OR } \\
\text { house) NOT office }\end{array}$ \\
\hline $\begin{array}{l}\text { ("Thermal envelope" OR "Building envelope" } \\
\text { OR Insulation) AND ("Life Cycle Assessment" } \\
\text { OR LCA) AND (residential OR house) NOT } \\
\text { office }\end{array}$ & $\begin{array}{l}\text { ("Thermal envelope" OR "building envelope" } \\
\text { OR Insulation) AND ("environmental impact") } \\
\text { AND (residential OR house) NOT office }\end{array}$ \\
\hline $\begin{array}{l}\text { ("Thermal envelope" OR "Building envelope" } \\
\text { OR Insulation OR "low energy") AND ("Life } \\
\text { Cycle Assessment" OR LCA) AND (residential } \\
\text { OR house) NOT office }\end{array}$ & $\begin{array}{l}\text { ("Thermal envelope" OR "building envelope" } \\
\text { OR Insulation OR "low energy") AND } \\
\text { ("environmental impact") AND (residential OR } \\
\text { house) NOT office }\end{array}$ \\
\hline $\begin{array}{l}\text { ("Thermal envelope" OR "Building envelope" } \\
\text { OR Insulation OR "low energy") AND ("Life } \\
\text { Cycle Assessment" OR LCA) AND (residential } \\
\text { OR house) NOT office NOT commercial }\end{array}$ & $\begin{array}{l}\text { ("Thermal envelope" OR "building envelope" } \\
\text { OR Insulation OR "low energy") AND } \\
\text { ("environmental impact") AND (residential OR } \\
\text { house) NOT office NOT commercial }\end{array}$ \\
\hline
\end{tabular}

Use of "Life Cycle Assessment" in the search phrase resulted in an average 11,419 results over all the phrases compared to 34,275 results from using "environmental impact". This difference is triple in size but does not mean that the term is necessarily more appropriate than the other. In this case, the decision was made to use both terms in the final search phrase.

The average number of results from each database is shown in Table 9. Again, Google Scholar had the largest number of results. Birkhauser resulted in 0 results across all searches. Three databases had a maximum over 1,000 results and Google Scholar 27,500. This number of results is too large to sort manually, so more refinement of the search phrase is required only to include relevant literature. An interesting point to note is that adding the term "commercial" to the exclusion part of 
the search phrase, resulted in a decrease of results of 3,802 and 9,341 from the two search phrase sets in Table 9 .

Table 9 Literature results from databases

\begin{tabular}{|c|c|c|}
\hline Database & $\begin{array}{l}\text { Average result range } \\
\text { for all search terms }\end{array}$ & $\begin{array}{l}\text { Maximum number } \\
\text { of results }\end{array}$ \\
\hline $\begin{array}{l}\text { Australian Building Construction and } \\
\text { Engineering Database: BUILD }\end{array}$ & 2 & 5 \\
\hline Birkhauser & 0 & 0 \\
\hline EBSCOhost & 190 & 294 \\
\hline Emerald & 50 & 104 \\
\hline Gale Infotrac PowerSearch & 220 & 502 \\
\hline Google Scholar & 16,080 & 27,500 \\
\hline IEEE Explore & 1 & 8 \\
\hline ProQuest & 2,620 & 5,724 \\
\hline Sage Premier Journal Collection & 80 & 188 \\
\hline Sage: Science and Geography Education & 2 & 5 \\
\hline Science Direct & 2,020 & 4,664 \\
\hline Scopus & 140 & 268 \\
\hline SpringerLink & 750 & 2,117 \\
\hline Tayler and Francis & 280 & 699 \\
\hline Wiley & 390 & 911 \\
\hline
\end{tabular}

The same process from earlier was performed to determine relevant keywords to include based on the scoping searches by screening titles and through discussion with colleagues. Table 10 details keywords that can be added to the final search phrase.

Table 10 Inclusion and exclusion keywords

\begin{tabular}{ll}
\hline Inclusion & Exclusion \\
\hline Passive house & Retail \\
Zero-energy buildings & Renovation \\
\hline
\end{tabular}




\begin{tabular}{ll}
\hline Comparative & Retrofit \\
Wall & Refurbishment \\
Wall-systems & Economics \\
Wall assembly & Glazing \\
Roof & Window \\
Energy efficiency & Window Wall Ratio (WWR) \\
Zero-energy & Rainwater for toilets flushing \\
Embodied energy & Waste management \\
Operating energy & PV systems \\
Operational energy & Feedstock supply \\
Energy savings/reduction & Food supply chain \\
Environmental benefits & Dairy production \\
Greenhouse gas & \\
Global warming potential & \\
Carbon footprint & \\
Building materials & \\
R-value & \\
U-value & \\
\hline
\end{tabular}

\subsubsection{Final search strategy}

The final detailed search phrase is shown in Table 11. The significant difference between this phrase and the others is that the exclusion criteria have a significant number of terms to remove all irrelevant results from the searches.

Table 11 Final who, what, how and where keywords

\begin{tabular}{|c|c|c|c|c|c|}
\hline $\begin{array}{l}\text { Research } \\
\text { question }\end{array}$ & Who & What & How & Where & $\begin{array}{l}\text { Exclusion } \\
\text { criteria }\end{array}$ \\
\hline $\begin{array}{l}\text { Can residential } \\
\text { thermal } \\
\text { envelopes meet } \\
\text { indoor } \\
\text { environmental } \\
\text { quality } \\
\text { requirements } \\
\text { and have a low } \\
\text { environmental } \\
\text { impact? }\end{array}$ & $\begin{array}{l}\text { ("Thermal } \\
\text { envelope" } \\
\text { OR } \\
\text { "building } \\
\text { envelope" } \\
\text { OR Wall OR } \\
\text { roof OR } \\
\text { floor) }\end{array}$ & $\begin{array}{l}\text { (Insulation } \\
\text { OR "R- } \\
\text { value" OR } \\
\text { "U value") }\end{array}$ & $\begin{array}{l}\text { ("Life Cycle } \\
\text { Assessment" } \\
\text { OR LCA OR } \\
\text { "Environmental } \\
\text { impact") }\end{array}$ & $\begin{array}{l}\text { (Residential } \\
\text { OR house } \\
\text { OR "passive } \\
\text { house") }\end{array}$ & $\begin{array}{l}\text { (Office OR } \\
\text { commercial } \\
\text { OR retail OR } \\
\text { Glazing OR } \\
\text { window OR } \\
\text { economic OR } \\
\text { retrofit OR } \\
\text { renovation } \\
\text { OR } \\
\text { refurbishment } \\
\text { OR } \\
\text { government) }\end{array}$ \\
\hline
\end{tabular}


Below is an example of how the terms are joined into one search phrase for use in each database. This phrase incorporates boolean operators to connect terms.

("Thermal envelope" OR "building envelope" OR Wall OR roof OR floor) AND (Insulation OR "R-value" OR "U value") AND ("Life Cycle Assessment" OR LCA OR "Environmental impact") AND (residential OR house OR "passive house") NOT (office OR commercial OR retail OR Glazing OR window OR economic OR retrofit OR renovation OR refurbishment OR government)

Each database was searched with the search phrase, and the results exported to citation management software Endnote. This process resulted in 1,442 citations before duplicates were removed. Removing duplicates resulted in 1,427 citations.

\subsubsection{Determination of relevant literature}

The titles of each citation were compared against the inclusion criteria in Table 10. Citations that did not meet the criteria were excluded. Many of these citations were related to economics, government, motor industry, infrastructure, medicine, biology, waste, industrial processes (waterways, energy). Assessing these citations against the criteria identified 158 relevant citations and 1,269 irrelevant citations.

Screening the titles a second time found that the initial screening was not strict on focusing on environmental impact caused by the thermal envelope. Instead, citations that were related to acoustics, structure and durability were still included. Upon a second screening with focus given to environmental impact caused by the thermal envelope, this resulted in 109 irrelevant citations being removed, and 49 relevant citations included. Irrelevant citations included studies on acoustics, structural performance, durability, hygrothermal, seismic, steel, green roof and solar systems.

The full-text citations were then found so that abstracts of the 49 citations could be assessed. Seven citations were excluded because the full texts could not be obtained. The remainder (42) were assessed against the inclusion criteria in Table 10. Several studies were focused on green roofs or commercial buildings; these were excluded, leaving 20 citations to be included in the review.

Figure 6 shows the flow chart process of the literature screening process. 


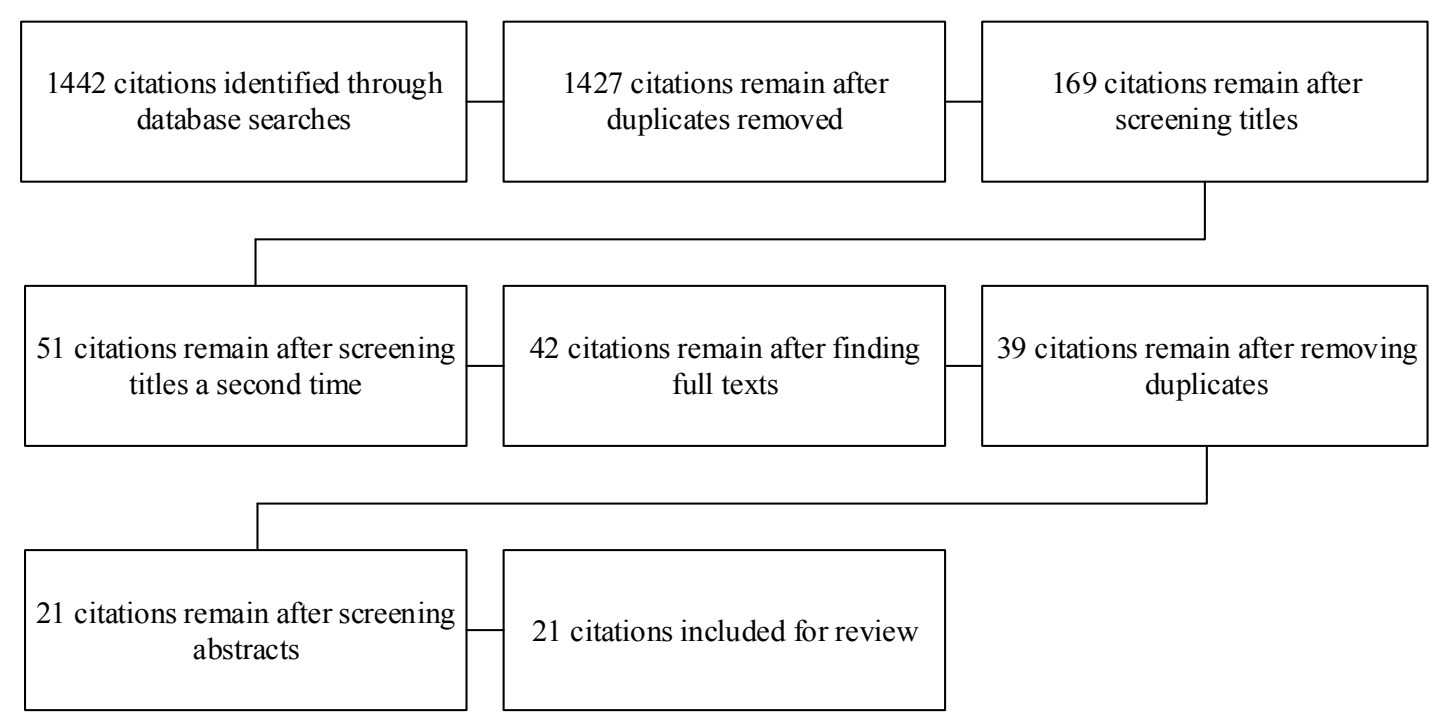

Figure 6 Flow chart of the systematic review process

\subsection{Quality assessment of relevant literature}

With 20 studies identified, the systematic review process requires that they are assessed on their quality and trustworthiness, these are measured by assessing "the degree to which a study employs measures to minimize bias and error in its design, conduct and analysis" (Boland et al., 2014).

A tool was developed to enable this assessment. The tool was a checklist consisting of 11 questions (Table 12). These questions were developed from Boland et al. and can be categorised into three sections, background, methodology and analysis. Each question was designed to have either a yes, no or not applicable answer. Each question was designed to identify whether any bias or flaws are present in the three categories. For example, "Were appropriate criteria used to assess environmental impacts?" If the study did not use appropriate criteria, then this may result in the analysis and findings to be inaccurate, reducing the quality of the study.

\section{Table 12 Quality assessment questions}

\section{Questions}

Was the study purpose clearly stated?

Was relevant background literature reviewed?

Was the building/element described in detail? 
Was the intervention described in detail?

Were preventative measures taken to minimise bias and errors in the quality assessment process?

Were preventative measures taken to minimise bias and errors in the data extraction process?

Were appropriate criteria used to assess environmental impacts?

Did they present the results of all the simulations/calculations?

Were they critical of the environmental results?

Were conclusions appropriate, given study methods and results?

Could the study be replicated with data provided?

The tool was piloted on three studies to determine whether it was appropriate for this situation. A colleague also used the tool on the same three studies to eliminate bias from occurring during the quality assessment stage. After this pilot test, it was found that three questions were not appropriate or needed altering. These questions are shown in Table 13, where one question was too similar to another. One question did not apply to any study and the final question needed to be split into three separate questions. The new questions to include in the final tool are:

- Did they quality assure the quantities of materials for the buildings?

- Did they quality assure life cycle indicator/environmental impact data?

- Did they quality assure building heating and cooling energy?

The quality assessment process was undertaken, and a colleague used again to eliminate bias by checking the authors' use of the tool on a selection of studies. It was found that the author and colleague agreed, and the next stage could commence.

\section{Table 13 Quality assessment questions}

\begin{tabular}{lll}
\hline Questions & Included/excluded & Reasoning \\
\hline $\begin{array}{l}\text { Was the building/element described in } \\
\text { detail? }\end{array}$ & Excluded & $\begin{array}{l}\text { Question is too similar to the } \\
\text { intervention question. From the } \\
\text { pilot, these two questions were } \\
\text { resulting in the same answer }\end{array}$ \\
$\begin{array}{l}\text { Were preventative measures taken to } \\
\text { minimise bias and errors in the quality } \\
\text { assessment process? }\end{array}$ & Excluded & $\begin{array}{l}\text { No studies performed systematic } \\
\text { literature reviews. }\end{array}$ \\
\hline
\end{tabular}


Were preventative measures taken to minimise bias and errors in the data extraction process?
Excluded

Data extraction needs to be split into three areas, material quantities, environmental impact data and heating and cooling energy.

A ranking system was used to assess each study giving points based on the answer to each quality assessment question. If the study answered "yes" it was given one point with a maximum of 11 points available.

Studies which received $1-3$ points are classed as "weak", studies receiving 4 -7 points are classed as "medium" and studies with $8-11$ points classed as "strong". The answer to each question and the ranking of studies is shown in Figure 7. The weak papers were like one another, as were the strong papers. However, medium studies did not align with one another.

Of the 20 studies, two of these were rated as weak, eight as medium and ten as strong. The weak studies both received only three points, which were for a clear purpose, presentation of all simulation results, and a mixture of intervention detail and appropriate criteria for assessing environmental impacts. For all other questions, the score was no or not applicable.

The medium strength studies did not have similar patterns to their assessment. All medium and weak studies did not review background literature, whereas all strong studies did. No medium studies quality assured quantities of materials.

Strong studies did align closely with one another. All the strong studies clearly stated their purpose, reviewed background literature, described their intervention, presented all simulation results, were critical of environmental results, and gave appropriate conclusions. Only one of the ten did not quality-assure life cycle indicator/environmental impact data, and half could not be replicated with the data provided. Of the strongest literature, one failed to quality assure quantities of materials and another building heating and cooling energy. 


\begin{tabular}{|c|c|c|c|c|c|c|}
\hline Reference & $\begin{array}{l}\text { Was the study } \\
\text { purpose clearly } \\
\text { stated? }\end{array}$ & $\begin{array}{l}\text { Was relevant } \\
\text { background } \\
\text { literature } \\
\text { reviewed? }\end{array}$ & $\begin{array}{l}\text { Was the } \\
\text { intervention } \\
\text { described in } \\
\text { detail? }\end{array}$ & $\begin{array}{l}\text { Did they quality } \\
\text { assure the } \\
\text { quantities of } \\
\text { materials for the } \\
\text { buildings? }\end{array}$ & $\begin{array}{l}\text { Did they quality } \\
\text { assure life cycle } \\
\text { indicator/environm } \\
\text { ental impact data? }\end{array}$ & $\begin{array}{l}\text { Did they quality } \\
\text { assure building } \\
\text { heating and } \\
\text { cooling energy? }\end{array}$ \\
\hline (M Dovjak et al., 2017) & $\mathrm{Y}$ & $\mathrm{N}$ & $\mathrm{N}$ & $\mathrm{N}$ & $\mathrm{Y}$ & NA \\
\hline (Cuce et al., 2014) & $\mathrm{Y}$ & $\mathrm{Y}$ & $\mathrm{Y}$ & $\mathrm{N}$ & $\mathrm{N}$ & $\mathrm{Y}$ \\
\hline (Čuláková and Vilčeková, 2013) & $\mathrm{Y}$ & $\mathrm{Y}$ & $\mathrm{Y}$ & $\mathrm{N}$ & $\mathrm{Y}$ & $\mathrm{N}$ \\
\hline (D'Alessandro et al., 2017) & $\mathrm{Y}$ & $\mathrm{Y}$ & $\mathrm{Y}$ & $\mathrm{N}$ & $\mathrm{Y}$ & $\mathrm{Y}$ \\
\hline (Erlandsson et al., 1997) & $\mathrm{Y}$ & $\mathrm{N}$ & $\mathrm{Y}$ & $\mathrm{N}$ & $\mathrm{N}$ & $\mathrm{Y}$ \\
\hline (Estokova et al., 2017) & $\mathrm{Y}$ & $\mathrm{Y}$ & NA & $\mathrm{N}$ & $\mathrm{N}$ & $\mathrm{N}$ \\
\hline (Frenette et al., 2008) & $\mathrm{Y}$ & $\mathrm{N}$ & $\mathrm{Y}$ & $\mathrm{N}$ & $\mathrm{Y}$ & $\mathrm{Y}$ \\
\hline (Galán-Marín et al., 2015) & $\mathrm{Y}$ & $\mathrm{Y}$ & $\mathrm{Y}$ & $\mathrm{Y}$ & $\mathrm{Y}$ & NA \\
\hline (Gorshkov et al., 2015) & $\mathrm{Y}$ & $\mathrm{N}$ & $\mathrm{Y}$ & $\mathrm{N}$ & $\mathrm{N}$ & $\mathrm{Y}$ \\
\hline (Islam et al., 2015) & $\mathrm{Y}$ & $\mathrm{Y}$ & $\mathrm{Y}$ & $\mathrm{N}$ & $\mathrm{Y}$ & $\mathrm{N}$ \\
\hline (Karami et al., 2015) & $\mathrm{Y}$ & $\mathrm{Y}$ & $\mathrm{Y}$ & $\mathrm{Y}$ & $\mathrm{Y}$ & $\mathrm{N}$ \\
\hline (Kunič and Kutnar, 2013) & $\mathrm{Y}$ & $\mathrm{N}$ & $\mathrm{Y}$ & $\mathrm{Y}$ & $\mathrm{Y}$ & NA \\
\hline (Kylili et al., 2017) & $\mathrm{Y}$ & $\mathrm{Y}$ & NA & $\mathrm{Y}$ & $\mathrm{Y}$ & $\mathrm{N}$ \\
\hline (Lawania and Biswas, 2017) & $\mathrm{Y}$ & $\mathrm{Y}$ & $\mathrm{Y}$ & $\mathrm{N}$ & $\mathrm{Y}$ & $\mathrm{N}$ \\
\hline (Mikulic et al., 2010) & $\mathrm{Y}$ & $\mathrm{N}$ & $\mathrm{Y}$ & $\mathrm{N}$ & $\mathrm{N}$ & $\mathrm{N}$ \\
\hline (Monteiro and Freire, 2011) & $\mathrm{Y}$ & $\mathrm{Y}$ & $\mathrm{Y}$ & $\mathrm{N}$ & $\mathrm{Y}$ & $\mathrm{N}$ \\
\hline (Nemry et al., 2010) & $\mathrm{Y}$ & $\mathrm{N}$ & $\mathrm{Y}$ & $\mathrm{N}$ & $\mathrm{Y}$ & $\mathrm{N}$ \\
\hline (Proietti et al., 2013) & $\mathrm{Y}$ & $\mathrm{N}$ & NA & $\mathrm{N}$ & $\mathrm{Y}$ & $\mathrm{N}$ \\
\hline (Vilčeková et al., 2015) & $\mathrm{Y}$ & $\mathrm{Y}$ & $\mathrm{Y}$ & $\mathrm{N}$ & $\mathrm{Y}$ & $\mathrm{N}$ \\
\hline (Vilćeková et al., 2013) & $\mathrm{Y}$ & $\mathrm{N}$ & NA & $\mathrm{N}$ & $\mathrm{N}$ & $\mathrm{N}$ \\
\hline Strength & Strong & Medium & Strong & Weak & Medium & Weak \\
\hline Reference & $\begin{array}{l}\text { Were appropriate } \\
\text { criteria used to } \\
\text { assess } \\
\text { environmental } \\
\text { impacts? }\end{array}$ & $\begin{array}{l}\text { Did they present } \\
\text { the results of all } \\
\text { the } \\
\text { simulations/calcul } \\
\text { ations? }\end{array}$ & $\begin{array}{l}\text { Were they critical } \\
\text { of the } \\
\text { environmental } \\
\text { results? }\end{array}$ & $\begin{array}{l}\text { Were conclusions } \\
\text { appropriate given } \\
\text { study methods } \\
\text { and results? }\end{array}$ & $\begin{array}{l}\text { Could the study } \\
\text { be replicated with } \\
\text { data provided? }\end{array}$ & Study strength \\
\hline (M Dovjak et al., 2017) & $\mathrm{Y}$ & $\mathrm{Y}$ & $\mathrm{Y}$ & $\mathrm{Y}$ & $\mathrm{Y}$ & Medium \\
\hline (Cuce et al., 2014) & $\mathrm{N}$ & $\mathrm{Y}$ & $\mathrm{Y}$ & $\mathrm{Y}$ & $\mathrm{Y}$ & Strong \\
\hline (Čuláková and Vilčeková, 2013) & $\mathrm{Y}$ & $\mathrm{Y}$ & $\mathrm{Y}$ & $\mathrm{Y}$ & $\mathrm{N}$ & Strong \\
\hline (D'Alessandro et al., 2017) & $\mathrm{Y}$ & $\mathrm{Y}$ & $\mathrm{Y}$ & $\mathrm{Y}$ & $\mathrm{Y}$ & Strong \\
\hline (Erlandsson et al., 1997) & $\mathrm{N}$ & $\mathrm{Y}$ & $\mathrm{Y}$ & $\mathrm{Y}$ & $\mathrm{N}$ & Medium \\
\hline (Estokova et al., 2017) & $\mathrm{Y}$ & $\mathrm{Y}$ & $\mathrm{N}$ & $\mathrm{Y}$ & $\mathrm{N}$ & Medium \\
\hline (Frenette et al., 2008) & $\mathrm{Y}$ & $\mathrm{Y}$ & NA & $\mathrm{Y}$ & $\mathrm{N}$ & Medium \\
\hline (Galán-Marín et al., 2015) & $\mathrm{Y}$ & $\mathrm{Y}$ & $\mathrm{Y}$ & Y & $\mathrm{Y}$ & Strong \\
\hline (Gorshkov et al., 2015) & $\mathrm{N}$ & $\mathrm{Y}$ & $\mathrm{N}$ & $\mathrm{N}$ & $\mathrm{Y}$ & Medium \\
\hline (Islam et al., 2015) & $\mathrm{Y}$ & $\mathrm{Y}$ & $\mathrm{Y}$ & $\mathrm{Y}$ & $\mathrm{Y}$ & Strong \\
\hline (Karami et al., 2015) & $\mathrm{Y}$ & $\mathrm{Y}$ & $\mathrm{Y}$ & $\mathrm{Y}$ & $\mathrm{Y}$ & Strong \\
\hline (Kunič and Kutnar, 2013) & $\mathrm{Y}$ & $\mathrm{N}$ & $\mathrm{Y}$ & $\mathrm{N}$ & $\mathrm{Y}$ & Medium \\
\hline (Kylili et al., 2017) & $\mathrm{Y}$ & $\mathrm{Y}$ & $\mathrm{Y}$ & $\mathrm{Y}$ & $\mathrm{Y}$ & Strong \\
\hline (Lawania and Biswas, 2017) & $\mathrm{Y}$ & $\mathrm{Y}$ & $\mathrm{Y}$ & $\mathrm{Y}$ & $\mathrm{N}$ & Strong \\
\hline (Mikulic et al., 2010) & $\mathrm{N}$ & $\mathrm{Y}$ & $\mathrm{N}$ & $\mathrm{N}$ & $\mathrm{N}$ & Weak \\
\hline (Monteiro and Freire, 2011) & $\mathrm{Y}$ & $\mathrm{Y}$ & $\mathrm{Y}$ & $\mathrm{Y}$ & $\mathrm{N}$ & Strong \\
\hline (Nemry et al., 2010) & $\mathrm{Y}$ & $\mathrm{Y}$ & $\mathrm{Y}$ & $\mathrm{y}$ & $\mathrm{N}$ & Medium \\
\hline (Proietti et al., 2013) & $\mathrm{Y}$ & $\mathrm{Y}$ & $\mathrm{N}$ & $\mathrm{Y}$ & $\mathrm{N}$ & Medium \\
\hline (Vilčeková et al., 2015) & $\mathrm{Y}$ & $\mathrm{Y}$ & $\mathrm{Y}$ & $\mathrm{Y}$ & $\mathrm{N}$ & Strong \\
\hline (Vilćeková et al., 2013) & $\mathrm{Y}$ & $\mathrm{Y}$ & $\mathrm{N}$ & $\mathrm{N}$ & $\mathrm{N}$ & Weak \\
\hline Strength & Strong & Strong & Medium & Strong & Medium & - \\
\hline
\end{tabular}

Figure 7 Quality assessment of included literature

The 'yes' responses were then assessed against each question to gain an understanding of gaps in the literature. Each question was again ranked on a weak, 
medium, strong system. Questions that received 1 - 7 points are classed as "weak", literature receiving 8-14 points are classed as "medium" and studies with $15-20$ points classed as "strong".

The two questions where the literature was the weakest were related to quality assurance. Very few studies performed quality assurance on the quantities of materials, life cycle environmental data, and building energy use. Six studies quality assured two of the categories, 11 studies only quality assured one category, and three did no quality assurance. Lack of quality assurance severely impacts the quality of the literature as, without this quality assurance, it is unclear whether the results and conclusions are reliable.

Eleven of the studies reviewed background literature, and 14 were critical of the environmental impacts. These fall in the medium range.

The questions with the strongest yes response were clearly stating the purpose and presenting all results of the simulations. The other three strong questions were describing the intervention, using appropriate criteria for assessment, and presenting appropriate conclusions.

Overall, the quality of the assessed literature is in favour of strong studies with eight medium and ten strong studies. The two weak studies, however, scored significantly lower than the lowest medium studies. These low studies were Mikulic, 2010, and Vilćeková, 2013. The categories which reduced the quality of the studies were related to quality assurance of the data being used for the simulations. No study quality assured all data used and a majority (eleven) only quality assured one category. Eleven studies could not be replicated, and seven of these only quality assured one data category.

\subsection{Data extraction}

Now that quality of the citations had been established data from the full texts were extracted. To extract data from the full texts questions were created in Table 14 relating to the study type, what specific materials and methods were used as well as the findings and conclusions. 
Table 14 Data extraction questions

\section{Questions}

What is the study type?

What materials/construction are altered?

What materials/construction are used for insulation?

What kind of environmental analysis?

What indicators are used to assess impact?

What is the building type and classification?

What were the findings?

What were the conclusions?

The questions were applied to three studies with a colleague again, also answering the questions with the same studies. The process is to ensure that no bias was given by the author when extracting data and interpretations of the questions are clear from the question-wording. The answers from both researchers were then compared, and decisions were made to alter several questions and include additional questions.

It was decided to extract more data than necessary to reduce the possibility of having to return to the studies to extract additional necessary data.

The new questions in Table 15 were again tested on the small selection of studies and the colleague's answers compared. The answers were in alignment and interpretation of the questions was clear between the two researchers.

\section{Table 15 Data extraction questions - expanded}

\section{Questions}

Did the study assess a thermal envelope?

Was Indoor Environmental Quality (IEQ) met?

Does the study result in low environmental impact?

What is the study type?

What is the building type?

What is the building classification? 
What is the energy classification?

How large is the building $\left(\mathrm{m}_{2}\right)$ ?

What building element was altered?

How many changes were made?

How many house designs were assessed?

What is the construction type?

What insulation materials were used?

What country was the study performed?

Is energy for heating/cooling calculated?

Does the study calculate the cost?

Did the study perform an LCA

What were the LCA stages used?

What was the LCA database used?

How many environmental indicators were used?

What environmental indicators were used?

What is the analysis methodology?

What were the findings?

What were the conclusions?

How did the buildings environmental impact change?

\subsubsection{Study characteristics}

Eighteen of the 20 studies used simulation methodology. Cuce et al.(2014) conducted a simulation and measured empirical data, and D'Alessandro et al. (2017) only measured empirical data.

The range of buildings studied varied from three storeys to twelve-storeys. One study focused on just the elements of the building (Kunič \& Kutnar, 2013). Estokova et al. (2017) and Nemry et al. (2010) performed studies using a representative building or multiple buildings to act as a representative building for the setting.

Twelve studies assessed just the wall's thermal envelope in relation to environmental impact. Two studies assessed the wall and roof, and four studies 
assessed the wall, roof and floor elements in combination. The remaining two studies, Proietti et al. (2013) and Vilćeková et al. (2013), assessed the entire house, but no alterations or changes in materials were simulated to reduce environmental impact.

Twenty-two insulating materials were used across the studies detailed in the table below.

Table 16 Insulation materials examined in the 20 studies identified in the systematic literature review process

\begin{tabular}{|c|c|c|c|c|c|c|c|}
\hline \multicolumn{8}{|c|}{ Materials } \\
\hline Aerogel & Cork & $\begin{array}{l}\text { Extruded } \\
\text { Polystyrene }\end{array}$ & $\begin{array}{l}\text { Foam } \\
\text { glass }\end{array}$ & Hemp & $\begin{array}{l}\text { Low and } \\
\text { high- } \\
\text { density } \\
\text { stone } \\
\text { wool }\end{array}$ & Straw & Wool \\
\hline $\begin{array}{l}\text { Blown } \\
\text { cellulose }\end{array}$ & Earth & Flax & $\begin{array}{l}\text { Glass } \\
\text { fibre }\end{array}$ & $\begin{array}{l}\text { High- } \\
\text { density } \\
\text { mineral } \\
\text { wool }\end{array}$ & $\begin{array}{l}\text { Mineral } \\
\text { wool }\end{array}$ & $\begin{array}{l}\text { Vacuum } \\
\text { Insulated } \\
\text { Panels }\end{array}$ & \\
\hline Cellulose & $\begin{array}{l}\text { Exterior } \\
\text { Thermal } \\
\text { Insulation } \\
\text { Composite } \\
\text { System } \\
\text { (ETICS) }\end{array}$ & Fleece & $\begin{array}{l}\text { Glass } \\
\text { wool }\end{array}$ & Linen & $\begin{array}{l}\text { Rock } \\
\text { wool }\end{array}$ & $\begin{array}{l}\text { Wood } \\
\text { fibre } \\
\text { board }\end{array}$ & \\
\hline
\end{tabular}

Eighteen studies performed an LCA, whereas Cuce et al. (2014) and Mikulic et al. (2010 created their own method of assessing the environmental impact. In total, 15 unique environmental indicators were used across all the studies. The most popular were Acidification and Global Warming with 11 and 14 studies using these indicators, respectively. On average, four indicators were included in each study. Kylili et al. (2017) included eight environmental indicators.

The calculated environmental impact in each of the studies is directly related to the LCA database or Environmental Product Declarations (EPDs) that the study uses. Location of the study or building also has a significant impact on this. The studies were from Europe, America and Australia. 


\subsubsection{Relation to review question}

Each study was assessed against the three parts of the literature review question these being whether the study is focused on the thermal envelope, whether the indoor environmental quality is met and whether this results in low environmental impact.

All 20 studies assessed the environmental impact and 18 of these resulted in adequate indoor environmental quality (IEQ). This assessment of adequate IEQ is based on the assumption that energy for heating and cooling is used to control the indoor comfort of the building. Estokova et al. (2017) and Galán-Marín et al. (2015) were two studies where it is not known whether IEQ was maintained this is because the studies both do not consider operational energy use or benchmark the thermal envelope constructions. Three other studies, Čuláková and Vilčeková (2013), Kunič and Kutnar (2013) and Vilćeková et al. (2013) did not calculate operational energy but benchmarked the thermal envelope that was altered to have the same $\mathrm{R}$-value. Therefore, in theory, use the same operational energy. However, this cannot be assumed without calculations as the building may be using more energy than required in relation to the thermal envelope.

The third part of the question relates to the building having a low environmental impact caused by the thermal envelope. Fourteen studies resulted in low impact or reduced impact. Estokova et al. (2017) was the only study that resulted in an increased impact, states insulation contributes negatively to the environment but does not consider alternative materials for the thermal envelope. It is not clear whether the three remaining studies Gorshkov et al. (2015), M Dovjak et al. (2017) and Mikulic et al. (2010) have a low or high environmental impact as they do not account for the impact from the materials used, only operational energy.

\subsubsection{Methodology used}

All studies used a similar methodology of calculating the environmental impact of a base building and then altering the thermal envelope by changing the construction and finally calculating the resultant impact. Two of the studies, however Proietti et al. (2013) and Vilćeková et al. (2013) did not change or alter any part of the thermal envelope as they just performed an LCA on buildings which were low energy buildings. Five studies assessed natural insulation, while one Cuce et al. (2014) 
assessed superinsulation materials. The rest all focused on alternative insulation materials.

The number of changes to materials/construction techniques varied between studies from as little as 1 to 175 (Vilčeková, Čuláková, Burdová, \& Katunská, 2015). Excluding Vilčeková et al. (2015), the average number of changes was ten. Most studies performed a case study of an existing house or used plans of a house. Nemry et al. (2010) created 72 building types, which represented $80 \%$ of the whole European building stock, which allowed conclusions to be made on a wider scale compared with other studies which were very specific to the case study building.

Once materials were changed/altered, 15 studies then calculated operational energy to heat and cool the building and included the resultant environmental impact from this in the total impacts. One of the remaining five, Galán-Marín et al. (2015), only focused on the building elements and materials; therefore, did not need to include energy use in the study. Vilčeková et al. (2015), Čuláková and Vilčeková (2013) and Kunič and Kutnar (2013) used a method of benchmarking all altered constructions to the same R-value, therefore, resulting in the same energy use. The remaining study, Estokova et al. (2017), did not have a justification for not calculating operational energy use. By excluding operational energy, this means that the buildings entire environmental impact cannot be calculated since the thermal envelope relates directly to the required energy to heat and cool the building.

Three studies Gorshkov et al. (2015) and Mikulic et al. (2010) do not account for the impact caused by the materials used in the envelope as they are only focused on the operational energy reductions achieved from different alterations to the thermal envelope.

\subsubsection{Analysis}

To assess the environmental impacts, the studies which used an LCA either compared the total impact from the materials/building elements against the environmental indicators or the total impact from materials/building elements per each stage of the building life cycle against the environmental indicators. Four studies, Čuláková and Vilčeková (2013), Frenette, Beauregard, Salenikovich, and Derome (2008), Islam, Jollands, Setunge, and Bhuiyan (2015) and Vilčeková et al. (2015) used 
Multi-Criteria Decision Analysis (MCDA) to select the optimum building material taking into account energy performance and environmental impact. Frenette et al. (2008) and Islam et al. (2015) included the cost in this MCDA. These four studies had 12, 6, 30 and 175 different constructions and used 3, 1, 3 and 3 environmental indicators respectively to include into the analysis creating many scenarios and impacts to assess.

Other studies which had large numbers of constructions to assess were Kylili et al. (2017) and Mikulic et al. (2010), but they were only increasing the thickness of one insulation material, therefore, were assessing the change in total environmental impact with more insulation added. Another study with a large number of buildings is Nemry et al. (2010), this study assessed 72 buildings and used primary energy as a proxy indicator to compare the building types.

Other studies, M Dovjak et al. (2017) and Monteiro and Freire (2011) did not use a technique to select which constructions were the best for the purpose. Instead, they highlighted which indicators had a high or low impact. These two methods both result in bias affecting the findings as the author must select which impacts are more important than others. This is similar for the remaining 11 studies.

\subsubsection{Findings}

Fourteen studies found that a buildings environmental impact decreases from changing insulation materials or having insulation that achieves high thermal resistance and in turn reduces operational energy use for heating and cooling. Estokova et al. (2017), Galán-Marín et al. (2015), Gorshkov et al. (2015), Kunič and Kutnar (2013), Kylili et al. (2017) and M Dovjak et al. (2017) all performed LCA's on natural insulation materials (straw, flax, cork, hemp, wool, earth, linen) the findings were that natural insulation could have a lower environmental impact compared to synthetic materials in some environmental indicators. However, these natural materials as stand-alone materials such as straw bale, have adequate thermal resistance but score poorly in durability, structural, acoustics, moisture and fire resistance. Meaning the materials would have to be used in conjunction with other materials and in turn, their environmental impact considered. Galán-Marín et al. (2015) was the only study that considered this aspect but failed to acknowledge the operational energy and 
change in thermal resistance of the new construction. Proietti et al. (2013) and (Vilćeková et al., 2013) performed an LCA on a low energy home and presented the recommendation of altering insulation materials to reduce the building's environmental impact but did not calculate the new impact or specify what materials to use as alternatives. Without this, these claims lack the trustworthiness of the study's conclusions. This is where the other studies are stronger as they test alternative constructions in the methodology and present the impact for each construction, increasing the quality of the study.

The studies that used MCDA Čuláková and Vilčeková (2013), Frenette et al. (2008), Islam et al. (2015) and Vilčeková et al. (2015) selected a single construction that met all the criteria specified by the author including cost, structural performance, thermal performance and others. These all increased IEQ and decreased environmental impact. Comparing this to the studies that did not perform an MCDA, many of these other studies only accounted for the environmental impact and no other factors. Using MCDA results in bias affecting the analysis and findings as the user specifies the weighting of each criterion. These studies do not identify the weighting or how bias was addressed and minimised, therefore affecting the quality of the studies. Erlandsson, Levin, and Myhre (1997), Estokova et al. (2017), Karami, Al-Ayish, and Gudmundsson (2015) concluded that the impact resulting from materials is minor in comparison to the impact caused by energy use, although the focus is given to reducing this impact. If two materials result in the same energy use, but one has a lesser environmental impact, then choosing that one would be preferred as they have the same effect on IEQ.

Erlandsson et al. (1997), Kylili et al. (2017) and Mikulic et al. (2010) adjusted the thickness of a single type of insulation in the wall, but neither of the studies considered the change in structural materials required from the increase or decrease in insulation thickness. Although new heating and cooling energy use was calculated, this method does not consider all aspects of the flow-on effects from the change in insulation.

When materials are assessed, they are assessed as what indicators are high and what is low in comparison to alternative materials. In the studies which did not perform MCDA, environmental indicators were treated as equal with no weighting 
determining which indicator should be targeted over others. This leaves room for bias to affect the findings, which were not addressed in any study.

Nemry et al. (2010), was the only study that used a set of buildings that were representative of the setting, in this instance, the European Union. Using representative buildings allows the conclusion that a specific type of building has the most potential to reduce that areas impact through insulation measures.

\subsubsection{Summary}

Fourteen studies address all parts of the review question meaning the thermal envelope meets IEQ requirements (indoor temperature) and results in low environmental impact. The issue with 13 of these studies is that these only relate to a single case study building, and the findings are not representative of the wider context. Nemry et al. (2010) is the only study which uses a representative building resulting in representative results.

These studies also use different insulation materials, environmental indicators, LCA/EPD databases and are in different climates. There is little consistency between studies, including the methods of analysis with some focusing on individual materials, elements, stages and overall impact.

Consideration is needed towards the material impacts, resultant operational energy use, change in materials, the LCA/EPD database used, environmental indicators, building, analysis method and presentation of all results and quality assurance of results. Failure to do so results in studies where the quality is reduced significantly as a result. No studies were able to fulfil all off these requirements.

It is important to note that following the literature review, two further studies were identified as relevant to this study. These were BRANZ SR350 New Zealand Whole Building Whole of Life Framework: Development of reference office buildings for use in early design and Beacon's Life Cycle Assessment of the Waitakere NOW Home (Pathway, 2008). Although these studies assess a different house typology, they were used as a reference of an LCA in a New Zealand context. 


\subsection{Review of this studies research question}

This studies research question is "How can an LCA be integrated into a designer's workflow to inform design decisions?" A range of buildings or designs was required to answer this so that an LCA could be performed and barriers to implementation of LCA resolved.

\subsubsection{What is the issue identified?}

In New Zealand, KiwiBuild, a government programme aims to deliver 100,000 affordable, quality homes from the period of 2019 - 2028 to fulfil housing demand. The question, however, is how can designers design low impact homes? The only way to quantify this impact is to undertake an LCA on these proposed houses following the considerations of the findings in the literature review. At this stage of the programme, it is unknown what type of dwellings will make up the total 100,000. These are predicted to be a majority stand-alone and a portion of MDH units based on nationwide housing forecasts. The question now is, how can design decisions be made when using an LCA on a range of houses using multiple environmental indicators?

\subsubsection{What is planned to resolve this issue?}

The Building Research Association of New Zealand (BRANZ) have a database of the environmental impact of a range of stand-alone detached houses with detailed LCAs performed. To make comparisons of different housing types that will be used in KiwiBuild, this study focused on the process of assessing the environmental impact of MDH through an LCA.

\subsubsection{Outline of methodology}

Case study buildings were selected from existing buildings or to be built buildings. LCA of these was conducted, including the creation of a BIM model and energy model of each building. The environmental impact was then calculated, and the process presented in thorough detail. Focusing on resolving issues that designers are facing to implement LCA into their workflow to inform design decisions. 
Literature Review 
A Life Cycle Assessment of Medium Density Houses in New Zealand 


\section{Chapter 3 \\ Medium Density Housing}

This chapter reports the method of selecting MDH units for inclusion in this study. From Chapter 2, it is important that representative houses are selected for an LCA to create a strong study and ensure results are representative of the wider context. Selecting representative MDH units is a complicated process due to the lack of information available for this housing type. Therefore, a method is created that can be used on any housing type which can identify common characteristics of houses and then select houses that have those characteristics. A floor plan mapping exercise was performed by selecting 24 random MDH units and documenting the floor area, the number of bedrooms, stories and the floor plan. The 24 units were assessed with three selected for inclusion in this study. 


\subsection{Size and construction}

Comprehensive datasets about $\mathrm{MDH}$ at this stage are difficult to source because of the proportion of MDH compared to stand-alone dwellings in New Zealand. Data from Statistics New Zealand shows that the average floor area of new homes in 2013 was 191m2 quoted in Iman, 2017. From Statistics New Zealand data of consents from $2008-2017$, the average floor area for apartments and townhouses is $114 \mathrm{~m} 2$ (it is assumed that the townhouse definition includes $\mathrm{MDH}$ ). Stand-alone houses have an average floor area of $213 \mathrm{~m} 2$ (Statistics NZ, 2018). From this data, it shows that multiunit dwellings have a significantly smaller floor area then stand-alone houses.

\begin{tabular}{lc}
$\begin{array}{l}\text { Table } 17 \text { Average floor area of consented dwellings - } 2008-2017 \\
\text { 2018) }\end{array}$ & m2tatistics $\mathbf{N Z}$, \\
\hline Building Classification & 213 \\
\hline Houses & 114 \\
\hline
\end{tabular}

Data from 1,200 building consent applications across New Zealand from the past ten years shows that timber framing was and still is a standard construction method in New Zealand (Brunsdon \& Morgan, 2018). Having a higher use than other structural materials, except in flooring where insulated concrete is higher (Figure 8). Use of fibreglass insulation has dropped slightly over the past two years in favour of polyester and polystyrene. This data shows that houses in New Zealand are typically timberframed with fibreglass insulation and a concrete floor slab. Whether this applies to MDH is unknown because of a lack of data from this housing type. 


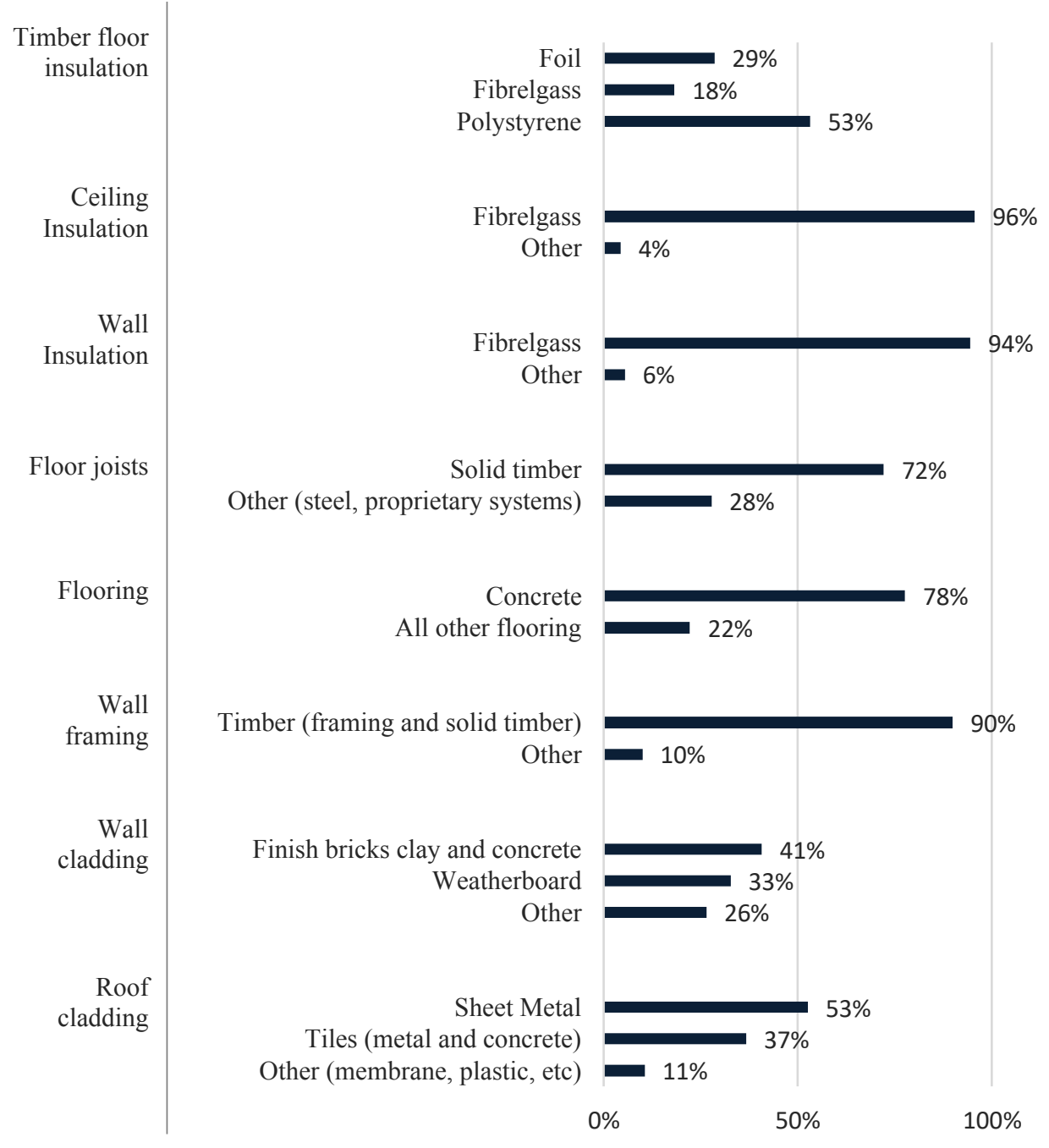

Figure 8 Average percentage of residential constructions (Brunsdon \& Morgan, 2018)

\subsection{Thermal performance of Medium Density Housing}

Energy use in MDH units is particularly important when conducting an LCA because the energy use has a direct relationship to the buildings environmental impact. If a unit's energy use increases so too will the building's environmental impact.

MDH units that are horizontally attached to the adjacent unit lose heat through the walls to the next unit and vice versa (Figure 9). This heat loss applies to the middle units in a long row of units with the two end units having one of their long walls exposed to the exterior. End units, therefore, have a larger total area of wall exposed 
to the exterior compared to middle units. Friedman estimates that heat loss is reduced by up to $42 \%$ for middle units compared to end units (Firedman, 2012).

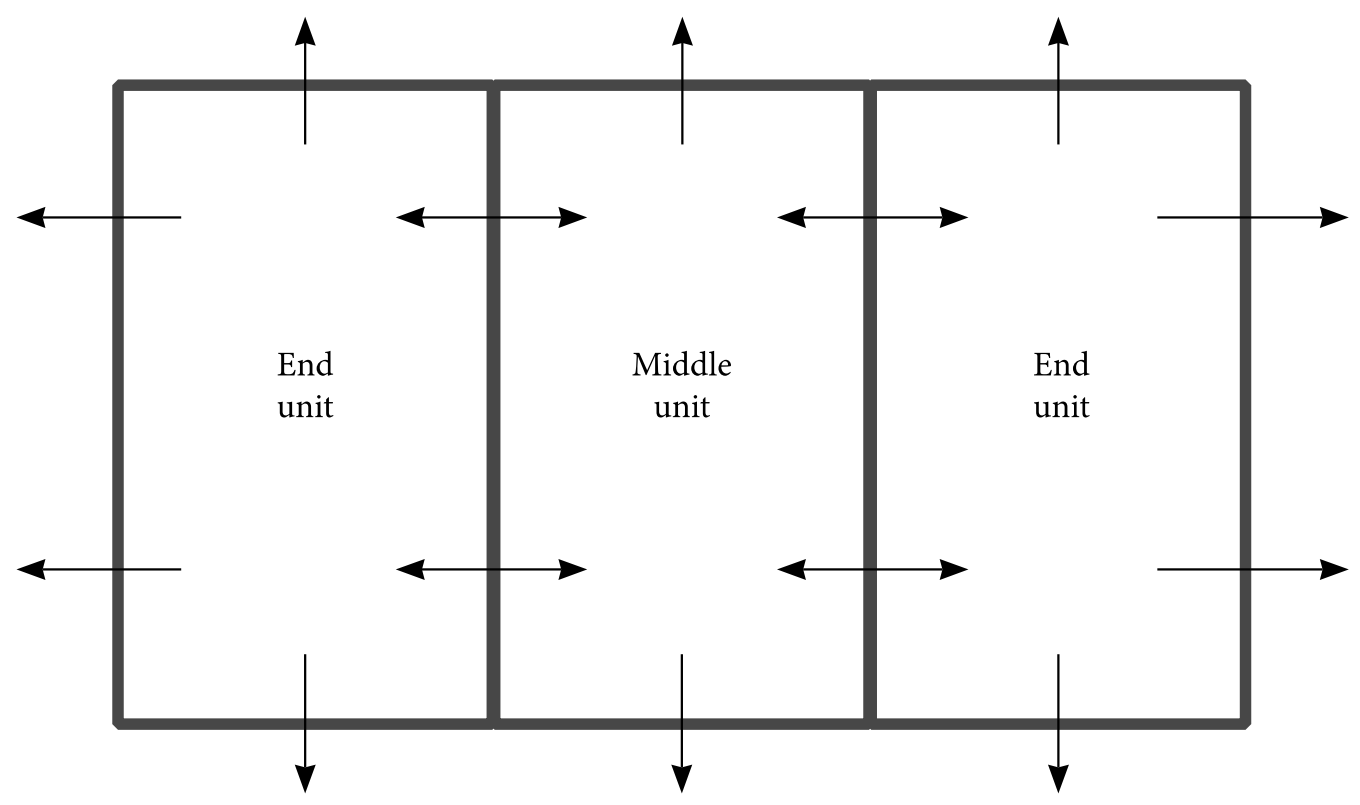

Figure 9 Heat loss to adjoining units and exterior

Because of the narrow-exposed façade for middle units, it is theorised that these façades will have a large proportion of glazing for passive solar design to allow daylight into the building. In warmer months, heat is gained through these windows but in cooler months, and overnight heat is lost. Creating an interesting balance of solar gains through the glazing and heat losses back through the glazing and into adjoining units. This poses the question of how much glazing is necessary on these façades where heat gains are maximised, and heat losses minimised. Another interesting question is how much of an impact does orientation have on these units? If a block of units is orientated east/west, will these units use more energy than a unit orientated north/south because it is not oriented towards the sun (north)?

Donn et al. (2015) study of two terrace houses in a large multi-unit development found that orientation of units had little impact on the thermal performance of the units. The units were rotated in $15^{\circ}$ increments to a complete $360^{\circ}$. For the first set of units shown in Figure 10 and Figure 11, the difference in energy use from the worst to best orientation was $7 \%$. 


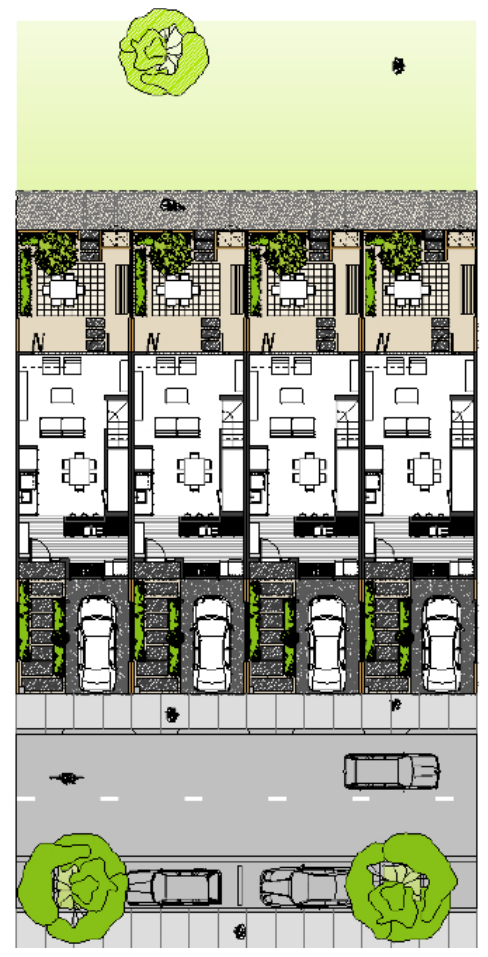

Figure 10 Type-A house - floor plan (Donn et al., 2015)

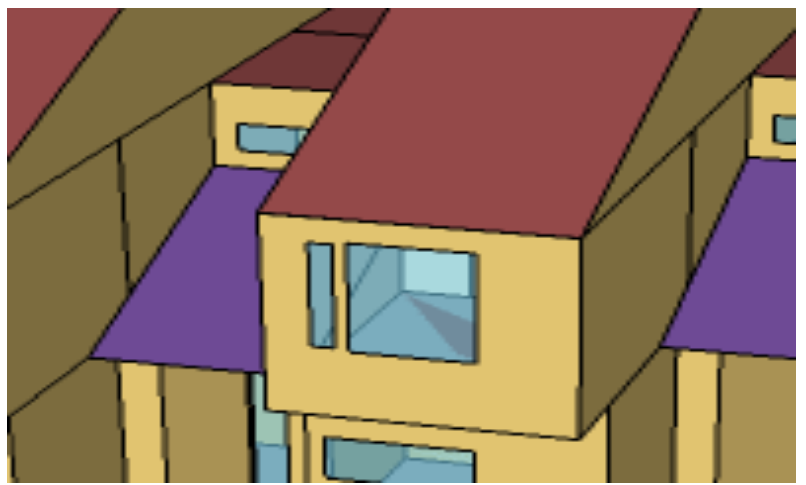

Figure 11 Type-A house - energy model (Donn et al., 2015)

Changing insulation and increasing natural ventilation had a larger impact on increasing the thermal performance of the units. Due to the units being simulated in a warm climate (Auckland, New Zealand) the best thermal performance was found by orientating the façade with the largest Window to Wall Ratio (WWR) away from the sun to reduce overheating.

The second unit (Figure 12) from Donn et al. (2015) is larger in floor area than the first unit, and the difference between worst and best energy was 5\%, concluding that module size and layout had little to no effect on which orientation is optimal. The 
worst performance resulted when the façade with the largest WWR was oriented towards the sun (north), again because of overheating.

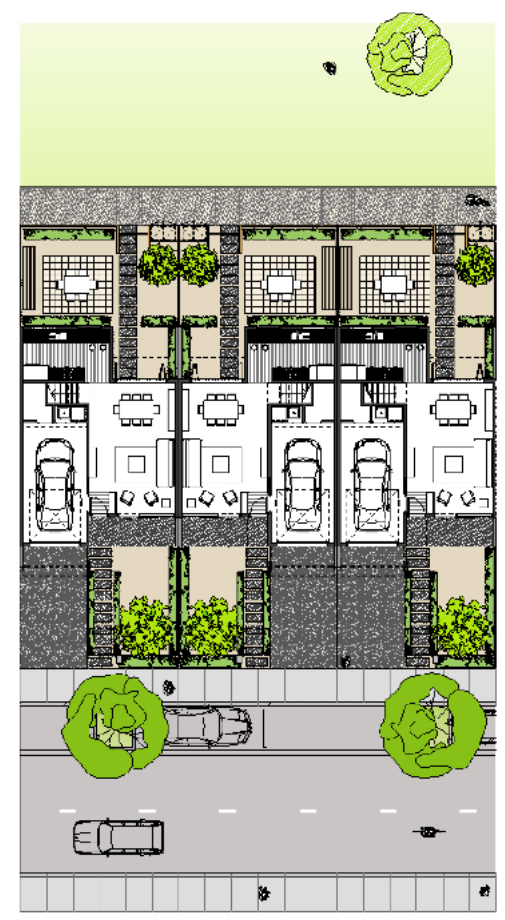

Figure 12 Type B house - floor plan (Donn et al., 2015)

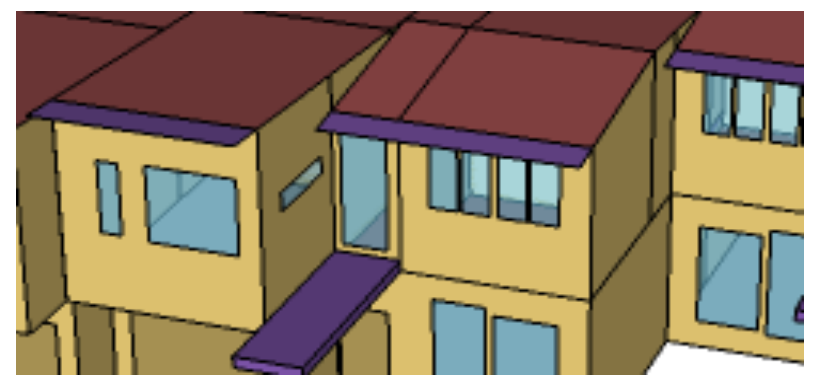

Figure 13 Type B house - energy model (Donn et al., 2015)

Further analysis showed for the two scenarios that reducing the WWR to $20 \%$, and then $10 \%$ on both exposed facades made the impact on thermal performance from different orientations negligible. Meaning energy use remained the same at different orientations. Having an equal WWR on both exposed facades eliminates the need for consideration of the units' orientation. The findings suggest that orientation will have a significant impact on thermal performance if the difference in WWR between the two exposed facades is large in a warm climate like Auckland. 


\subsection{Medium Density Housing internal layout}

The long narrow shape that is common of MDH units restricts internal layout as the most commonly used areas like the living room and bedroom are positioned near the exposed facades to maximise solar gains, daylight and ventilation. This layout is thought to rarely change between different designs of MDH units because of the tight, narrow floor plan and the want by occupants to place living areas near the exposed facades. The MDH units from Donn et al. (2015) were both two-storey and were placed in rows of four or more units side by side. Shown in Figure 14 as an overlay are the different thermal zones which were used for energy modelling purposes (Donn et al., 2015).
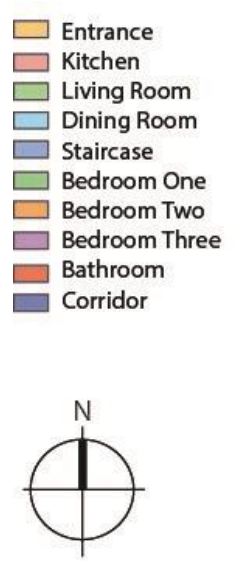

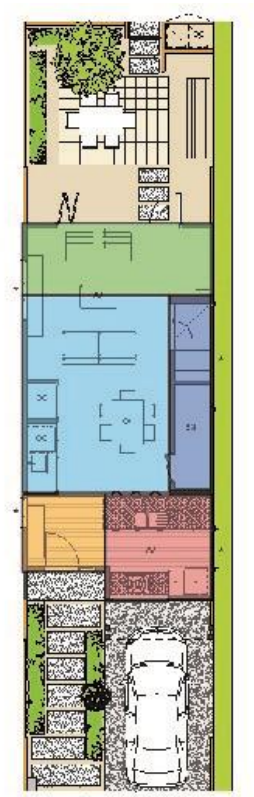

TYPE A: 5M MODULE

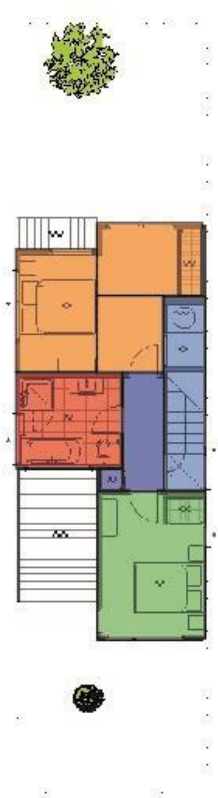

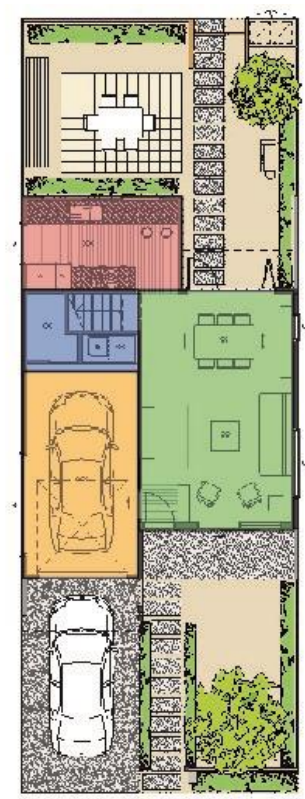

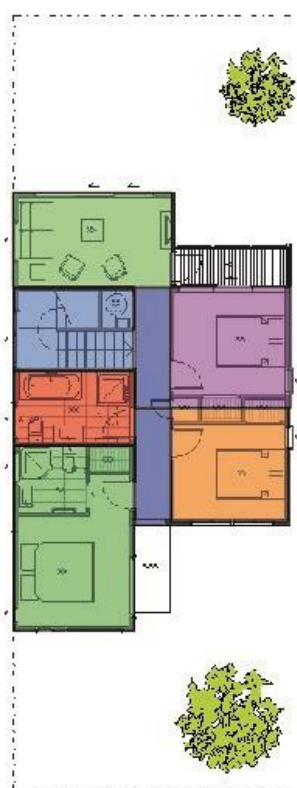

TYPE B: 7.5M MODULE

Figure 14 Type A and B floor plan

Observing the floor plans, the storage and bathroom areas are typically placed in the middle of the building, and living areas (living rooms, kitchen, dining and bedrooms) are placed on the outer edges. The internal layout will influence energy use as having living areas on the outer edges can maximise solar heat gains and have natural ventilation for cooling. Storage, circulation and bathroom spaces do not need these solar gains so can be placed in the middle of the floor plan. If the living areas are in the middle of the unit, they may require more energy to heat or cool. If they are 
in the middle of the unit, they will also have a room buffer between them and the outside, meaning there are no external walls for heat to be lost. The reduction of heat loss is all well from a building performance perspective, but from an occupant perspective, they are likely to want living areas on the façade connected to the outdoors even if this potentially increases energy use.

A thermal simulation study would have to be done to understand this complicated relationship between energy use and room locations, but this is not the aim of this study.

\subsubsection{Precedent Medium Density Housing}

So far, the common characteristics of stand-alone houses and theory about MDH thermal performance and internal layout have been discussed. The next step was to select MDH units for inclusion in this study so that an LCA can be performed and the workflow assessed. A research method was created to select appropriate case study units, which lead to accurate, unbiased results. The following section will cover this process and the logic behind each decision at each stage of the process.

The first step of the research method was to understand whether the internal layout of Donn et al. (2015) applies to other MDH units. A floor plan mapping exercise was performed by selecting 20 random MDH units and documenting the floor area, the number of bedrooms, stories and the floor plan. The MDH units were selected by searching for listed houses on real estate websites in New Zealand. The search criteria included "townhouse", "Medium Density Housing" and "terraced housing". Houses that met the category $2 \mathrm{MDH}$ definition ( $2-4$ storey attached houses) were selected for inclusion (Bryson \& Allen, 2017). Units that did not meet this requirement were not selected. All selected units were middle units in a block of multiple units. If floor plans were not available, then that unit was not selected. The selected units ranged from two-three stories, three-four bedrooms and $70-199 \mathrm{~m} 2$ floor area with a median of $145 \mathrm{~m}_{2}$ (Figure 15). 


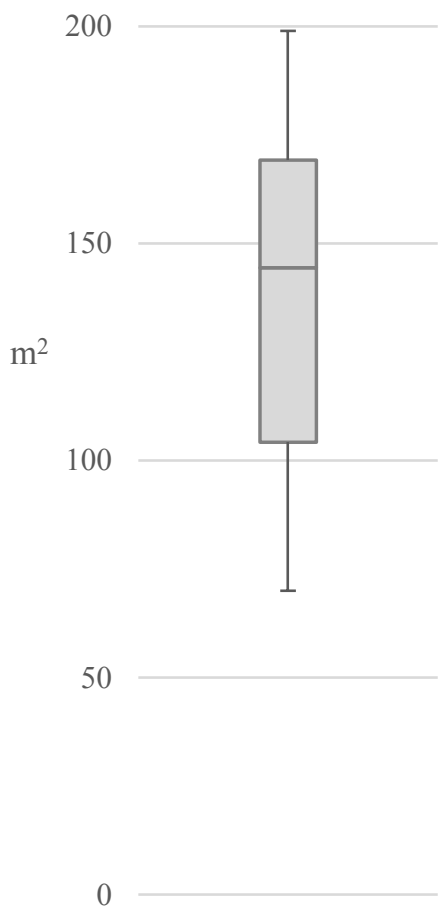

Figure 15 Estimated conditioned floor area for the 20 MDH units surveyed

Once selected, the units floor plans were zoned into up to eight different zones (entrance, kitchen, hall, bedroom, living room, dining room, bathroom and garage) with the zones overlaid on the floor plans (Figure 16). In all 20 units, the bedrooms were located on the narrow-exposed façade ends of the units. No bedrooms were in the middle of the floor plan as this area was mostly built up of bathrooms, storage areas, hallways and staircases. Living rooms, dining rooms and kitchens were also commonly on the façade.

The floor plans of the twenty units were all similar between one another. Four more units were selected from another real estate website using the same search criteria to see if the trends remain the same. The four units again had all the bedrooms located at the exposed façade with hallways and storage areas located in the middle areas. Three of the four units had a garage. Two units had two bedrooms and the rest three. 
Living Room

Dining Room

Kitchen

Bedroom

Bathroom

Garage

Hall

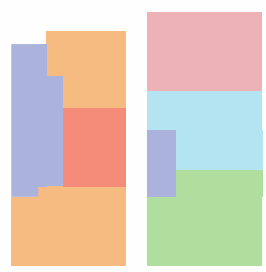

1

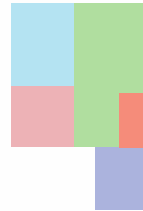

2
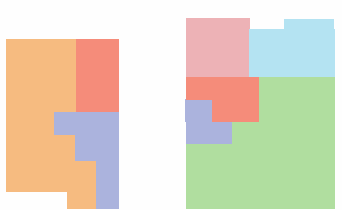

3

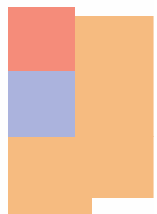

Entrance

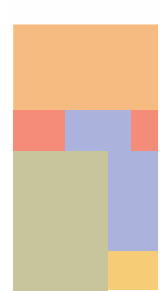

4
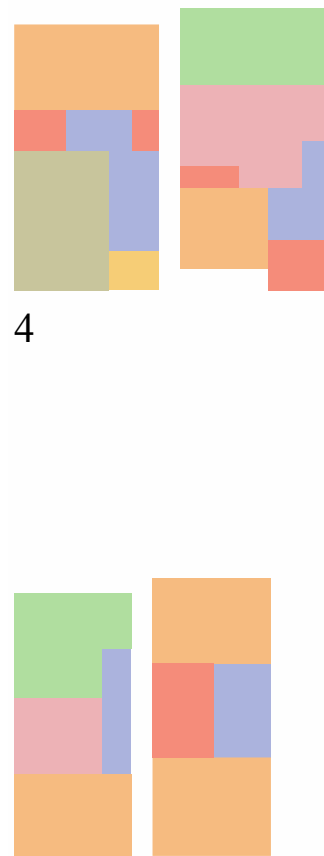

7
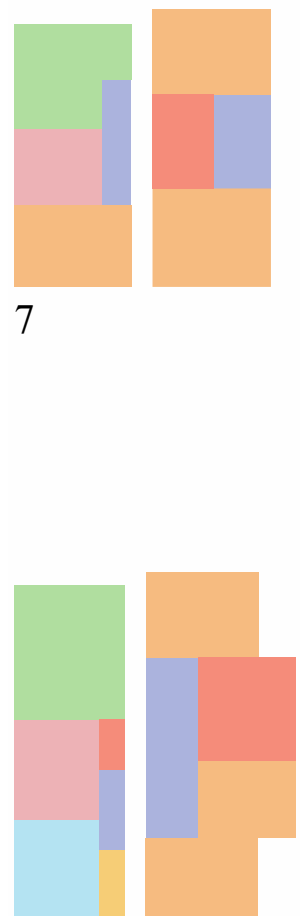

10

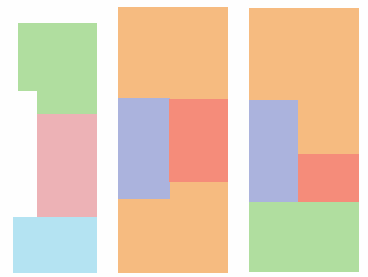

5

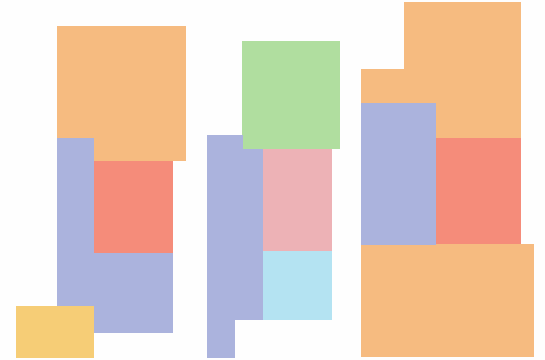

8

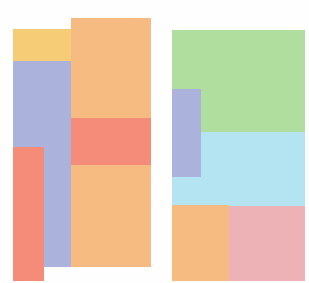

11

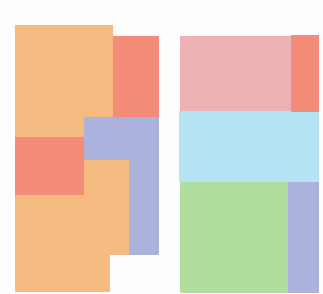

6
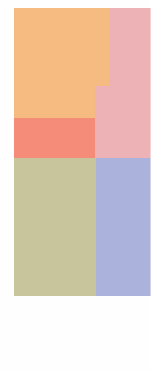

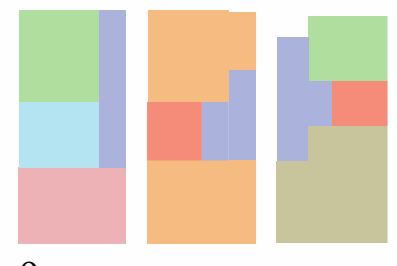

9

Figure 16 Zone layouts for the twenty units - not to scale 
Medium Density Housing

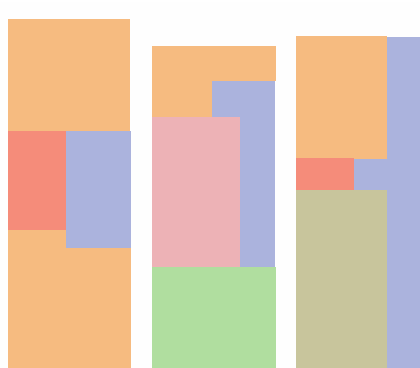

13

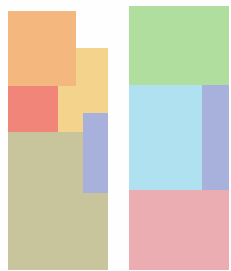

16

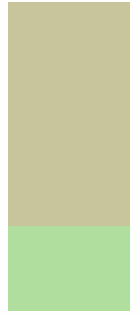

19
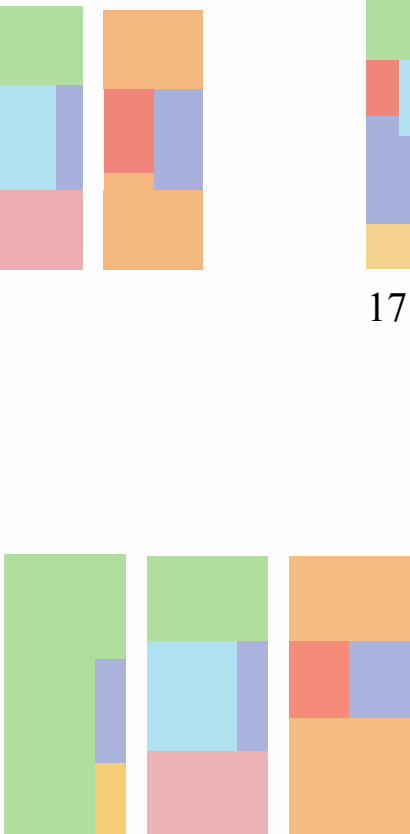

17

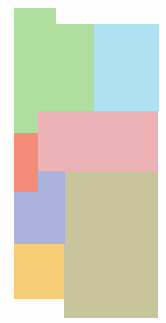

20

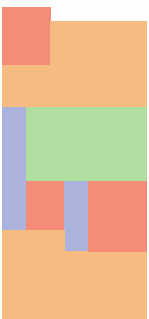

18

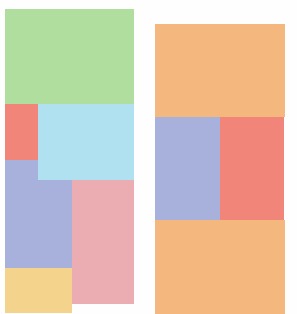

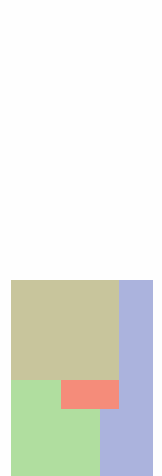

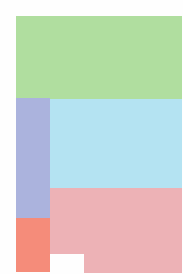

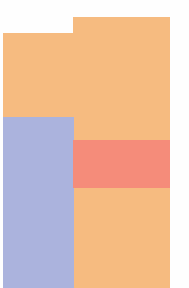

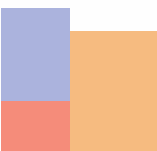

15
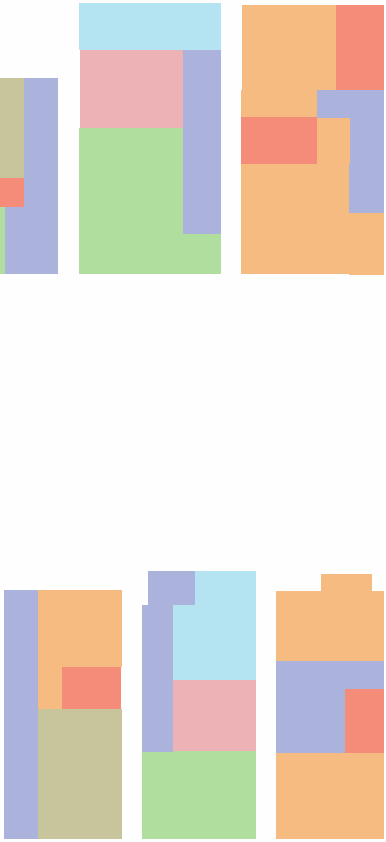

21

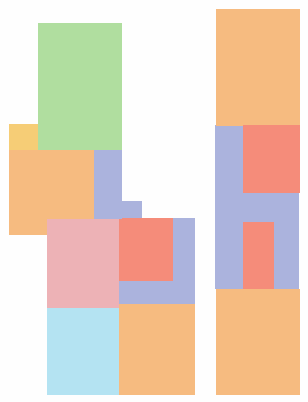

22

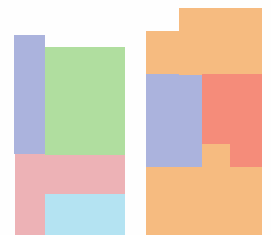

23

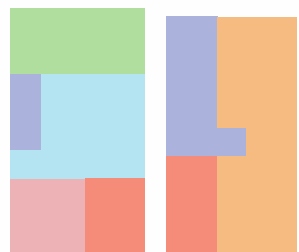

24 
This analysis of the $24 \mathrm{MDH}$ units shows that the 24 units have similarities with one another and match the overall layout in Donn et al. (2015), having living areas mostly at the façade areas and circulation, bathrooms and storage in the centre area. Because the zone that is located at the façade will have an impact on the energy use for heating and cooling, the next section will assess the proportions of the façade that relate to each zone.

\subsection{Façade}

For this section, the façade area for each unit is calculated, and the proportion of this façade designated to each zone is calculated. The aim of this is to determine how much of the façade relates to each zone and in turn, see if any trends appear between the units.

An example of this process is shown in Figure 17, which shows the four exposed facades of a randomly selected two-storey unit with the façade zones labelled. The area for each zone is calculated assuming the same height of the building for consistency. In this example, the living room is $25 \%$ of the total façade area and bedrooms $32 \%$.

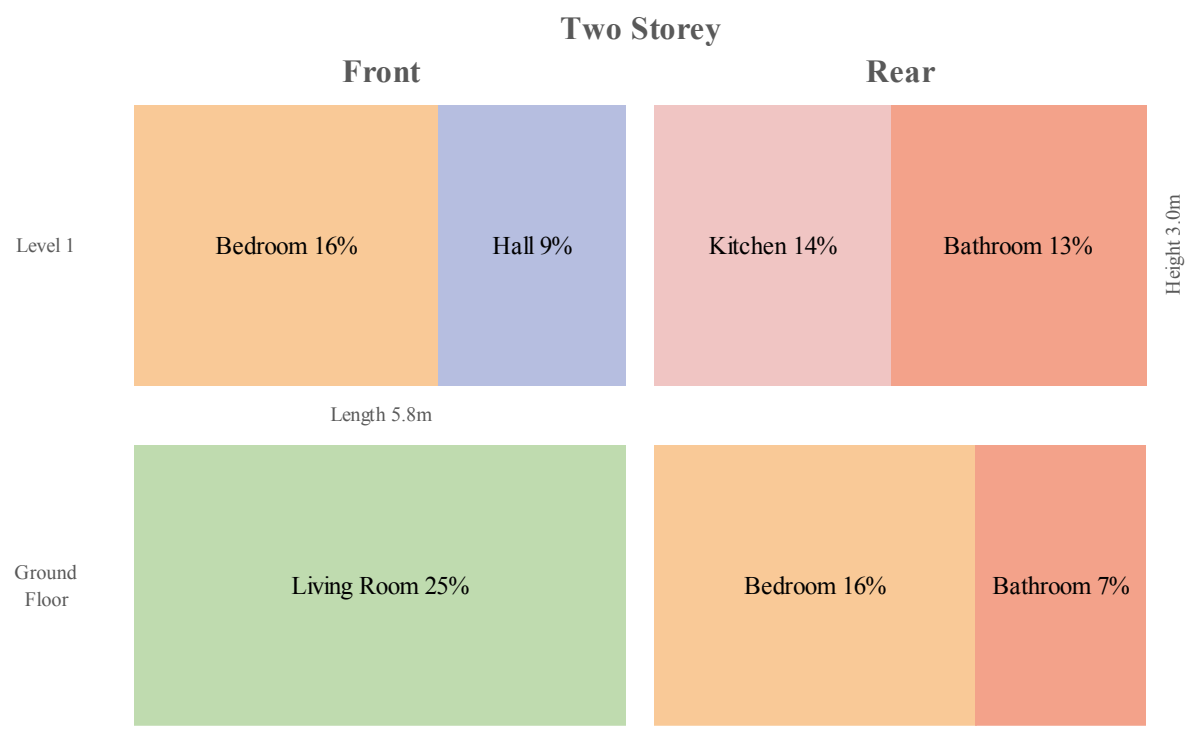

Figure 17 Example of a randomly selected units' façade

This process was repeated for all 24 units and the average area for each zone calculated. Figure 18 shows the variation in the façade areas for each zone and 
identifies that living rooms and bedrooms take up a larger proportion of the façade compared to other zones. One unit had $63 \%$ of the façade as bedrooms, and at a minimum, one unit had $25 \%$ of the façade as bedrooms. The living room had the largest spread ranging from 0 to $47 \% .0 \%$ area means that there was a single unit or more that had no living room on the façade, which is why in Figure 18, the bottom whiskers are located at $0 \%$. This $0 \%$ façade area also applies to all the other zones apart from the bedroom, meaning some units did not have that specific zone located at the façade.

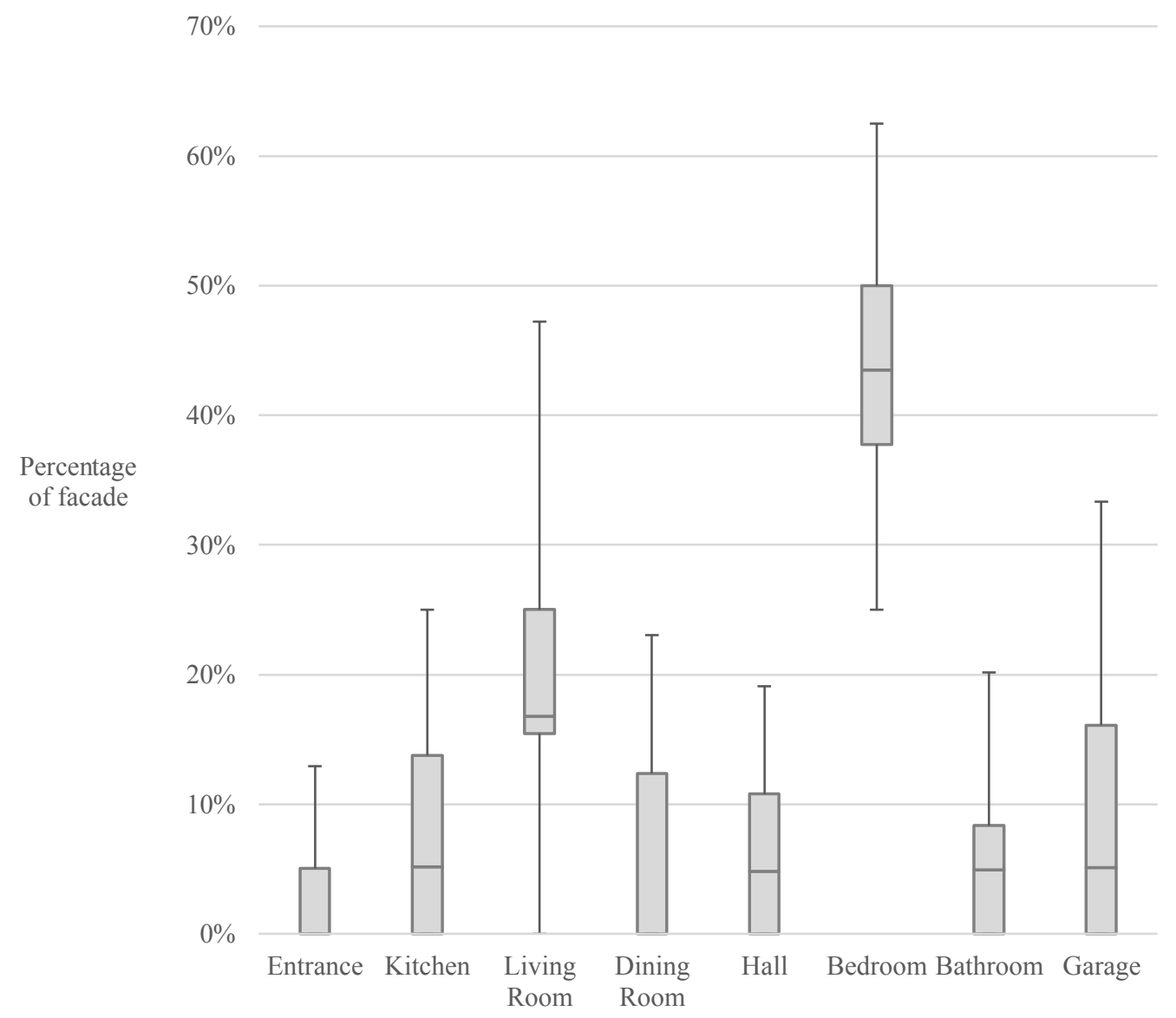

Figure 18 Percentage of façade area - all units

To visualise what the average of the 24 units façade could look like the average façade width was calculated and an estimated height assumed. The proportions of the zones were mapped on an example façade for a two-storey and three-storey MDH unit with the average width. Figure 19 and Figure 20 shows the proportions of the façade assigned to each zone based on the average figures determined earlier. The figures 
show visually that a large portion of the façade is dedicated to living areas which can include kitchen, dining room, living room and bedrooms. Totalling these areas up gives an average figure of $75 \%$ of the façade area.

However, this approximation of averages has some flaws because the garage area in the examples is $1.6 \mathrm{~m}$ and $2.4 \mathrm{~m}$, respectively, which is too small width for a car garage. The units with garages typically had the garage span either the entire façade width with a small entrance/hall adjacent to this. Since so few units had garages, this brings the average area for garages down because of the high number of units. Therefore, the average figures should be used as an approximation of what the average façade could look like when the proportions differ.

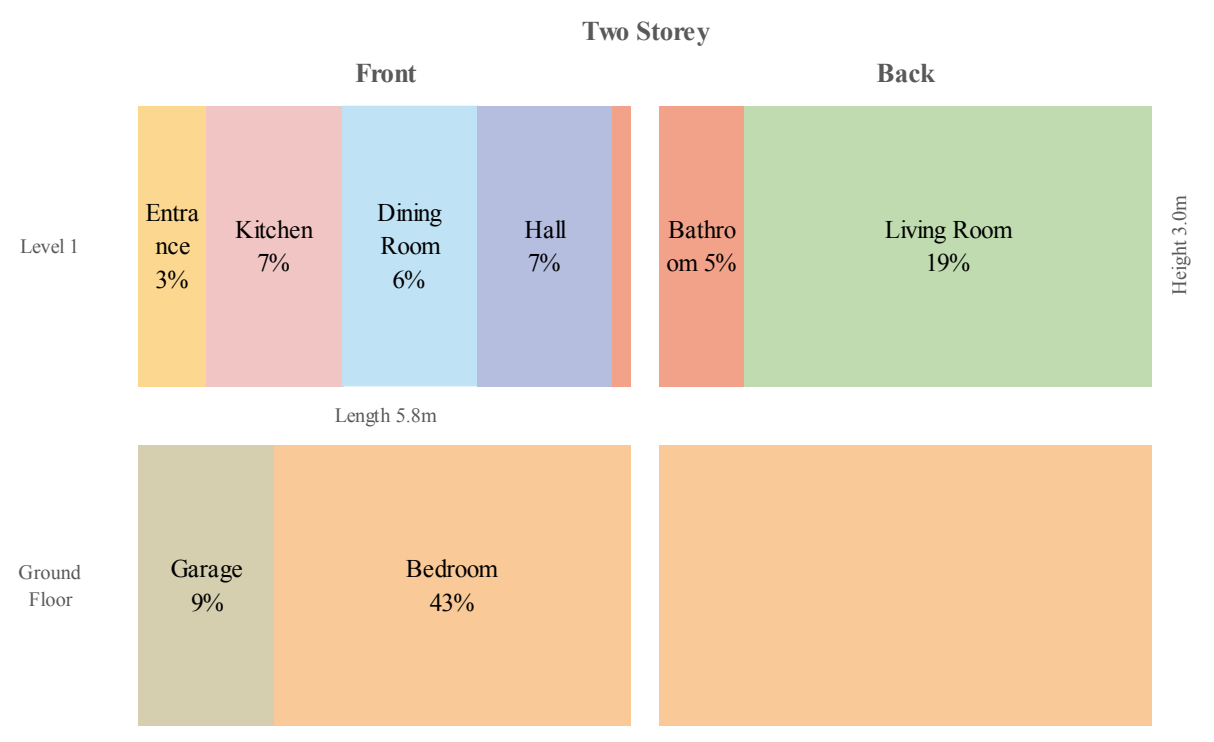

Figure 19 Average façade area of for a two-storey unit 


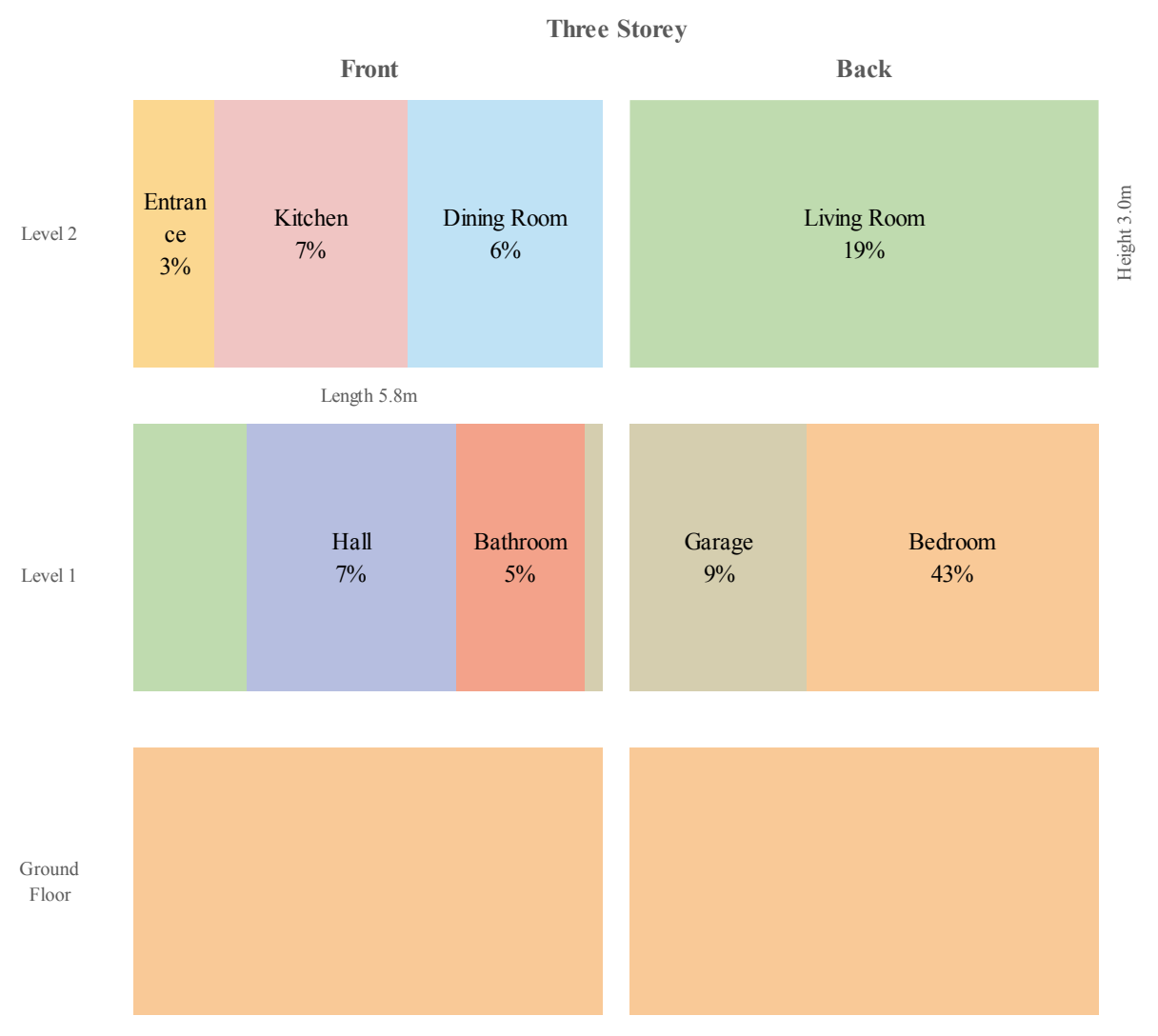

Figure 20 Average façade area of for a three-storey unit

Another issue with this approximation is that the entranceways and halls were very similar to one another in terms of their use inside the unit. Typically, these zones connect without any internal walls with the hall having a staircase to the upper floors, therefore, separating these into different zones for energy modelling is logical. However, for façade mapping, separating these does not fit because of the openness and flow of these two zones into one another. Therefore, these zones were consolidated into one zone called "Entrance".

The final issue with this process is the simplification of the living areas. Typically, these units feature an open plan layout with the living room, dining room and kitchen all connected without any internal walls. Figure 21 shows the three living areas with the other areas of the building in white with black outline. These new plans show that the zones are connected and, in some cases, span the entire length of the unit. Splitting these living zones up is appropriate for energy modelling, but for assessment of the façade, these areas can be combined into a single living area as they are similar in use. 
Living Room

Dining Room

Kitchen
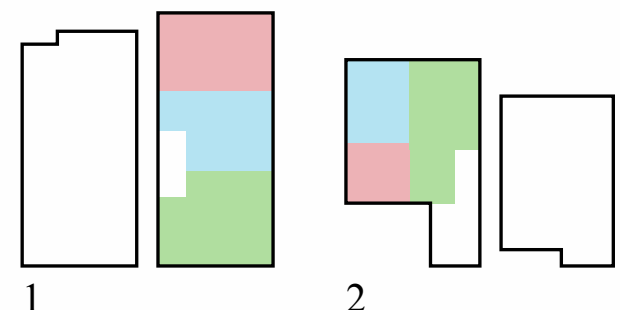

2
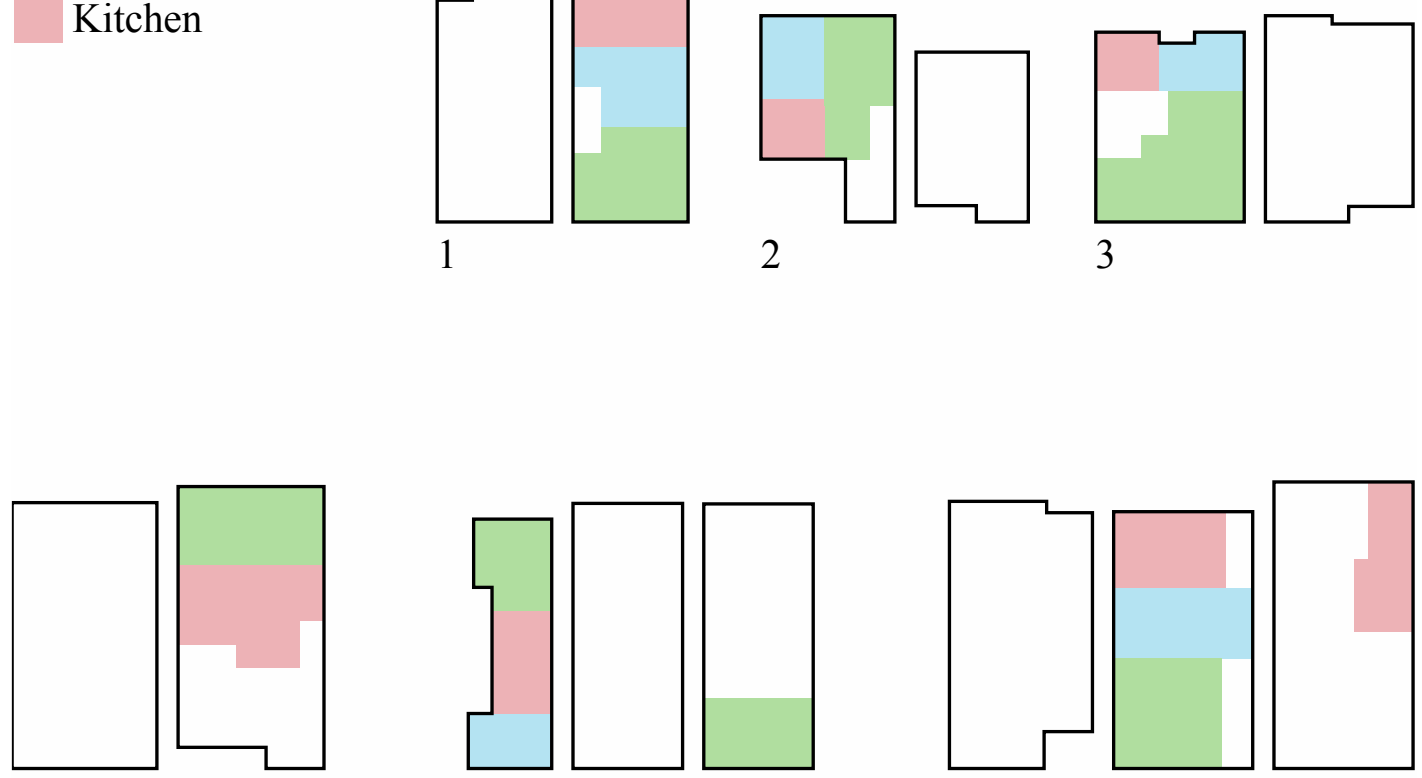

4

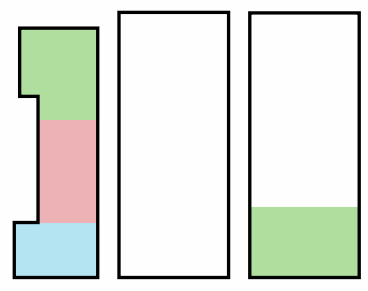

5

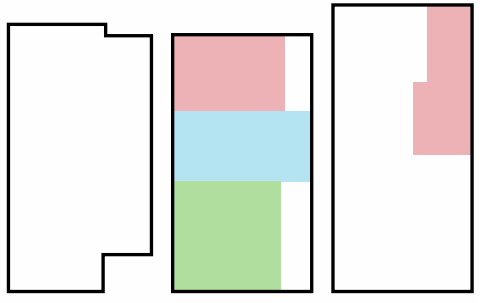

6

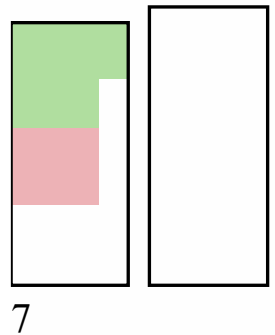

7
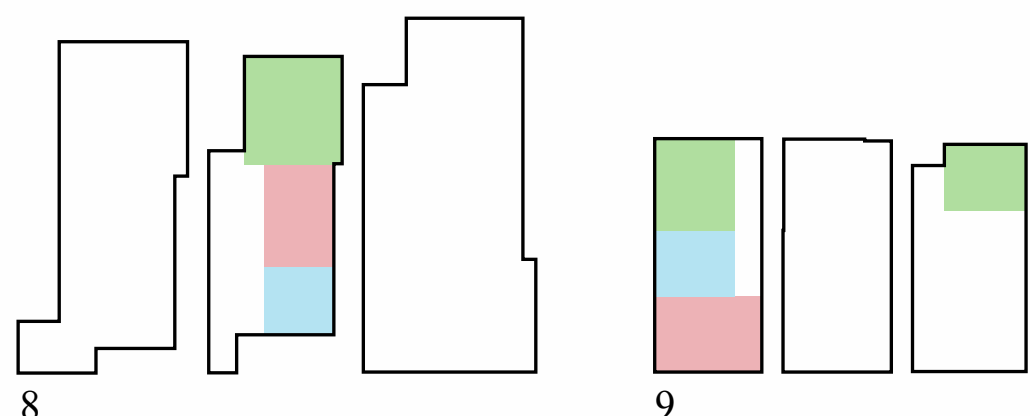

9

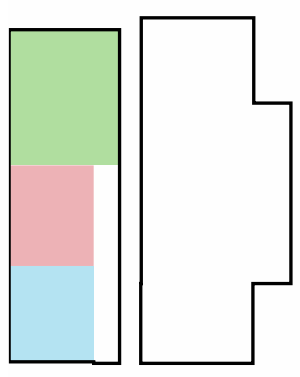

10

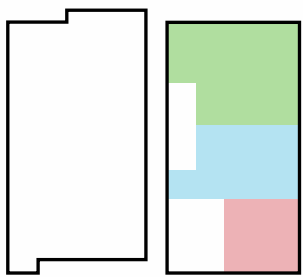

11

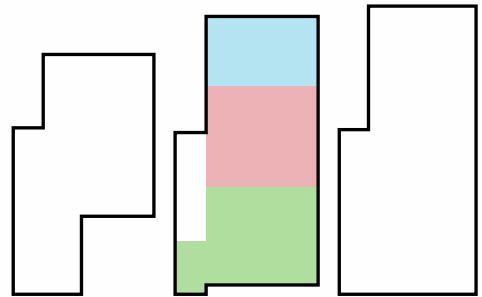

12

Figure 21 Selected units living zones - not to scale 
Medium Density Housing
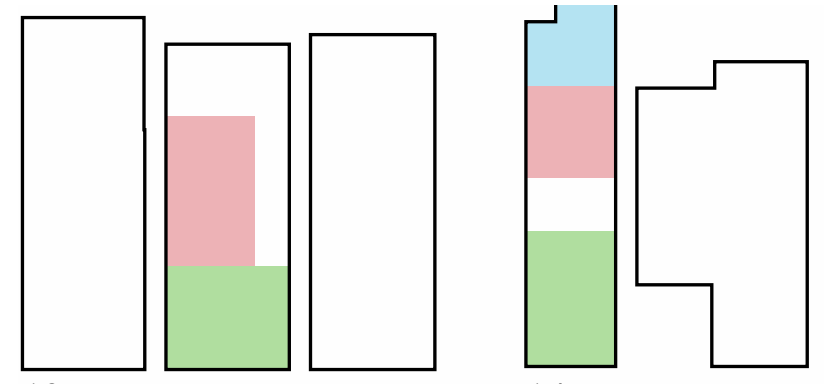

14

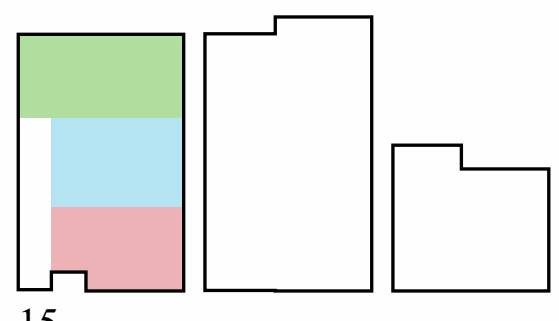

15

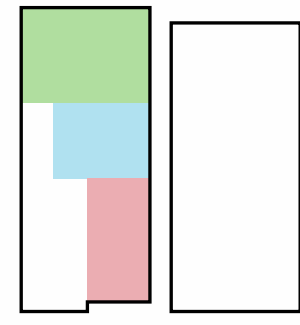

17

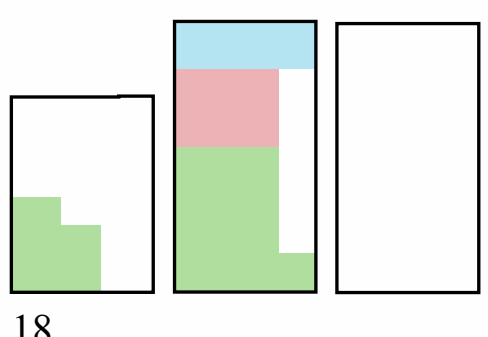

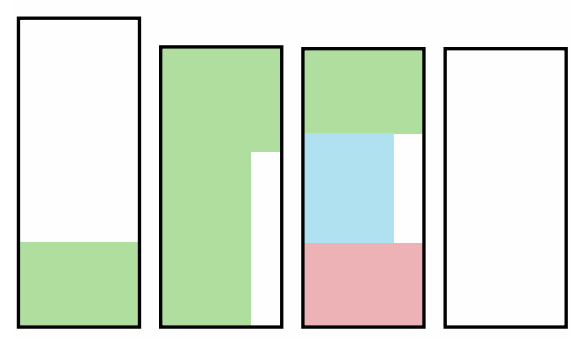

19

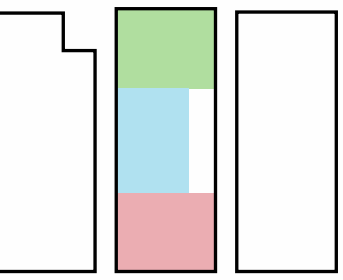

16

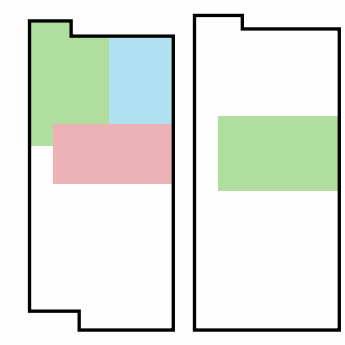

20

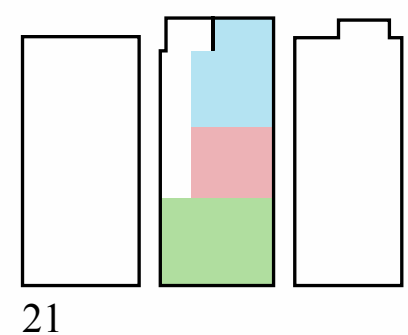

21

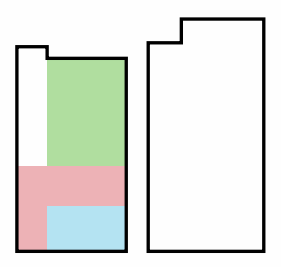

23

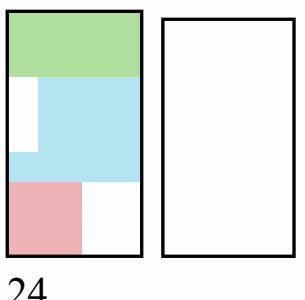

24 
Combining the three living zones (living, dining and kitchen) into one singular living zone, gives an average façade area for living of 33\% (Figure 22 and Figure 23). Combining the entrance and halls into one zone gives a façade area of $10 \%$ and a total of five different zones. In the two-storey unit example, the living and bedroom makeup at least one façade each and on the three-storey unit example makeup two façades.

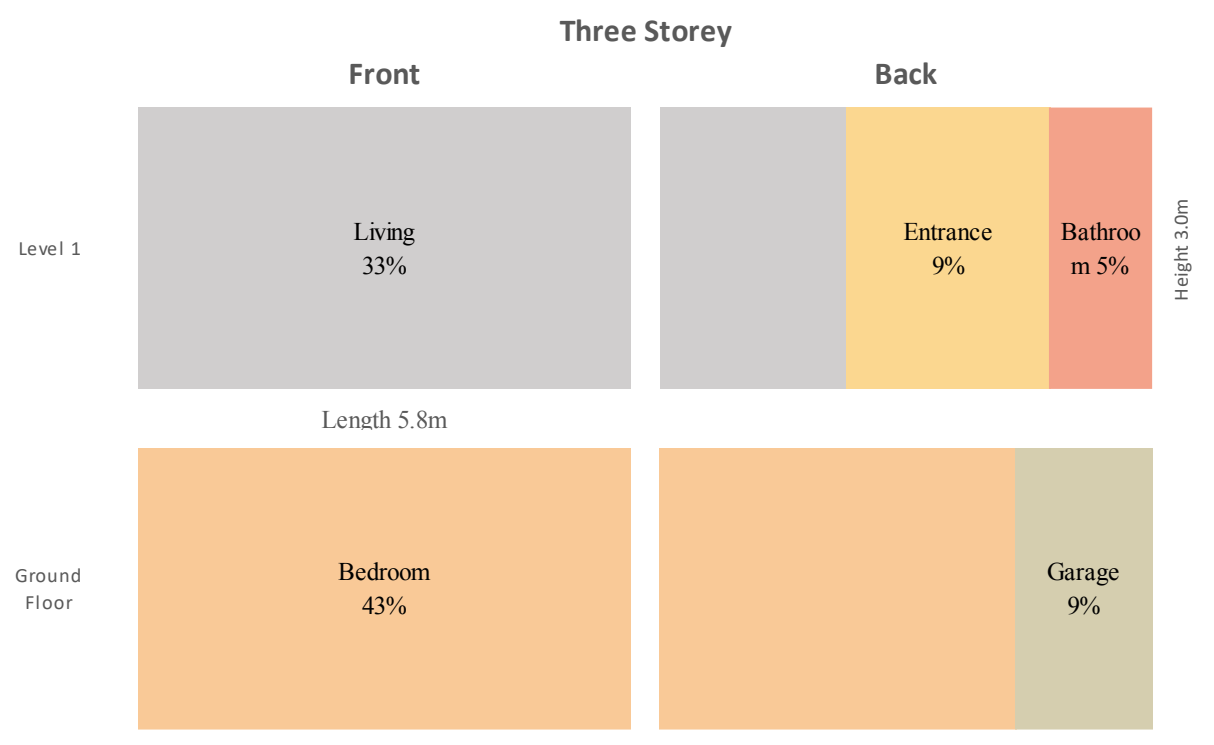

Figure 22 Average façade area of a two-storey unit - revised 


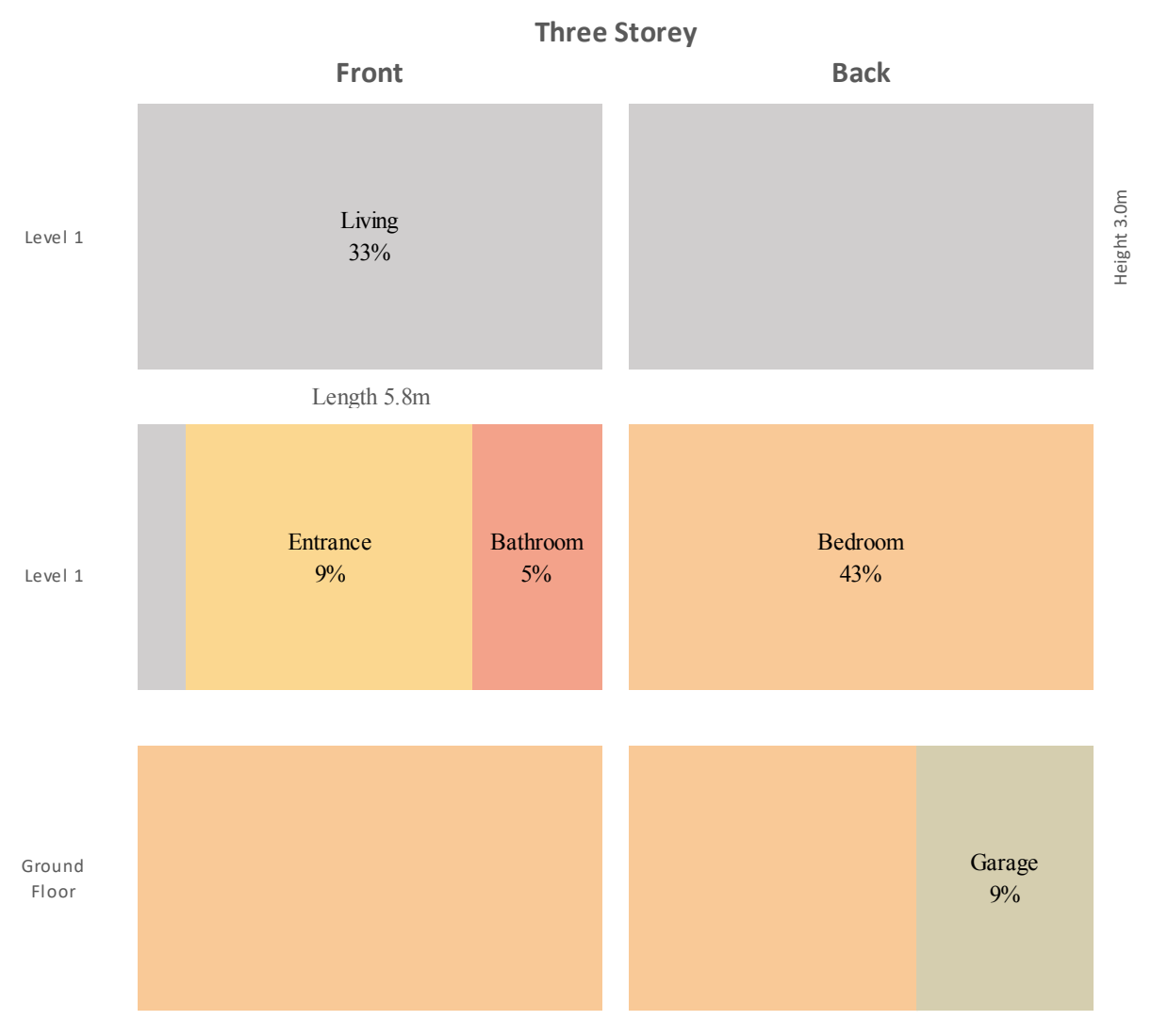

Figure 23 Average façade area of a three-storey unit - revised

Figure 24, shows all the units with the updated "living" zone, which include living, dining and kitchen area in grey. The images show that in a large portion of units, the living areas span the entire length of the unit because of the open-plan layout and minimal internal walls. 
Living

\begin{tabular}{|l|}
\hline Bedroom \\
Bathroom \\
Garage \\
Hall
\end{tabular}

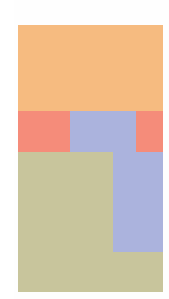

4
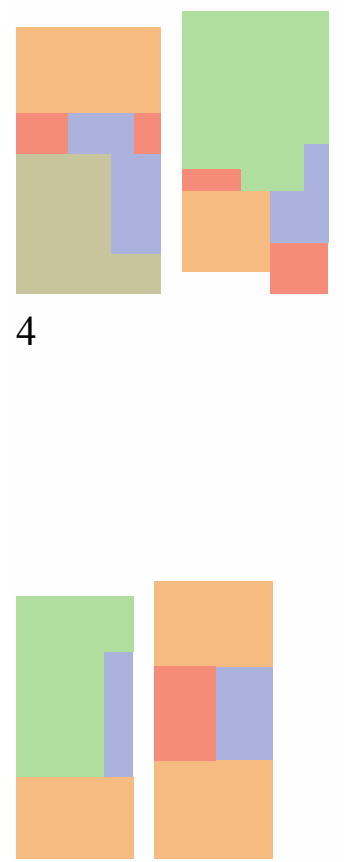

7
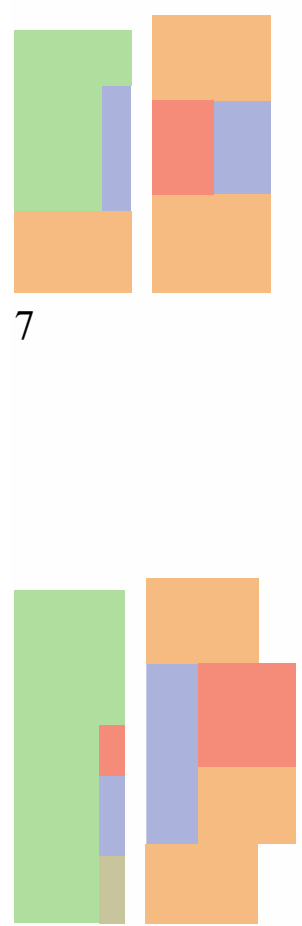

10

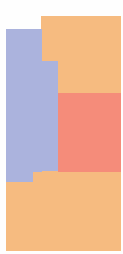

1

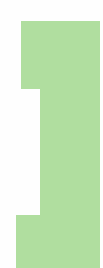

5
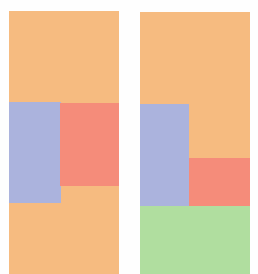

2

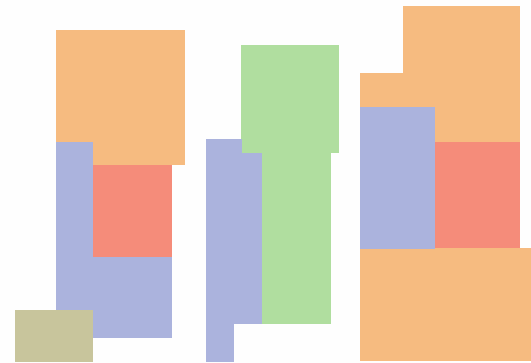

8

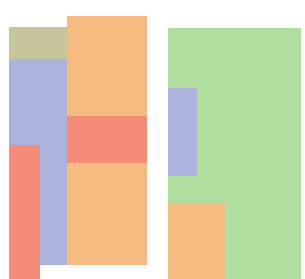

11
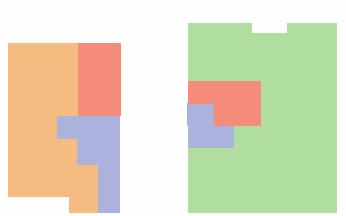

3

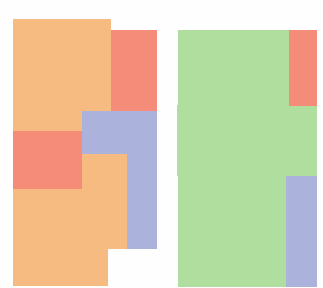

6

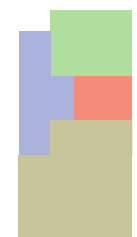

9

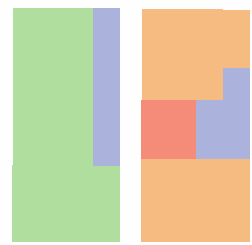

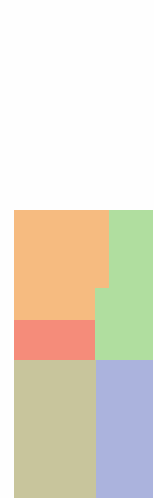

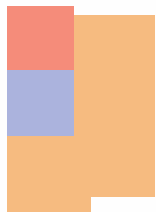


Medium Density Housing

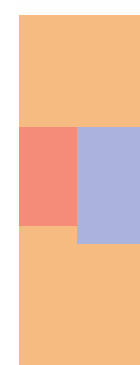

13
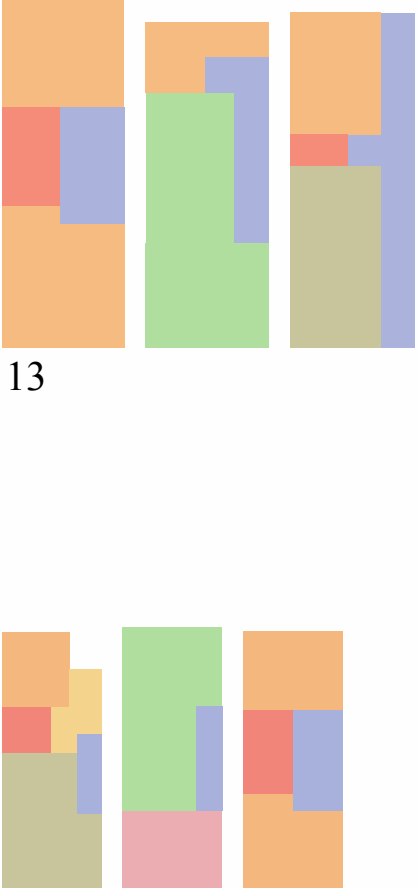

16
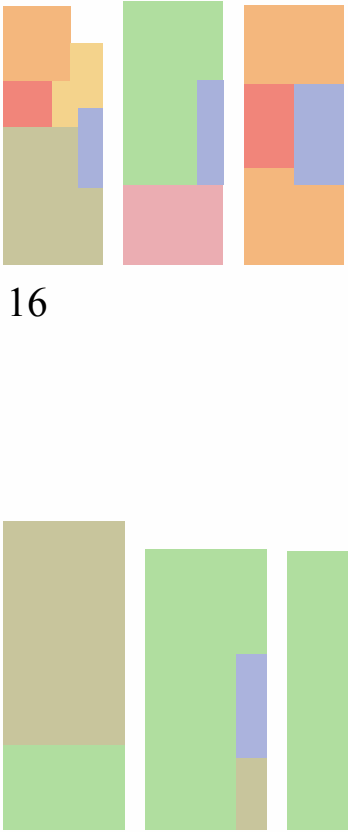

19
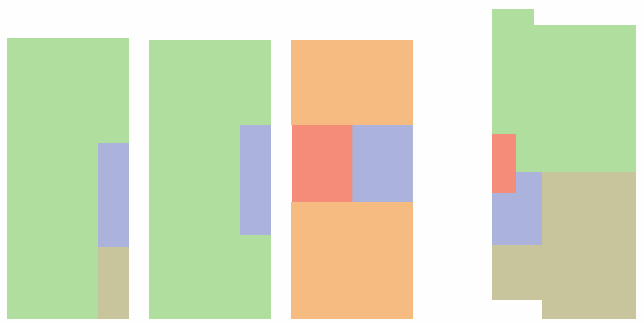

20
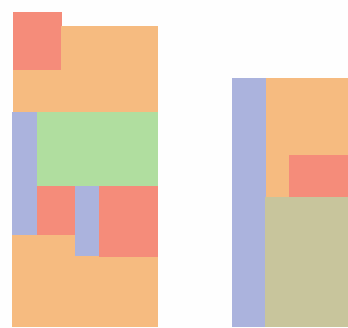

21
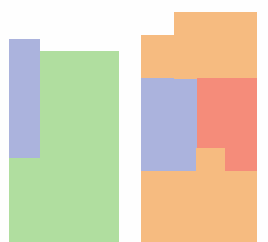

23

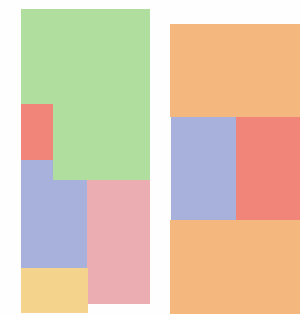

17
22

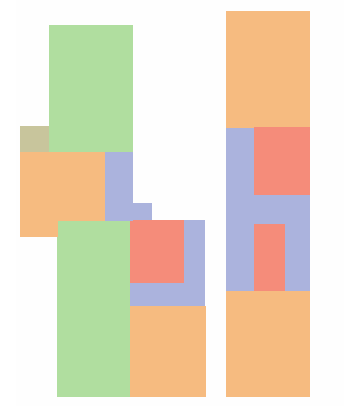

23

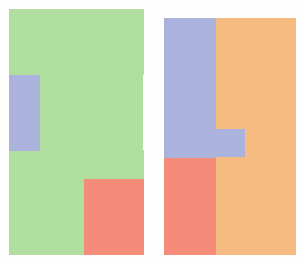

24

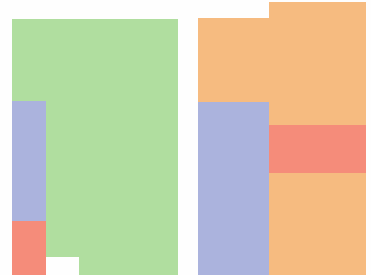

15

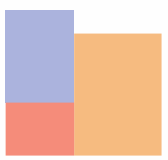

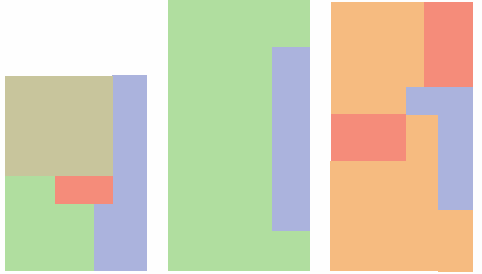

18 
The updated zones show that "living" had a minimum of $9 \%$ and a maximum of $60 \%$, showing a greater variation with an average of $33 \%$ (Figure 25). The new "Entrance" zone still has a minimum of $0 \%$, but the maximum has increased to $28 \%$. In some instances, nearly $30 \%$ of the façade is dedicated to entrance/hallways.

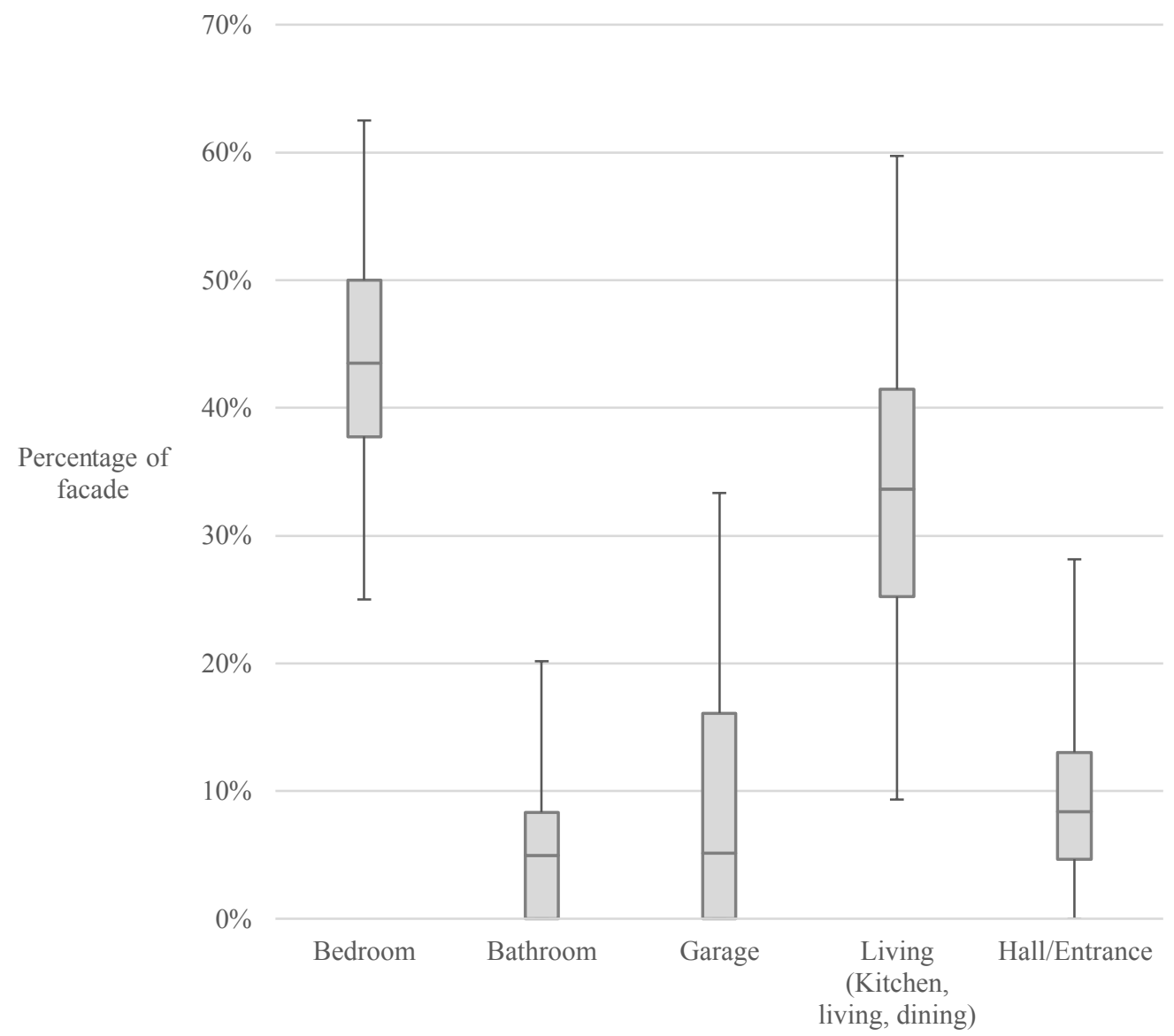

Figure 25 Percentage of façade area - all units - revised

\subsubsection{Glazing on façades}

So far, this process has focussed on the zones at the façade, one important aspect that will also affect energy use is the amount of glazing on the façade. In section 3.2 for MDH units, a large WWR in a warmer climate can cause overheating when oriented towards the sun, therefore increasing cooling energy use. The WWR for all 24 units was calculated based on floor plans and photographs of the buildings. Figure 26 shows the variation of WWR across the selected units with an average WWR of $35 \%$. At the ends of the spectrum are units with a maximum WWR of $51 \%$ and a 
minimum of $23 \%$. These two units are important because they are at the opposite ends of the spectrum, meaning they may have widely different operational energy use.

$60 \%$

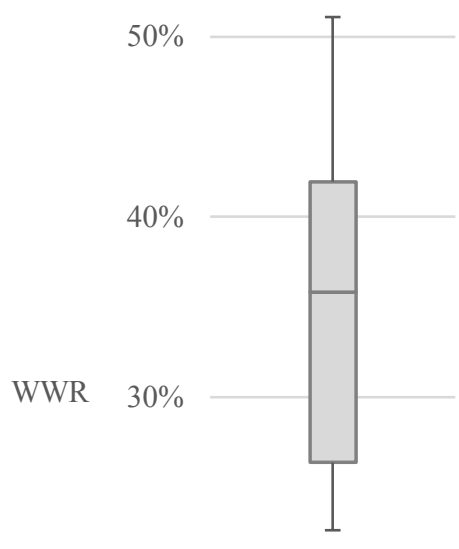

$20 \%$

$10 \%$

$0 \%$

Figure 26 WWR - all units

\subsubsection{Process summary}

This process aimed to understand what commonality MDH units have with one another from the sample selection of 24 units. By doing so, this helps in the selection of appropriate case study units leading to accurate, unbiased environmental impact results. The process was able to identify the key characteristics listed in Table 18.

\section{Table 18 List of Medium Density Housing characteristics}

\section{Characteristics}

Average gross floor area $70-199 \mathrm{~m}_{2}$

$2-3$ bedrooms 
$2-3$ stories

All units have both a living and bedroom component on the façade

Bedroom and living areas make up most of the façade totaling on average $77 \%$

Bedrooms were always located on the façade, never internally

Thin long units, with circulation, storage, bathroom areas in the middle area with no connection to the outside

Average façade areas:

Living $-33 \%$

Bedroom $-43 \%$

Entrance - 9\%

Bathroom - 6\%

Garage $-9 \%$ (only $30 \%$ of the 24 units had a garage. Garages spanned the whole façade or nearly the whole façade with a narrow hallway next to it)

WWR $-35 \%$

The key findings from the process were that all the units followed a similar internal layout with living areas on the façade and storage, circulation, and bathrooms in the middle area. Another point to note was that bedrooms were always located on the façade and totalled on average $43 \%$ of the façade. On average, the units had $35 \%$ WWR with one unit having an extreme WWR of $51 \%$, and at the lower end, one unit $23 \%$, which may have a large impact on the operational energy use of the unit.

\subsection{Medium Density Houses selected for inclusion}

Assessing the characteristics and similarities between MDH units can be achieved following the process created in this study. From the $24 \mathrm{MDH}$ units, three units which have characteristics that are common of the 24 were selected for inclusion in this study shown in Table 19, Figure 27, Figure 28 and Figure 29. From this point on each of the selected units will be referred to as House H, House P and House W.

Table 19 Selected houses key information

\begin{tabular}{llll} 
& House H & House P & House W \\
\hline Floors & 3 & 2 & 2 \\
Bedrooms & 3 & 3 & 3 \\
\hline
\end{tabular}




\begin{tabular}{lccc}
\hline Floor area $(\mathrm{m} 2)$ & 123 & 134 & 125 \\
WWR & $26 \%$ & $23 \%$ & $42 \%$ \\
\hline
\end{tabular}

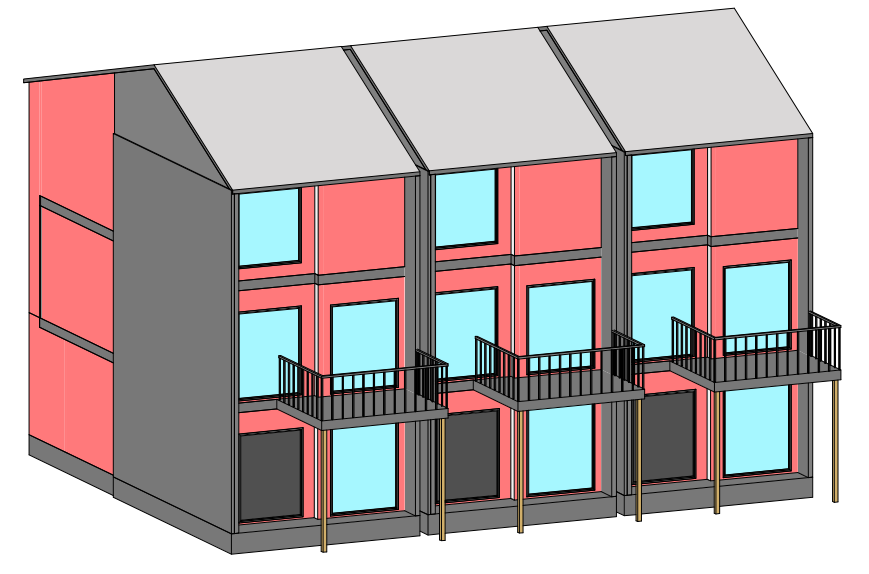

Figure 27 House H

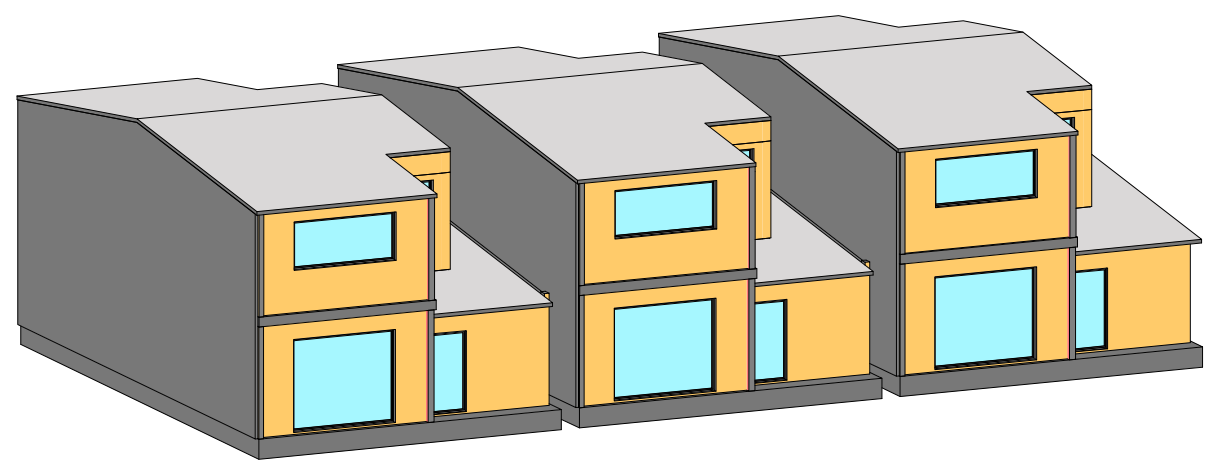

Figure 28 House P 


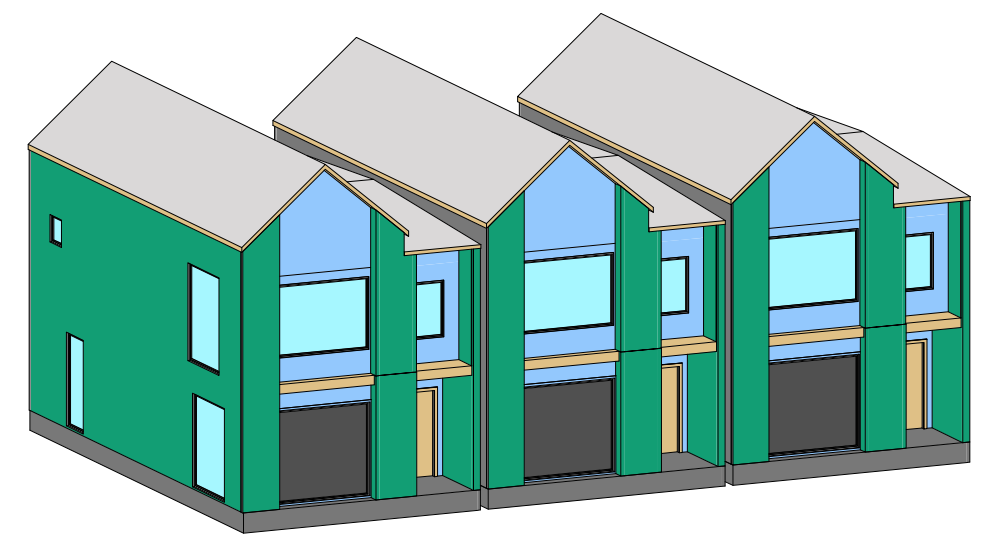

Figure 29 House $w$ 
Medium Density Housing 
A Life Cycle Assessment of Medium Density Houses in New Zealand 


\section{Chapter 4 Modelling Methodology}

The previous chapter created a process to determine the key characteristics of MDH units in New Zealand and selected three MDH units to be included in this study. To answer the question “How can an LCA be integrated into a designer's workflow to inform design decisions?". The process of taking a designer's model and preparing it for an LCA was performed so that the issues identified by designers could be recreated and resolved.

BIM has the potential to take a designer's building model and connect this to other software for energy simulation and LCA. By having a single BIM model, this eliminates the need to recreate the building model in each individual software saving time for the designer. This process has been done by Hollberg and Ruth (2016) but with software that is not commonly used by designers. Revit is an example of BIM capable software which is commonly used by designers.

This chapter reports on the input process of an LCA and the data required to perform a trustworthy LCA. The process of taking a BIM model from Revit and conducting an energy simulation is explored. Followed by the creation of BIM and energy models and methods of quality assurance of these models. The output of this chapter is a database of input data that can be used by designers to create reliable BIM and energy simulation models. 


\subsection{LCAQuick}

LCAQuick is a free Microsoft Excel tool developed by BRANZ, which combines material quantities and energy data with environmental impact data to calculate a buildings potential environmental impact in an LCA (BRANZ, 2019a). LCAQuick calculates the impact of a building over the different life-cycle stages outlined in section 1.4.3. The potential environmental impact of the seven environmental indicators in Table 20 is calculated using a 90-year life span for residential buildings. The frequency of maintenance, including washing and replacement of materials is predetermined for individual materials in the tool. Environmental impact of the transport of materials is also included. Material data is sourced from a range of sources, including AusLCI, EcoInvent, EN15804-compliant and some ISO 14025-compliant EPDS. LCAQuick uses midpoint characterisation factors for all impacts. LCAQuick may solve some of the issues designers are facing in Meex et al. (2018) by having a database of materials, clear inputs with a description of the process and simple reporting of results in graph form.

For full information about LCAQuick, see BRANZ SR349 "New Zealand wholebuilding whole-of-life framework: An overview (Dowdell \& Berg, 2016).

Table 20 LCAQuick environmental indicators (BRANZ, 2019a)

\begin{tabular}{ll}
\hline Indicator Name & Unit \\
\hline Acidification (Land and Water) & $\mathrm{kg} \mathrm{SO}$ eq. \\
\hline Global Warming (100 year) & $\mathrm{kg} \mathrm{CO}$ eq. (100 year) \\
\hline Eutrophication & $\mathrm{kg} \mathrm{PO} 43$-eq. \\
\hline Abiotic Depletion - Fossil Fuels & $\mathrm{MJ}$ \\
\hline Abiotic Depletion - Elements & $\mathrm{kg} \mathrm{Sb}$ eq. \\
\hline Stratospheric Ozone Depletion & $\mathrm{kg} \mathrm{CFC} 11$ eq. \\
\hline Tropospheric Ozone Formation & $\mathrm{kg} \mathrm{C} 2 \mathrm{H}_{4}$ eq. \\
\hline
\end{tabular}

LCAQuick has been designed to integrate with outputs from Autodesk Revit, a BIM software that allows designers to design buildings and structures in 3D (Autodesk, 2018). Elements of buildings can be modelled in different Levels of 
Development (LOD) with different levels of information attached to each element. Figure 30 shows an element selected in the Revit BIM model and the associated material layers of the element. The model of the base building may not look like the actual building. The reason for this is that the model only requires a certain amount of visual detail as it contains metadata containing the material name and other information.

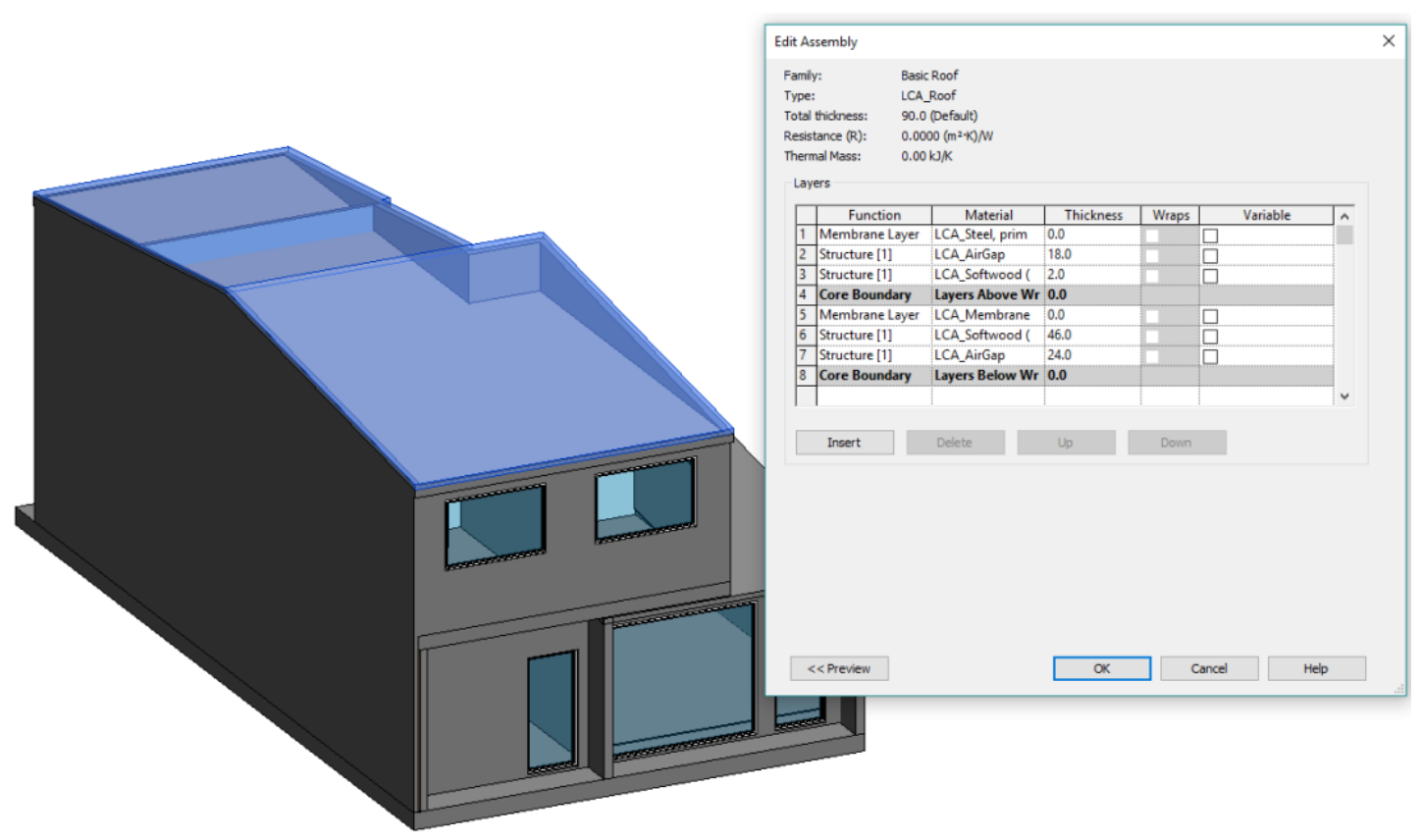

Figure 30 Example of selected Revit element and LOD

Once the base building has been modelled, a Schedule of Quantities (SoQ) is created which details the family, type, material description, material name, comments, area and volume (Figure 31). This SoQ is then exported to a CSV text file. The SoQ and calculated predicted energy use can then be input into LCA quick, which then calculates the potential environmental impact.

\begin{tabular}{|c|c|c|c|c|c|c|}
\hline \multicolumn{7}{|c|}{$<$ LCAQuick_Floor Material Takeoff $>$} \\
\hline A & B & $\mathrm{c}$ & D & $\mathrm{E}$ & $F$ & G \\
\hline Family & Type & Material: Description & Material: Name & Material: Comments & Material: Area & Material: Volume \\
\hline Floor & LCA_Carpet & PR_35_57_11_64_2_1 & LCA_Carpet - tufted wall-to-wall (pile material $1000-1100 \mathrm{~g} /$ & Area dependent [LClA/m2] & 713 & 14.27 \\
\hline Floor & LCA_Lowerfloor & PR_15_57_30_47_ 1 & LCA_Membrane, building wrap, polyethylene (PE) & Area dependent, to derive volu & 909 & 0.00 \\
\hline Floor & LCA_LowerFloor & PR_20_31_16_2_-2_1_1 & LCA_Reinforced concrete, $20 \mathrm{MPa}$, in-situ, inc. $50 \mathrm{~kg} / \mathrm{m} 3$ steel & Volume dependent [LClA/m3] & 909 & 181.73 \\
\hline Floor & LCA_LowerFloor & PR_25_57_6_29 & LCA_Insulation, polyester & Volume dependent [LClA/m3] & 909 & 90.86 \\
\hline Floor & LCA_Tiles & PR_35_93_96_19 & LCA_Tiles (ceramic) & Area dependent $[\mathrm{LC} \mathrm{C} / \mathrm{m}$ 2] $]$ & 87 & 1.30 \\
\hline Floor & LCA_UpperFloor & & LCA_AirGap & & 571 & 85.72 \\
\hline Floor & LCA_UpperFloor & PR_25_71_14_30_13 & LCA_Flooring, underlay (fibre cement, $6 \mathrm{~mm}$ thickness) & Area dependent [LClA/m2] & 571 & 5.14 \\
\hline Floor & LCA_UpperFloor & PR_25_71_97_83_1_B & LCA_Softwood (dressed, kiln dried) floor [from unsustainable & Volume dependent [LClA/m3] & 571 & 45.72 \\
\hline
\end{tabular}


This process of taking a designer's BIM model from Revit to LCAQuick does not include energy modelling, which needs to be done in different software. This exclusion is a disincentive raised by designers in section 1.1. If it is possible to integrate an energy simulation into this process, this will help with the uptake of LCA in the designer's workflows.

\subsection{What software is appropriate for energy modelling?}

Many energy simulation tools can be used to predict the energy use of a building using a designer's BIM model. The selected tool must be able to read outputs from a BIM model as this will be used to model the buildings SoQ. The first is Green Building Studio (GBS), a cloud-based service for simulating operational energy use in buildings from a Revit BIM model. The second is EnergyPlus (by US DOE), a whole building energy simulation program to model energy consumption. EnergyPlus can be used with different graphical interfaces; two of these are Honeybee and OpenStudio. All these tools result in an estimate of energy use and have both pros and cons. A key pro of these tools is the ability to have a single BIM model and the ability to generate both an SoQ and estimate operational energy use without the need to have two independent models. Reducing both the time and the chance of modelling errors occurring. This workflow also gives the option to make construction changes to the initial model and run the LCA analysis quickly without the need to remodel anything apart from the construction changes in the initial model which is what designers said they require in (Meex et al., 2018).

\subsubsection{Green Building Studio}

Green Building Studio (GBS) which uses the DOE-2.2 simulation engine allows a BIM model created for LCA purposes to have its operational energy use calculated without the need to create two separate models, thus reducing time and errors. GBS is meant for use in the early stages of design to run quick energy simulations for optimising the form of the building.

A BIM model is created in Revit, and an energy analysis run on a cloud-based system targeted at users with little energy modelling experience. Creating a freeflowing workflow where construction changes can be made to the BIM model and 
then reflected automatically in the energy model. Eliminating the need to create an independent energy model and reducing time and the chance of modelling errors in the second model.

Users are unable to create unique HVAC systems instead only given the ability to select predetermined HVAC systems from a list provided by GBS. This list is not extensive, and the setup of these systems is unknown. This list of HVAC systems is catered towards commercial buildings rather than residential.

The ability to have two unique HVAC systems in use in one building is not present, meaning an MDH unit with for example a heat pump, and electric wall heaters in other rooms cannot be modelled.

Analysis of energy simulation results is limited to energy use and cost. If the user wishes to run a model passively with no HVAC systems to determine indoor room temperatures, this cannot be performed and would need to be performed in a thirdparty application where the model needs to be recreated entirely.

Documentation and tutorials of this software are inadequate due to lack of information and outdated documentation which extends to user-generated online community forums.

\subsubsection{Honeybee and EnergyPlus}

Another option to reduce modelling time is to export a gbXML file from Revit and use import it into Grasshopper 3D with plug-in Honeybee.

Like GBS, Honeybee uses the geometry created in the Revit BIM model as the geometry for energy analysis. Again, it allows for construction changes to be made and reflected automatically in the energy model. Honeybee is an interface to EnergyPlus by US DOE (US Department of Energy, 2013). It is a whole building energy simulation program to model energy consumption for HVAC systems, lighting, plug and process loads. With this software, there is greater customisability with full user control over all modelling inputs when compared to GBS. These two points make for a very strong energy modelling workflow, but these are the only pros.

This workflow creates several issues relating to the export and import of geometry, specifically complex geometry. It was found that the model in Revit needs to be altered to a certain level to be recognised and used in Honeybee. 
When defining spaces in the Revit model, the boundaries of these must be aligned to the centre of the bounding walls. If the boundary is aligned to the face of the walls, then the adjoining space that shares the same boundary wall is not recognised as sharing the same boundary wall, and 'air walls' are created where there is a mismatch in geometry alignment.

When the boundary condition of space is set to the centre of the wall, then the walls in Revit must line up centre to centre shown on the left side of Figure 32.

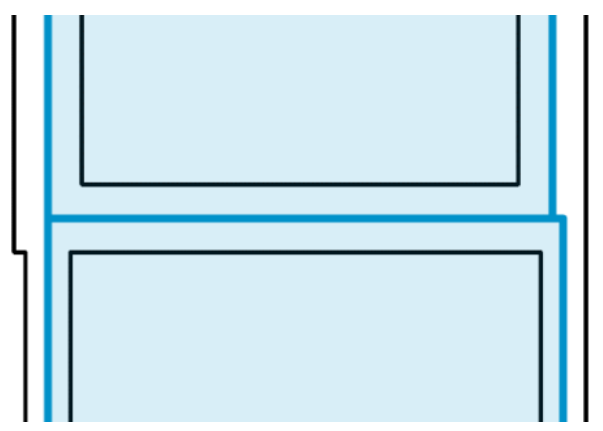

\section{Figure 32 Alignment of geometry centres in Revit for GBS}

If the walls are aligned with the face on the same line, then a perpendicular 'air wall' is created to connect the two centres of the wall boundary walls shown on the right of Figure 32 which can cause errors in the simulation if not addressed.

These are modelling issues that can be remedied with altering of the modelling methodology. It is important to note that every change to the model that differs from the original plans and specifications will affect both the SoQ and energy prediction.

The next issue relates to the modelling of complex geometry. When a roof shown in Figure 33 on the lower level connects to the walls on the upper level, this creates issues of mismatched geometry with the exported geometry walls extending past their boundary which does not represent the plans and specifications of the model. 


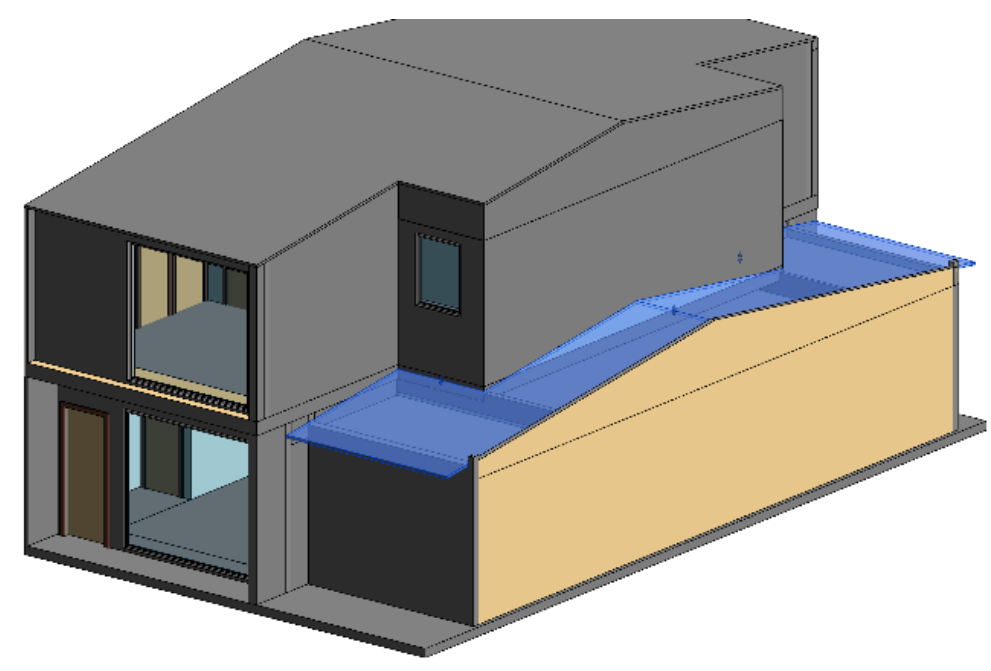

Figure 33 Example of complex geometry in Revit for GBS

To fix these issues for complex buildings is a time-consuming process taking more time than it would to model the geometry of these models in a different energy modelling software package. Therefore, another method of creating geometry for energy analysis should be considered rather than the export of existing geometry from Revit. However, this new methodology outside of Revit will not meet the requirements of designers in (Meex et al., 2018). This is the only possible workflow at this stage in time due to the limitations of the software above. This will, however, increase the chance of modelling errors, so a process is needed for designers, so this risk is reduced.

\subsubsection{OpenStudio and EnergyPlus}

OpenStudio plug-in for SketchUp is a graphical interface that allows users to create geometry for EnergyPlus. The building's geometry is represented in 2D elements like the gbXML file for Honeybee. Meaning simplifications to the model is necessary.

The geometry is drawn using line 2D lines to create a 3D model. The geometry can then be exported for use in EnergyPlus which like in the previous section allows for full customisation of the energy model.

This process is time-intensive as it does not allow for changes to the Revit model to be reflected in the energy model automatically. Meaning each construction change to the original model will need to be again modelled in OpenStudio. Unfortunately, this is the only available workflow currently. 
The Revit model should be created first to represent the plans and specifications, and then the geometry for the energy model created using the Revit model as a reference for dimensions and materials.

Table 21 Pros and cons of energy simulation software

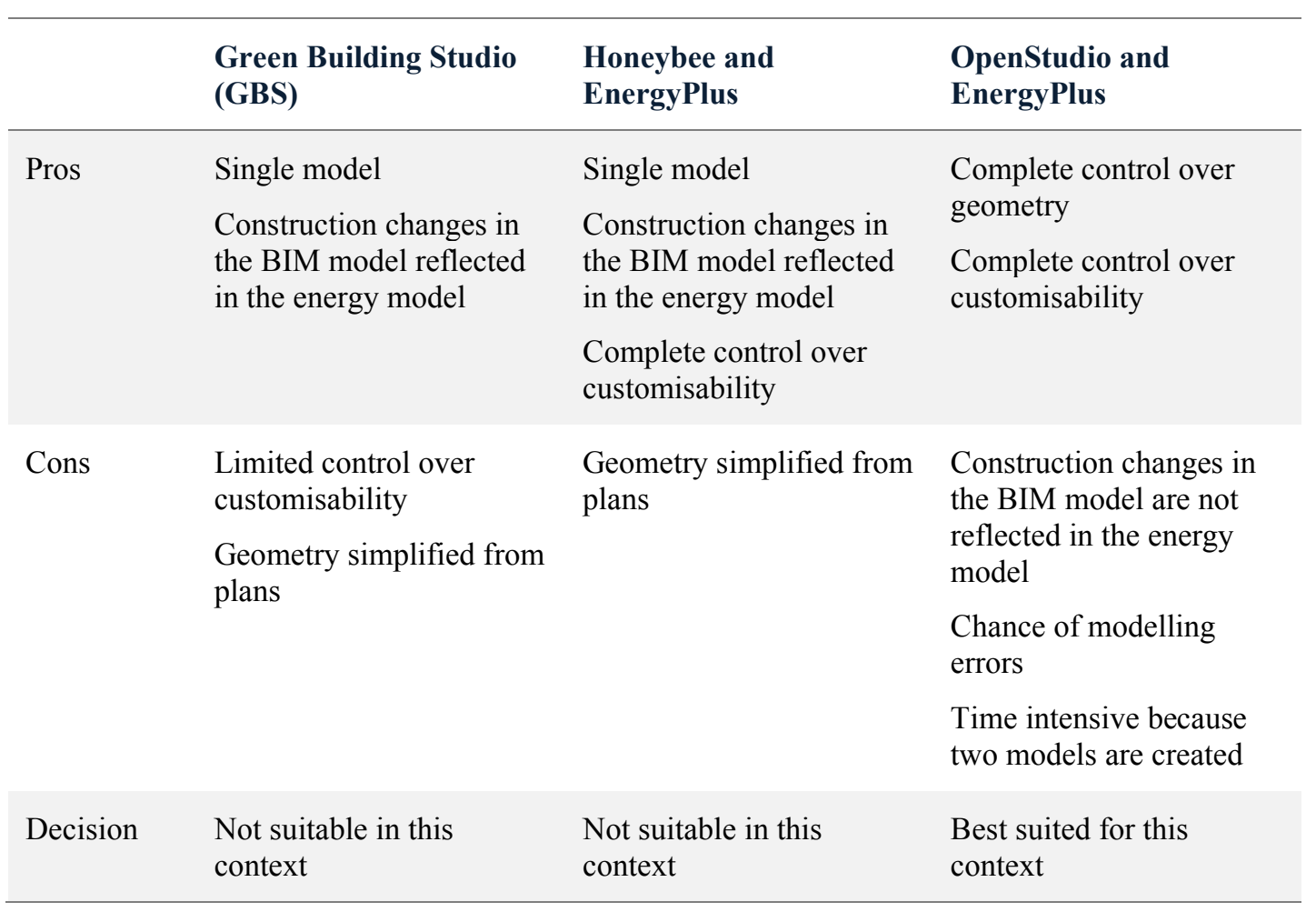

Although GBS and Honeybee allow the Revit BIM model to be translated into an energy model with construction changes reflected, the limitations of simplified geometry and limited control on customisability make OpenStudio the best-suited software for this task even with the downside of modelling twice or more with different construction changes.

\subsection{BIM modelling}

This section discusses the simplifications and assumptions made for each BIM model. It is important to note which stage of the design process where building performance simulations are most important in affecting the design of a building before determining the scope of the BIM model for an LCA. Morbitzer (2003) specifies that BPS has the most impact on the design during the outline design stage, scheme design stage and detailed design stage. If a building performance simulation 
is performed early on, this can positively affect the building design compared to doing a building performance simulation at a later stage. However, assumptions must be made as there are still a lot of unknown factors to the design as the design team have not yet finalised the entire design. Because of this, the scope of what is being modelled in the LCA was limited to the scheme design, including the structure and finishes of the building, excluding elements in Table 22. These specific elements are excluded because they are outside the scheme design stage scope, to reduce modelling time and because there is a lack of reliable New Zealand data available for these elements.

\section{Table 22 List of excluded LCA elements}

Elements

HVAC systems

Sanitary systems

Electrical systems

Fixed fire-fighting systems

Fixed lighting systems

Communication and security systems

Drainage systems

Landscaping

External lighting

On-site drainage

Water treatment systems

To model the houses to the level of detail required, several assumptions were made for each of the three selected houses due to the limited information provided from the plans and specifications available. Table 23 outlines the information available for each house from the plans and specifications. Information not specified, such as the floor structure for House H, was assumed to be the same or similar to the other two houses. Where no information was provided like external doors, information from local hardware stores was used to determine the element material. Conducting an LCA with a lack of information is like the situation of an LCA being performed during the 
scheme design stage. Where design decisions have not been finalised, and assumptions must be made.

Table 23 BIM Modelling specifications provided $(Y=\operatorname{specified,~} N=$ Not specified)

\begin{tabular}{|c|c|c|c|}
\hline House & House $H$ & House P & House W \\
\hline $\begin{array}{l}\text { Documents } \\
\text { provided }\end{array}$ & $\begin{array}{l}\text { Floor plans - materials } \\
\text { specified on plans - very } \\
\text { limited, elevations, no } \\
\text { sections, no material } \\
\text { specification documents }\end{array}$ & $\begin{array}{l}\text { Floor plans, elevations, } \\
\text { sections, details, } \\
\text { specification document }\end{array}$ & $\begin{array}{l}\text { Floor plans, elevations, } \\
\text { sections, details, } \\
\text { specification document }\end{array}$ \\
\hline $\begin{array}{l}\text { Floor } \\
\text { structure }\end{array}$ & $\mathrm{N}$ & $\mathrm{Y}$ & $\mathrm{Y}$ \\
\hline Wall structure & $\mathrm{Y}$ & $\mathrm{Y}$ & $\mathrm{Y}$ \\
\hline $\begin{array}{l}\text { Ceiling } \\
\text { structure }\end{array}$ & $\mathrm{Y}$ & $\mathrm{Y}$ & $\mathrm{Y}$ \\
\hline $\begin{array}{l}\text { Roof } \\
\text { structure }\end{array}$ & $\mathrm{Y}$ & $\mathrm{Y}$ & $\mathrm{Y}$ \\
\hline Insulation & $\mathrm{N}$ & $\mathrm{Y}$ & $\mathrm{Y}$ \\
\hline $\begin{array}{l}\text { Flooring } \\
\text { finish }\end{array}$ & $\mathrm{Y}$ & $\mathrm{Y}$ & $\mathrm{Y}$ \\
\hline $\begin{array}{l}\text { Internal wall } \\
\text { finish }\end{array}$ & $\mathrm{Y}$ & $\mathrm{Y}$ & $\mathrm{Y}$ \\
\hline Ceiling finish & $\mathrm{Y}$ & $\mathrm{Y}$ & $\mathrm{Y}$ \\
\hline Roof finish & $\mathrm{Y}$ & $\mathrm{Y}$ & $\mathrm{Y}$ \\
\hline $\begin{array}{l}\text { External wall } \\
\text { cladding }\end{array}$ & $\mathrm{Y}$ & $\mathrm{Y}$ & $\mathrm{Y}$ \\
\hline Foundation & $\mathrm{N}$ & $\mathrm{Y}$ & $\mathrm{N}$ \\
\hline Glazing & $\mathrm{N}$ & $\mathrm{Y}$ & $\mathrm{Y}$ \\
\hline $\begin{array}{l}\text { Glazing } \\
\text { framing }\end{array}$ & $\mathrm{N}$ & $\mathrm{Y}$ & $\mathrm{Y}$ \\
\hline Internal doors & $\mathrm{Y}$ & $\mathrm{Y}$ & $\mathrm{N}$ \\
\hline $\begin{array}{l}\text { External } \\
\text { doors }\end{array}$ & $\mathrm{N}$ & $\mathrm{N}$ & $\mathrm{N}$ \\
\hline Garage door & $\mathrm{Y}$ & $\mathrm{Y}$ & $\mathrm{N} / \mathrm{a}$ \\
\hline
\end{tabular}


The selected houses are each constructed from a timber frame for the walls, roof, and upper floors, which is similar to the houses in section 3.1 where a majority of the housing stock in New Zealand are constructed from timber.

Incorrect estimation of the ratio of timber and insulation in the building envelope will affect the SoQ and thermal resistance of the building envelope and in turn, the heating/cooling energy use of each house. The amount of timber in the external envelope of a building affects the thermal resistance of that envelope. A high timber to insulation ratio (timber ratio) in either the floor, roof or walls means an increase in thermal bridging causing a decrease in thermal resistance. Whereas a low timber ratio decreases the amount of thermal bridging and allows for more insulation in that envelope. The House Insulation Guide Fifth Edition gives figures of the timber ratio for floor, roof and walls. These figures are estimates of what could be expected in timber-framed houses. However, a recent study by Donn, 2019, which estimated the timber ratio in the walls of five case study MDH houses and then simulated the timber ratios using CAD software found that the estimates (specified) were well below that of the simulated (built) timber ratio. The ratios are shown in Figure 34, where the difference between the specified and built timber ratios was on average, $137 \%$. The estimated timber ratios for this study (14 to $18 \%$ ) were at the lower end of the House Insulation Guide Fifth Edition, which ranges from $14-30 \%$. The simulated timber ratios ranged from 30 to $42 \%$, which is well above the estimate from the House Insulation Guide Fifth Edition.

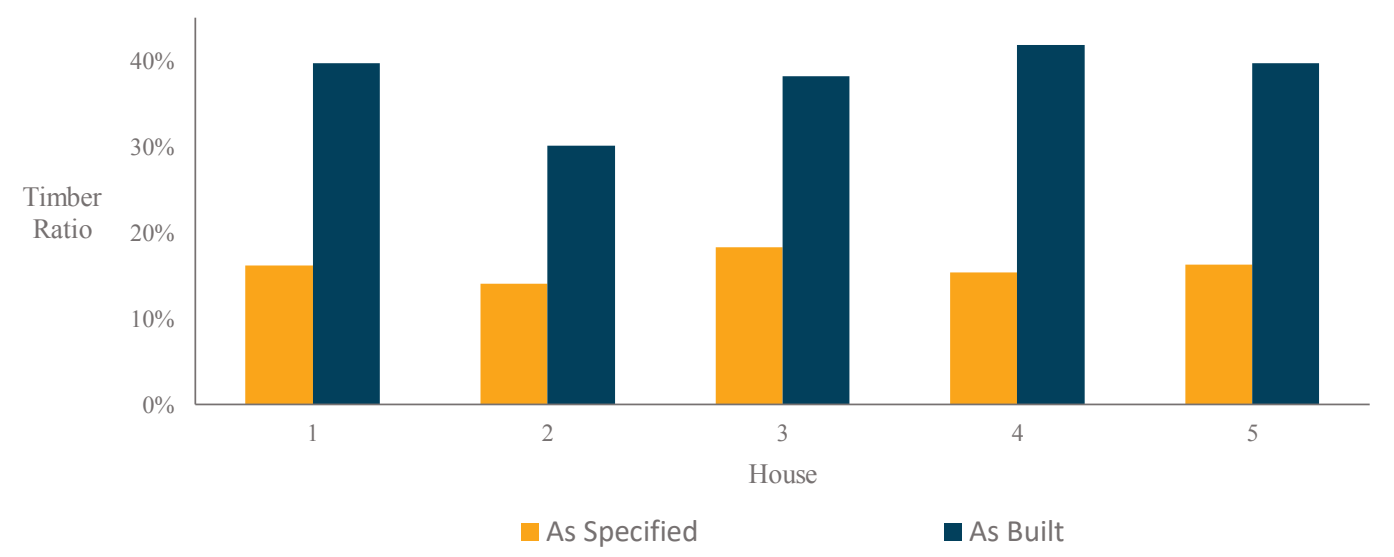

Figure 34 Average percentage of timber in the external envelope (as a percentage of the total wall envelope area) (Donn, 2019) 
There are several factors which have an impact on the timber ratio in the external envelope, in particular, walls outlined in Table 24. Because of these factors, the selected timber ratios for this study will be $35 \%$ for the mid-floor, roof and walls and $10 \%$ for battens. These values are best estimates based on past data and recent simulated data shown in Table 25.

\section{Table 24 Factors that affect timber-insulation ratios in walls}

Factors that affect timber-insulation ratios in walls

Height of walls

Span of walls

Load walls are supporting

The number and size of penetrations in the walls for doors and windows

Adjoining perpendicular walls

Staircases

Number of corners in element

Table 25 Estimated percentage of timber in building elements

\begin{tabular}{lllll}
\hline & Mid-floor & Roof & Wall & Battens \\
\hline $\begin{array}{l}\text { House Insulation } \\
\begin{array}{l}\text { Guide Fifth } \\
\text { Edition (Pringle, } \\
\text { 2014) }\end{array}\end{array}$ & $7.5-11.3 \%$ & $3.8-15.7 \%$ & $14-30 \%$ & $\mathrm{n} / \mathrm{a}$ \\
$\begin{array}{l}\text { (Donn, 2019) } \\
\text { Selected values }\end{array}$ & $35 \%$ & $\mathrm{n} / \mathrm{a}$ & $38 \%$ & \\
\hline
\end{tabular}

\subsubsection{Complete BIM models}

The MDH houses that this study is focused on are units that share inter-tenancy walls. The number of total units sharing these walls depends on the site size and other factors which are outside the scope of this study. The houses were modelled in a block of three adjoining units each, and the results then scaled to reflect eight units in a block. The blocks may contain a lower or higher number than this, but eight was selected to ensure consistency between results. Modelling the units in a block allows 
for any extreme differences in material use from middle and end units to average out in the analysis. These houses are shown in Figure 35, Figure 36 and Figure 37. The energy models will be replicas of these using the plans generated in Revit as a reference for dimensions of elements.

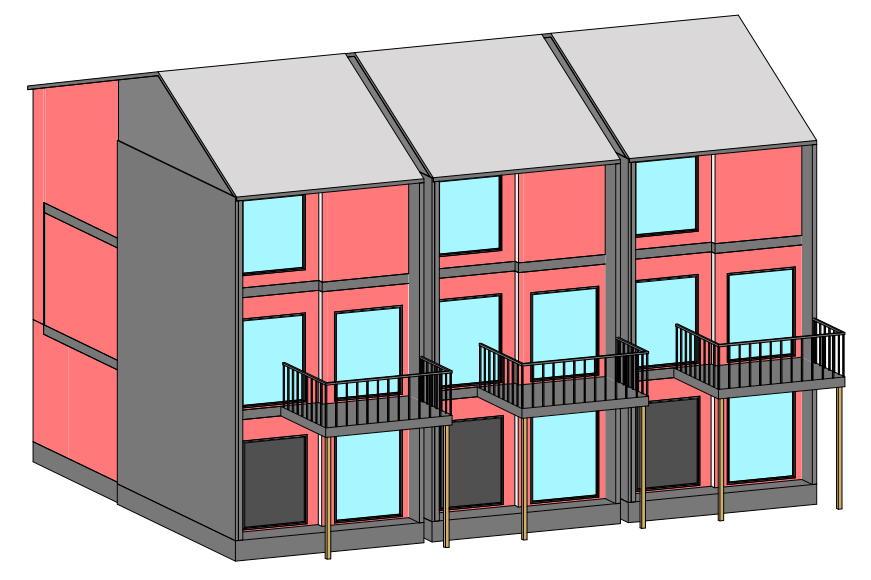

Figure 35 House H - Revit model

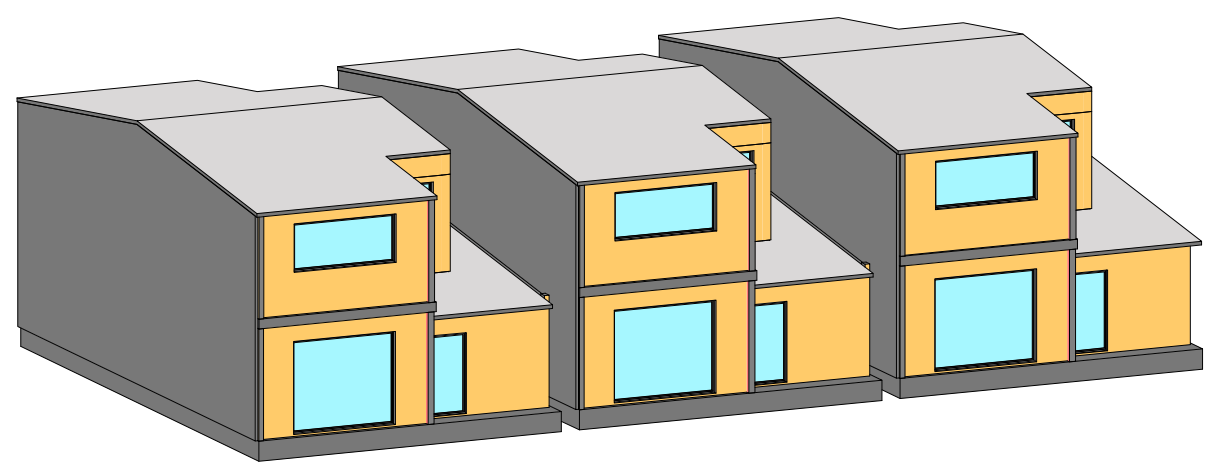

Figure 36 House P - Revit model 


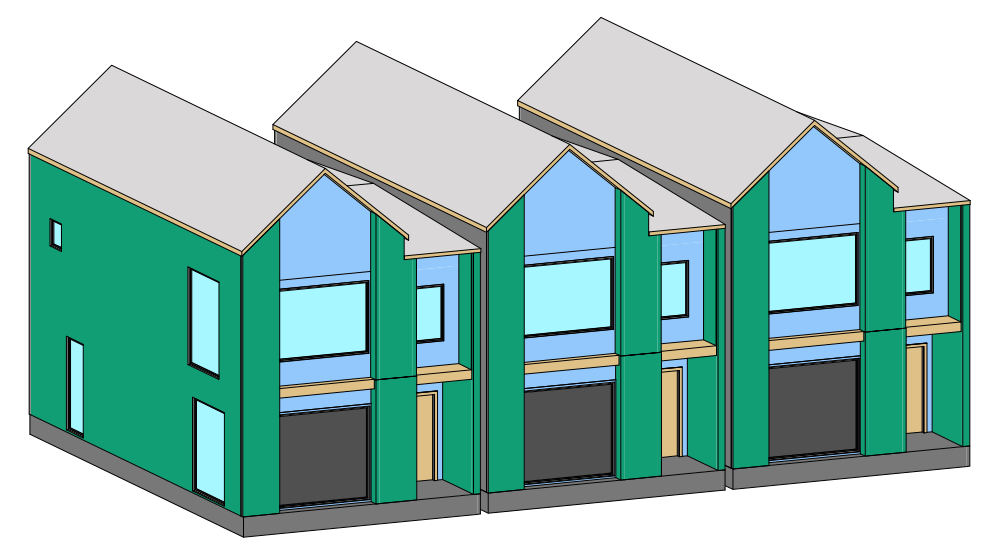

Figure 37 House W-Revit model
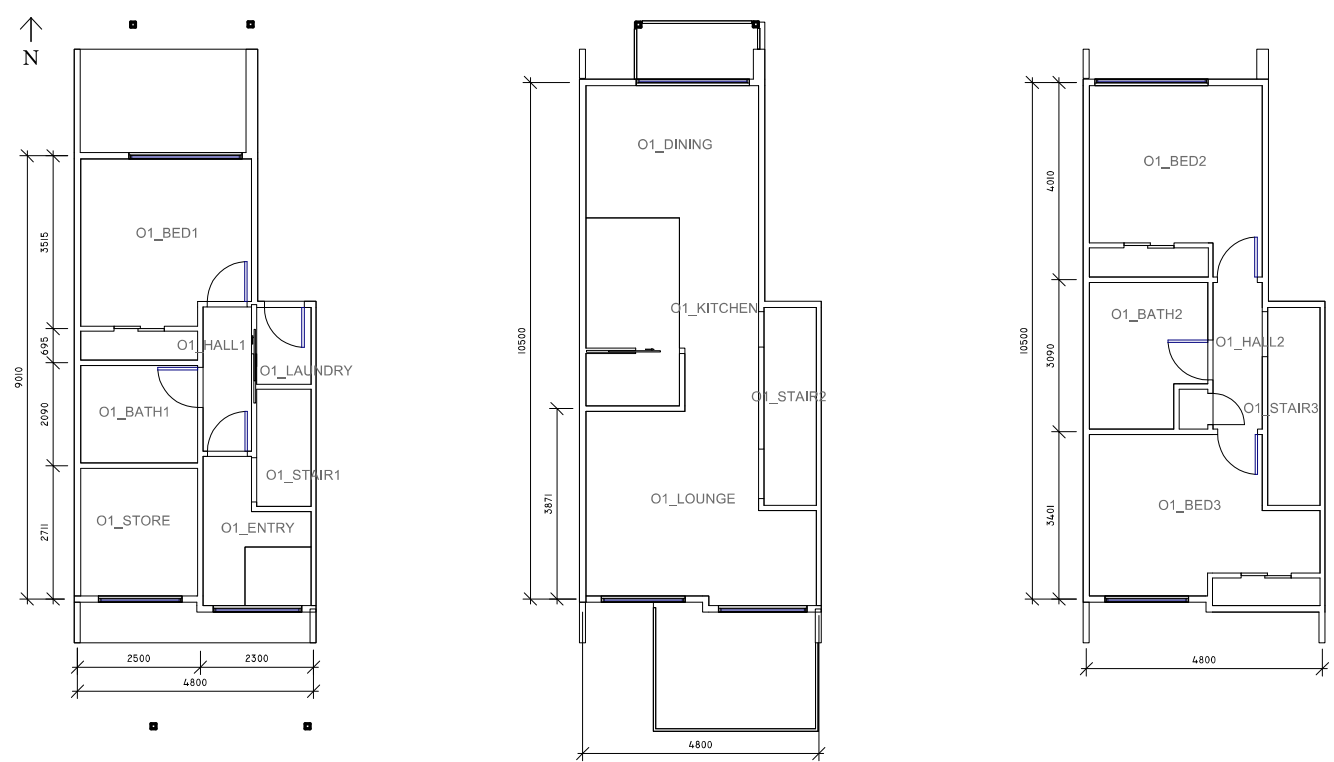

Figure 38 House $H$ - plans (1:200) 

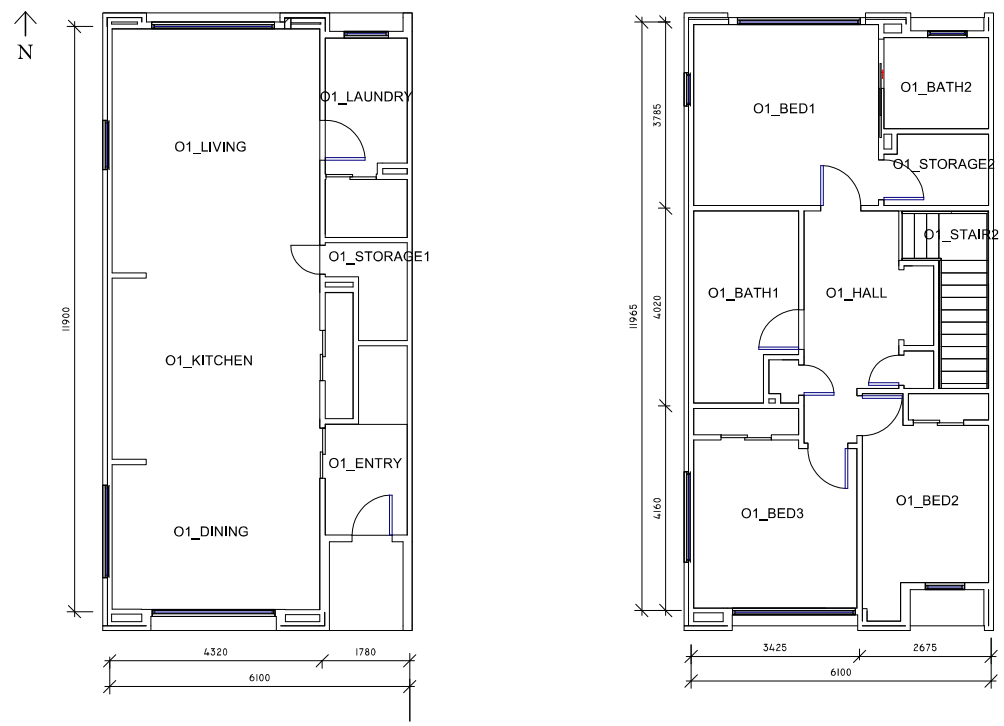

Figure 39 House P - plans (1:200)
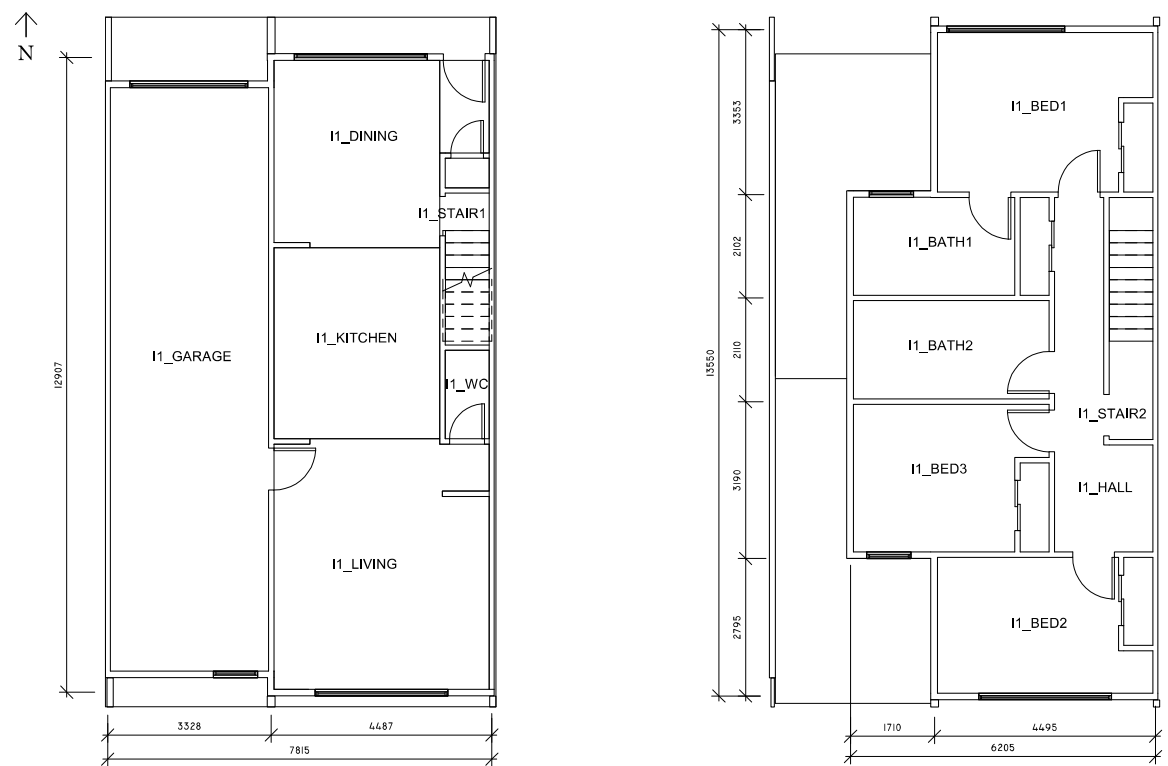

Figure 40 House W - plans (1:200)

Each element of the models was modelled with a LOD of 300 as this creates necessary information of the construction of the elements for an LCA. An example of the construction of two elements to an LOD 300 is shown in Figure 41 and Figure 42. Each material was input into Revit with a unique name and reference code to be recognised by LCAQuick. Each SoQ was exported to a text file and then imported into LCAQuick once the energy modelling was complete. 


\begin{tabular}{|c|c|c|c|}
\hline & Function & Material & Thickness \\
\hline 1 & Membrane Layer & LCA_Paint (exterior), water-borne, for timber ( 2 coats $/ \mathrm{m}$ & 0.0 \\
\hline 2 & Membrane Layer & LCA_Paint (exterior), water-borne, primer/sealer ( 1 coat / & 0.0 \\
\hline 3 & Structure [1] & LCA_Cladding, all profiles (fibre cement, $9 \mathrm{~mm}$ thickness) & 10.0 \\
\hline 4 & Structure [1] & LCA_AirGap & 2.0 \\
\hline 5 & Structure [1] & LCA_Softwood (dressed, kiln dried) floor [from unsustain & 18.0 \\
\hline 6 & Core Boundary & Layers Above Wrap & 0.0 \\
\hline 7 & Structure [1] & LCA_Rigid air barrier (fibre cement, $4.5 \mathrm{~mm}$ thickness) & 4.5 \\
\hline 8 & Thermal/Air Layer [3] & LCA_Insulation ( $90 \mathrm{~mm}$ wall), Pink@ Batts $®$ Classic R1.8 & 59.0 \\
\hline 9 & Structure [1] & LCA_Softwood (dressed, kiln dried) floor [from unsustain & 31.0 \\
\hline 10 & Core Boundary & Layers Below Wrap & 0.0 \\
\hline 11 & Substrate [2] & LCA_Plasterboard (GIB@ standard $10 \mathrm{~mm})$ & 10.0 \\
\hline 12 & Membrane Layer & LCA_Paint, water-borne, walls (Dulux Wash\&Wear $@$ low & 0.0 \\
\hline
\end{tabular}

Figure 41 LOD 300 layers for example wall

\begin{tabular}{|l|l|l|l|}
\hline & \multicolumn{1}{|c|}{ Function } & \multicolumn{1}{c|}{ Material } & \multicolumn{1}{c|}{ Thickness } \\
\hline 1 & Core Boundary & Layers Above Wrap & 0.0 \\
\hline 2 & Structure [1] & LCA_Reinforced concrete, 20 MPa, in-sit & 200.0 \\
\hline 3 & Structure [1] & LCA_Insulation, polyester & 100.0 \\
\hline 4 & Core Boundary & Layers Below Wrap & 0.0 \\
\hline 5 & Membrane Layer & LCA_Membrane, building wrap, polyeth & 0.0 \\
\hline
\end{tabular}

Figure 42 LOD 300 layers for example floor

\subsection{LCAQuick input data}

Information about each model was added into LCAQuick so that the correct building lifespan was used (90 years) and reporting can be shown at a building level and $\mathrm{m}_{2}$ level. Figure 43 shows the inputs for the model in LCAQuick for House W. 


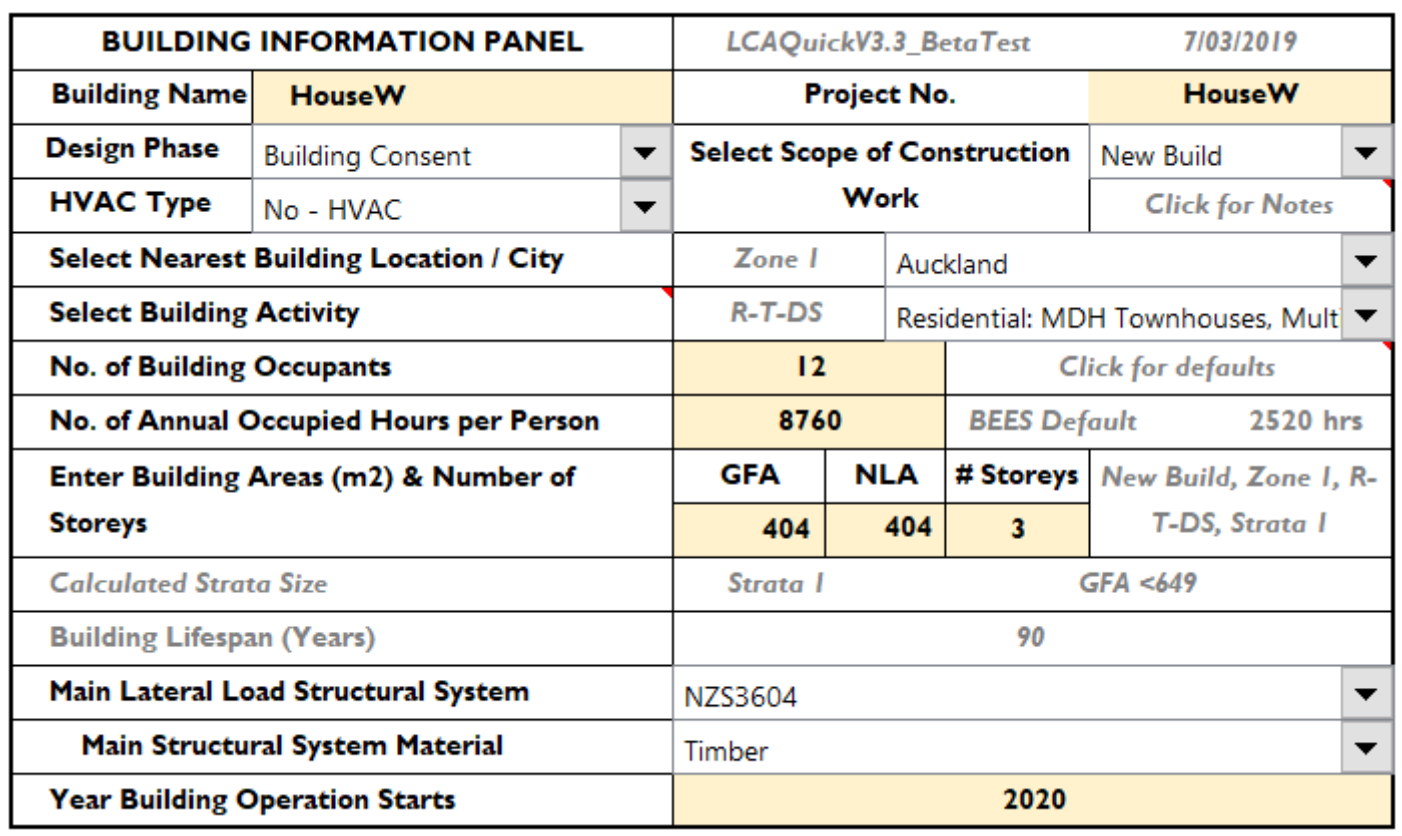

Figure 43 LCAQuick input data interface (BRANZ, 2019a)

\subsection{Energy modelling quality assurance measures}

This section discusses the energy modelling process, inputs into the energy model, assumptions and simplifications.

\subsubsection{Geometry}

Because no satisfactory means could be found of deriving a useful energy model from the Revit geometry. The geometry of the blocks of units was created in Sketchup first as a two-dimensional plan model using the BIM model as a reference for dimensions. Because walls are represented as lines with no thickness, the energy model dimensions differ slightly from the BIM model as the energy models' dimensions of spaces are measured from the inside wall rather than the outside. This difference in geometry location will likely have a negligible impact on the thermal performance because the construction of each wall considers both the materials and their thickness.

The BIM models were modelled in blocks of three units as modelling eight units in a block in the energy model significantly adds to modelling and simulation run time. Therefore, the units are modelled with the outer two units and middle units shown in 
Figure 44, Figure 45 and Figure 46. It is assumed that the middle unit will have the same or similar energy use to its adjacent units in the block as they are identical, and all share inter-tenancy walls with other units. This way of modelling meant that the modelled middle units energy use was multiplied by the number of identical units in the block and added with the outer units to calculate the entire blocks energy use.

The units were split into 'zones' like in Chapter 3, as different equipment loads, and operating schedules can be applied to each zone independently of one another. Zones were typically defined where walls were present. The open plan areas of the house like in Chapter 3 were split, depending on the depth of the room, the effect of solar gains and use of the space. If the units were not zoned appropriately, then this would result in either an over or underestimation of heating and cooling energy. If an open plan layout is not zoned appropriately, one end of the unit may be cool, and the other warm but heating or cooling is applied to the entire unit when it is only needed in one area.

The roof cavity above the upper floor ceiling is modelled with a flat roof at an average height of the original roof so that it still has the same volume. This simplification reduces time in the modelling and calculation process and results in similar energy use because the modelled roof has the same volume.

Shading elements modelled are shown in purple in Figure 44, Figure 45 and Figure 46. Only shading elements that were of the significant size of $400 \mathrm{~mm}$ or over were modelled as below this they are unlikely to have significant impact shading the windows.

Naming conventions of modelled elements help to identify specific elements and their associated attributes quickly. Naming conventions were used throughout the model, including thermal zones, loads, equipment and surfaces. Explanation of conventions can be found in section Appendix C. 


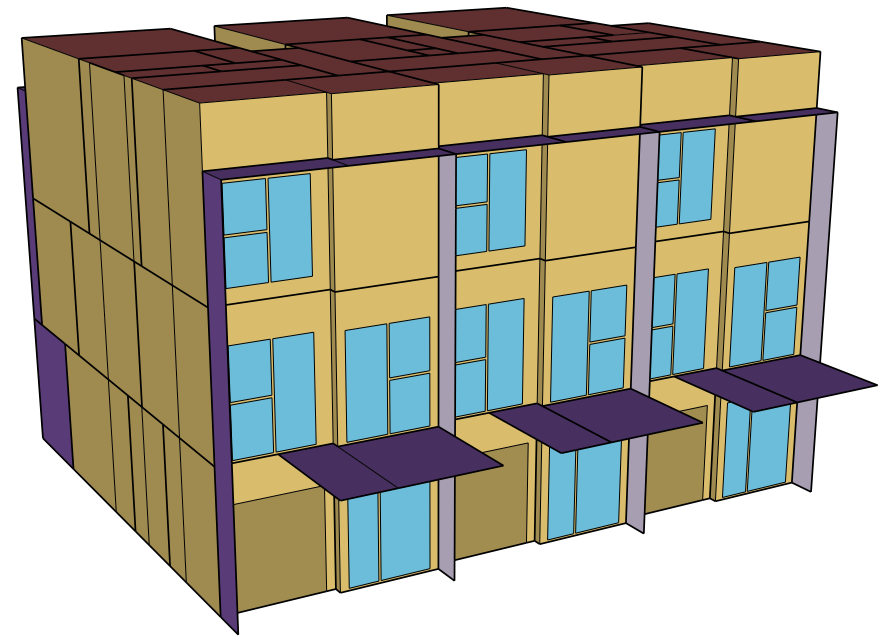

Figure 44 House H - energy model geometry - Openstudio

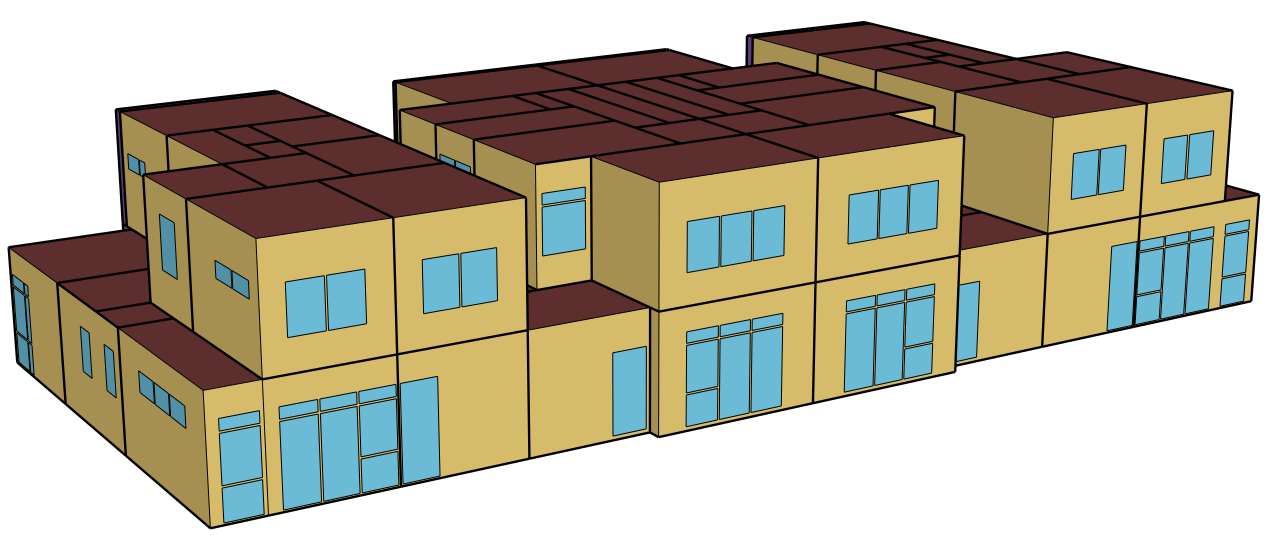

Figure 45 House P - energy model geometry - Openstudio

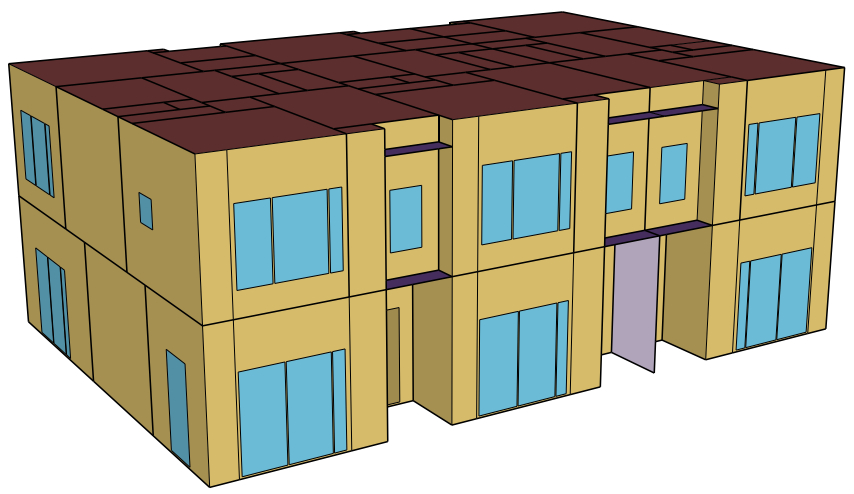

Figure 46 House W-energy model geometry - Openstudio 


\subsubsection{Location and orientation}

The houses were only modelled in two climates, which are Auckland and Christchurch, New Zealand. A TMY data file provided by NIWA New Zealand is used for the energy simulations (Liley, Hisako, Sturman, \& Wratt, 2008).

All houses were orientated with the short length of each individual unit oriented north.

\subsubsection{Shading}

Shading from other buildings/trees were not modelled due to the difficulty of modelling representative shading onto a building. Representative shading would include many assumptions which may not apply to the conditions of every site. Therefore, shading from other elements should only be modelled when a specific site is selected.

\subsubsection{Materials}

The construction of the building was exported from the BIM model as an SoQ and added to the energy model inputs. The materials outlined in Other material inputs are shown in Table 27, Table 28 and Table 29.

Table 26, are taken from New Zealand Standard 4214:2006 Methods of Determining the Total Thermal Resistance of Parts of Buildings. No specific reference is provided in this standard as to where each material data is sourced. However, there are references in the standard to other New Zealand Standards (NZS 4215:2004 and NZS 4243:1996), Joint Australian/New Zealand Standard AS/NZS 4859, International Standard ISO 12579, American Standard ASTM C1363:05 and Australian Standard AS 1366. The references may mean that the material data is not fully representative of actual New Zealand data but is a close approximation. To trace the reference data from each of these sources is outside the scope of this study. The most important part of selecting materials from NZS 4214:2006 is that this ensures consistency between this study and other studies in New Zealand that use this standard as a reference. Other material inputs are shown in Table 27, Table 28 and Table 29. 
Table 26 Energy modelling material inputs (Standards New Zealand, 2006)

\begin{tabular}{|c|c|c|c|c|c|c|c|c|}
\hline Name & Roughness & $\begin{array}{l}\text { Thickness } \\
\text { (m) }\end{array}$ & $\begin{array}{l}\text { Conductivity } \\
(\mathrm{W} / \mathrm{m}-\mathrm{K})\end{array}$ & $\begin{array}{l}\text { Density } \\
\left(\mathbf{k g} / \mathbf{m}_{3}\right)\end{array}$ & $\begin{array}{l}\text { Specific } \\
\text { Heat } \\
(\mathrm{J} / \mathrm{kg}-\mathrm{K})\end{array}$ & $\begin{array}{l}\text { Thermal } \\
\text { Absorptance }\end{array}$ & $\begin{array}{l}\text { Solar } \\
\text { Absorptance }\end{array}$ & $\begin{array}{l}\text { Visible } \\
\text { Absorptance }\end{array}$ \\
\hline Brick & $\begin{array}{l}\text { Medium } \\
\text { Smooth }\end{array}$ & 0.07 & 1.2 & 1920 & 790 & 0.9 & 0.7 & 0.7 \\
\hline Carpet & Rough & 0.02 & 0.059 & 320 & 840 & 0.9 & 0.7 & 0.7 \\
\hline $\begin{array}{l}\text { Concrete } \\
\text { slab }\end{array}$ & $\begin{array}{l}\text { Medium } \\
\text { Rough }\end{array}$ & 0.2 & 1.6 & 2300 & 840 & 0.9 & 0.65 & 0.65 \\
\hline $\begin{array}{l}\text { Engineered } \\
\text { wood } \\
\text { plywood }\end{array}$ & $\begin{array}{l}\text { Medium } \\
\text { Smooth }\end{array}$ & 0.009 & 0.13 & 550 & 1220 & 0.9 & 0.78 & 0.78 \\
\hline $\begin{array}{l}\text { Fibre } \\
\text { cement } \\
\text { boards }\end{array}$ & Smooth & 0.009 & 0.25 & 1500 & 837 & 0.9 & 0.7 & 0.7 \\
\hline $\begin{array}{l}\text { Gypsum } \\
\text { plasterboard }\end{array}$ & Smooth & 0.013 & 0.22 & 800 & 840 & 0.9 & 0.92 & 0.92 \\
\hline Membrane & $\begin{array}{l}\text { Medium } \\
\text { Smooth }\end{array}$ & 0.003 & 0.3 & 930 & 2100 & 0.9 & 0.7 & 0.7 \\
\hline $\begin{array}{l}\text { Polystyrene } \\
\text { XPS 25mm } \\
\text { Perimeter } \\
\text { Insulation }\end{array}$ & Smooth & 0.025 & 0.025 & 16 & 1210 & 0.9 & 0.7 & 0.7 \\
\hline Steel (150) & $\begin{array}{l}\text { Medium } \\
\text { Smooth }\end{array}$ & 0.00055 & 50 & 7800 & 480 & 0.8 & 0.5 & 0.5 \\
\hline Tiles & Smooth & 0.015 & 0.8 & 1900 & 840 & 0.9 & 0.7 & 0.7 \\
\hline Timber & $\begin{array}{l}\text { Medium } \\
\text { Smooth }\end{array}$ & 0.05 & 0.12 & 450 & 1220 & 0.9 & 0.78 & 0.78 \\
\hline $\begin{array}{l}\text { Timber } \\
\text { Battens }\end{array}$ & $\begin{array}{l}\text { Medium } \\
\text { Smooth }\end{array}$ & 0.002 & 0.12 & 450 & 1220 & 0.9 & 0.78 & 0.78 \\
\hline $\begin{array}{l}\text { Timber } \\
\text { Floor }\end{array}$ & $\begin{array}{l}\text { Medium } \\
\text { Smooth }\end{array}$ & 0.08 & 0.12 & 450 & 1220 & 0.9 & 0.78 & 0.78 \\
\hline $\begin{array}{l}\text { Timber } \\
\text { Roof }\end{array}$ & $\begin{array}{l}\text { Medium } \\
\text { Smooth }\end{array}$ & 0.024 & 0.12 & 450 & 1220 & 0.9 & 0.78 & 0.78 \\
\hline $\begin{array}{l}\text { Timber } \\
\text { Wall }\end{array}$ & $\begin{array}{l}\text { Medium } \\
\text { Smooth }\end{array}$ & 0.031 & 0.12 & 450 & 1220 & 0.9 & 0.78 & 0.78 \\
\hline Vinyl & Smooth & 0.003 & 0.79 & 2050 & 840 & 0.9 & 0.7 & 0.7 \\
\hline
\end{tabular}


Table 27 Energy modelling no mass material inputs

\begin{tabular}{llllll}
\hline Name & Roughness & $\begin{array}{l}\text { Thermal } \\
\text { Resistance } \\
\mathbf{m} / \mathbf{K} / \mathbf{W}\end{array}$ & $\begin{array}{l}\text { Thermal } \\
\text { Absorptance }\end{array}$ & $\begin{array}{l}\text { Solar } \\
\text { Absorptance }\end{array}$ & $\begin{array}{l}\text { Visible } \\
\text { Absorptance }\end{array}$ \\
\hline Insulation R1.3 & VerySmooth & 1.3 & 0.9 & 0.7 & 0.7 \\
Insulation R1.8 & VerySmooth & 1.8 & 0.9 & 0.7 & 0.7 \\
Insulation R1.9 & VerySmooth & 1.9 & 0.9 & 0.7 & 0.7 \\
Insulation R2.9 & VerySmooth & 2.9 & 0.9 & 0.7 & 0.7 \\
\hline
\end{tabular}

Table 28 Energy modelling air gap material inputs

\begin{tabular}{ll}
\hline Name & Thermal Resistance $\left(\mathbf{m}_{2}-\mathbf{k} / \mathbf{W}\right)$ \\
\hline Airgap & 0.16 \\
\hline
\end{tabular}

Table 29 Energy modelling window material inputs

\begin{tabular}{llll}
\hline Name & R-value & SHGC & $\begin{array}{l}\text { Visible } \\
\text { Transmittance }\end{array}$ \\
\hline Double glazing & 0.30 & 0.74 & 0.68 \\
\hline
\end{tabular}

\subsubsection{Building foundations}

Each model was modelled with a concrete slab foundation, as indicated on the plans of the houses. This construction requires the ground conditions to be modelled to simulate ground-coupled heat transfer from the ground to the foundations of the building. The ground conditions that were input into the model are listed in Table 30 with associated references. Again, like the material data from NZS 4214:2006, this data cannot be traced back to the source but may have been sourced from ASHRAE Handbook, Fundamentals 2001 as this is listed as a reference in the standard. The values input for the soil properties has an effect on the heat transfer from the soil to the concrete floor slab modelled. As heat loss to the ground is one of the largest contributors to the heat loss of a building, it is essential that the selected values were not severely over or underestimated. 
Table 30 Building foundation Inputs

\begin{tabular}{lll}
\hline Input & Value & Reference \\
\hline Soil thermal conductivity & $1.25 \mathrm{~W} / \mathrm{m}-\mathrm{K}$ & (Standards New Zealand, 2006) \\
Soil density & $1500 \mathrm{~kg} / \mathrm{m} 3$ & (Standards New Zealand, 2006) \\
Soil-specific heat & $920 \mathrm{~J} / \mathrm{kg}-\mathrm{K}$ & (ASHRAE, 2005) \\
\hline
\end{tabular}

\subsubsection{Ground temperatures}

Ground temperature data was sourced from available data in the Auckland and Christchurch region at a depth of $0.3 \mathrm{~m}$ (P. R. Chappell, 2013). EnergyPlus recommend ground temperatures are recorded at a depth of $0.5 \mathrm{~m}$ however, only a depth of $0.3 \mathrm{~m}$ was available from reliable sources (US Department of Energy, 2017). The difference in temperature between the depths will affect the heat transfer between the soil and concrete floor slab. The impact of this on energy use, however, is unknown.

\subsubsection{Internal loads}

Internal loads and associated schedules apart from lighting were taken from New Zealand Standard Thermal Insulation - Housing and Small Buildings (NZS 4218:2009). Like NZS 4214:2006, references to each specific input was not provided. Instead, references for the entire document were given, which makes it difficult to determine whether the inputs are relevant to a New Zealand context. The reason for selecting this standard as a reference is to ensure consistency of this study with studies that also use this standard as a reference.

High values for internal loads increase the indoor air temperature causing less heating in cooler months and possible more cooling in warmer months, leading to an overestimate of heating energy. However, these values are assumptions taken from the reference and will not directly reflect all activities in the building. Again, the main point of using this reference is to ensure consistency between studies. 


\subsubsection{People}

It was assumed there were four occupants per three-bedroom unit. Two adults and two children. Sensible heat gain is assumed $150 \mathrm{~W}$ while active and $70 \mathrm{~W}$ while sleeping (Standards New Zealand, 2009).

\subsubsection{Lighting}

Lighting was assumed to be $4.42 \mathrm{~W} / \mathrm{m} 2$ for living rooms, $6.42 \mathrm{~W} / \mathrm{m} 2$ for kitchen and dining, $1.03 \mathrm{~W} / \mathrm{m}_{2}$ for bedrooms and $2.60 \mathrm{~W} / \mathrm{m}_{2}$ for all other spaces (Burgess, 2007).

\subsubsection{Electrical equipment}

Plug loads for electrical equipment were assumed to be $24.5 \mathrm{~W} / \mathrm{m} 2$ for each room except bathrooms, laundry, storage rooms and circulation spaces because very little electrical equipment is used in these spaces except lighting (Standards New Zealand, 2009).

\subsubsection{Domestic hot water}

A single domestic hot water cylinder was assumed to be used in each unit located on the ground floor with a plug load of 100W (Standards New Zealand, 2009).

\subsubsection{Schedules}

The schedules in Table 31 from NZS 4218:2009, reflect an ideal situation where occupants are predictable and are away from home during the day in the week and at home at nights and during the weekend. These schedules use assumptions for a 'typical' situation that does not reflect what occurs inside a real building. The aim is for these models to be consistent with other studies. Using unique schedules would mean the models better reflect the operation of the building, but they would not be able to be compared to models which use NZS 4218:2009 schedules. 
Table 31 Internal load schedule - the percentage of maximum power density (Burgess, 2007)

\begin{tabular}{|c|c|c|c|c|c|}
\hline Hour & Occupancy & & Electrical & & Lighting \\
\hline & Weekday & Weekend & Weekday & Weekend & Any day \\
\hline 0 & $3 \%$ & $3 \%$ & $100 \%$ & $100 \%$ & $16 \%$ \\
\hline 1 & $3 \%$ & $3 \%$ & $100 \%$ & $100 \%$ & $11 \%$ \\
\hline 2 & $3 \%$ & $3 \%$ & $100 \%$ & $100 \%$ & $10 \%$ \\
\hline 3 & $3 \%$ & $3 \%$ & $100 \%$ & $100 \%$ & $10 \%$ \\
\hline 4 & $3 \%$ & $3 \%$ & $100 \%$ & $100 \%$ & $9 \%$ \\
\hline 5 & $3 \%$ & $3 \%$ & $100 \%$ & $100 \%$ & $10 \%$ \\
\hline 6 & $3 \%$ & $3 \%$ & $100 \%$ & $100 \%$ & $23 \%$ \\
\hline 7 & $3 \%$ & $3 \%$ & $100 \%$ & $100 \%$ & $36 \%$ \\
\hline 8 & $23 \%$ & $23 \%$ & $60 \%$ & $100 \%$ & $23 \%$ \\
\hline 9 & $23 \%$ & $23 \%$ & $60 \%$ & $100 \%$ & $15 \%$ \\
\hline 10 & $23 \%$ & $23 \%$ & $60 \%$ & $100 \%$ & $13 \%$ \\
\hline 11 & $23 \%$ & $23 \%$ & $60 \%$ & $50 \%$ & $12 \%$ \\
\hline 12 & $23 \%$ & $23 \%$ & $60 \%$ & $50 \%$ & $11 \%$ \\
\hline 13 & $23 \%$ & $23 \%$ & $60 \%$ & $50 \%$ & $11 \%$ \\
\hline 14 & $23 \%$ & $23 \%$ & $60 \%$ & $50 \%$ & $11 \%$ \\
\hline 15 & $23 \%$ & $23 \%$ & $60 \%$ & $50 \%$ & $13 \%$ \\
\hline 16 & $23 \%$ & $23 \%$ & $60 \%$ & $50 \%$ & $21 \%$ \\
\hline 17 & $23 \%$ & $23 \%$ & $60 \%$ & $50 \%$ & $60 \%$ \\
\hline 18 & $27 \%$ & $27 \%$ & $100 \%$ & $70 \%$ & $98 \%$ \\
\hline 19 & $27 \%$ & $27 \%$ & $100 \%$ & $70 \%$ & $100 \%$ \\
\hline 20 & $27 \%$ & $27 \%$ & $100 \%$ & $70 \%$ & $90 \%$ \\
\hline 21 & $27 \%$ & $27 \%$ & $100 \%$ & $70 \%$ & $75 \%$ \\
\hline 22 & $20 \%$ & $20 \%$ & $100 \%$ & $100 \%$ & $54 \%$ \\
\hline 23 & $20 \%$ & $20 \%$ & $100 \%$ & $100 \%$ & $30 \%$ \\
\hline
\end{tabular}




\subsubsection{Blinds}

Blinds were applied to the windows and glass doors in the bedrooms and living areas. Blinds are set to be drawn at night from 21:00-07:00. This is to represent the occupants closing blinds at nights. Blinds are not set to close during the day. This is because of the complicated relationship to solar radiation into the space, indoor air temperature and occupants being at home, which if modelled, will not reflect a realistic scenario. Excluding blinds entirely would allow heat to escape through the windows at night, which is not representative of residential houses.

\subsubsection{Natural ventilation}

Cooling a building in a warm climate like Auckland can be achieved by opening windows or using mechanical systems. To reduce energy consumption, using windows and natural ventilation is most ideal, although occupants may not do so because of privacy, security or other reasons. For these models, windows and exterior doors were set to be opened if necessary when the occupancy schedule suggests occupants are awake and closed when no occupants are home. Other conditions that must be met for the windows to open are that the indoor air temperature is $24^{\circ} \mathrm{C}$ or above, the outdoor air temperature is lower than the indoor air temperature by $2^{\circ} \mathrm{C}$ degrees, and there is air pressure at the window/door opening to push the cooler air into the building. If there is no pressure difference between indoor and outdoor, then no air will flow through the openable window/door.

The openable windows were selected based on the plans of the building. All openable windows are top hung

Air movement between rooms was included in an airflow network with interior doors behaving the same as windows and exterior doors, opening when the above conditions are met.

Excluding natural ventilation from the simulation would result in a simulation where no windows or doors, both internal and external, are opened causing a simulation which is not representative of how the building is operated. 


\subsubsection{Infiltration}

Air leakage through gaps at wall and window joints contribute to the heat loss of the building. The magnitude of this depends on the Effective Leakage Area (ELA) and like openable windows, the outdoor temperature and air pressure. ELA is the total infiltration area in $\mathrm{m} 2$, where leakage occurs over the entire building's exterior surfaces. ELA is calculated using Sherman (1986) as follows:

$$
E L A=Q\left(\frac{p}{2 \Delta P}\right)^{\frac{1}{2}}
$$

Where: $E L A=$ the total leakage area of the unit $\left(\mathrm{m}_{2}\right)$

$$
Q=\text { volume flow rate }\left(\mathrm{m}_{3} / \mathrm{s}\right)
$$$$
p=\text { density of air }\left(\mathrm{kg} / \mathrm{m}_{3}\right)
$$

$\Delta P=$ pressure difference across the opening (4Pa) (Sherman, 1986)

4Pa reference pressure is used as this represents ambient driving forces of air on the building (Liddament, 1996).

The volume flow rate was calculated using an assumed Air Change per Hour (ACH) @50Pa for the entire building. A BRANZ study of 36 randomly selected houses built after 1994 found ACH rates ranged from 3.1 - 7.8 ACH @50PA. These findings were lower than earlier studies showing houses are becoming more airtight and construction methods more consistent (McNeil, Plagmann, McDowall, \& Bassett, 2015). On the other end of the airtightness spectrum is Passivhaus certification, where passive design principles are used to create low energy buildings that have a maximum ACH of $0.6 @ 50 \mathrm{~Pa}$ (Passive House Institute, 2016). There is no New Zealand data available on the infiltration of $\mathrm{MDH}$ houses.

Because of the design of MDH where middle units only have two exterior facades, this means there is less area for air to leak out of the building around cracks and openings, meaning they will have less infiltration - compared to end units where there is a larger amount of cracks and openings. 
For simplicity, an infiltration rate of $3 \mathrm{ACH} @ 50 \mathrm{~Pa}$ is selected for each block of units modelled. For House $\mathrm{H}$, there is $3 \mathrm{ACH}$ divided by three modelled units. The calculated ELA in Table 32, is distributed proportionally across all exterior walls of the units.

It is common in energy simulations to assume a constant $\mathrm{ACH}$ rate applied to each room. This constant rate does not account for greater infiltration on windy days, or for the peakiness of different MDH units where end units have more external surface wall area through which to leak air. This study used a process where a base ACH rate typical of a construction was combined with the air pressure on the building envelope to determine the amount of infiltration into the building.

Table 32 Calculation of Effective Leakage Area for each house

\begin{tabular}{llll}
\hline & House H & House P & House W \\
\hline Total Floor area per unit $\left(\mathrm{m}_{2}\right)$ & 123 & 125 & 134 \\
Height $(\mathrm{m})$ & 3.2 & 3.2 & 3.2 \\
Unit volume (m3) & 393.6 & 400.0 & 428.8 \\
Number of units modelled & 3 & 4 & 3 \\
Total volume (m3) & 1180 & 1600 & 1286 \\
ACH @ 50 & 3 & 3 & 3.07 \\
Volume Flow Rate (m3/s) & 0.98 & 1.33 & 1.2 \\
Air density (kg/m3) & 1.2 & 1.2 & 4 \\
\hline $\begin{array}{l}\text { Pressure difference across } \\
\text { opening (Pa) }\end{array}$ & 4 & 4 & 0.42 \\
\hline \begin{tabular}{l} 
ELA (m2) \\
\hline
\end{tabular} & 0.38 & 0.52 & \\
\hline
\end{tabular}

\subsubsection{Heating systems}

The plans and specifications for all the house did not outline the heating systems used in the units. A BRANZ survey on housing condition in New Zealand found that most houses in New Zealand are heated in some form (White \& Jones, 2017). Either with portable heaters only (11\%) fixed heating only (44\%) or a mixture of both (43\%). Many of these houses (80\%) use electricity as the heating fuel source, and $11 \%$ use 
natural gas. Heat pumps are typically used in living areas, $80 \%$ of homes with heat pumps had only one single heat pump.

For the selected units, a single heat pump would not be able to provide heat to other living areas because the units are split over two and three stories with no mechanical system to move heat around. The BRANZ survey found that of the houses with a heat pump, $69 \%$ of these had other forms of heating in other areas of the house.

Bedroom heating was not common, with $46 \%$ of houses, not heating bedrooms and $32 \%$ of houses always heating occupied bedrooms (Table 33). The data does not line up with typical energy modelling simulations in New Zealand where an assumption is made that all bedrooms and living areas are heated when the reality is that a large portion does not heat bedrooms.

Table 33 Proportion of households heating bedrooms (White \& Jones, 2017)

\begin{tabular}{ll}
\hline Room & Percentage \\
\hline All occupied bedrooms heated & $32 \%$ \\
Some occupied bedrooms heated & $22 \%$ \\
No bedrooms heated & $46 \%$ \\
\hline
\end{tabular}

The survey findings show that of bedrooms which are heated, $38 \%$ of these use electric heaters.

Although the literature determined that heating all living areas is not common, in this study, all living areas and bedrooms are heated for all hours of the day. The goal was to match other recent studies and to ensure adequate indoor environmental conditions. The models were therefore expected to use more energy than current New Zealand homes as they were heated $24 / 7$ to a minimum of $18^{\circ} \mathrm{C}$.

\subsubsection{Heat pump parameters}

Single-speed direct exchange electric heat pumps were assigned to the conditioned zones (bedrooms, living, dining and kitchen). These heat pumps provide both heating and cooling with the setpoints being $18^{\circ} \mathrm{C}-24^{\circ} \mathrm{C}$ (Burgess, 2007). The heat pump's supplied air flow rate is set to auto-size and heating is available any time of the day. 
Cooling is only available when natural ventilation is unavailable. Parameters of these heat pumps can be found in the online repository referenced at the end of this report.

\subsubsection{Outputs}

The outputs of the simulation are used to assess the indoor and outdoor conditions, energy use and the operation of systems in the building like the airflow network. The outputs of each simulation are listed below:

- $\quad$ Site Outdoor Air Wetbulb Temperature $\left({ }^{\circ} \mathrm{C}\right)$,

- Site Outdoor Air Drybulb Temperature $\left({ }^{\circ} \mathrm{C}\right)$.

- $\quad$ Site Wind Speed $(\mathrm{m} / \mathrm{s})$,

- Zone Mean Air Temperature $\left({ }^{\circ} \mathrm{C}\right)$,

- People Occupant Count,

- Cooling Coil Electric Energy (J),

- Heating Coil Electric Energy (J),

- Fan Electric Energy (J),

- Lights Electric Energy (J),

- Electrical Equipment Energy (J),

- Hot Water Equipment District Heating Energy (J),

- AFN Surface Venting Window or Door Opening Factor,

- AFN Zone Infiltration Air Change Rate.

\subsubsection{Timesteps}

A timestep is used to determine the number of calculations performed per hour for the energy simulation. A minimum timestep of one and a maximum of 60 can be input. A value of 60 (1-minute timestep), theoretically gives a higher level of accuracy compared to 30 (2-minute timestep) but increases the simulation run time. Values like 60 and 30 are typically used for models with complex HVAC and plant systems. This timestep also determines how long HVAC systems like a heat pump are active. For example, if a timestep of one is used this will mean if a heat pump is required it will remain on for the entire 60 minutes when it may only need to be on for 30 minutes. The difference in timestep causes an increase in energy, which is seen in Table 34, 
where the models with a timestep of one have higher energy than the lower timesteps (6). With higher timesteps like 6 (10-minute timestep), the systems or windows may turn on and off/open and close rapidly over an hour whereas the occupants may leave them on/open for a longer time. A timestep of 2 (30-minute timestep) has a percentage difference in energy use of -0.8 to $-1.4 \%$ (Table 34 ), which is not a significant difference and will better align with occupants' behaviour. Therefore, a timestep of 2 was used for simulations.

Table 34 Energy difference for different timesteps

\begin{tabular}{llll}
\hline Timestep & $\begin{array}{l}\mathbf{6}(\mathbf{1 0}-\text { minute } \\
\text { timestep) }\end{array}$ & $\begin{array}{l}\mathbf{2 ( 3 0 - m i n u t e} \\
\text { timestep) }\end{array}$ & $\begin{array}{c}\mathbf{1} \text { (60-minute } \\
\text { timestep) }\end{array}$ \\
\hline House $\mathrm{H}$ & $0 \%$ & $-1.2 \%$ & $-2.5 \%$ \\
House P & $0 \%$ & $-1.4 \%$ & $-7.9 \%$ \\
House W & $0 \%$ & $-0.8 \%$ & $-1.8 \%$ \\
\hline
\end{tabular}

\subsubsection{Window opening check}

The models were checked to determine whether the openable windows were being opened when the indoor temperature is above the natural ventilation setpoint, the outdoor temperature is lower than the indoor, no mechanical ventilation is being used, and the occupants are awake. A north-facing zone shown in Figure 47 with the zone highlighted in red, was selected because of its orientation and high WWR. Three of the windows in the zone are openable. A period of 24 hours was selected in midsummer for this analysis. 


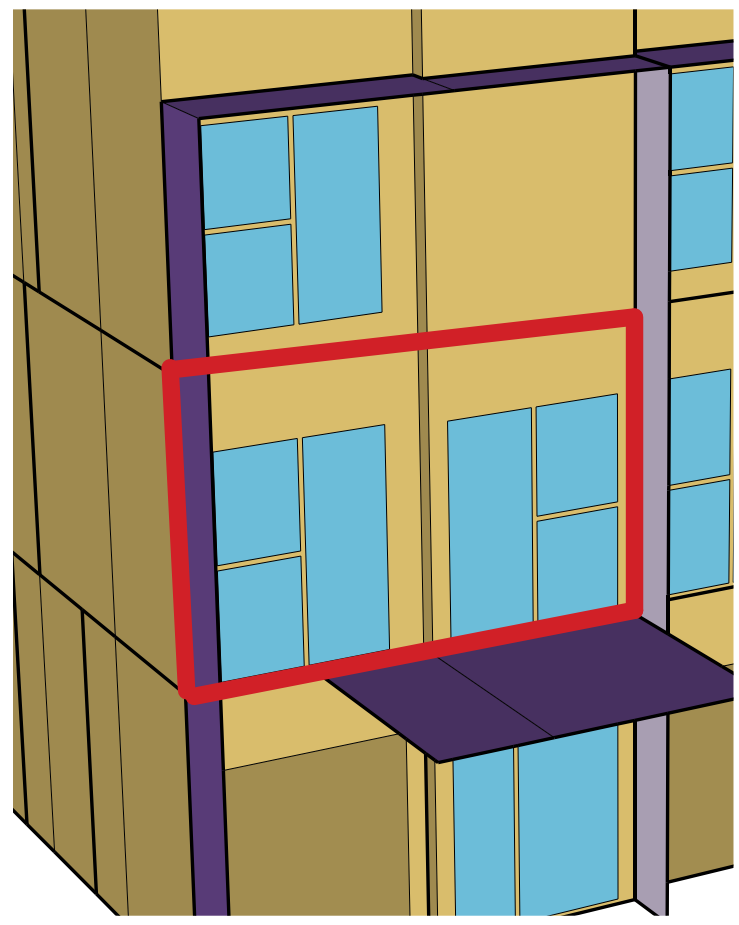

\section{Figure 47 Selected thermal zone and window for window opening quality assurance}

First, the simulation was run with all windows and doors closed and no heating or cooling systems. These conditions were set to determine what the zone air temperature would be if the house was left to run on its own. During this simulation period, the outdoor temperature ranged from $19-24^{\circ} \mathrm{C}$. While the indoor temperature reached up to $31^{\circ} \mathrm{C}$, well above the setpoint for windows to open $\left(22^{\circ} \mathrm{C}\right)$.

The model was then run with windows and doors set to open when required and mechanical ventilation active to provide cooling. A description of the zone conditions and simulation is described by the hour in Table 35 and Figure 48.

Table 35 Quality assurance of selected thermal zone and window

\begin{tabular}{ll}
\hline Hour & Notes \\
\hline 07:00 & Indoor temperature close to the cooling setpoint. \\
08:00 & Indoor temperature above the cooling setpoint. Windows opened to $100 \% .17 \mathrm{ACH}$. \\
$10: 00$ & Mechanical ventilation turned on to supplement windows cooling. \\
$12: 00$ & $\begin{array}{l}\text { Windows closed to } 17 \% \text { because of high outdoor temperature. Mechanical cooling } \\
\text { increased. }\end{array}$
\end{tabular}


13:00 Windows closed. Mechanical cooling only.

18:00 Windows closed. Mechanical cooling only

19:00 Outdoor temperature drops. Windows opened to 67\%. Mechanical cooling supplement

20:00 Windows opened 100\%. No mechanical cooling.

23:00 Indoor temperature below the cooling setpoint. Windows shut because occupants are asleep.
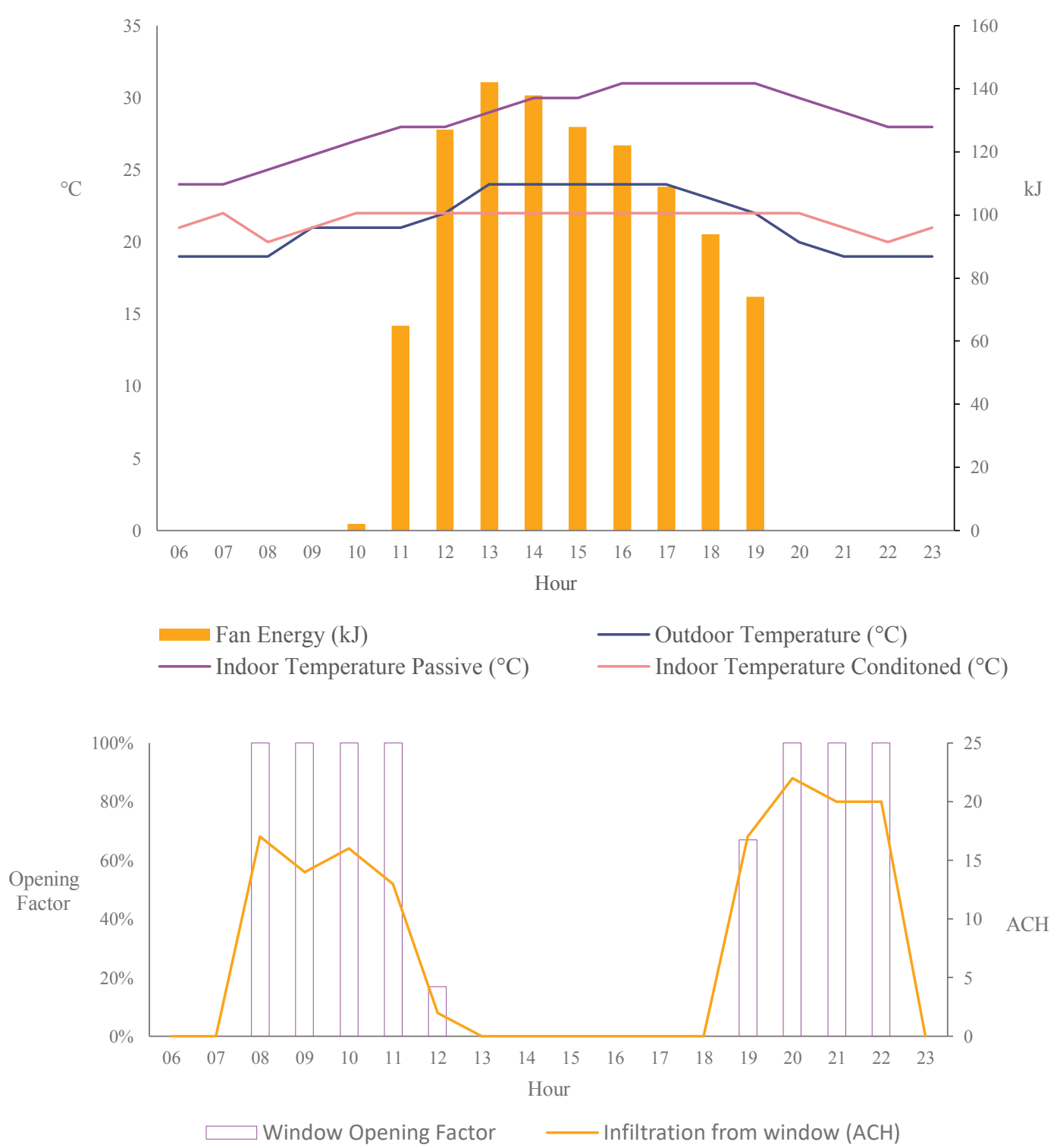

Figure 48 Indoor and outdoor environmental conditions for the selected zone 
When these settings are input, the windows open at 08:00 as the indoor temperature is above the ventilation setpoint, and the outdoor temperature is lower than the indoor. This achieves 17ACH. The windows remain open until 12:00.

At 10:00, mechanical ventilation is turned on to supplement the cooling from windows. As the outdoor temperature rises, more mechanical ventilation is needed until 13:00 where the windows are closed, and only mechanical ventilation used because the outdoor air temperature exceeds the indoor.

The heat pump is used for cooling until 19:00 where the outdoor temperature drops to the point that windows can be opened until 22:00 where ventilation is no longer required but also because this time of the day is outside the period which the windows can be opened. This assessment shows that the heat pump is only active when the specified conditions are met.

This check on whether the windows open when required shows that the windows are behaving as expected, opening when the outdoor temperature is lower than indoor and closing when the outdoor temperature is too high. This analysis shows that mechanical ventilation is also working when the windows cannot provide adequate ventilation.

\subsubsection{Passive simulation - results}

The houses were run passively to determine what the indoor temperatures were without any heating or cooling systems. If the temperatures were extremely high or low, then there would be something wrong with one or more of the inputs.

Figure 49 shows the outdoor temperatures over a year taken from the Auckland weather file. The low and high temperatures are $2^{\circ} \mathrm{C}$ and $27^{\circ} \mathrm{C}$. These extreme temperatures will affect the indoor thermal performance of the units.

Figure 50 shows the indoor air temperatures for a randomly selected zone with no heat pump system but includes the window opening and airflow network. The indoor temperatures low and high are $15^{\circ} \mathrm{C}$ and $27^{\circ} \mathrm{C}$, which is outside of the setpoint temperature range of $20-25^{\circ} \mathrm{C}$. 


\begin{tabular}{|c|c|c|c|c|c|c|c|c|c|c|c|c|c|}
\hline \multirow[t]{2}{*}{$\mathrm{T}\left({ }^{\circ} \mathrm{C}\right)$} & \multirow[t]{2}{*}{ Time } & \multicolumn{3}{|c|}{ Summer } & \multicolumn{6}{|c|}{ Winter } & \multicolumn{3}{|c|}{ Summer } \\
\hline & & Jan & $\mathrm{Feb}$ & Mar & Apr & May & Jun & Jul & Aug & Sep & Oct & Nov & Dec \\
\hline $\begin{array}{l}27 \\
25\end{array}$ & $\begin{array}{l}01: 00 \\
02: 00\end{array}$ & & & & & & & & & & & & \\
\hline 24 & 03:00 & & & & & & & & & & & & \\
\hline 23 & 04:00 & & & & & & & & & & & & \\
\hline 22 & 05:00 & & & & & & & & & & & & \\
\hline $\begin{array}{l}21 \\
20\end{array}$ & $\begin{array}{l}06: 00 \\
07: 00\end{array}$ & & & & & & & & & & & & \\
\hline 19 & 08:00 & & & & & & & & & & & & \\
\hline 18 & 09:00 & & & & & & & & & & & & \\
\hline 17 & 10:00 & & & & & & & & & & & & \\
\hline $\begin{array}{l}16 \\
15\end{array}$ & 11:00 & & & & & & & & & & & & \\
\hline $\begin{array}{l}13 \\
13\end{array}$ & $\begin{array}{l}12.00 \\
13: 00\end{array}$ & & & & & & & & & & & & \\
\hline 12 & 14:00 & & & & & & & & & & & & \\
\hline 11 & $15: 00$ & & & & & & & & & & & & \\
\hline 10 & 16:00 & & & & & & & & & & & & \\
\hline $\begin{array}{l}9 \\
8 \\
8\end{array}$ & $\begin{array}{ll}17: 00 \\
18.0\end{array}$ & & & & & & & & & & & & \\
\hline 7 & $\begin{array}{l}10.00 \\
19: 00\end{array}$ & & & & & & & & & & & & \\
\hline 6 & 20:00 & & & & & & & & & & & & \\
\hline 5 & 21:00 & & & & & & & & & & & & \\
\hline 4 & 22:00 & & & & & & & & & & & & \\
\hline $\begin{array}{l}3 \\
2\end{array}$ & $\begin{array}{l}23: 00 \\
00: 00\end{array}$ & & & & & & & & & & & & \\
\hline
\end{tabular}

Figure 49 Annual hourly outdoor air temperature $\left({ }^{\circ} \mathrm{C}\right)$

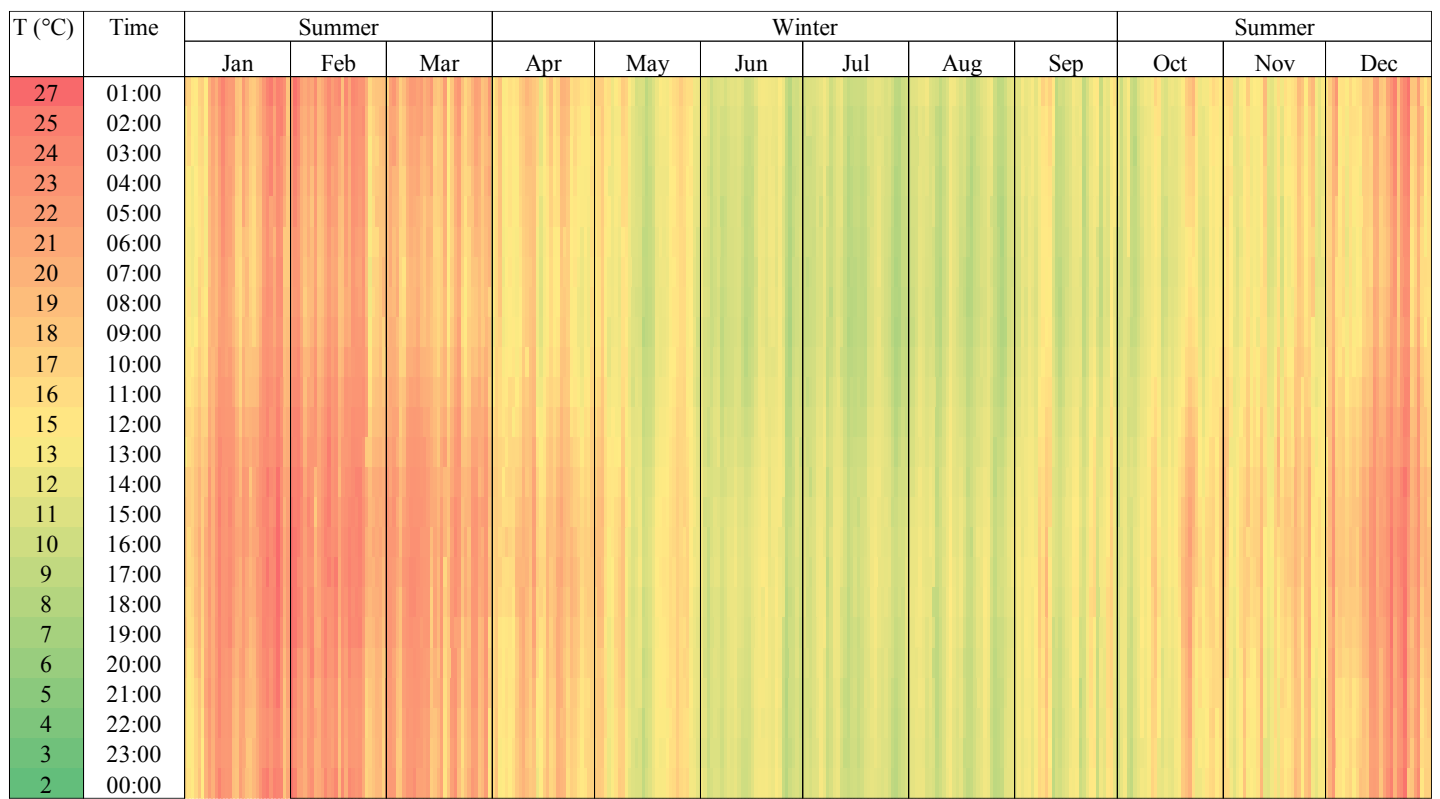

Figure 50 Annual hourly indoor air temperature (passive) $\left({ }^{\circ} \mathrm{C}\right)$

One trend that the building shows is that the temperature inside does not fluctuate rapidly compared to the outdoor temperature from December - March. Where the outside temperature reaches around $25^{\circ} \mathrm{C}$ during the day and then drops to around $17^{\circ} \mathrm{C}$ overnight. The indoor temperature remains around $25^{\circ} \mathrm{C}$ throughout this same period meaning that the building is retaining heat as no heat pump is operating. 
Extreme indoor air temperatures can be caused by incorrect internal gain inputs from lighting or electrical equipment as well as incorrect schedules associated with these. There are no internal gains from lighting or electrical equipment scheduled for use overnight. No internal gains overnight mean the only factor affecting the indoor air temperature is related to the building construction inputs. Since the temperature is maintained overnight, this means that there is low air leakage through cracks; otherwise, this heat would be removed through these cracks to the outside, decreasing the indoor air temperature.

This comparison shows that the indoor air temperature is not reaching extreme highs or lows from internal equipment or incorrect scheduling and that heat is being retained inside the building. This check shows the building is performing as expected for a building with no heating systems only natural ventilation, meaning it can be used for energy analysis purposes.

\subsection{Comparison to reference buildings}

\subsubsection{HEEP}

BRANZ SR155 Energy Use in New Zealand Households (HEEP study) measured energy use in 400 randomly selected houses across New Zealand for 11 months. This data was used to help quality assure the created models energy use. The measured houses were monitored over 13 years ago. It is predicted that the selected houses for this study should have lower energy use as the houses monitored were built under different building regulations.

Average energy use per dwelling from the HEEP study is reported as $9960 \mathrm{kWh} / \mathrm{yr}$ for houses in warm climates. Using the average floor area for all dwellings this gives an energy use of $80 \mathrm{kWh} / \mathrm{m} 2 . \mathrm{yr}$.

\subsubsection{Waitakere Now Home}

A more recent study of a monitored house in the same region as this studies' buildings is the Waitakere Now Home built in 2005 shown in plan in Figure 51. This house was intended to be an example of how energy efficiency can be achieved as well as affordability. The house uses energy reduction measures like north-facing 
living areas, thermal mass, natural ventilation and energy-efficient lighting. The construction of the home uses above minimum Building Code R-values, which are R4.6 roof and R2.8 walls and double-glazed aluminium windows. There is no heating system in the home. A small fan heater is used for less than ten days of the year. Monitoring of the home's energy use was taken over two years with three occupants living in the home. Indoor temperatures were maintained to $21.6^{\circ} \mathrm{C}$ in living areas and $17.5^{\circ} \mathrm{C}$ in bedrooms overnight. Monitoring of the home shows the home used $70 \mathrm{kWh} / \mathrm{m} 2 . y r$, which is lower than the house from the HEEP study.

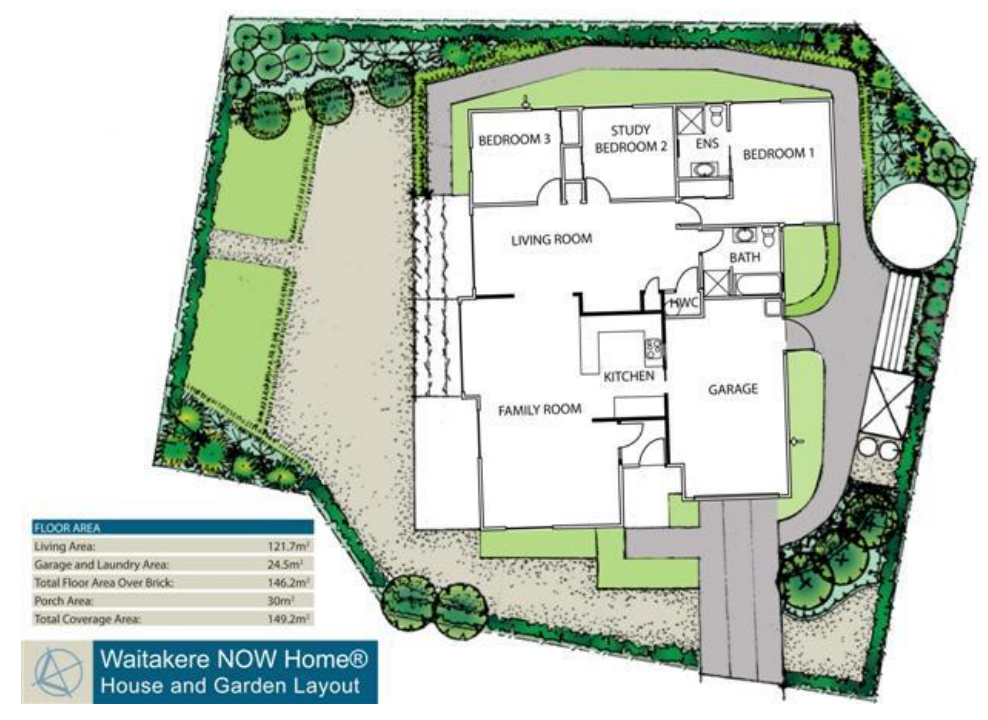

Figure 51 Now Home floor plan (Pathway, 2008)

\subsubsection{Passivhaus}

On the other end of the spectrum for houses is designing towards Passivhaus standard, which requires an energy use of $15 \mathrm{kWh} / \mathrm{m} 2 . y r$ (Passive House Institute, 2016). This level of energy use is on the high end of energy efficiency and is well below the HEEP study and Waitakere Now Home energy use. This studies' buildings should not be near this target energy use as they have not been designed following the principles of this standard, which include very high levels of insulation and very low infiltration. 


\subsubsection{Modelled houses energy use}

The modelled houses energy use ranged from $49-55 \mathrm{kWh} / \mathrm{m} 2 . y r$. From the first observations of Table 36, the modelled buildings' energy is significantly lower than the Now House and HEEP houses.

Table 36 Percentage breakdown of annual end energy use between reference homes and simulated

\begin{tabular}{|c|c|c|c|c|c|}
\hline & HEEP & Now Home & House $\mathbf{H}$ & House P & House W \\
\hline $\begin{array}{l}\text { Total Energy Use } \\
(\mathrm{kWh} / \mathrm{yr})\end{array}$ & 9660 & 8500 & 6047 & 6927 & 6371 \\
\hline $\mathrm{kWh} / \mathrm{m} 2 . \mathrm{yr}$ & 80 & 70 & 49 & 55 & 47 \\
\hline $\begin{array}{l}\text { Space heating } \\
\text { (Conditioned) }(\% \text { of } \\
\text { total) }(\mathrm{kWh} / \mathrm{m} 2 . \mathrm{yr})\end{array}$ & $34 \%(27)$ & $7 \%(5)$ & $18 \%(8)$ & $18 \%(9)$ & $13 \%(5)$ \\
\hline Lighting & $8 \%(6)$ & $5 \%(4)$ & $17 \%(8)$ & $16 \%(9)$ & $19 \%(9)$ \\
\hline Electrical Equipment & $29 \%(23)$ & $48 \%(34)$ & $52 \%(26)$ & $53 \%(30)$ & $55 \%(27)$ \\
\hline Hot water & $29 \%(23)$ & $40 \%(28)$ & $14 \%(7)$ & $12 \%(7)$ & $13 \%(7)$ \\
\hline
\end{tabular}

The first point to note is the energy use of water compared to the Now Home $\left(28 \mathrm{kWh} / \mathrm{m}_{2}\right.$ and $\left.7 \mathrm{kWh} / \mathrm{m}_{2}\right)$. This difference is because only the standing losses of the Hot Water Cylinder (HWC) were modelled in energy simulation. There are two reasons for this. First, a building thermal simulation is interested in heat flows in the house that affects the heating and cooling - in this case, the heat losses from the hot water systems into the building. Second, because of the complexity that is involved in creating a model where all plumbing equipment and flow rates of heat losses from hot water flowing down the drain, these were not specified. However, this results in a model that excludes the energy use related to heating water for use in the building.

This energy can be estimated and then added to the total with the following equation.

$$
W=(C \times L \times \Delta T)
$$

Where: $\quad W=\operatorname{Energy}(\mathrm{J})$ 


$$
C=\text { Heat capacity of water }\left(\mathrm{J} / \mathrm{g}^{\circ} \mathrm{C}\right)(4.186)
$$

$L=$ Water use per household (L) (160L for a four per person household)

$\Delta T=$ Temperature difference between ground and $\mathrm{HWC}\left({ }^{\circ} \mathrm{C}\right)$

$$
(60-16.48=43.52)
$$

The calculation gives an energy use for the HWC of $2955 \mathrm{kWh}$, which is like the Now Home, which was 3330kWh.

The modelled standing losses were modelled as a total of $876 \mathrm{kWh}$ whereas the Now Home measure this as $870 \mathrm{kWh}$. Although not exact, the two are similar, and this standing loss varies depending on the type of HWC. Therefore, $876 \mathrm{kWH}$ is an adequate approximation of this energy use.

Totalling the standing losses and heating of the hot water gives a total of $3831 \mathrm{kWh}$ compared to the Now Home, which is $4150 \mathrm{kWh}$. The two totals are different, but note needs to be given to the fact that the Now Home is only representative of itself.

Updating Table 36 with the manual water calculation brings the units total energy use to $69-79 \mathrm{kWh} / \mathrm{m}_{2}$ (Table 37).

Space heating energy is higher than the Now Home, which is expected but lower than HEEP. In the HEEP study, this included homes that were not heated, heated sometimes and heated all the time. This study was also completed 13 years ago, meaning heating equipment energy efficiencies have changed as well as building construction practices. These are factors which cause the modelled units to have a lower energy use than the HEEP homes.

The reason for a difference in electrical and lighting equipment can be attributed to the fact that there are numerous types of appliances that fall into this category and that these appliances are related to occupant use which varies from building to building. The rate applied to the modelled houses is on a per $\mathrm{m}_{2}$ basis which means House W, which has a slightly larger floor area has an increased total for electrical equipment compared to the other houses but the same energy in $\mathrm{kWh} / \mathrm{m} 2$. 
Table 37 Percentage breakdown of annual end energy use between reference homes and simulated with hot water addition

\begin{tabular}{llllll}
\hline & HEEP & Now Home & House H & House P & House W \\
\hline $\begin{array}{l}\text { Total Energy Use } \\
(\mathrm{kWh} / \mathrm{yr})\end{array}$ & 9660 & 8500 & 9002 & 9882 & 9326 \\
$\mathrm{kWh} / \mathrm{m} 2 . \mathrm{yr}$ & 80 & 70 & 73 & 79 & 69 \\
$\begin{array}{l}\text { Space heating } \\
\text { (Conditioned) }(\% \text { of } \\
\text { total) }(\mathrm{kWh} / \mathrm{m} 2 . \mathrm{yr})\end{array}$ & $34 \%(27)$ & $7 \%(5)$ & $11 \%(8)$ & $12 \%(9)$ & $7 \%(5)$ \\
$\begin{array}{l}\text { Lighting } \\
\text { Electrical Equipment }\end{array}$ & $29 \%(23)$ & $48 \%(34)$ & $35 \%(26)$ & $38 \%(30)$ & $39 \%(27)$ \\
\hline Hot water & $29 \%(23)$ & $40 \%(28)$ & $43 \%(31)$ & $39 \%(31)$ & $41 \%(28)$ \\
\hline
\end{tabular}

Although the houses energy use is higher than the Now Home, the main point to note is the consistency between the houses. There is a 5\% difference between House $\mathrm{H}$ and $\mathrm{W}$ for annual energy use. The distribution of energy use is also similar between units; however, House $\mathrm{H}$ has a higher energy use for space heating. The consistency between the houses is expected because of the measures taken to ensure consistency in modelling and input data. Together with similar floor plan layouts, WWR and materials, this creates three different but very similar house models.

The process before this point has documented the reasoning and justification for all inputs into the energy model. These inputs are broad and will not represent every building, therefore comparing heavily to a single building, which is a different housing type, for quality assurance, is not appropriate. The Now Home does not have all similar inputs as the modelled units; this means that occupant schedules, electrical equipment, lighting, and external climate will differ. This comparison does, however, show that the modelled energy use has not been severely underestimated or overestimated. If this were the case, then the modelling phase would need analysis.

\subsection{Heating energy breakdown between units}

Energy use between the middle and end units is as expected with the end units requiring a larger amount of energy for heating compared with the middle unit. 
Cooling, however, does not follow the same pattern. Less heating energy is required for middle units as there is less surface area to the outside compared to end units.

The West units use more heating than the East units (Table 38) because, in the morning, the sun is rising in the East, causing more solar gains. Cooling in the middle and end units is similar for House $\mathrm{P}$, but House $\mathrm{H}$ and $\mathrm{W}$ vary between the middle and end (Table 39).

Table 38 Unit location annual heating energy (kWh/m2.yr)

\begin{tabular}{lcccc}
\hline & West End & Middle 1 & Middle 2 & East End \\
\hline House H & 21.0 & 15.7 & - & 16.2 \\
\cline { 2 - 4 } & & & & \\
House P & 13.2 & 7.6 & 6.9 & 11.8 \\
& 17.2 & 9.2 & & 12.8 \\
\hline
\end{tabular}

Table 39 Unit location annual cooling energy (kWh/m2.yr)

\begin{tabular}{lcccc}
\hline & West End & Middle 1 & Middle 2 & East End \\
\hline House H & 1.5 & 1.5 & - & 3.2 \\
& & & & 3.3 \\
House P & 3.4 & 3.4 & & \\
& & & & \\
House W & 2.0 & 1.3 & & 2.0 \\
\hline
\end{tabular}

These comparisons and checks of energy use show that comparing these MDH simulations to a single stand-alone building is not appropriate. At best, it provides an indicator of whether energy use is being severely over or underestimated. This analysis indicated that the MDH model outputs are of a reasonable value. The difference in energy use between the end and middle units is as expected. The next stage of this 
quality assurance process was to perform sensitivity checks to see if the building again behaved as expected under well-understood criteria.

\subsection{Energy use operation - quality assurance}

So far, only annual energy use has been considered, but this risks giving a skewed image of what is occurring in the building and whether this energy is used when necessary. Figure 52 and Figure 53 show annual energy use for cooling and heating for a living zone in a middle unit for House $\mathrm{H}$. Cooling energy for this zone is required most often in the summer months and very rarely in winter. In winter, this cooling occurs between 12:00 and 18:00, which is when the indoor air temperature

Figure 54) rises to the overheating mark of $25^{\circ} \mathrm{C}$. In Figure 53, heating energy is required from May - late November when in Figure 55 outdoor temperatures, are below the heating setpoint of $20^{\circ} \mathrm{C}$.

This analysis shows that heating is required as expected in winter and cooling in the summer months and very seldom in winter. The energy use simulated represents ideal conditions with heating and cooling set to turn on the moment setpoints of temperature and time are reached. However, this would be different in practice as it would be controlled by people who would not turn on/off the equipment in the same way as the simulation.

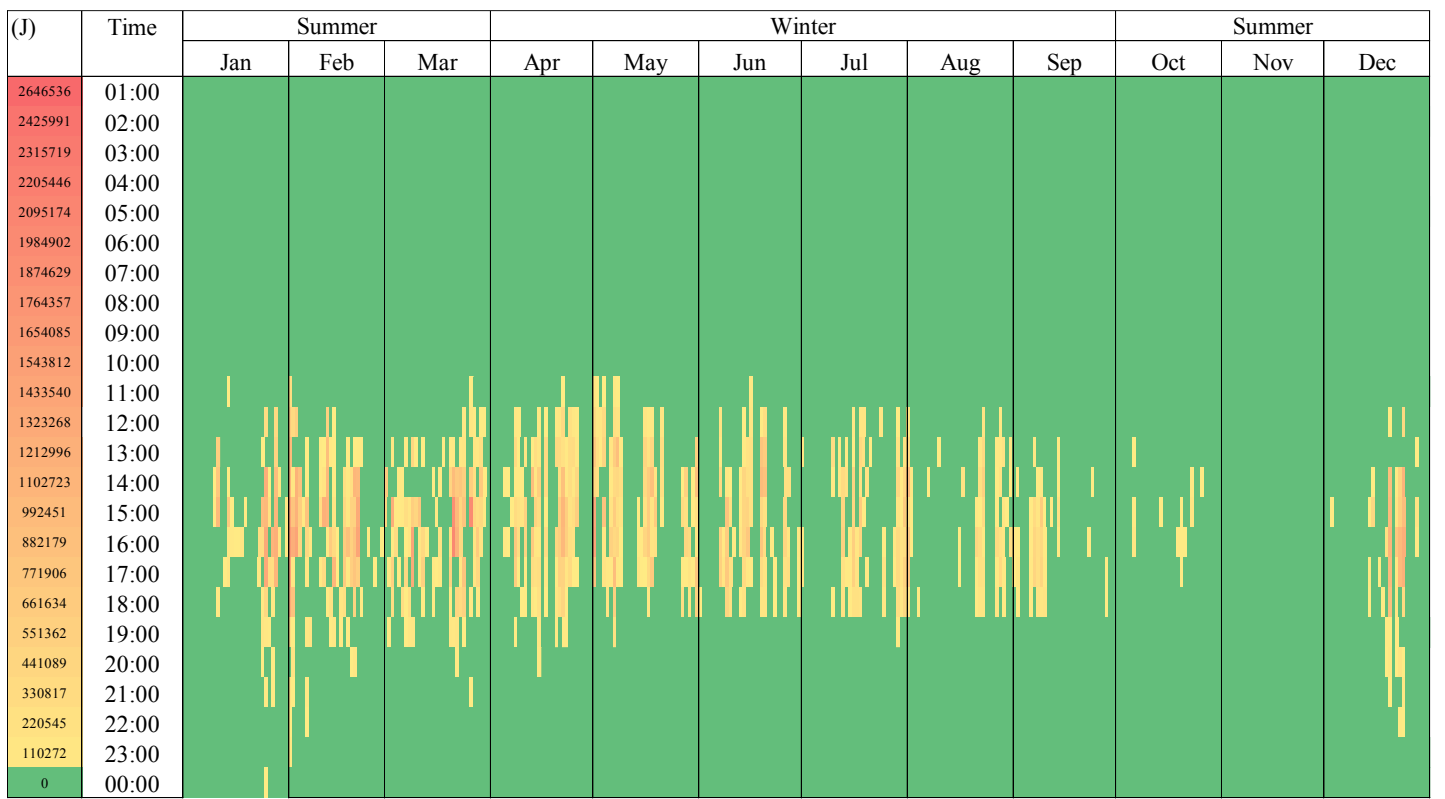

Figure 52 Annual hourly cooling energy (J) for the living area of House H 


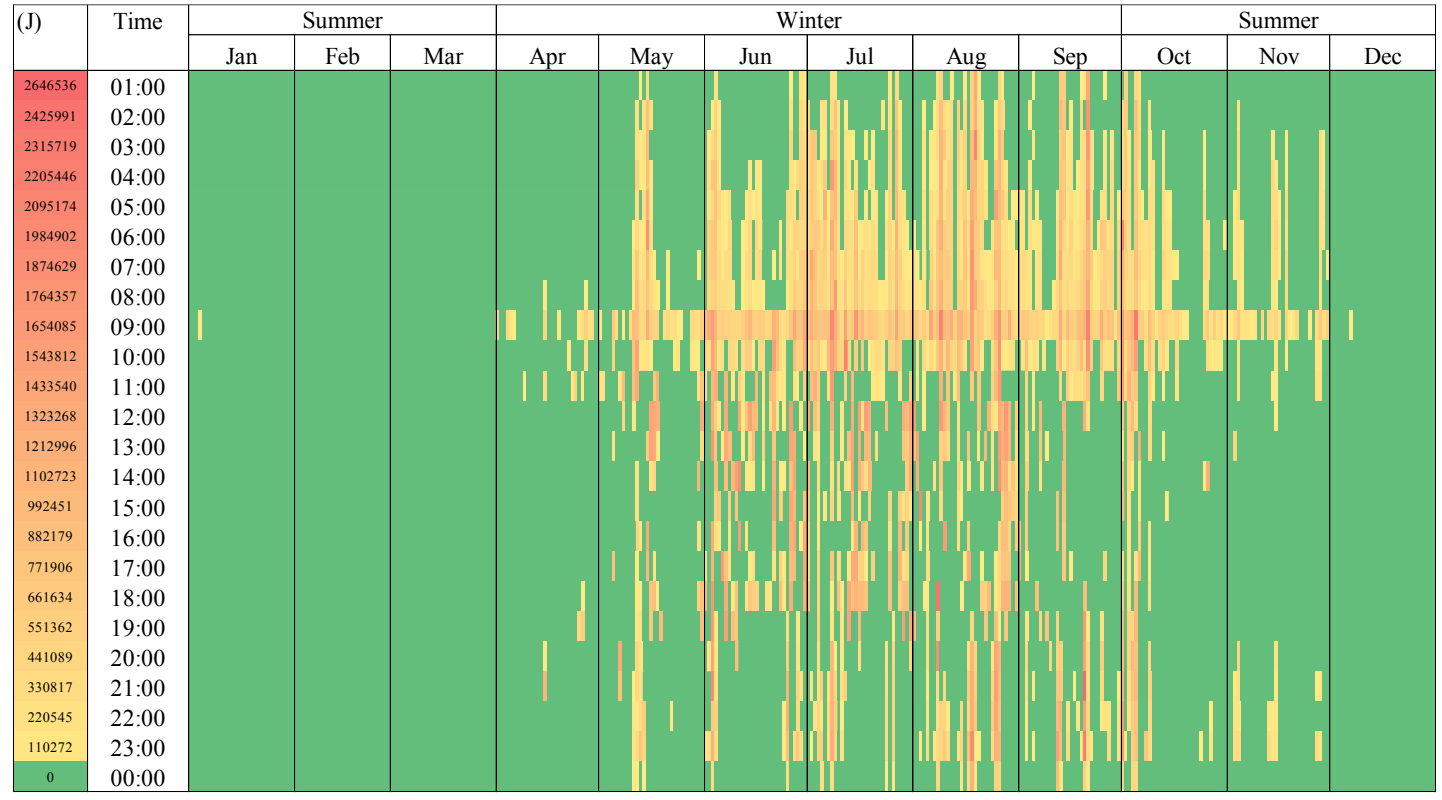

Figure 53 Annual hourly heating energy (J) for the living area of House H

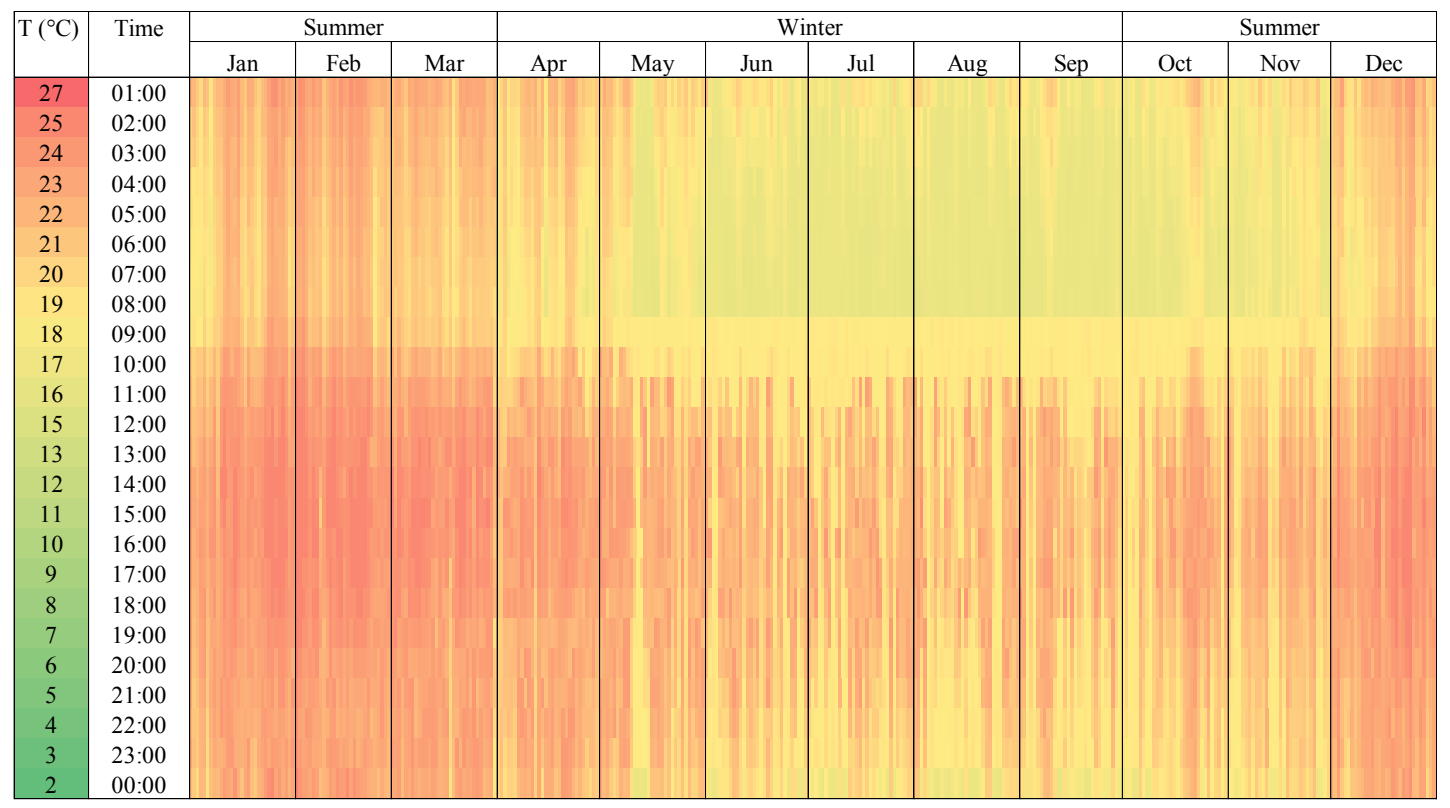

Figure 54 Annual hourly indoor air temperature $\left({ }^{\circ} \mathrm{C}\right)$ for the living area of House $\mathrm{H}$ 


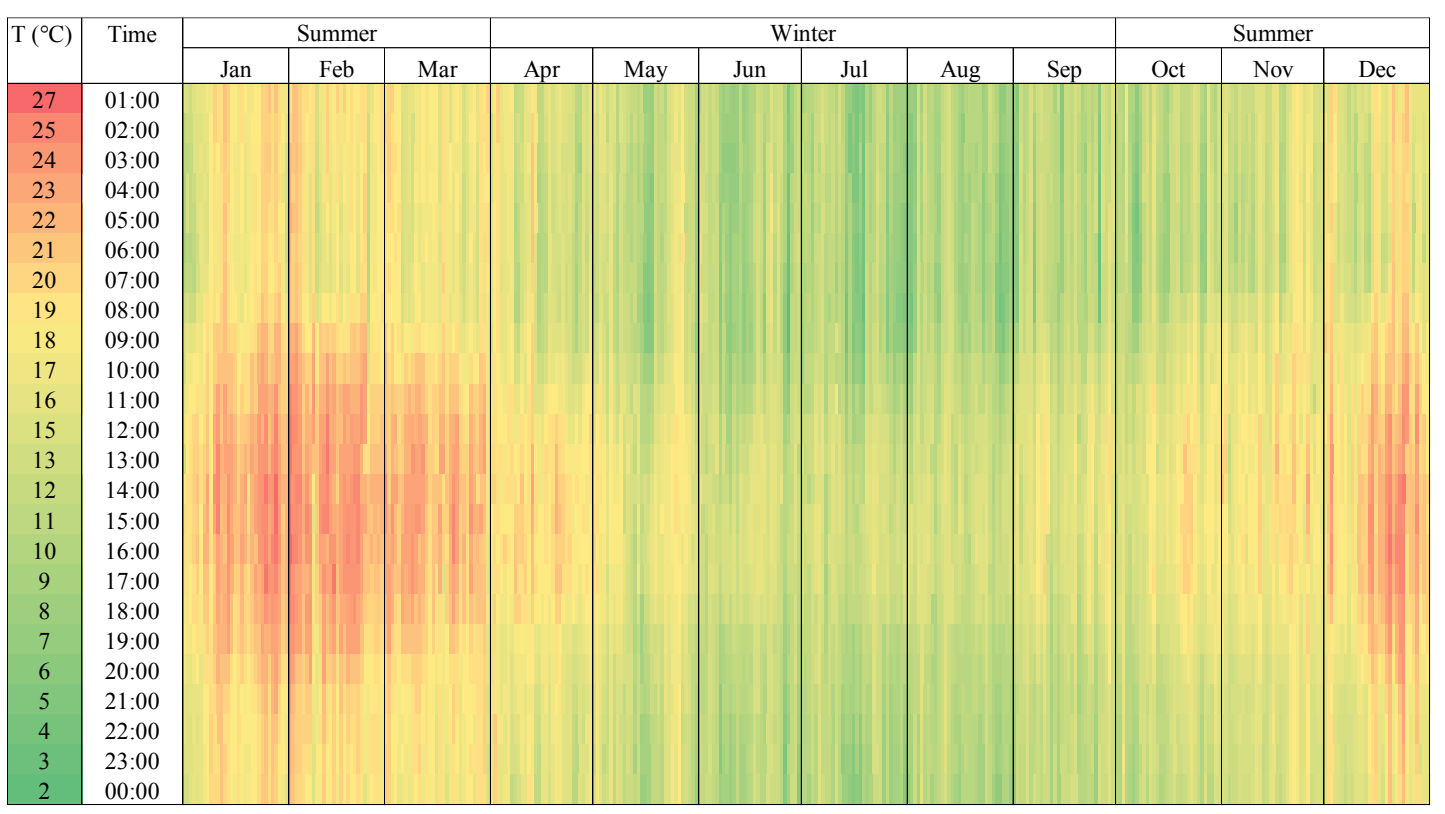

Figure 55 Annual hourly outdoor air temperature $\left({ }^{\circ} \mathrm{C}\right)$ for the living area of House H

Figure 56 shows the opening factor indicating when the windows in the space are open. From this, windows are typically opened in summer to prevent overheating. No windows are open at night because windows have been set to only open during daytime hours in section 4.5.20. This graph compared alongside the indoor temperatures show that the two follow the same trend with the air temperature (Figure 54) reaching a high level and causing the window to open. The window opening shows like section 4.5.20 that the windows are operating as intended. 


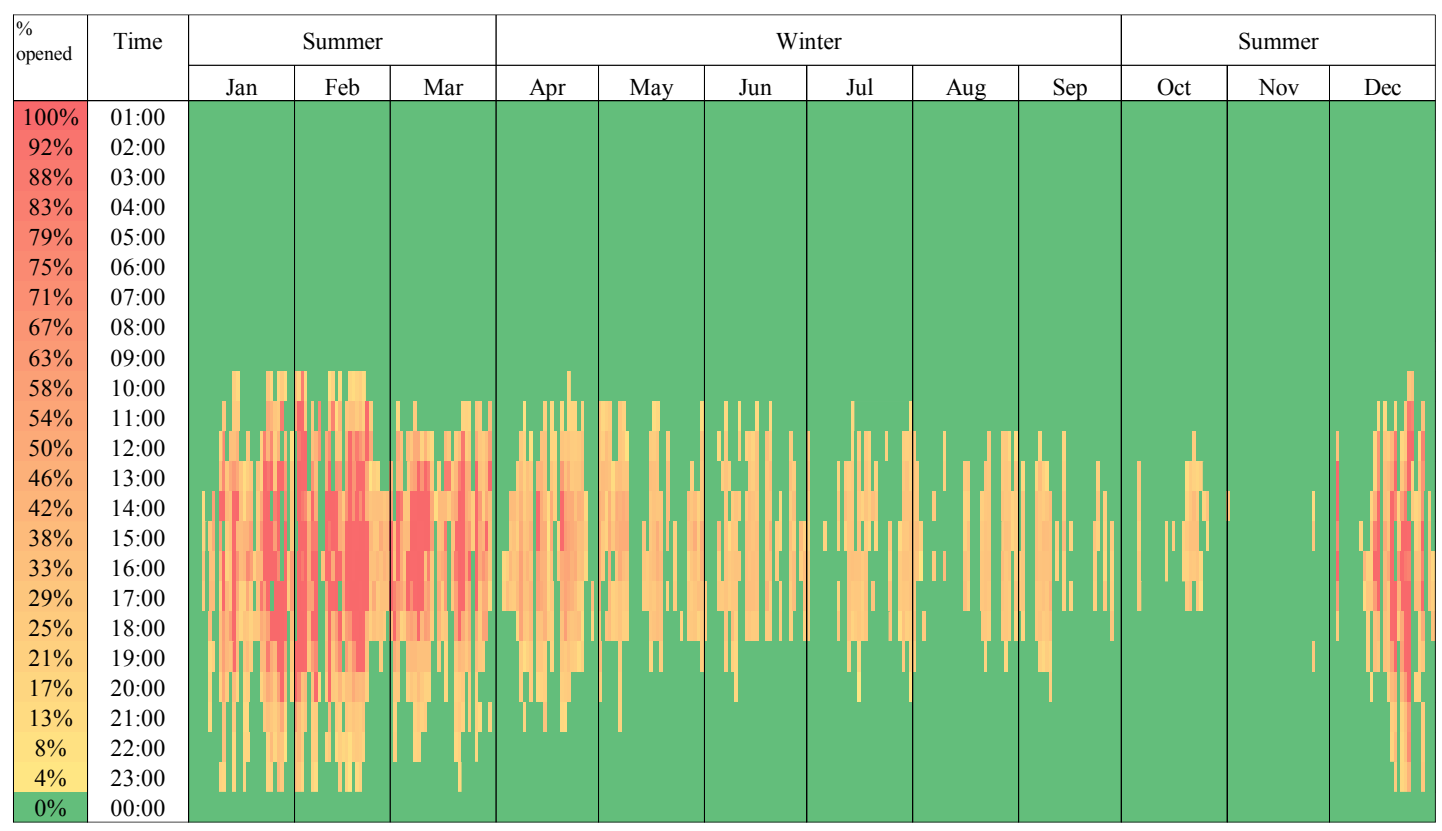

Figure 56 Annual hourly window opening factor (\%) for the selected zone

\subsection{Sensitivity analysis}

Sensitivity analysis techniques can be used to determine whether the energy models are behaving as expected. This technique involves varying inputs and verifying the variation in the outputs.

Westphal 2005, identifies key inputs which have an impact on the thermal performance of buildings (Westphal \& Lamberts, 2005). These are listed in Table 40. For this section, one input variable from each section was varied. These variables are the equipment and lighting power density, number of occupants and R-values of insulation materials. It is predicted that increasing power density and number of occupants will decrease the heating energy because of a higher internal gain. A reduction in insulation $\mathrm{R}$-values will increase heating. While increasing insulation $\mathrm{R}$ values will have the opposite effect.

Table 40 Input variables for sensitivity analysis (Westphal \& Lamberts, 2005)

\begin{tabular}{ll}
\hline Element & Change to Element \\
\hline Windows & Dimensions (WWR and Floor-to-floor height) \\
& U-value \\
& Shading coefficient \\
\hline
\end{tabular}




\begin{tabular}{ll}
\hline & External solar protection \\
Walls/Roof/Floor & Dimensions \\
& U-value \\
Thermal capacity \\
Short-wave absorptance \\
Equipment/lights & Power \\
& Schedule \\
People & Quantity \\
& Metabolic rate \\
& Schedule \\
\hline
\end{tabular}

For this section, due to the number of simulations to run (18), the timestep was changed from six to one to reduce simulation run time. The effect this has on simulated energy use is discussed in section 4.5.19. The tests were conducted on all three houses. The following sections explain the changes made to the base model and the expected effect on energy use. Each input variable was changed on all houses in Table 41, Table 42 and Table 43.

\subsubsection{Equipment}

The equipment power density was doubled from $24.5 \mathrm{~W} / \mathrm{m} 2$ to $50 \mathrm{~W} / \mathrm{m} 2$.

As expected, heating loads decreased and cooling increased. Interior equipment increased, causing the total energy use to increase from the base model.

\subsubsection{Lighting}

The lighting power density was doubled for each zone.

As expected, heating loads decreased, and cooling increased shown. Lighting increased, causing the total energy use to increase from the base model.

\subsubsection{People}

The number of occupants was doubled in each room.

As expected, heating loads decreased, and cooling increased shown. Electrical equipment remained the same as the lighting as it is not related to the number of occupants. Overall, energy use decreased from the base model. 


\subsubsection{Insulation R-value - doubled}

Insulation materials R-values were doubled.

As expected, heating loads decreased. Cooling remained the same, and overall energy use decreased.

\subsubsection{Insulation R-value - halved}

Insulation materials R-values were halved.

As expected, heating loads increased. Cooling remained the same as the building is not overheating. Overall, energy use increased.

\subsubsection{Glazing R-value - doubled}

Glazing R-values were doubled.

As expected, heating loads decreased. Cooling remained the same, and overall energy use decreased.

\subsubsection{Glazing R-value - halved}

Glazing R-values were halved.

As expected, heating loads increased. Cooling remained the same as the building is not overheating. Overall, energy use increased.

Table 41 House H annual breakdown of end energy use for each sensitivity analysis variable (kWh/m2)

\begin{tabular}{|c|c|c|c|c|c|c|c|c|}
\hline $\begin{array}{l}\text { Energy } \\
\text { end-use } \\
\text { category }\end{array}$ & Base & Equipment & Lights & People & $\begin{array}{l}\text { Wall } \\
\text { Double }\end{array}$ & Wall Half & $\begin{array}{l}\text { Glazing } \\
\text { Double }\end{array}$ & $\begin{array}{l}\text { Glazing } \\
\text { Half }\end{array}$ \\
\hline Heating & 18 & -14 & 16 & 16 & -16 & -19 & 16 & -19 \\
\hline Cooling & 2 & -3 & 2 & 3 & 2 & 2 & 2 & 2 \\
\hline $\begin{array}{l}\text { Interior } \\
\text { Lighting }\end{array}$ & 8 & -8 & 17 & 8 & - & 8 & 8 & 8 \\
\hline $\begin{array}{l}\text { Interior } \\
\text { Equipment }\end{array}$ & 33 & 60 & 33 & 33 & 33 & 33 & 33 & 33 \\
\hline
\end{tabular}




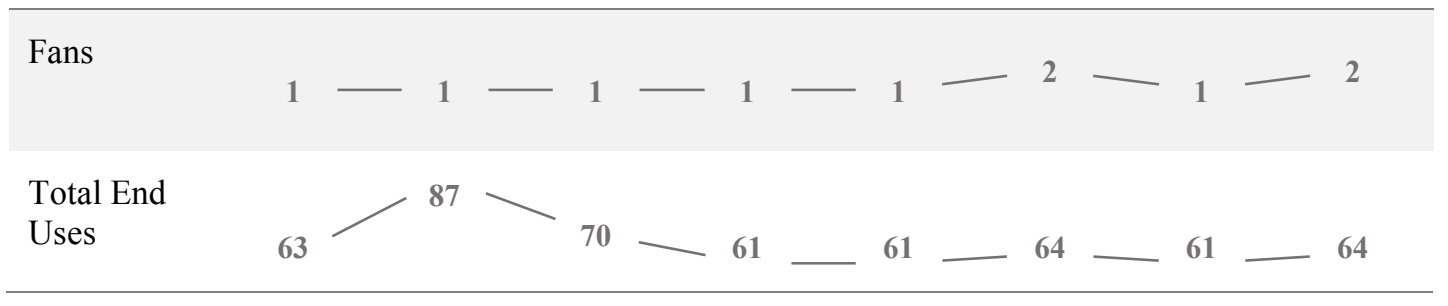

Table 42 House P annual breakdown of end energy use for each sensitivity analysis variable (kWh/m2)

\begin{tabular}{|c|c|c|c|c|c|c|c|c|}
\hline $\begin{array}{l}\text { Energy } \\
\text { end-use } \\
\text { category }\end{array}$ & Base & Equipment & Lights & People & $\begin{array}{l}\text { Wall } \\
\text { Double }\end{array}$ & Wall Half & $\begin{array}{l}\text { Glazing } \\
\text { Double }\end{array}$ & $\begin{array}{l}\text { Glazing } \\
\text { Half }\end{array}$ \\
\hline Heating & 10 & -8 & 10 & 9 & 9 & $-11-$ & 9 & - 11 \\
\hline Cooling & 3 & 4 & 4 & 4 & 4 & 3 & 4 & 3 \\
\hline $\begin{array}{l}\text { Interior } \\
\text { Lighting }\end{array}$ & 9 & -9 & 18 & 9 & 9 & 9 & 9 & 9 \\
\hline $\begin{array}{l}\text { Interior } \\
\text { Equipment }\end{array}$ & 37 & 68 & 37 & -37 & -37 & -37 & 37 & -37 \\
\hline Fans & 1 & $-\quad 1$ & 1 & 1 & 1 & 1 & 1 & 1 \\
\hline $\begin{array}{l}\text { Total End } \\
\text { Uses }\end{array}$ & 60 & $90-$ & 69 & 60 & 60 & 61 & 59 & 62 \\
\hline
\end{tabular}

Table 43 House W annual breakdown of end energy use for each sensitivity analysis variable (kwh/m2)

\begin{tabular}{|c|c|c|c|c|c|c|c|c|}
\hline $\begin{array}{l}\text { Energy } \\
\text { end-use } \\
\text { category }\end{array}$ & Base & Equipment & Lights & People & $\begin{array}{l}\text { Wall } \\
\text { Double }\end{array}$ & Wall Half & $\begin{array}{l}\text { Glazing } \\
\text { Double }\end{array}$ & $\begin{array}{l}\text { Glazing } \\
\text { Half }\end{array}$ \\
\hline Heating & 13 & $=11-$ & 12 & 12 & -12 & 15 & 11 & 15 \\
\hline Cooling & 2 & $\longrightarrow$ & 2 & 2 & 2 & 2 & 2 & 2 \\
\hline $\begin{array}{l}\text { Interior } \\
\text { Lighting }\end{array}$ & 9 & 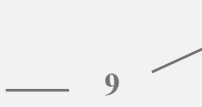 & 18 & 9 & 9 & 9 & 9 & 9 \\
\hline
\end{tabular}




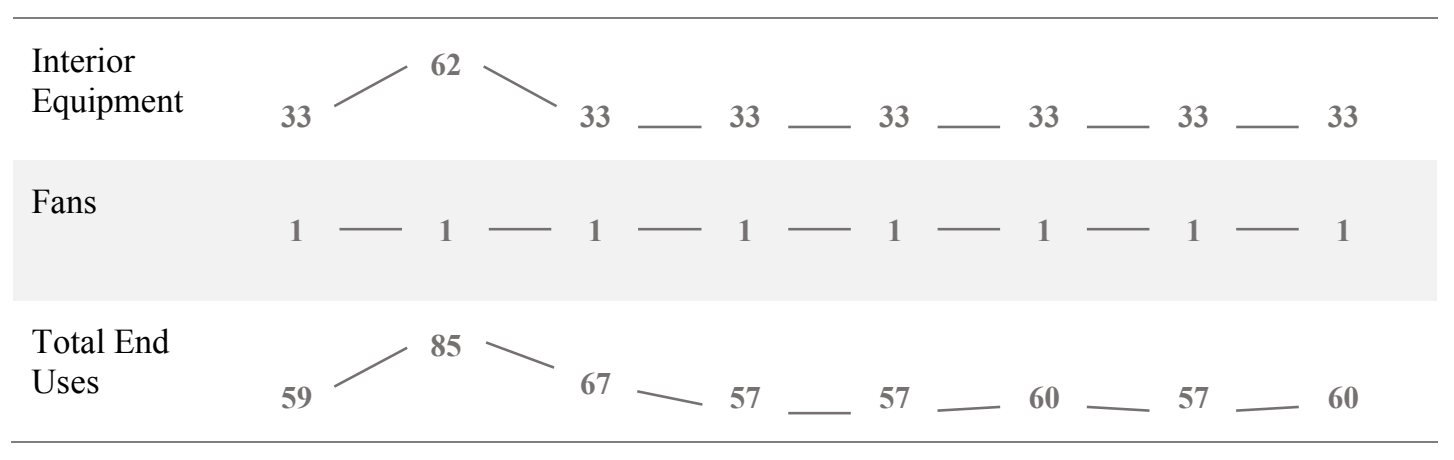

\subsubsection{Sensitivity analysis summary}

All changes to input variables had the intended effect on the output. These changes to the inputs showed that the simulation was behaving as expected with input components related to one another in the manner expected from the theoretical analysis in the literature.

\subsection{Quality assurance process summary}

The processes from this section have shown that the performance of the simulated buildings is not severely over or underestimated compared with reference buildings, that they are consistent with one another and are behaving appropriately. 
A Life Cycle Assessment of Medium Density Houses in New Zealand 


\section{Chapter 5 Findings}

This study aims to develop an analysis method that designers can use to undertake an LCA on multiple building designs to inform design decisions. Barriers that designers face in this process are that it is a time and resource-intensive process requiring multiple analysis tools, numerous inputs, quality assurance steps and assessment of outputs. The earlier chapters determined case study houses and developed part of an analysis method to quality assure the LCA workflow for designers. This chapter examines the assessment of the outputs of an LCA for each house.

Construction changes are made to the thermal envelope of each house following voluntary design standards for high performing energy homes where the insulation levels are increased to reduce heating and cooling energy use. The raw data is assessed in table form, followed by visualisation of data resolving issues faced by designers. Design decisions are then made using visualisations and raw data to inform decision making.

When discussing end energy use and LCA outputs, this will be expressed on a per $\mathrm{m} 2$ of GFA basis by dividing the total blocks results by the number of units modelled then by the GFA of the unit. 


\subsection{End energy use}

The average end energy use for each of the units is the same as from section 0 , where the energy use was analysed. This section aims not to repeat any information but to summarise the key points that will help with the analysis of the houses' energy use. Total end energy use for the units is shown in Table 44, where the totals range from $69-79 \mathrm{kWh} / \mathrm{m} 2 . y r$. Lighting and electrical equipment energy use is input on a per $\mathrm{m} 2$ basis; therefore, is the same across the units when comparing absolute values. Total hot water energy use is also the same for each of the houses in absolute values.

Table 44 Percentage breakdown of annual end energy use between houses

\begin{tabular}{llll}
\hline & House H & House P & House W \\
\hline Total Energy Use (kWh/yr) & 9002 & 9882 & 9326 \\
kWh/m2.yr & 73 & 79 & 69 \\
$\begin{array}{l}\text { Space heating and cooling (\% } \\
\text { of total) }(\mathrm{kWh} / \mathrm{m} 2 . \mathrm{yr})\end{array}$ & $11 \%(8)$ & $12 \%(9)$ & $7 \%(5)$ \\
Lighting & $12 \%(8)$ & $12 \%(9)$ & $13 \%(9)$ \\
Electrical Equipment & $35 \%(26)$ & $38 \%(30)$ & $39 \%(27)$ \\
Hot water & $43 \%(31)$ & $39 \%(31)$ & $41 \%(28)$ \\
\hline
\end{tabular}

Space conditioning is broken down into three categories, heating, cooling and fan energy in Table 45. House P and House W have a similar total energy use for heating but have differences between the cooling energy. These differences can be attributed to the building design and form as all other inputs to the models are the same. House $\mathrm{P}$ has the largest proportion of exposed exterior walls, which means a larger surface area per square metre of floor area for heat to be lost. House W has the lowest amount of total heating and cooling energy compared to the other houses, which is due to the building external surface area and floor layout. Table 45 shows the average end energy use for space heating for the houses. Space heating is calculated by totalling the block of units' end energy use and dividing it by the number of units in that block and then by the GFA. However, this calculation ignores whether there is a relationship between the location of a unit in a block and the total end energy use. 
Table 45 Average annual heating/cooling energy (kWh/m2.yr) - Auckland

\begin{tabular}{|c|c|c|c|c|}
\hline $\mathbf{k W h} / \mathrm{m}_{2 . y r}$ & Heating & Cooling & Fan & Total \\
\hline House H & 4.6 & 2.6 & 0.6 & 7.7 \\
\hline House P & 4.9 & 3.7 & 0.8 & 9.4 \\
\hline House W & 2.4 & 2.0 & 0.4 & 4.8 \\
\hline
\end{tabular}

Table 46 shows the actual modelled end energy use for space heating and cooling for the west and east end units, and the middle units. Since only one middle unit was modelled in the energy model, the energy of the modelled middle unit is assumed to be the same for the other five middle units because of heat being lost to the next unit rather than the exterior (Figure 57). The end units in all blocks of units use more energy than the middle units with east units in House P and W, using less energy than the West units due to solar gains in the morning meaning less heating energy is required. Whereas House $\mathrm{H}$ has a higher energy use in the East unit, which is attributed to a high cooling load due to overheating.

Table 46 Unit location annual heating/cooling energy (kWh/m2.yr) - Auckland

\begin{tabular}{|c|c|c|c|c|c|c|c|c|}
\hline $\mathbf{k W h} / \mathbf{m}^{2 . y r}$ & $\begin{array}{l}\text { West } \\
\text { End }\end{array}$ & Middle & Middle & Middle & Middle & Middle & Middle & $\begin{array}{l}\text { East } \\
\text { End }\end{array}$ \\
\hline House H & 9.0 & -7.1 & -7.1 & - 7.1 & -7.1 & 7.1 & 7.1 & 10.4 \\
\hline House P & 13.1 & -8.6 & -8.6 & -8.6 & -8.6 & 8.6 & 8.6 & 11.2 \\
\hline House W & 8.1 & $-\quad 4.0$ & -4.0 & -4.0 & -4.0 & 4.0 & $4.0-$ & 6.4 \\
\hline
\end{tabular}




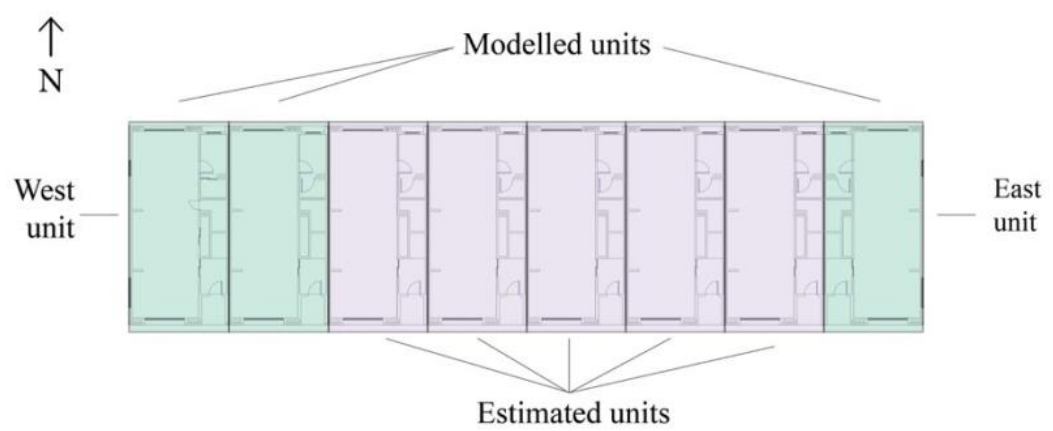

Figure 57 Diagram of modelled and estimated units in a block of eight

\subsection{Life Cycle Assessment}

The data output from the LCA can be shown in either impact per life cycle stage of the house or the combined impact of all stages of the house. For the next sections, only the combined impact of all stages of the houses will be presented and discussed.

The reason for this is due to a large amount of data that would need to be assessed. There are seven life cycle stages, seven environmental indicators, three houses, and when multiplied together give 147 different results to assess.

The environmental indicator data exported from LCAQuick is an absolute value for all materials and energy data input into the BIM model. This value is then divided by the number of units modelled and then by the GFA of that unit to express results in environmental impact per m2 of GFA. All results will be presented in this unit unless specified otherwise.

With no reference MDH building, there is no way to determine whether the impacts calculated are high or low; therefore, the houses must be compared relative to one another. On first analysis, the data in Table 47 shows that the environmental impact for House $\mathrm{H}$ is on average across all environmental indicators $12 \%$ lower than House P, and House W on average 19\% lower than House P. In this instance, House $\mathrm{P}$ has the highest environmental impact per $\mathrm{m}_{2}$ of GFA. Table 47 presents the LCAQuick seven environmental indicators in a form designed to meet designers' requirements of visually comparing designs to help inform design decisions. This method allows both visual analysis of all indicators and the raw data is presented if the designers wish to do a more detailed analysis. The visual analysis reduces the need for extensive LCA reports of each building's environmental impact. 
Table 47 Environmental impacts per m2 of GFA per house per environmental indicator

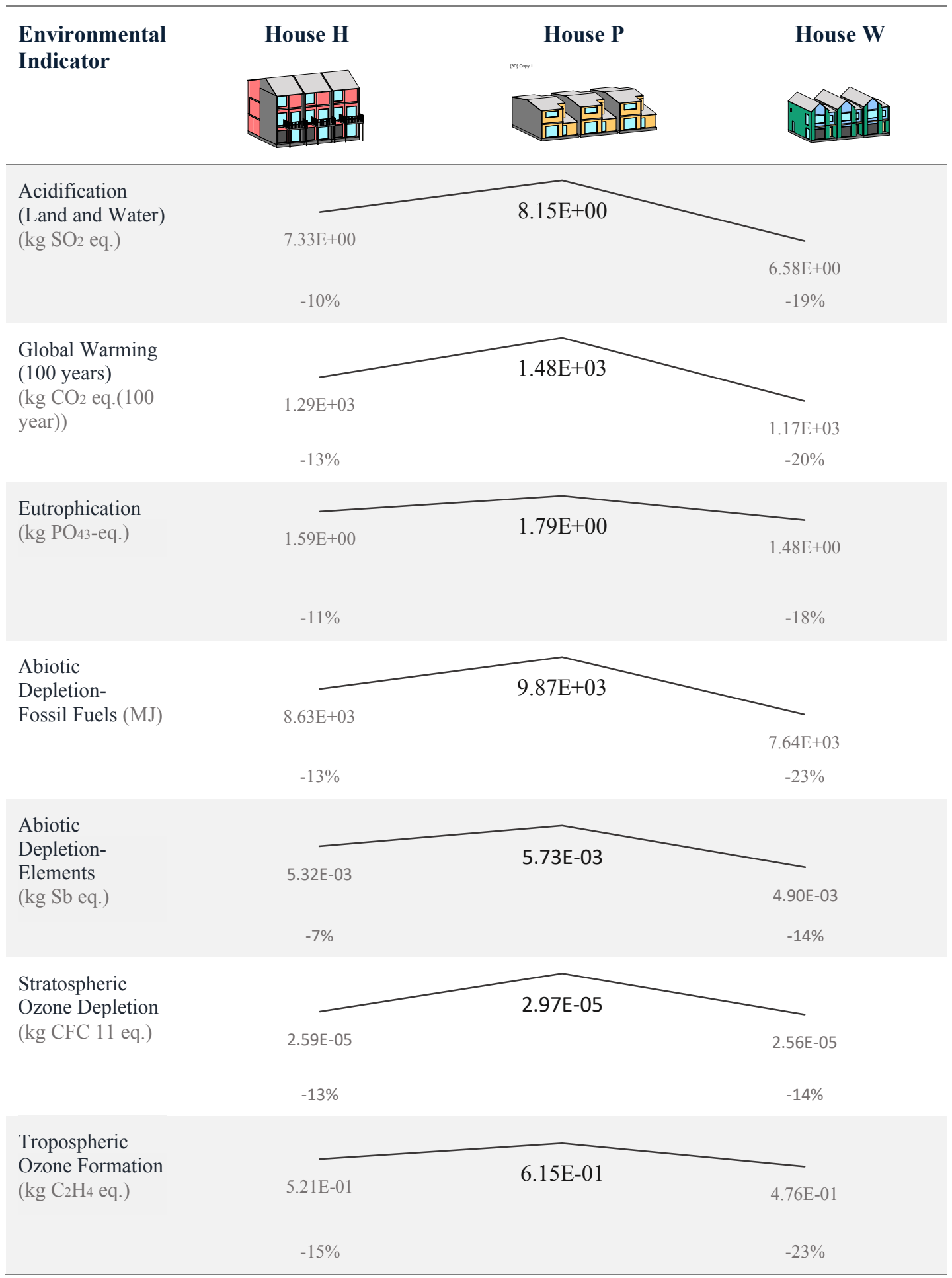

\subsubsection{The impact of construction materials}

The contributors to the seven environmental indicators are the materials and the end energy use. There was a total of 23 unique materials used over the three houses 
with a range of different cladding systems used. House $\mathrm{H}$ uses timber weatherboard and fibre cement, House P fibre cement, and House W a mixture of brick and fibre cement. Other differences in the material are Laminated Veneer lumber (LBL) used in House $\mathrm{H}$ and $\mathrm{P}$. The reason for these differences is due to the specifications of the houses. Figure 58 shows the materials in each house, and the impact of each material as a percentage of that houses total impact in each of the seven indicators.

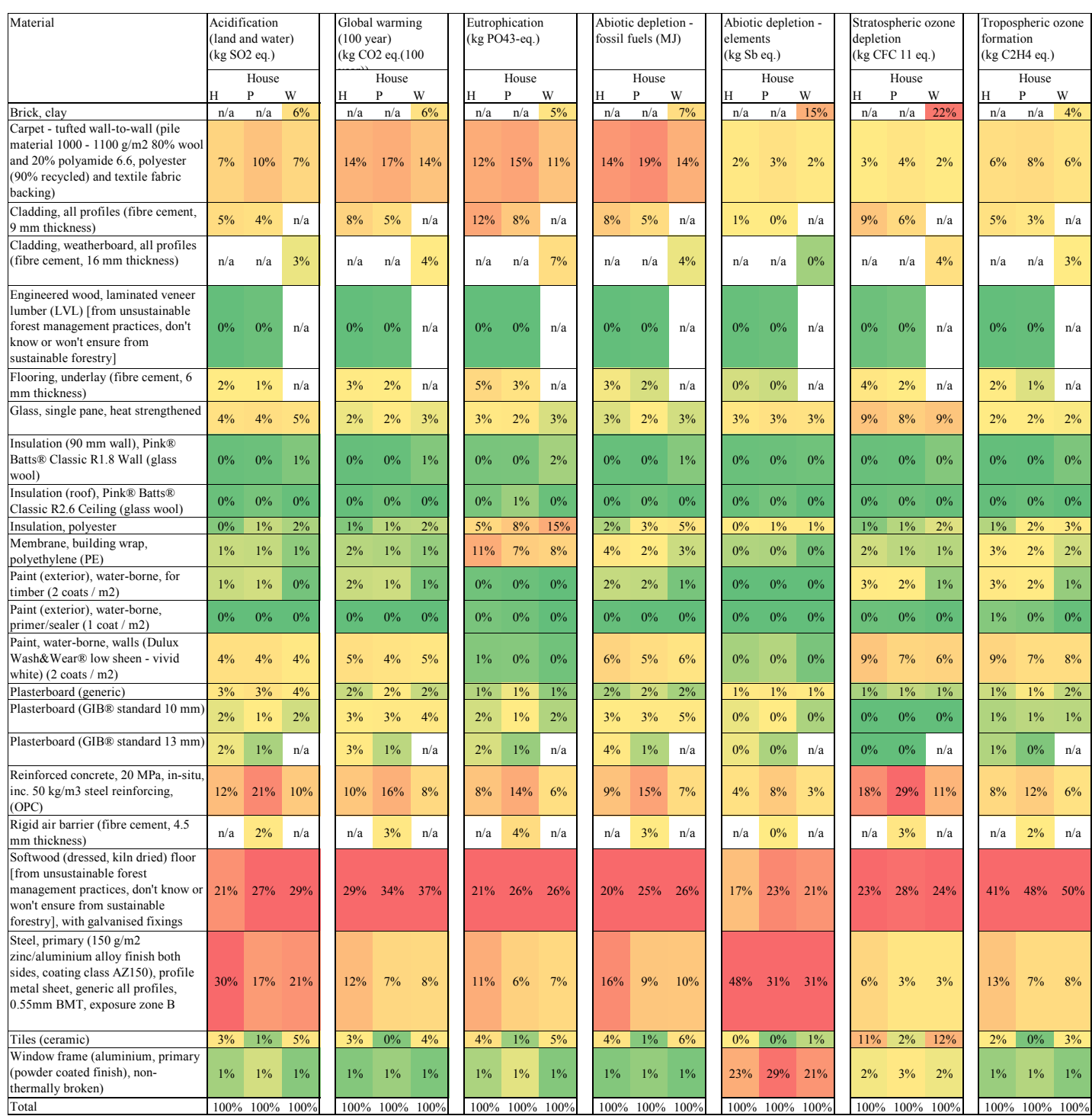

Figure 58 Percentage of environmental impact per environmental indicator for each house

From this figure, there are five key materials which contribute most to the building LCA. These materials in alphabetical order are; 
- Carpet - tufted wall-to-wall (pile material 1000 - $1100 \mathrm{~g} / \mathrm{m}_{2} 80 \%$ wool and $20 \%$ polyamide 6.6 , polyester $(90 \%$ recycled) and textile fabric backing),

- Reinforced concrete, $20 \mathrm{MPa}$, in-situ, inc. $50 \mathrm{~kg} / \mathrm{m} 3$ steel reinforcing, (OPC),

- Softwood (dressed, kiln dried) floor [from unsustainable forest management practices], with galvanised fixings,

- Steel, primary (150 g/m2 zinc/aluminium alloy finish both sides, coating class AZ150), profile metal sheet, generic all profiles, $0.55 \mathrm{~mm}$ BMT, exposure zone B,

- Window frame (aluminium, primary (powder-coated finish), nonthermally broken).

The summed total impact of these five materials ranges from $43 \%$ to $94 \%$ of the total house's impact (Figure 59). This type of analysis does not, however, indicate whether these materials are good or bad in terms of environmental impact; it just shows the impact relative to other materials in the houses. Softwood timber depending on its source can have a low or high environmental impact. Although the selected softwood timber comes from unsustainable forest management practices, this timber sequesters carbon which reduces its environmental impact for Global Warming. Since there is a high quantity of this material in each house, this causes it to have a large contribution to the total impact. Whether or not this material could be substituted for different materials to lower the impact of the building is outside the scope of this study. 


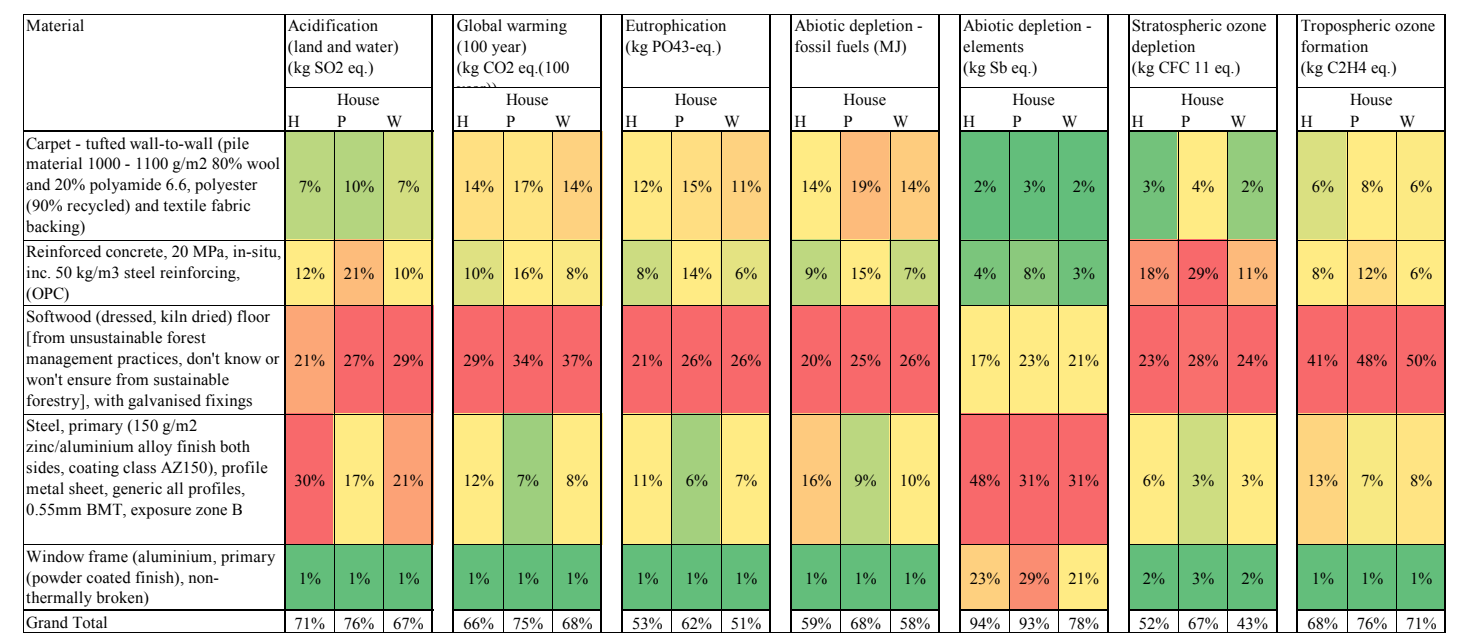

Figure 59 Percentage of environmental impact per environmental indicator for each house - top five materials

\subsubsection{Material quantity}

The quantity of the materials used in each house has a significant effect on the environmental impact, as shown in the previous section. To compare each material and the difference in quantity used in each house would be a significant task which is outside the scope of this study. Therefore, only the top five materials that contribute the most will be assessed in this section. These five materials from section 5.2.1 are highlighted in red in Table 48 and Table 49. House P has a significant amount of carpet, reinforced concrete and steel, which is due to the larger net floor area and roof area. House P also has more softwood and window frame than the other houses. These materials significantly add to the environmental impact.

Table 48 Material quantity - area (m2)

\begin{tabular}{llll}
\hline Material & House H & House P & House W \\
\hline $\begin{array}{l}\text { Carpet - tufted wall-to-wall (pile material 1000 - 1100 } \\
\text { g/m2 80\% wool and 20\% polyamide 6.6, polyester (90\% } \\
\text { recycled) and textile fabric backing) }\end{array}$ & 442 & 713 & 403 \\
$\begin{array}{l}\text { Cladding, all profiles (fibre cement, 9 mm thickness) } \\
\text { Cladding, weatherboard, all profiles (fibre cement, 16 mm }\end{array}$ & n/a & n/a & 377 \\
\begin{tabular}{l} 
thickness) \\
\hline
\end{tabular}
\end{tabular}




\begin{tabular}{|c|c|c|c|}
\hline Flooring, underlay (fibre cement, $6 \mathrm{~mm}$ thickness) & 784 & 571 & $\mathrm{n} / \mathrm{a}$ \\
\hline Paint (exterior), water-borne, for timber ( 2 coats / $\mathrm{m} 2)$ & 1355 & 1175 & 377 \\
\hline Paint (exterior), water-borne, primer/sealer (1 coat / m2) & 1355 & 1175 & 377 \\
\hline $\begin{array}{l}\text { Paint, water-borne, walls (Dulux Wash\&Wear }{ }^{\circledR} \text { low sheen } \\
\text { - vivid white) }(2 \text { coats } / \mathrm{m} 2)\end{array}$ & 3981 & 3830 & 3296 \\
\hline Rigid air barrier (fibre cement, $4.5 \mathrm{~mm}$ thickness) & $\mathrm{n} / \mathrm{a}$ & 1167 & $\mathrm{n} / \mathrm{a}$ \\
\hline Tiles (ceramic) & 478 & 87 & 592 \\
\hline Membrane, building wrap, polyethylene (PE) & 2348 & 1807 & 1792 \\
\hline $\begin{array}{l}\text { Steel }(150 \mathrm{~g} / \mathrm{m} 2 \text { zinc/aluminium alloy finish both sides), } \\
\text { profile metal sheet, generic all profiles, } 0.55 \mathrm{~mm} \text { BMT }\end{array}$ & 1348 & 938 & 784 \\
\hline
\end{tabular}

Table 49 Material quantity - volume (m3)

\begin{tabular}{|c|c|c|c|}
\hline Material & House H & House P & House W \\
\hline Brick, clay & $\mathrm{n} / \mathrm{a}$ & $\mathrm{n} / \mathrm{a}$ & 37.0 \\
\hline $\begin{array}{l}\text { Engineered wood, laminated veneer lumber (LVL) [from } \\
\text { unsustainable forest management practices, don't know or } \\
\text { won't ensure from sustainable forestry] }\end{array}$ & 1.1 & 1.9 & $\mathrm{n} / \mathrm{a}$ \\
\hline Glass, heat strengthened & 1.6 & 1.8 & 1.8 \\
\hline $\begin{array}{l}\text { Insulation ( } 90 \mathrm{~mm} \text { wall), Pink }{ }^{\circledR} \text { Batts }{ }^{\circledR} \text { Classic R1.8 Wall } \\
\text { (glass wool) }\end{array}$ & 64.2 & 63.3 & 103.9 \\
\hline $\begin{array}{l}\text { Insulation (roof), Pink }{ }^{\circledR} \text { Batts }{ }^{\circledR} \text { Classic R2.6 Ceiling } \\
\text { (glass wool) }\end{array}$ & 79.2 & 75.4 & 51.1 \\
\hline Insulation, polyester & 43.0 & 90.9 & 126.1 \\
\hline Plasterboard & 56.9 & 67.6 & 56.1 \\
\hline $\begin{array}{l}\text { Reinforced concrete, } 20 \mathrm{MPa} \text {, in-situ, inc. } 50 \mathrm{~kg} / \mathrm{m} 3 \text { steel } \\
\text { reinforcing, (OPC) }\end{array}$ & 85.9 & 181.7 & 63.1 \\
\hline $\begin{array}{l}\text { Softwood (dressed, kiln dried) [from unsustainable forest } \\
\text { management practices, don't know or won't ensure from } \\
\text { sustainable forestry], with galvanised fixings }\end{array}$ & 171.9 & 262.5 & 203.6 \\
\hline $\begin{array}{l}\text { Window frame (aluminium, primary (powder coated } \\
\text { finish), non-thermally broken) }\end{array}$ & 0.2 & 0.3 & 0.2 \\
\hline
\end{tabular}




\subsubsection{Life cycle stages}

So far, the results have been assessed on total environmental impact per environmental indicator. A component of an LCA is that it can assess environmental impacts over the entire building's life-cycle. Assessing the houses from this study over the different life-cycle stages identified in section 1.4.3 gives a detailed breakdown of which stages of the life-cycle contribute the most to a building's total environmental impact. This analysis is, however, outside the scope of this study, so will not be covered. It is important to note that stage B6 Operational Energy, contributes to the highest proportion of the buildings environmental impact for each of the seven environmental indicators. The proportions are shown, for example, in Figure 60, for the environmental indicator Acidification. B6 has the largest impact, followed by stages A1-A3 (raw material supply, transport, and manufacturing).

The difference in environmental impact is significant as it shows that the operational phase can be a target towards reducing a building's environmental impact. The full analysis can be found in the online repository referenced at the end of this report for each house, environmental indicator, phase and construction change so that analyses of this data can be performed outside of this study.

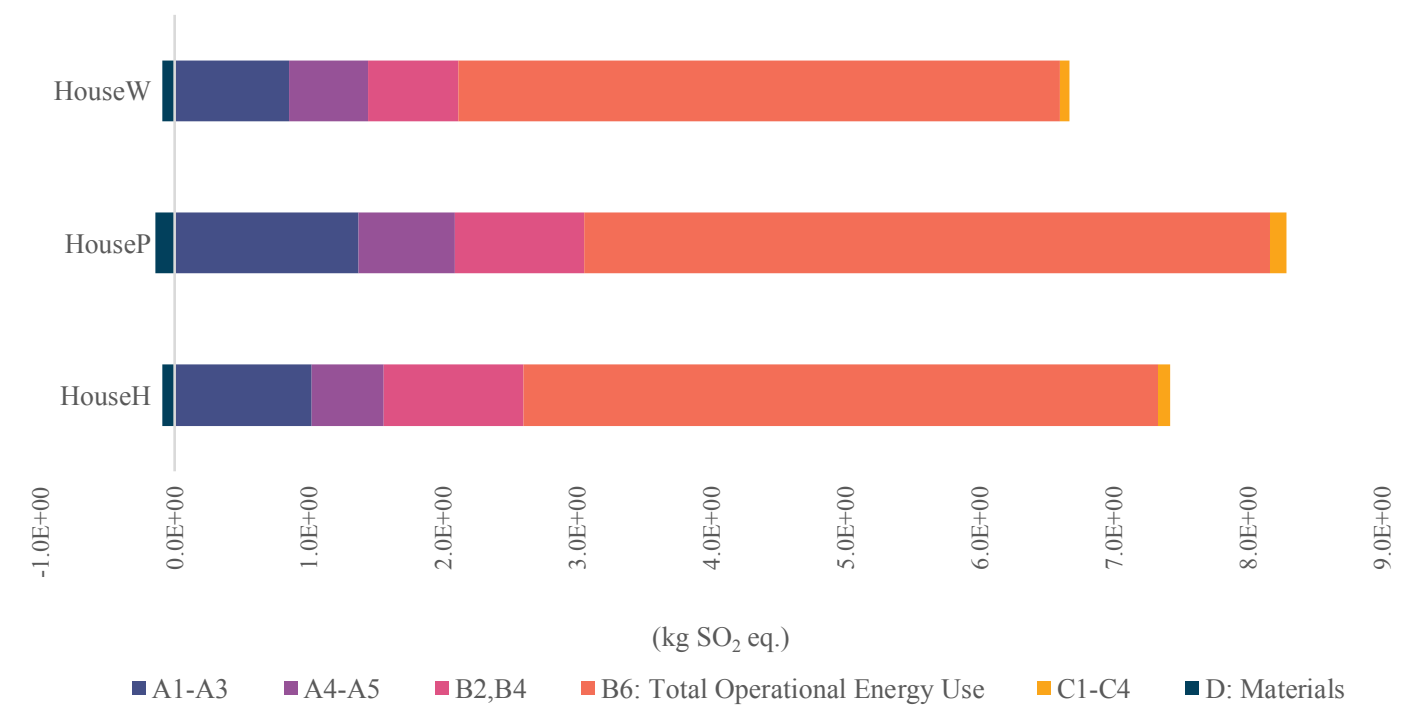

Figure 60 Breakdown of life cycle stages environmental impact for Global Warming (100 years) of Building Code minimum buildings 


\subsection{Construction changes}

This LCA is simulated to be conducted during the scheme design stage, meaning that the design is not final, and changes will be made to the design. Therefore, testing the process of changing the design was required. Another reason for construction changes was to assess the method of visual analysis of multiple designs.

Identified in section 1.1, designers require visual analysis of results to compare designs and help inform design decisions. Table 47 manages to do this showing the difference between the impacts for each indicator and house with the values presented for more detailed analysis. However, this is only for three designs, if there are more designs, another way of showing this data is required.

In section 4.2 , it is identified that the changes have to be done manually to both the BIM model and the energy model because of the limitations of software at this point in time. Once changes are made to each model, and new energy simulations run, these results must be transferred into LCAQuick and then exported from there for detailed analysis. This process is time-consuming but cannot yet be done another way. Zabalza Bribián et al. (2009), altered the insulation levels in houses and determined a point where environmental impact starts increasing due to an increase in material quantities, although operational energy use decreases. The next step in this process was to do the same to see whether this applies to $\mathrm{MDH}$ and show whether the results can be presented visually for designers. The starting point insulation levels for the walls, roof, floor and glazing of the houses are minimum values from the New Zealand Building Code.

Four changes to the building envelope were made following BRANZ recommendations on "Better" and "Best" R-values for each element, Passivhaus requirements and a Voluntary New Zealand Standard aimed at exceeding the minimum building code requirements with superinsulation techniques. The changes to each element are shown in Table 50. As the R-value for each element increases, the building element thickness increases required to accommodate additional insulation. Meaning that operational energy use may decrease in the building for heating and cooling, but the environmental impact may rise because of the additional material added to the building. 
Table 50 Construction changes to the thermal envelope

\begin{tabular}{|c|c|c|c|c|c|c|}
\hline Element & Change & $\begin{array}{l}\text { Building } \\
\text { Code } \\
\text { minimum }\end{array}$ & $\begin{array}{l}\text { BRANZ } \\
\text { Better } \\
\text { (Berg, } \\
\text { 2019) }\end{array}$ & $\begin{array}{l}\text { BRANZ } \\
\text { Best (Berg, } \\
\text { 2019) }\end{array}$ & $\begin{array}{l}\text { Passivhaus } \\
\text { (Passive } \\
\text { House } \\
\text { Institute, } \\
\text { 2016) }\end{array}$ & $\begin{array}{l}\text { Voluntary } \\
\text { Standard }\end{array}$ \\
\hline \multirow[t]{2}{*}{ Roof } & R-value & 2.9 & 3.3 & 3.7 & 3.3 & 8 \\
\hline & $\begin{array}{l}\text { Thickness } \\
\text { of element } \\
(\mathrm{mm})\end{array}$ & 115 & 115 & 165 & 115 & 300 \\
\hline \multirow[t]{2}{*}{ Walls } & R-value & 1.9 & 2.3 & 4.2 & 3.3 & 5 \\
\hline & $\begin{array}{l}\text { Thickness } \\
\text { of element } \\
(\mathrm{mm})\end{array}$ & 90 & 90 & 140 & 140 & 180 \\
\hline \multirow[t]{2}{*}{ Floor } & R-value & 1.3 & 2 & 3.1 & 3.3 & 4.5 \\
\hline & $\begin{array}{l}\text { Thickness } \\
\text { of element } \\
(\mathrm{mm})\end{array}$ & 100 & 100 & 200 & 200 & 300 \\
\hline
\end{tabular}

Requirements for glazing from the four standards above are specified in Table 51. The R-values for Passivhaus (R-0.95) and the Voluntary Standard (R-1.0) are well above the New Zealand Building Code minimum requirements. A simulated window was created to determine what an appropriate R-value is to enter into the EnergyPlus thermal simulation program. The window simulation used the Standard Window Rvalue Calculation Procedure (SCP) and the software for window performance calculation from the same US Government software development project - Window 7.5 (BRANZ, 2009; Laboratory, 2017). Using the specified window with uPVC frame and triple glazing with Low-E argon fill, the EnergyPlus compatible R-value was R0.81. R-0.81 is below Passivhaus, and the Voluntary Standard stated values showing it is not possible to achieve what these standards have stated. Having high values stated by these standards which are not compatible with a widely used freely available energy 
simulation program is an issue in the construction industry, if these values were used without quality assurance, this would lead to unobtainable results in energy model simulations. Therefore R-0.81 was used in this study for Passivhaus and the Voluntary Standard simulations.

Table 51 Construction changes to windows

\begin{tabular}{|c|c|c|c|c|c|}
\hline & $\begin{array}{l}\text { Building } \\
\text { Code } \\
\text { minimum }\end{array}$ & $\begin{array}{l}\text { BRANZ } \\
\text { Better (Berg, } \\
\text { 2019) }\end{array}$ & $\begin{array}{l}\text { BRANZ Best } \\
\text { (Berg, 2019) }\end{array}$ & $\begin{array}{l}\text { Passivhaus } \\
\text { (Passive } \\
\text { House } \\
\text { Institute, } \\
\text { 2016) }\end{array}$ & $\begin{array}{l}\text { Voluntary } \\
\text { Standard }\end{array}$ \\
\hline $\begin{array}{l}\text { R-value } \\
\text { specified }\end{array}$ & 0.26 & 0.26 & 0.6 & 0.95 & 1 \\
\hline $\begin{array}{l}\text { Frame } \\
\text { Material }\end{array}$ & $\begin{array}{l}\text { Aluminium, } \\
\text { primary } \\
\text { (powder } \\
\text { coated } \\
\text { finish), non- } \\
\text { thermally } \\
\text { broken }\end{array}$ & $\begin{array}{l}\text { Aluminium, } \\
\text { primary } \\
\text { (powder } \\
\text { coated } \\
\text { finish), non- } \\
\text { thermally } \\
\text { broken }\end{array}$ & $\begin{array}{l}\text { Aluminium, } \\
\text { primary } \\
\text { (powder } \\
\text { coated } \\
\text { finish), } \\
\text { thermally } \\
\text { broken }\end{array}$ & uPVC & uPVC \\
\hline Glazing & $\begin{array}{l}\text { Glass, heat } \\
\text { strengthened }\end{array}$ & $\begin{array}{l}\text { Glass, heat } \\
\text { strengthened }\end{array}$ & $\begin{array}{l}\text { Triple glazed } \\
\text { low-e argon }\end{array}$ & $\begin{array}{l}\text { Triple glazed } \\
\text { low-e argon }\end{array}$ & $\begin{array}{l}\text { Triple glazed } \\
\text { low-e argon }\end{array}$ \\
\hline $\begin{array}{l}\text { R-value } \\
\text { calculated }\end{array}$ & 0.26 & 0.26 & 0.6 & 0.81 & 0.81 \\
\hline
\end{tabular}

\subsubsection{End energy use}

The end energy use for heating and cooling of the houses with the new constructions is presented in Figure 61.

Electrical equipment, lighting and hot water end energy use remain the same as before as these inputs were not adjusted nor are they affected by the input changes, therefore, they are not shown in Figure 61. As the changes in R-values increase, each house's heating energy use decreases, whereas cooling energy use increases due to overheating. 


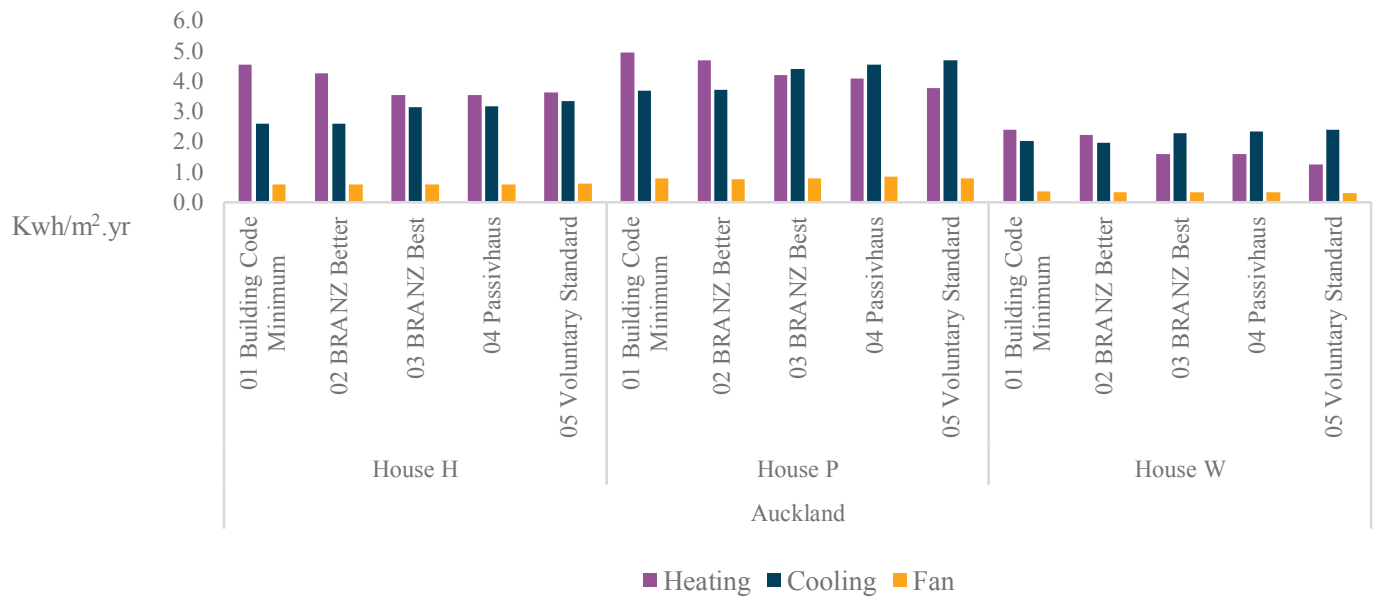

Figure 61 Annual heating and cooling energy use for all houses and changes Auckland

Comparing the change in energy use for heating and cooling to the Building Code minimum results in a decrease in energy use with each construction change.

House $\mathrm{P}$ - Passivhaus has an increase in heating and cooling energy use because it requires more energy to cool the building as it is overheating, but this increase is minor at $0.2 \mathrm{kWh} / \mathrm{m} 2$ which is a $0.7 \%$ increase. House $\mathrm{H}$ and House $\mathrm{P}$ have the greatest decrease in energy use at the BRANZ Best level and House W at Voluntary Standard (Figure 62).

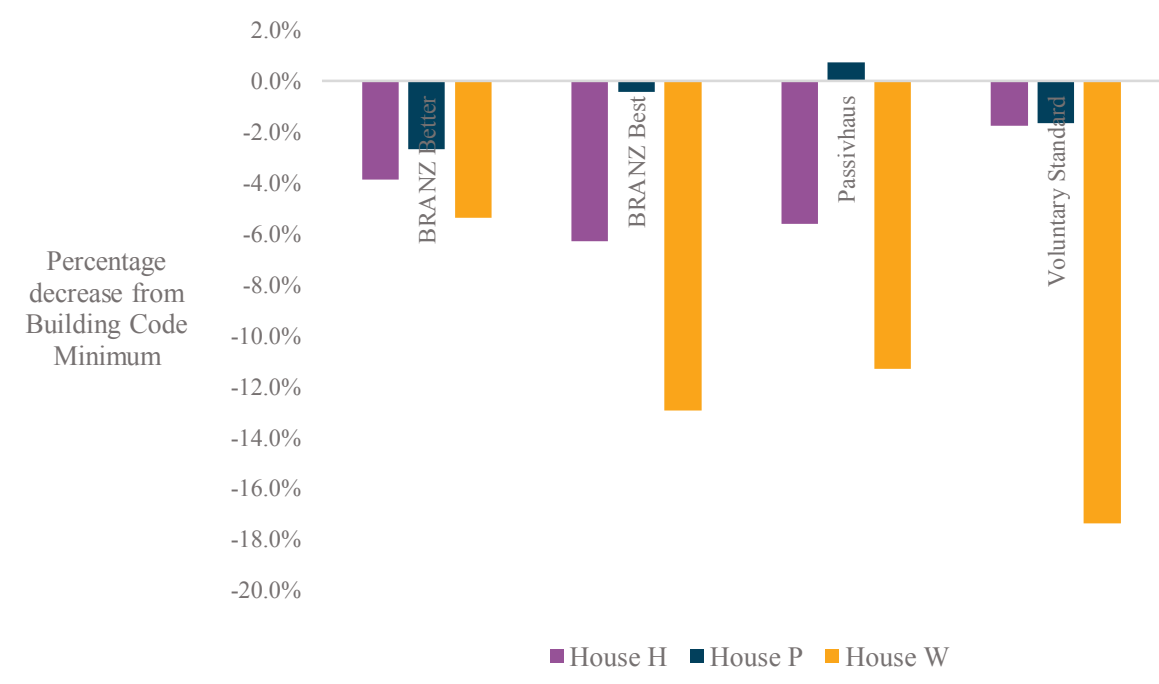

Figure 62 Difference in heating/cooling energy use from Building Code minimum Auckland 


\subsubsection{Life Cycle Assessment analysis}

With a total of five scenarios and three house designs, this results in 15 different scenarios for analysis with seven environmental indicators each. One way to show all of this data is shown in Table 52, which allows visual assessment of each house and the effect that the construction changes have on each environmental impact. For all houses, Voluntary Standard results in the largest environmental impact for six out of seven environmental indicators. BRANZ Better resulted in the lowest impact for all environmental indicators except for House H Stratospheric Ozone Depletion.

This analysis shows that changing the insulation levels can decrease end energy use, but there is a point where this starts to affect the building's environmental impact negatively. The reason for this is that a large quantity of materials is being added to the building to try and reduce end energy use for space heating, but this results in diminishing returns where the environmental impact from reducing energy use is not enough to offset the increase in environmental impact from the additional materials. This relationship is true for all three buildings, which show that there is a point (BRANZ Best) where it is not effective to reduce energy use. Although increasing Rvalues would reduce the operating cost of the house and demand on the energy grid, this will not reduce environmental impact showing how important materials are towards the building's total environmental impact.

Table 52 Environmental impact of construction changes for each environmental indicator and house per m2 of GFA - Auckland (Percentage increase/decrease in comparison to Building Code minimum)

\begin{tabular}{|c|c|c|c|c|c|c|}
\hline House & $\begin{array}{l}\text { Environmental } \\
\text { Indicator }\end{array}$ & $\begin{array}{l}\text { Building } \\
\text { Code } \\
\text { minimum }\end{array}$ & $\begin{array}{l}\text { BRANZ } \\
\text { Better }\end{array}$ & BRANZ Best & Passivhaus & $\begin{array}{l}\text { Voluntary } \\
\text { Standard }\end{array}$ \\
\hline \multirow{7}{*}{$\begin{array}{l}\text { House H } \\
\text { H }\end{array}$} & \multirow{3}{*}{$\begin{array}{l}\text { Acidification } \\
\text { (Land and } \\
\text { Water) } \\
\text { (kg SO} 2 \text { eq.) }\end{array}$} & \multirow{3}{*}{$7.33 \mathrm{E}+00$} & & & & \\
\hline & & & $7.28 \mathrm{E}+00$ & $7.30 \mathrm{E}+00$ & $7.31 \mathrm{E}+00$ & \\
\hline & & & $-1 \%$ & $0 \%$ & $0 \%$ & $2 \%$ \\
\hline & \multirow{4}{*}{$\begin{array}{l}\text { Global } \\
\text { Warming } \\
\text { (100 year) } \\
\text { (kg } \mathrm{CO}_{2} \\
\text { eq.(100 year)) }\end{array}$} & \multirow{4}{*}{$1.29 \mathrm{E}+03$} & & & & \multirow{4}{*}{$1.32 \mathrm{E}+03$} \\
\hline & & & & & & \\
\hline & & & $1.27 \mathrm{E}+03$ & $1.29 \mathrm{E}+03$ & $1.29 \mathrm{E}+03$ & \\
\hline & & & $-1 \%$ & $0 \%$ & $0 \%$ & \\
\hline
\end{tabular}


A Life Cycle Assessment of Medium Density Houses in New Zealand

\begin{tabular}{|c|c|c|c|c|c|c|}
\hline & \multirow[t]{3}{*}{$\begin{array}{l}\text { Eutrophication } \\
\text { (kg PO43-eq.) }\end{array}$} & & & & & \multirow{2}{*}{$1.32 \mathrm{E}+03$} \\
\hline & & \multirow[t]{2}{*}{$1.29 \mathrm{E}+03$} & $1.27 \mathrm{E}+03$ & $1.29 \mathrm{E}+03$ & $1.29 \mathrm{E}+03$ & \\
\hline & & & $-1 \%$ & $0 \%$ & $0 \%$ & $3 \%$ \\
\hline & \multirow{4}{*}{$\begin{array}{l}\text { Abiotic } \\
\text { Depletion- } \\
\text { Fossil Fuels } \\
(\mathrm{MJ})\end{array}$} & \multirow{4}{*}{$1.29 \mathrm{E}+03$} & & & & \multirow{3}{*}{$1.32 \mathrm{E}+03$} \\
\hline & & & & & & \\
\hline & & & $1.27 \mathrm{E}+03$ & $1.29 \mathrm{E}+03$ & $1.29 \mathrm{E}+03$ & \\
\hline & & & $-1 \%$ & $0 \%$ & $0 \%$ & $3 \%$ \\
\hline & \multirow{3}{*}{$\begin{array}{l}\text { Abiotic } \\
\text { Depletion- } \\
\text { Elements } \\
\text { (kg Sb eq.) }\end{array}$} & \multirow{3}{*}{$5.32 \mathrm{E}-03$} & & & & - \\
\hline & & & $5.30 \mathrm{E}-03$ & $6.00 \mathrm{E}-03$ & $5.86 \mathrm{E}-03$ & $5.94 \mathrm{E}-03$ \\
\hline & & & $0 \%$ & $13 \%$ & $10 \%$ & $12 \%$ \\
\hline & \multirow{3}{*}{$\begin{array}{l}\text { Stratospheric } \\
\text { Ozone } \\
\text { Depletion } \\
\text { (kg CFC } 11 \text { eq.) }\end{array}$} & \multirow{3}{*}{$2.59 \mathrm{E}-05$} & & & & \multirow{2}{*}{$2.62 \mathrm{E}-05$} \\
\hline & & & $2.59 \mathrm{E}-05$ & $2.58 \mathrm{E}-05$ & $2.55 \mathrm{E}-05$ & \\
\hline & & & $0 \%$ & $0 \%$ & $-1 \%$ & $1 \%$ \\
\hline & \multirow{3}{*}{$\begin{array}{l}\text { Tropospheric } \\
\text { Ozone } \\
\text { Formation } \\
\text { (kg } \mathrm{kg}_{2} \mathrm{H}_{4} \text { eq.) }\end{array}$} & & & & & \multirow[b]{2}{*}{$5.67 \mathrm{E}-01$} \\
\hline & & $5.21 \mathrm{E}-01$ & $5.18 \mathrm{E}-01$ & $5.36 \mathrm{E}-01$ & 5.39E-01 & \\
\hline & & & $-1 \%$ & $3 \%$ & $3 \%$ & $9 \%$ \\
\hline \multirow{13}{*}{ 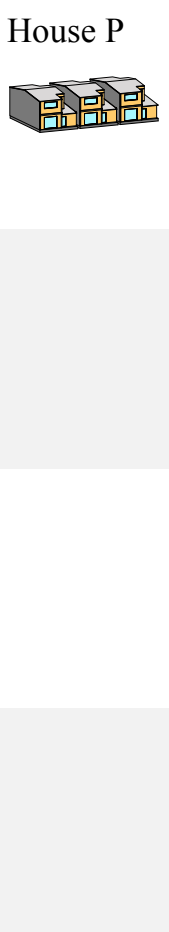 } & \multirow{3}{*}{$\begin{array}{l}\text { Acidification } \\
\text { (Land and } \\
\text { Water) } \\
\text { (kg SO} \mathrm{SO}_{2} \text { eq.) }\end{array}$} & & & & & \multirow{3}{*}{$8.34 \mathrm{E}+00$} \\
\hline & & $8.15 \mathrm{E}+00$ & $8.13 \mathrm{E}+00$ & $8.15 \mathrm{E}+00$ & $8.18 \mathrm{E}+00$ & \\
\hline & & & $0 \%$ & $0 \%$ & $0 \%$ & \\
\hline & \multirow{3}{*}{$\begin{array}{l}\text { Global } \\
\text { Warming } \\
(100 \text { year }) \\
\text { (kg CO2 } \\
\text { eq. }(100 \text { year }))\end{array}$} & & & & & \multirow{3}{*}{$1.53 \mathrm{E}+03$} \\
\hline & & $1.48 \mathrm{E}+03$ & $1.47 \mathrm{E}+03$ & $1.49 \mathrm{E}+03$ & $1.49 \mathrm{E}+03$ & \\
\hline & & & $0 \%$ & $1 \%$ & $1 \%$ & \\
\hline & \multirow[t]{3}{*}{$\begin{array}{l}\text { Eutrophication } \\
\text { (kg PO43-eq.) }\end{array}$} & \multirow{3}{*}{$1.79 \mathrm{E}+00$} & & & & \multirow{3}{*}{$2.01 \mathrm{E}+00$} \\
\hline & & & $179 F+00$ & $1.85 \mathrm{E}+00$ & $1.93 \mathrm{E}+00$ & \\
\hline & & & $0 \%$ & $3 \%$ & $8 \%$ & \\
\hline & \multirow{4}{*}{$\begin{array}{l}\text { Abiotic } \\
\text { Depletion- } \\
\text { Fossil Fuels } \\
(\mathrm{MJ})\end{array}$} & \multirow{4}{*}{$1.79 \mathrm{E}+00$} & & & & \multirow{3}{*}{$2.01 \mathrm{E}+00$} \\
\hline & & & & & $1.93 \mathrm{E}+00$ & \\
\hline & & & $1.79 \mathrm{E}+00$ & $1.85 \mathrm{E}+00$ & & \\
\hline & & & $0 \%$ & $3 \%$ & $8 \%$ & $12 \%$ \\
\hline
\end{tabular}




\begin{tabular}{|c|c|c|c|c|c|c|}
\hline & \multirow{3}{*}{$\begin{array}{l}\text { Abiotic } \\
\text { Depletion- } \\
\text { Elements } \\
\text { (kg Sb eq.) }\end{array}$} & \multirow{3}{*}{$1.79 \mathrm{E}+00$} & & \multirow[b]{2}{*}{$1.85 \mathrm{E}+00$} & \multirow{2}{*}{$1.93 \mathrm{E}+00$} & \multirow[t]{2}{*}{$2.01 \mathrm{E}+00$} \\
\hline & & & $1.79 \mathrm{E}+00$ & & & \\
\hline & & & $0 \%$ & $3 \%$ & $8 \%$ & $12 \%$ \\
\hline & \multirow{4}{*}{$\begin{array}{l}\text { Stratospheric } \\
\text { Ozone } \\
\text { Depletion } \\
\text { (kg CFC } 11 \text { eq.) }\end{array}$} & \multirow{4}{*}{$1.79 \mathrm{E}+00$} & & & & \\
\hline & & & & & $1.93 \mathrm{E}+00$ & $2.01 \mathrm{E}+00$ \\
\hline & & & $1.79 \mathrm{E}+00$ & $1.85 \mathrm{E}+00$ & & \\
\hline & & & $0 \%$ & $3 \%$ & $8 \%$ & $12 \%$ \\
\hline & \multirow{4}{*}{$\begin{array}{l}\text { Tropospheric } \\
\text { Ozone } \\
\text { Formation } \\
\text { (kg } \mathrm{C}_{2} \mathrm{H}_{4} \text { eq.) }\end{array}$} & & & & & \\
\hline & & & & & & 6.69E-01 \\
\hline & & $6.15 \mathrm{E}-01$ & $6.14 \mathrm{E}-01$ & $6.30 \mathrm{E}-01$ & $6.36 \mathrm{E}-01$ & \\
\hline & & & $0 \%$ & $3 \%$ & $3 \%$ & $9 \%$ \\
\hline \multirow{22}{*}{ House W } & \multirow{3}{*}{$\begin{array}{l}\text { Acidification } \\
\text { (Land and } \\
\text { Water) } \\
\text { (kg SO} 2 \text { eq.) }\end{array}$} & & & & & - \\
\hline & & & & $6.72 \mathrm{E}+00$ & $6.71 \mathrm{E}+00$ & $0.84 E+00$ \\
\hline & & & $0 \%$ & $2 \%$ & $2 \%$ & $4 \%$ \\
\hline & \multirow{4}{*}{$\begin{array}{l}\text { Global } \\
\text { Warming } \\
\text { (100 year) } \\
\text { (kg CO2 } \\
\text { eq.(100 year)) }\end{array}$} & \multirow{4}{*}{$6.58 \mathrm{E}+00$} & & & & \\
\hline & & & & $6.72 \mathrm{E}+00$ & $6.71 \mathrm{E}+00$ & $6.84 \mathrm{E}+00$ \\
\hline & & & $6.57 \mathrm{E}+00$ & & & \\
\hline & & & $0 \%$ & $2 \%$ & $2 \%$ & $4 \%$ \\
\hline & \multirow[t]{3}{*}{$\begin{array}{l}\text { Eutrophication } \\
\text { (kg PO43-eq.) }\end{array}$} & & & & & \\
\hline & & $1.48 \mathrm{E}+00$ & $1.48 \mathrm{E}+00$ & $1.51 \mathrm{E}+00$ & $1.54 \mathrm{E}+00$ & $1.60 \mathrm{E}+00$ \\
\hline & & & $0 \%$ & $2 \%$ & $4 \%$ & $8 \%$ \\
\hline & \multirow{4}{*}{$\begin{array}{l}\text { Abiotic } \\
\text { Depletion- } \\
\text { Fossil Fuels } \\
(\mathrm{MJ})\end{array}$} & & & & & $828 \mathrm{~F}+03$ \\
\hline & & & & $7.94 \mathrm{E}+03$ & $7.93 \mathrm{E}+03$ & \\
\hline & & $7.64 \mathrm{E}+03$ & $7.64 \mathrm{E}+03$ & & & \\
\hline & & & $0 \%$ & $4 \%$ & $4 \%$ & $8 \%$ \\
\hline & \multirow{4}{*}{$\begin{array}{l}\text { Abiotic } \\
\text { Depletion- } \\
\text { Elements } \\
\text { (kg Sb eq.) }\end{array}$} & & & & & \\
\hline & & & & $5.44 \mathrm{E}-03$ & $5.32 \mathrm{E}-03$ & 5.37E-03 \\
\hline & & $4.90 \mathrm{E}-03$ & 4.89E-03 & & & \\
\hline & & & $0 \%$ & $11 \%$ & $9 \%$ & $10 \%$ \\
\hline & \multirow{4}{*}{$\begin{array}{l}\text { Stratospheric } \\
\text { Ozone } \\
\text { Depletion } \\
\text { (kg CFC } 11 \text { eq.) }\end{array}$} & \multirow{4}{*}{$2.56 \mathrm{E}-05$} & & & & \\
\hline & & & & $2.64 \mathrm{E}-05$ & $261 \mathrm{~F} 05$ & $2.67 \mathrm{E}-05$ \\
\hline & & & $2.56 \mathrm{E}-05$ & & $2.01 \mathrm{~L}-\mathrm{OJ}$ & \\
\hline & & & $0 \%$ & $3 \%$ & $2 \%$ & $4 \%$ \\
\hline
\end{tabular}




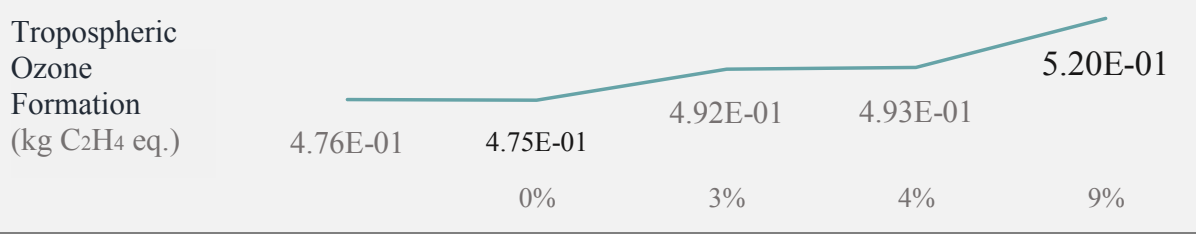

Another way to assess the data is to do so visually using radar diagrams shown in Figure 63, where each point of the diagram represents one of the seven environmental indicators. The following equation was used to scale the data relative to one another for each house's seven environmental impacts.

(Value of impact - Minimum value in environmental indicator category) $\overline{\text { (Maximum value in environmental indicator category - Minimum value in environmental indicator category) }}$

This equation converts the lowest values for each environmental indicator category and places them with a value of zero near the centre of the radar diagram. The highest values now have a value of one and appear at the outer end of the diagram. Visually assessing the environmental impacts in the radar images, shows the impacts for each building decrease when the "BRANZ Better" R-values are used compared to Building Code minimum. The environmental impacts visually begin to increase moving along the page up to "Voluntary Standard" which has the highest environmental impacts. 
Findings

This page is intentionally left blank. 


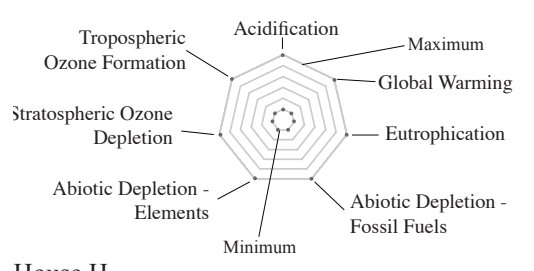

House $\mathrm{H}$

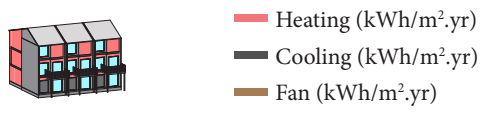

Acidification (Land and Water) ( $\mathrm{kg} \mathrm{SO}_{2}$ eq.)

Global Warming (100 year)

(kg CO 2 eq.(100 year))

Eutrophication

( $\mathrm{kg} \mathrm{PO}_{4}{ }^{3}$-eq.)

Abiotic Depletion - Fossil

Fuels (MJ)

Abiotic Depletion - Elements

(kg Sb eq.)

Stratospheric Ozone Depletion

(kg CFC 11 eq.)

Tropospheric Ozone Formation ( $\mathrm{kg} \mathrm{C}_{2} \mathrm{H}_{4}$ eq.)

House P

$\begin{aligned}- & \text { Heating }\left(\mathrm{kWh} / \mathrm{m}^{2} . \mathrm{yr}\right) \\ - & \text { Cooling }\left(\mathrm{kWh} / \mathrm{m}^{2} . \mathrm{yr}\right)\end{aligned}$ - Cooling $\left(\mathrm{kWh} / \mathrm{m}^{2} . \mathrm{yr}\right.$

Acidification (Land and Water) ( $\mathrm{kg} \mathrm{SO}_{2}$ eq.)

Global Warming (100 year)

(kg CO eq.(100 year))

Eutrophication

( $\mathrm{kg} \mathrm{PO}_{4}{ }^{3}$-eq.)

Abiotic Depletion - Fossil

Fuels (MJ)

Abiotic Depletion - Elements

(kg Sb eq.)

Stratospheric Ozone Depletion

(kg CFC 11 eq.)

Tropospheric Ozone Formation

( $\mathrm{kg} \mathrm{C}_{2} \mathrm{H}_{4}$ eq.)

House W

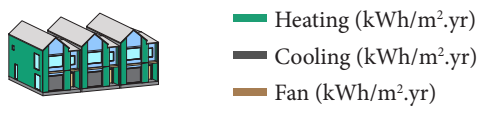

Acidification (Land and Water) ( $\mathrm{kg} \mathrm{SO}_{2}$ eq.)

Global Warming (100 year)

(kg CO 2 eq.(100 year))

Eutrophication

(kg $\mathrm{PO}_{4}^{3}$-eq.)

Abiotic Depletion - Fossil

Fuels (MJ)

Abiotic Depletion - Elements

(kg Sb eq.)

Stratospheric Ozone Depletion (kg CFC 11 eq.)

Tropospheric Ozone Formation ( $\mathrm{kg} \mathrm{C}_{2} \mathrm{H}_{4}$ eq.)

$1.59 \mathrm{E}+00$
$8.15 \mathrm{E}+00$

$1.48 \mathrm{E}+03$

$1.79 \mathrm{E}+00$

$9.87 \mathrm{E}+03$

5.73E-03

2.97E-05

$6.15 \mathrm{E}-01$
$1.17 \mathrm{E}+03$

$1.48 \mathrm{E}+00$

7.64E+03

4.90E-03

$2.56 \mathrm{E}-05$

4.76E-01
Building Code

Minimum

\begin{tabular}{ll} 
& R-value \\
Roof & 2.9 \\
Walls & 1.9 \\
Floor & 1.9 \\
Glazing & $0.26 \quad$ Total energy use \\
& \multicolumn{2}{c}{$\quad \mathrm{kWh} / \mathrm{m}^{2} . \mathrm{yr}$}
\end{tabular}

BRANZ

Better

Roof R-value

Walls 2.3

Floor $\quad 2.0$

Glazing $\quad 0.26$

$\mathrm{kWh} / \mathrm{m}^{2} \cdot \mathrm{yr}$

7.4

$7.28 \mathrm{E}+00$

$7.33 \mathrm{E}+00$

$1.29 \mathrm{E}+03$

$8.63 \mathrm{E}+03$

$5.32 \mathrm{E}-03$

2.59E-05
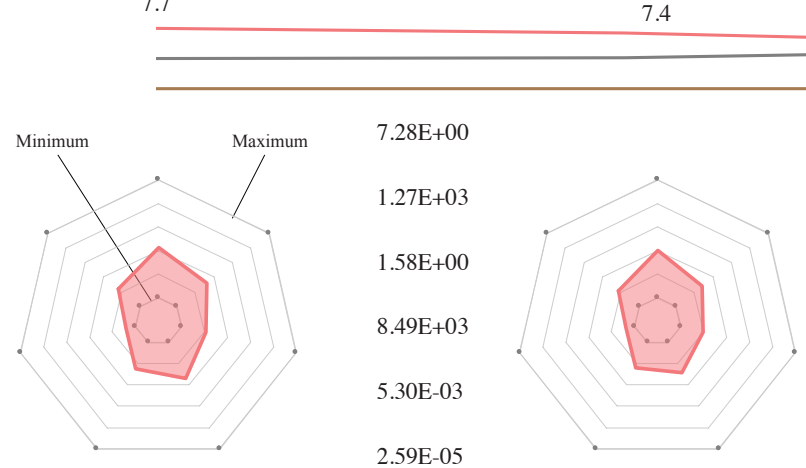

$2.59 \mathrm{E}-05$

5.18E-01

$-1 \%$

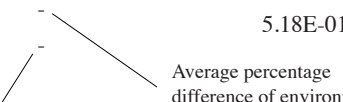

difference of environmental

Minimum
$8.13 \mathrm{E}+00$

1.47E+03

$1.79 \mathrm{E}+00$

$9.86 \mathrm{E}+03$

5.72E-03

2.97E-05

$6.14 \mathrm{E}-01$

$0 \%$

$13 \%$

$14 \%$

$6.57 \mathrm{E}+00$

$1.17 \mathrm{E}+03$

$1.48 \mathrm{E}+00$

$7.64 \mathrm{E}+03$

4.89E-03

$2.56 \mathrm{E}-05$

4.75E-01

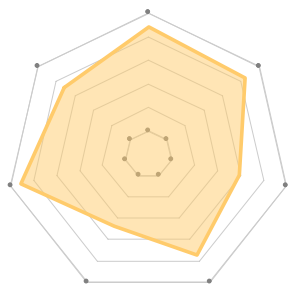

Figure 63 Environmental impact for each environmental indicator - Auckland 
Findings

\begin{tabular}{|c|c|c|c|c|c|}
\hline \multicolumn{2}{|c|}{$\begin{array}{c}\text { BRANZ } \\
\text { Best }\end{array}$} & \multicolumn{2}{|c|}{ Passivhaus } & \multicolumn{2}{|c|}{$\begin{array}{l}\text { Voluntary } \\
\text { Standard }\end{array}$} \\
\hline & R-value & & R-value & & R-value \\
\hline Roof & 3.7 & Roof & 3.3 & Roof & \\
\hline Walls & 4.2 & Walls & 3.3 & Walls & 5 \\
\hline Floor & 3.1 & Floor & 3.3 & Floor & 4.5 \\
\hline Glazing & 0.6 & Glazing & 0.81 & Glazing & 0.81 \\
\hline
\end{tabular}

\begin{tabular}{llll}
\hline \multicolumn{2}{c}{7.3} & & \\
\hline & & & \\
\hline
\end{tabular}

9.4

9.5

9.3

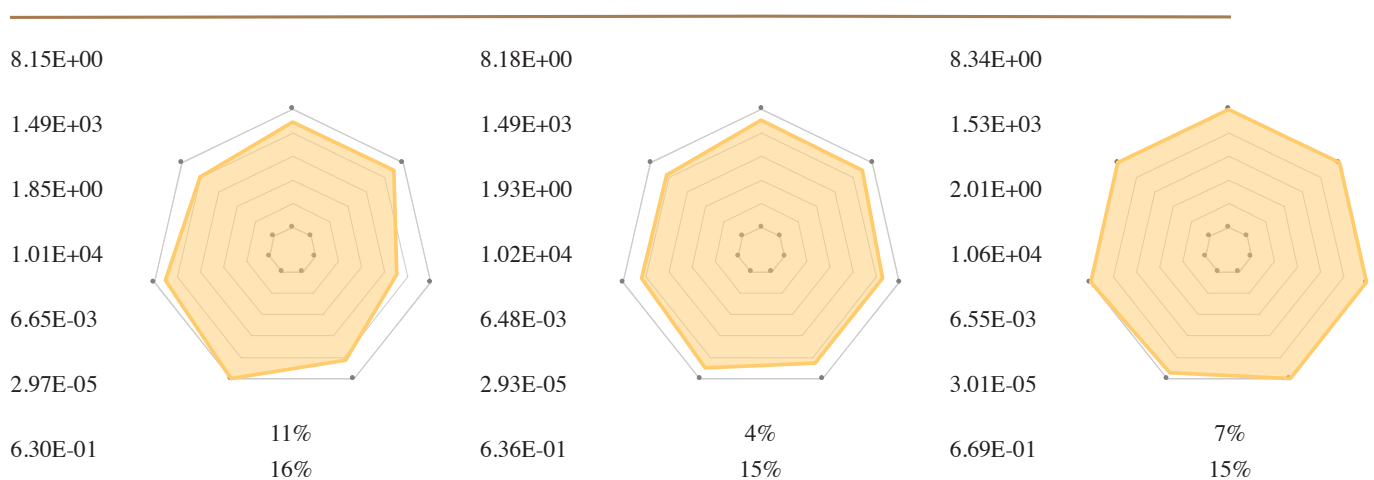

4.2

4.2

4.0

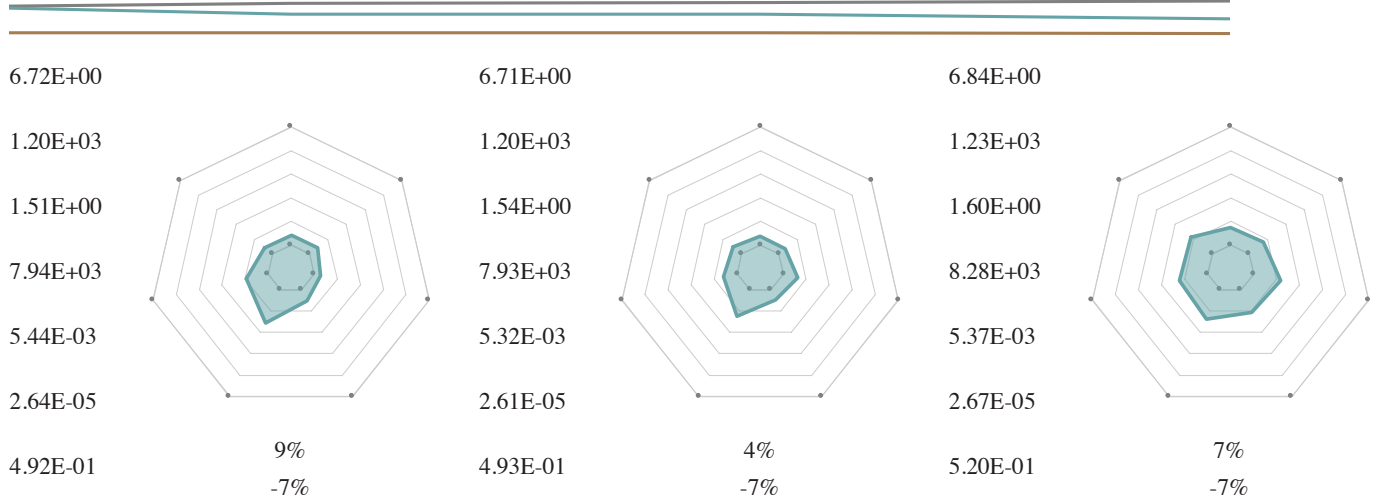


However, the difference in environmental impact between the insulation changes is relatively slim when compared to the difference in environmental impact between the house designs (down the page). The difference between insulation changes ranges from -1 to $7 \%$ (Table 53), whereas the differences in house design range from 21 to 22\% (Table 54). The differences can be seen visually in Figure 63, where the differences in radars across the page are much less visually noticeable compared to reading down the page between house designs. Reading down the page, House $\mathrm{W}$ has a significantly lower impact across all environmental indicators compared to the other designs and House P, the largest. All the houses have a similar GFA and had the same number of bedrooms so they can accommodate the same number of occupants. This analysis leads to the conclusion that the effort used to decrease heating/cooling end energy use to decrease environmental impact, in this scenario, is better spent on the building form and quantity of materials used.

\begin{tabular}{|c|c|c|c|c|c|}
\hline & $\begin{array}{l}\text { Building } \\
\text { Code } \\
\text { minimum }\end{array}$ & $\begin{array}{l}\text { BRANZ } \\
\text { Better }\end{array}$ & BRANZ Best & Passivhaus & $\begin{array}{l}\text { Voluntary } \\
\text { Standard }\end{array}$ \\
\hline House H & - & $-1 \%$ & $2 \%$ & $3 \%$ & $6 \%$ \\
\hline House P & - & $0 \%$ & $4 \%$ & $4 \%$ & $7 \%$ \\
\hline House W & - & $0 \%$ & $4 \%$ & $4 \%$ & $7 \%$ \\
\hline Average & - & $0 \%$ & $3 \%$ & $3 \%$ & $7 \%$ \\
\hline
\end{tabular}

Table 54 Average difference of all seven environmental indicators from House H Auckland

\begin{tabular}{llllll}
\hline & $\begin{array}{l}\text { Building } \\
\text { Code } \\
\text { minimum }\end{array}$ & $\begin{array}{l}\text { BRANZ } \\
\text { Better }\end{array}$ & BRANZ Best & Passivhaus & $\begin{array}{l}\text { Voluntary } \\
\text { Standard }\end{array}$ \\
\hline House $\mathrm{H}$ & - & - & - & - & - \\
\hline House P & $13 \%$ & $14 \%$ & $15 \%$ & $15 \%$ & $15 \%$ \\
House $\mathrm{W}$ & $-8 \%$ & $-7 \%$ & $-6 \%$ & $-7 \%$ & $-7 \%$ \\
\hline
\end{tabular}




\begin{tabular}{llllll}
\hline Difference & $21 \%$ & $21 \%$ & $21 \%$ & $22 \%$ & $22 \%$ \\
from min to & & & & \\
$\max$ & & & \\
\hline
\end{tabular}

\subsection{Comparison between Gross Floor Area and absolute results}

A check was conducted to determine whether assessing results on an impact per $\mathrm{m} 2$ of GFA basis skews results. The check was achieved by performing the same analysis on the houses but using the absolute environmental impacts and absolute heating/cooling end energy use.

Table 55 shows that the only difference to the assessments of the results is when comparing house designs. For environmental impact, this impact has reduced to between $14 \%$ and $15 \%$ compared to on a per $\mathrm{m}_{2}$ basis of 21 to $22 \%$. The difference is important as it shows that focusing on one method of analysis can show different results with the same data. Since the houses were of a similar GFA ranging from 123 - $134 \mathrm{~m} 2$ using either method is appropriate, but when comparing houses of varying GFA such as $100 \mathrm{~m} 2$ and $250 \mathrm{~m} 2$ could yield significantly varying results between a per $\mathrm{m}_{2}$ of GFA basis and absolute value. The same is true for heating/cooling energy use between the house designs.

\section{Table 55 Comparison of per m2 of GFA and absolute analysis}

\begin{tabular}{llll}
\hline Assessment Category & Change & Per m2 & Absolute \\
\hline Environmental Impact & Insulation Changes & $-1-7 \%$ & $-1-7 \%$ \\
Environmental Impact & House Design & $21-22 \%$ & $14-15 \%$ \\
Heating/cooling Energy & Insulation Changes & $4-7 \%$ & $4-7 \%$ \\
Heating/cooling Energy & House Design & $6-13 \%$ & $2-10 \%$ \\
\hline
\end{tabular}

Assessing the environmental impacts on an absolute basis using the radar techniques shows similar trends to using a per $\mathrm{m} 2$ of GFA basis. Comparing absolute values in Figure 64 brings House $\mathrm{H}$ and $\mathrm{P}$ to similar environmental impact levels with $\mathrm{H}$ significantly higher. 


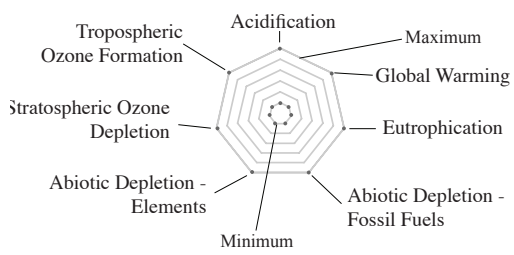

House $\mathrm{H}$

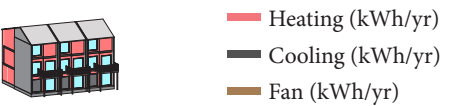

Acidification (Land and Water) ( $\mathrm{kg} \mathrm{SO}_{2}$ eq.)

Global Warming (100 year)

( $\mathrm{kg} \mathrm{CO}_{2}$ eq.(100 year))

Eutrophication

( $\mathrm{kg} \mathrm{PO}_{4}^{3}$-eq.)

Abiotic Depletion - Fossil

Fuels (MJ)

Abiotic Depletion - Elements

(kg Sb eq.)

Stratospheric Ozone Depletion (kg CFC 11 eq.)

Tropospheric Ozone Formation ( $\mathrm{kg} \mathrm{C}_{2} \mathrm{H}_{4}$ eq.)

House P

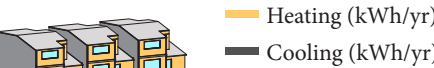

$$
\text { - Fan (kWh/yr) }
$$

Acidification (Land and Water) (kg SO${ }_{2}$ eq.)

Global Warming (100 year) ( $\mathrm{kg} \mathrm{CO}_{2}$ eq.(100 year))

Eutrophication

( $\mathrm{kg} \mathrm{PO}{ }_{4}^{3}$-eq.)

Abiotic Depletion - Fossil

Fuels (MJ)

Abiotic Depletion - Elements

(kg Sb eq.)

Stratospheric Ozone Depletion (kg CFC 11 eq.)

Tropospheric Ozone Formation

(kg C $\mathrm{H}_{4}$ eq.)

House W

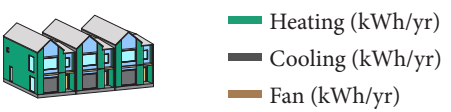

Acidification (Land and Water) ( $\mathrm{kg} \mathrm{SO}_{2}$ eq.)

Global Warming (100 year)

(kg CO 2 eq.(100 year))

Eutrophication

( $\mathrm{kg} \mathrm{PO}_{4}{ }^{3}$-eq.)

Abiotic Depletion - Fossil

Fuels (MJ)

Abiotic Depletion - Elements

(kg Sb eq.)

Stratospheric Ozone Depletion

(kg CFC 11 eq.)

Tropospheric Ozone Formation (kg C $\mathrm{H}_{4}$ eq.)

$8.85 \mathrm{E}+02$

$1.58 \mathrm{E}+05$

$1.99 \mathrm{E}+02$

$1.03 \mathrm{E}+06$

6.59E-01

3.45E-03

$6.40 \mathrm{E}+0$
Building Code

Minimum

$\begin{array}{ll} & \text { R-value } \\ \text { Roof } & 2.9 \\ \text { Walls } & 1.9 \\ \text { Floor } & 1.9 \\ \text { Glazing } & 0.26 \quad \text { Total energy use }\end{array}$

BRANZ

Better

$\begin{array}{ll} & \text { R-valu } \\ \text { Roof } & 3.3 \\ \text { Walls } & 2.3 \\ \text { Floor } & 2.0 \\ \text { Glazing } & 0.26\end{array}$

$$
\mathrm{kWh} / \mathrm{yr}
$$

916

$9.03 \mathrm{E}+02$

$1.58 \mathrm{E}+05$

$1.96 \mathrm{E}+02$

$1.06 \mathrm{E}+06$

$6.55 \mathrm{E}-01$

3.19E-03

Minimum $\quad$ Maximum $\quad 8.96 \mathrm{E}+02$

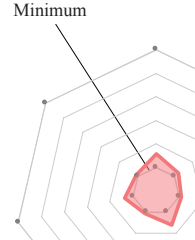

$1.57 \mathrm{E}+05$

$1.95 \mathrm{E}+02$

$1.05 \mathrm{E}+06$

6.53E-01

$3.18 \mathrm{E}-03$

$6.38 \mathrm{E}+0$

$-1 \%$

$6.42 \mathrm{E}+01$

Average percentag ifference of environmental impacts from House $\mathrm{H}$

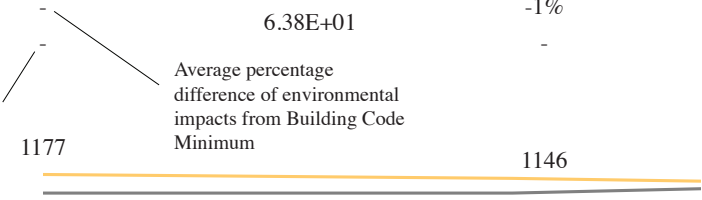

$1.02 \mathrm{E}+03$

$1.85 \mathrm{E}+05$

$2.24 \mathrm{E}+02$

$1.24 \mathrm{E}+06$

7.17E-01

3.72E-03

$7.69 \mathrm{E}+0$

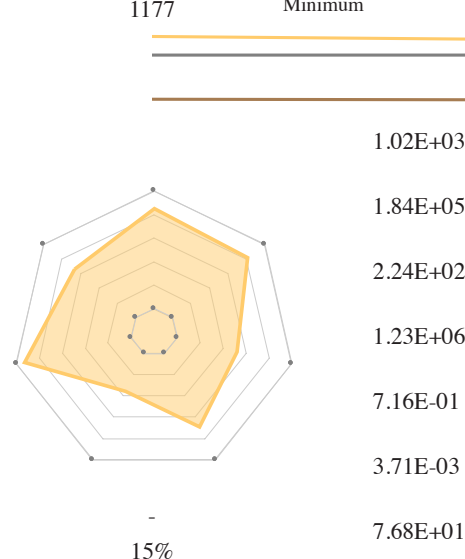

$1.84 \mathrm{E}+05$

$2.24 \mathrm{E}+02$

$.23 \mathrm{E}+06$

16E-01

71E-03

$68 \mathrm{E}+0$

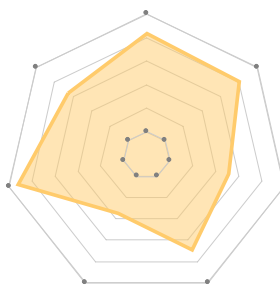

$0 \%$

$16 \%$

609

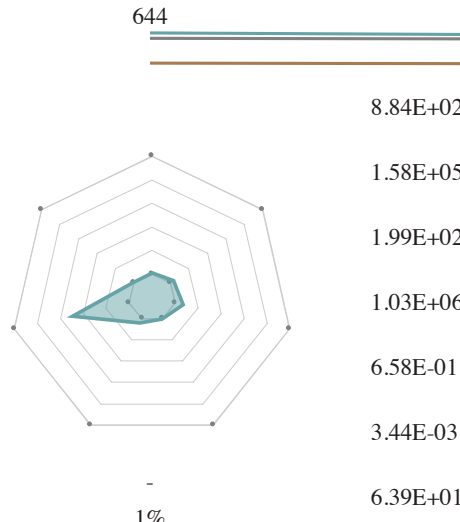

$84 \mathrm{E}+02$

$58 \mathrm{E}+05$

$99 \mathrm{E}+02$

$.03 \mathrm{E}+06$

$58 \mathrm{E}-01$

$6.39 \mathrm{E}+01$

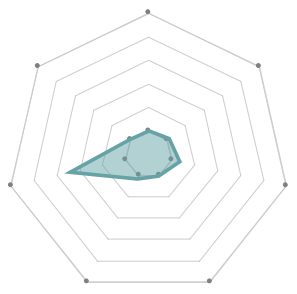

$0 \%$

$1 \%$ 
Findings

\begin{tabular}{|c|c|c|c|c|c|}
\hline \multicolumn{2}{|c|}{$\begin{array}{c}\text { BRANZ } \\
\text { Best }\end{array}$} & \multicolumn{2}{|c|}{ Passivhaus } & \multicolumn{2}{|c|}{$\begin{array}{l}\text { Voluntary } \\
\text { Standard }\end{array}$} \\
\hline & $R$-value & & $R$-value & & $\mathrm{R}$-value \\
\hline Roof & 3.7 & Roof & 3.3 & Roof & \\
\hline Walls & 4.2 & Walls & 3.3 & Walls & 5 \\
\hline Floor & 3.1 & Floor & 3.3 & Floor & 4.5 \\
\hline Glazing & 0.6 & Glazing & 0.81 & Glazing & 0.81 \\
\hline
\end{tabular}

\begin{tabular}{l|llllll} 
& \multicolumn{1}{c}{8} & \\
\hline & & & \\
\hline
\end{tabular}

561

571

532

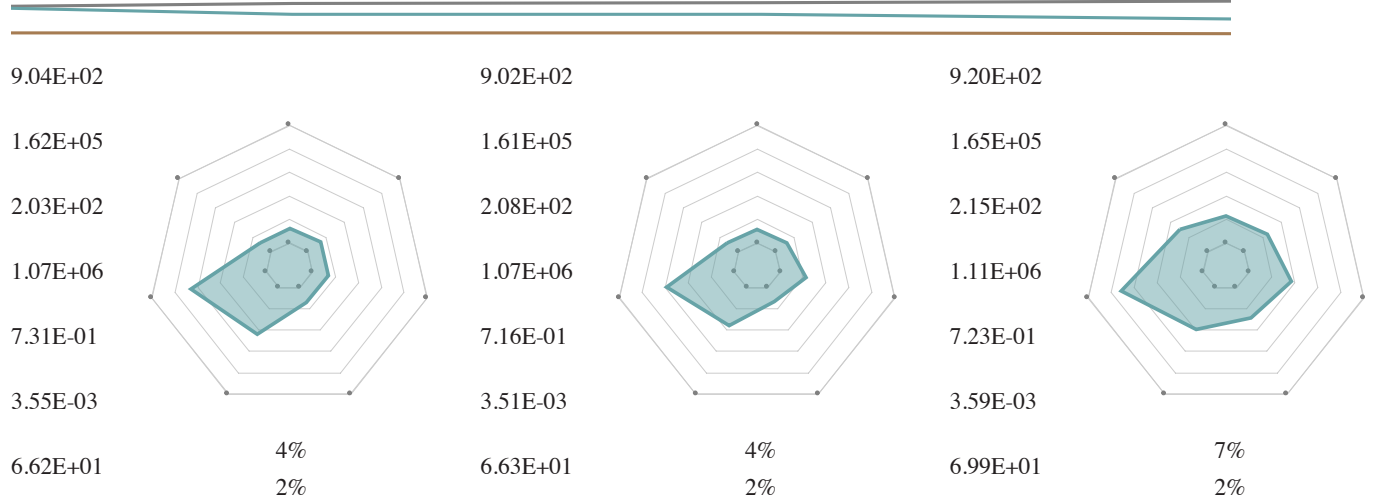




\subsection{Another climate - Christchurch}

Auckland is a warm climate where buildings require little heating energy compared to other parts of New Zealand. To see what happens to environmental impact in a cooler climate where more heating is required, the houses were simulated in Christchurch, New Zealand, which has more extreme weather events in both the summer and winter. Although the New Zealand Building Code states different Rvalues for elements in Christchurch. For modelling simplicity and analysis purposes, the Building Code minimum R-values used for the Christchurch houses remained the same as the Auckland houses.

\subsubsection{End energy use}

First, the houses with Building Code minimum R-values were simulated, these houses resulted in double the energy for space heating when compared to Auckland, which is as expected. Lighting, electrical equipment and hot water end energy use remain the same.

Table 56 Percentage breakdown of annual end energy use between houses Auckland and Christchurch

\begin{tabular}{|c|c|c|c|c|c|c|}
\hline & \multirow{2}{*}{$\begin{array}{c}\text { Auckland } \\
\text { House H }\end{array}$} & \multicolumn{5}{|c|}{ Christchurch } \\
\hline & & House P & House W & House H & House P & House W \\
\hline $\begin{array}{l}\text { Total } \\
\text { Energy } \\
\text { Use } \\
\text { (kWh/yr) }\end{array}$ & 9002 & 9882 & 9326 & 10547 & 11366 & 10473 \\
\hline $\mathrm{kWh} / \mathrm{m} 2 . \mathrm{yr}$ & 73 & 79 & 69 & 86 & 91 & 78 \\
\hline $\begin{array}{l}\text { Space } \\
\text { heating }\end{array}$ & $11 \%(8)$ & $12 \%(9)$ & $7 \%(5)$ & $24 \%(20)$ & $23 \%(21)$ & $17 \%(13)$ \\
\hline \multirow[t]{2}{*}{ Lighting } & $12 \%(8)$ & $12 \%(9)$ & $13 \%(9)$ & $10 \%(8)$ & $10 \%(9)$ & $12 \%(9)$ \\
\hline & $35 \%(26)$ & $38 \%(30)$ & $39 \%(27)$ & $30 \%(26)$ & $33 \%(30)$ & $35 \%(27)$ \\
\hline
\end{tabular}




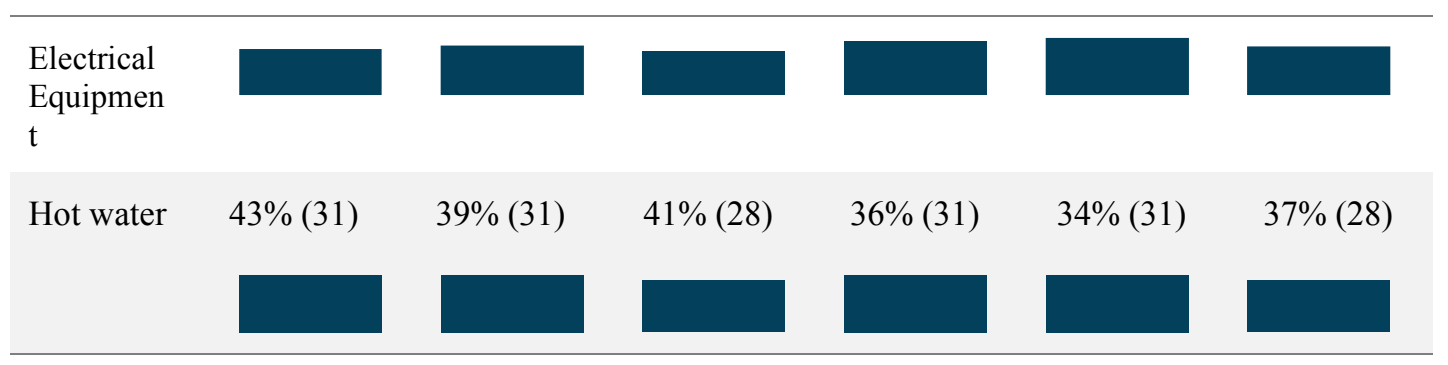

Graphing the breakdown of the heating and cooling energy use over the two locations and construction changes show a significant increase in heating for Christchurch for all buildings (Figure 65). Cooling energy follows the same trends in Auckland and Christchurch, increase as more insulation is added due to overheating in Figure 66.

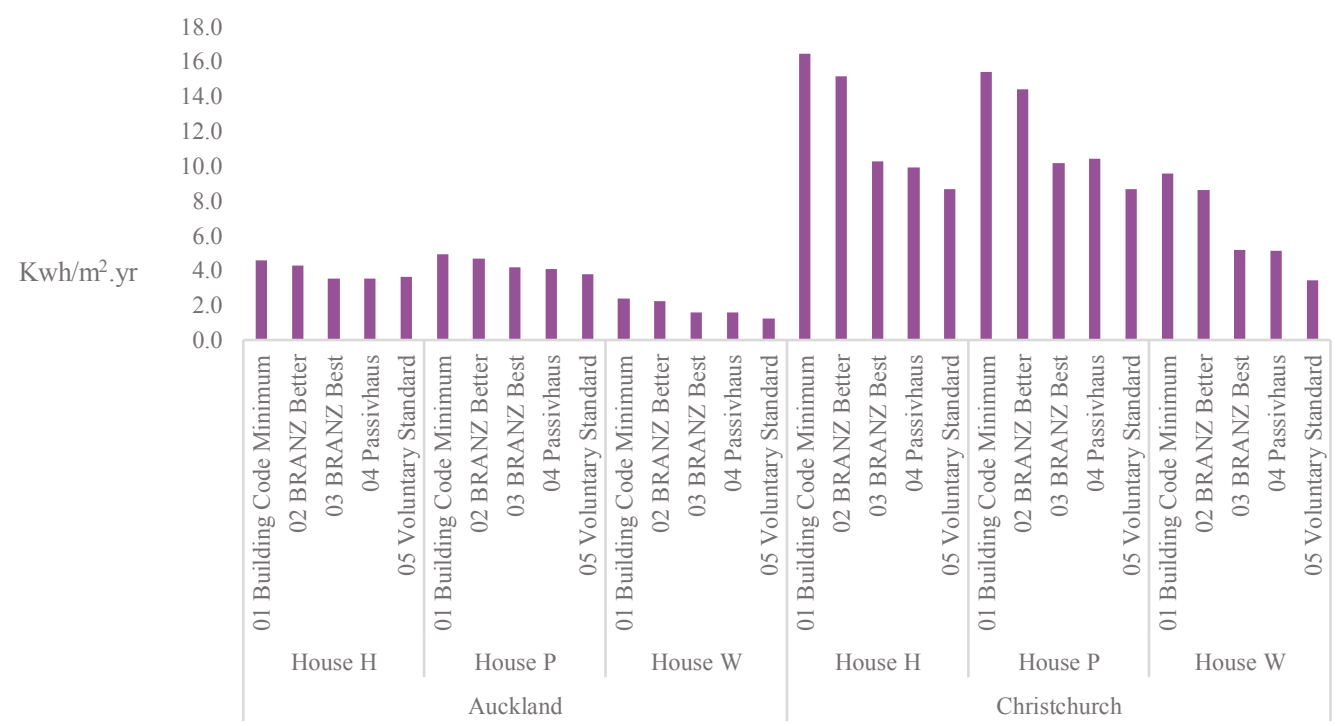

Figure 65 Annual heating energy use for all houses and changes - Auckland and Christchurch 


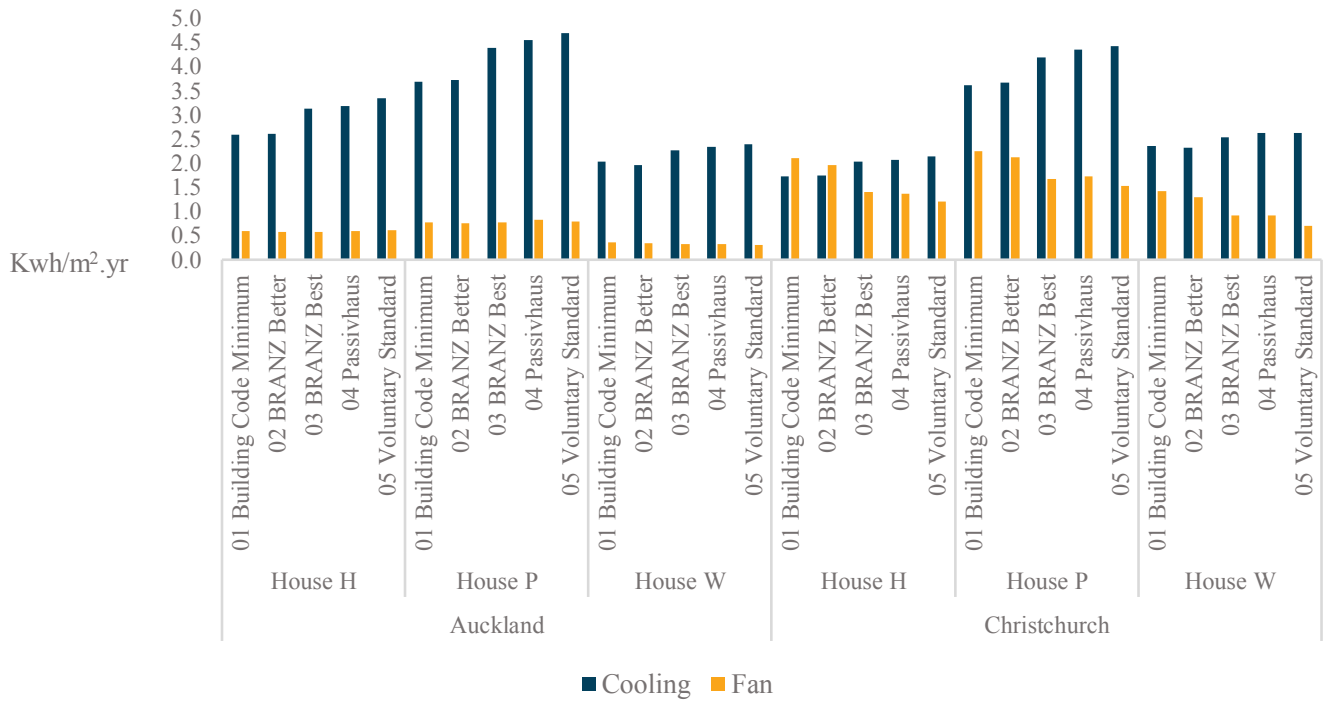

Figure 66 Annual cooling and fan energy use for all houses and changes Auckland and Christchurch

Similarly to Auckland, the total space heating end energy use decreases as more insulation is added to the building however the difference in energy use to Building Code minimum shown in Table 57 is greater than Auckland due to the differences in climate. At Voluntary Standard, Auckland experiences an average difference of 7\% whereas Christchurch is $40 \%$. When comparing differences in house design, there is an average $8 \%$ difference in Auckland compared to $11 \%$ in Christchurch shown in Table 58 .

Table 57 Difference in heating/cooling energy use from Building Code minimum All climates

\begin{tabular}{lllllll}
\hline & House & $\begin{array}{l}\text { Building } \\
\text { Code } \\
\text { minimum }\end{array}$ & $\begin{array}{l}\text { BRANZ } \\
\text { Better }\end{array}$ & $\begin{array}{l}\text { BRANZ } \\
\text { Best }\end{array}$ & Passivhaus & $\begin{array}{l}\text { Voluntary } \\
\text { Standard }\end{array}$ \\
\hline Auckland & House H & - & $-4 \%$ & $-7 \%$ & $-6 \%$ & $-2 \%$ \\
& House P & - & $-3 \%$ & $0 \%$ & $1 \%$ & $-2 \%$ \\
& House W & - & $-4 \%$ & $-12 \%$ & $-12 \%$ & $-17 \%$ \\
& Average & - & $-4 \%$ & $-6 \%$ & $-5 \%$ & $-7 \%$ \\
\hline \multirow{2}{*}{ Christchurch } & House H & - & $-7 \%$ & $-33 \%$ & $-34 \%$ & $-41 \%$ \\
& House P & - & $-5 \%$ & $-25 \%$ & $-22 \%$ & $-31 \%$ \\
\hline
\end{tabular}




\begin{tabular}{|c|c|c|c|c|c|c|}
\hline & House W & - & $-8 \%$ & $-35 \%$ & $-35 \%$ & $-49 \%$ \\
\hline & Average & - & $-7 \%$ & $-31 \%$ & $-31 \%$ & $-40 \%$ \\
\hline & House & $\begin{array}{l}\text { Building } \\
\text { Code } \\
\text { minimum }\end{array}$ & $\begin{array}{l}\text { BRANZ } \\
\text { Better }\end{array}$ & $\begin{array}{l}\text { BRANZ } \\
\text { Best }\end{array}$ & Passivhaus & $\begin{array}{l}\text { Voluntary } \\
\text { Standard }\end{array}$ \\
\hline \multirow[t]{4}{*}{ Auckland } & House H & - & - & - & - & - \\
\hline & House P & $22 \%$ & $23 \%$ & $30 \%$ & $30 \%$ & $23 \%$ \\
\hline & House W & $-39 \%$ & $-39 \%$ & $-42 \%$ & $-43 \%$ & $-48 \%$ \\
\hline & Average & $-9 \%$ & $-8 \%$ & $-6 \%$ & $-6 \%$ & $-13 \%$ \\
\hline \multirow[t]{4}{*}{ Christchurch } & House H & - & - & - & - & - \\
\hline & House P & $5 \%$ & $7 \%$ & $17 \%$ & $24 \%$ & $22 \%$ \\
\hline & House W & $-34 \%$ & $-35 \%$ & $-37 \%$ & $-35 \%$ & $-44 \%$ \\
\hline & Average & $-15 \%$ & $-14 \%$ & $-10 \%$ & $-5 \%$ & $-11 \%$ \\
\hline
\end{tabular}

\subsubsection{Life Cycle Assessment analysis}

The environmental impacts for the Auckland homes are shown in Figure 67 and Christchurch in Figure 68 using the same scale as one another. First, comparing environmental impact between locations, Auckland houses have a lower environmental impact than Christchurch as Christchurch houses require more space heating energy. Auckland has lower impacts than Christchurch when comparing between construction changes.

For Auckland, BRANZ Better had the lowest impact for each house and each environmental indicator except one. In Christchurch, the lowest impact moves around between BRANZ Best, Passivhaus and Voluntary Standard, as shown in Table 61. The reason this shift has occurred beyond BRANZ Better is that there is a higher heating energy demand in Christchurch because of cooler temperatures than Auckland. The shift shows that higher R-values are required to have a lower environmental impact in Christchurch, whereas, in Auckland, low R-values are required.

In Auckland, the average difference in environmental impact between insulation changes ranged from -1 to $7 \%$. In Christchurch, this ranges from -2 to $2 \%$. The house 
designs average difference in environmental impact in Auckland ranged from 21 to $22 \%$ and Christchurch 22 to $23 \%$ (Table 60 ). The difference confirms that the house design is more significant than changing the insulation levels in both Auckland and Christchurch.

Table 59 Average difference of all seven environmental indicators from Building Code minimum - All climates

\begin{tabular}{|c|c|c|c|c|c|c|}
\hline Location & House & $\begin{array}{l}\text { Building } \\
\text { Code } \\
\text { minimum }\end{array}$ & $\begin{array}{l}\text { BRANZ } \\
\text { Better }\end{array}$ & $\begin{array}{l}\text { BRANZ } \\
\text { Best }\end{array}$ & Passivhaus & $\begin{array}{l}\text { Voluntary } \\
\text { Standard }\end{array}$ \\
\hline \multirow[t]{4}{*}{ Auckland } & House H & - & $-1 \%$ & $2 \%$ & $3 \%$ & $6 \%$ \\
\hline & House P & - & $0 \%$ & $4 \%$ & $4 \%$ & $7 \%$ \\
\hline & House W & - & $0 \%$ & $4 \%$ & $4 \%$ & $7 \%$ \\
\hline & Average & & $0 \%$ & $3 \%$ & $3 \%$ & $7 \%$ \\
\hline \multirow[t]{4}{*}{ Christchurch } & House H & - & $-1 \%$ & $-2 \%$ & $-2 \%$ & $-1 \%$ \\
\hline & House P & - & $-1 \%$ & $0 \%$ & $0 \%$ & $2 \%$ \\
\hline & House W & - & $-1 \%$ & $0 \%$ & $0 \%$ & $2 \%$ \\
\hline & Average & & $-1 \%$ & $-1 \%$ & $-1 \%$ & $1 \%$ \\
\hline
\end{tabular}

Table 60 Average difference of all seven environmental indicators from House $\boldsymbol{H}$ All climates

\begin{tabular}{|lllllll}
\hline Location & House & $\begin{array}{l}\text { Building } \\
\text { Code } \\
\text { minimum }\end{array}$ & $\begin{array}{l}\text { BRANZ } \\
\text { Better }\end{array}$ & $\begin{array}{l}\text { BRANZ } \\
\text { Best }\end{array}$ & Passivhaus & $\begin{array}{l}\text { Voluntary } \\
\text { Standard }\end{array}$ \\
\hline Auckland & House H & - & - & - & - & - \\
& House P & $13 \%$ & $14 \%$ & $15 \%$ & $15 \%$ & $15 \%$ \\
& House W & $-8 \%$ & $-7 \%$ & $-6 \%$ & $-7 \%$ & $-7 \%$ \\
& $\begin{array}{l}\text { Difference } \\
\text { from } \\
\text { minimum } \\
\text { to } \\
\text { maximum }\end{array}$ & $21 \%$ & $21 \%$ & $21 \%$ & $22 \%$ & $22 \%$ \\
\hline \multirow{2}{*}{ Christchurch } & & & & & & \\
\hline & House H & - & - & - & - & - \\
\hline
\end{tabular}


Findings

\begin{tabular}{|c|c|c|c|c|c|}
\hline House W & $-11 \%$ & $-10 \%$ & $-8 \%$ & $-8 \%$ & $-8 \%$ \\
\hline $\begin{array}{l}\text { Difference } \\
\text { from } \\
\text { minimum } \\
\text { to } \\
\text { maximum }\end{array}$ & $22 \%$ & $23 \%$ & $22 \%$ & $23 \%$ & $23 \%$ \\
\hline
\end{tabular}




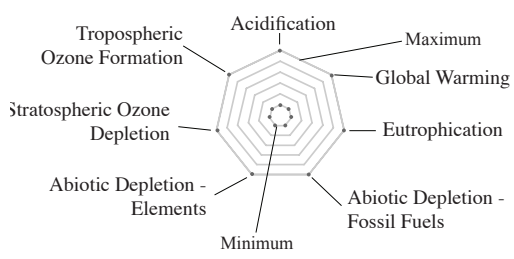

\begin{tabular}{|c|c|}
\hline \multicolumn{2}{|c|}{ Building Code } \\
\hline & $R$-value \\
\hline Roof & 2.9 \\
\hline Walls & 1.9 \\
\hline Floor & 1.9 \\
\hline Glazing & 0.26 \\
\hline
\end{tabular}

BRANZ

Better

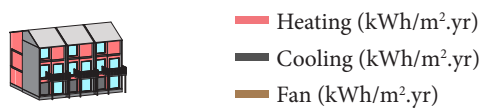

$$
\begin{aligned}
& \text { Total energy use } \\
& \mathrm{kWh} / \mathrm{m}^{2} . \mathrm{yr}
\end{aligned}
$$

$7.7-7.4$

Acidification (Land and Water) ( $\mathrm{kg} \mathrm{SO}_{2}$ eq.)

Global Warming (100 year)

( $\mathrm{kg} \mathrm{CO}$ eq.(100 year))

Eutrophication

$\left(\mathrm{kg} \mathrm{PO}{ }_{4}^{3}\right.$-eq. $)$

Abiotic Depletion - Fossil

Fuels (MJ)

Abiotic Depletion - Elements

(kg Sb eq.)

Stratospheric Ozone Depletion (kg CFC 11 eq.)

Tropospheric Ozone Formation

( $\mathrm{kg} \mathrm{C}_{2} \mathrm{H}_{4}$ eq.)

House P

$7.33 \mathrm{E}+00$

$1.29 \mathrm{E}+03$

$1.59 \mathrm{E}+00$

$8.63 \mathrm{E}+03$

5.32E-03

2.59E-05

Minimum $\quad$ Maximum $\quad 7.28 \mathrm{E}+00$

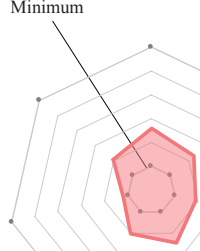

$7.28 \mathrm{E}+00$

Roof $\quad 3.3$

Walls $\quad 2.3$

Floor $\quad 2.0$

Glazing $\quad 0.26$

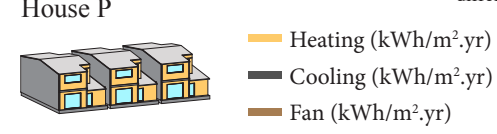

Acidification (Land and Water) (kg SO $\mathrm{S}_{2}$ eq.)

Global Warming (100 year) (kg CO eq.(100 year)

Eutrophication

( $\mathrm{kg} \mathrm{PO}{ }_{4}^{3}$-eq.)

Abiotic Depletion - Fossil

Fuels (MJ)

Abiotic Depletion - Elements

(kg Sb eq.)

Stratospheric Ozone Depletion (kg CFC 11 eq.)

Tropospheric Ozone Formation

( $\mathrm{kg} \mathrm{C}_{2} \mathrm{H}_{4}$ eq.)

House W

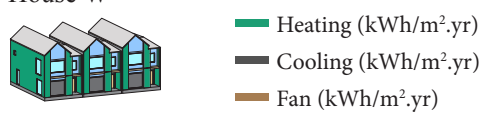

Acidification (Land and Water) (kg SO $\mathrm{S}_{2}$ eq.)

Global Warming (100 year)

(kg CO 2 eq.(100 year))

Eutrophication

( $\mathrm{kg} \mathrm{PO}_{4}{ }^{3}$-eq.)

Abiotic Depletion - Fossil

Fuels (MJ)

Abiotic Depletion - Elements

(kg Sb eq.)

Stratospheric Ozone Depletion

(kg CFC 11 eq.)

Tropospheric Ozone Formation

( $\mathrm{kg} \mathrm{C}_{2} \mathrm{H}_{4}$ eq.)
$8.15 \mathrm{E}+00$

$1.48 \mathrm{E}+03$

1.79E+00

$9.87 \mathrm{E}+03$

5.73E-03

2.97E-05

$6.15 \mathrm{E}-01$ vironmental macts from House $\mathrm{H}$ j

$1.27 \mathrm{E}+03$

$1.58 \mathrm{E}+00$

8.49E+03

$5.30 \mathrm{E}-03$

2.59E-05

$5.18 \mathrm{E}-01$

$-1 \%$

Average percentage difference of environmental impacts from Building Code Minimum 
Findings

\begin{tabular}{|c|c|c|c|c|c|}
\hline \multicolumn{2}{|c|}{$\begin{array}{c}\text { BRANZ } \\
\text { Best }\end{array}$} & \multicolumn{2}{|c|}{ Passivhaus } & \multicolumn{2}{|c|}{$\begin{array}{l}\text { Voluntary } \\
\text { Standard }\end{array}$} \\
\hline & R-value & & $\mathrm{R}$-value & & R-value \\
\hline Roof & 3.7 & Roof & 3.3 & Roof & \\
\hline Walls & 4.2 & Walls & 3.3 & Walls & 5 \\
\hline Floor & 3.1 & Floor & 3.3 & Floor & 4.5 \\
\hline Glazing & 0.6 & Glazing & 0.81 & Glazing & 0.81 \\
\hline
\end{tabular}

\begin{tabular}{llll}
\hline \hline 7.30E+00 & & & \\
\hline
\end{tabular}
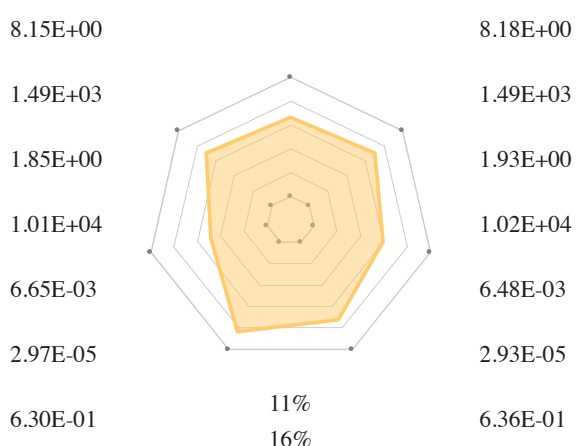

$8.34 \mathrm{E}+00$

$6.30 \mathrm{E}-01$

$\begin{array}{ll}11 \% & 6.36 \mathrm{E}-01 \\ 16 \% & \end{array}$

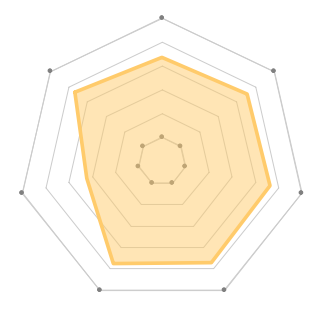

$1.53 \mathrm{E}+03$

$2.01 \mathrm{E}+00$

$1.06 \mathrm{E}+04$

$6.55 \mathrm{E}-03$

3.01E-05

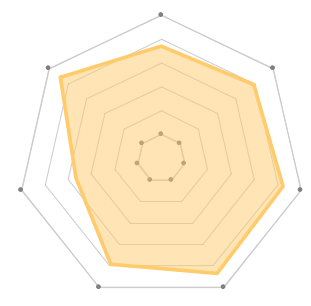

$4 \%$
$15 \%$

6.69E-01

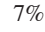

$15 \%$

\begin{tabular}{llll}
\hline & & & \\
\hline
\end{tabular}




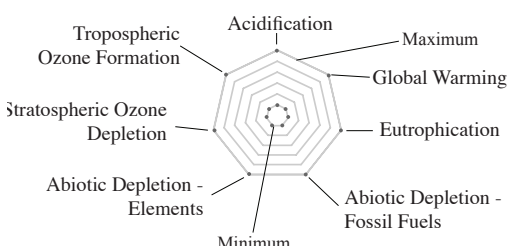

House $\mathrm{H}$

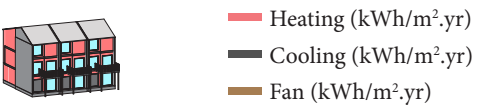

Acidification (Land and Water) ( $\mathrm{kg} \mathrm{SO}_{2}$ eq.)

Global Warming (100 year)

( $\mathrm{kg} \mathrm{CO}_{2}$ eq.(100 year))

Eutrophication

( $\mathrm{kg} \mathrm{PO}_{4}^{3}$-eq.)

Abiotic Depletion - Fossil

Fuels (MJ)

Abiotic Depletion - Elements

(kg Sb eq.)

Stratospheric Ozone Depletion (kg CFC 11 eq.)

Tropospheric Ozone Formation ( $\mathrm{kg} \mathrm{C}_{2} \mathrm{H}_{4}$ eq.)

House P

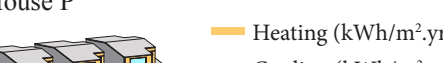
Cooling $\left(\mathrm{kWh} / \mathrm{m}^{2} . \mathrm{yr}\right)$

$$
\text { - Fan }\left(\mathrm{kWh} / \mathrm{m}^{2} . \mathrm{yr}\right)
$$

Acidification (Land and Water) (kg SO${ }_{2}$ eq.)

Global Warming (100 year)

( $\mathrm{kg} \mathrm{CO}_{2}$ eq.(100 year))

Eutrophication

( $\mathrm{kg} \mathrm{PO}_{4}{ }^{3}$-eq.)

Abiotic Depletion - Fossil

Fuels (MJ)

Abiotic Depletion - Elements

(kg Sb eq.)

Stratospheric Ozone Depletion (kg CFC 11 eq.)

Tropospheric Ozone Formation

(kg C $\mathrm{H}_{4}$ eq.)

House W

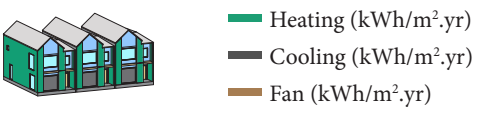

Acidification (Land and Water) (kg SO 2 eq.)

Global Warming (100 year)

(kg CO 2 eq.(100 year))

Eutrophication

( $\mathrm{kg} \mathrm{PO}_{4}{ }^{3}$-eq.)

Abiotic Depletion - Fossil

Fuels (MJ)

Abiotic Depletion - Elements

(kg Sb eq.)

Stratospheric Ozone Depletion

(kg CFC 11 eq.)

Tropospheric Ozone Formation

(kg $\mathrm{C}_{2} \mathrm{H}_{4}$ eq.)

$1.44 \mathrm{E}+03$

$9.43 \mathrm{E}+03$

5.97E-03

3.02E-05

\section{Building Code \\ Minimum}

$\begin{array}{ll} & \text { R-value } \\ \text { Roof } & 2.9 \\ \text { Walls } & 1.9 \\ \text { Floor } & 1.9 \\ \text { Glazing } & 0.26\end{array}$

BRANZ

Better

$\begin{array}{ll} & \text { R-val } \\ \text { Roof } & 3.3 \\ \text { Walls } & 2.3 \\ \text { Floor } & 2.0 \\ \text { Glazing } & 0.26\end{array}$

18.

$8.06 \mathrm{E}+00$

$8.18 \mathrm{E}+00$

$1.80 \mathrm{E}+00$

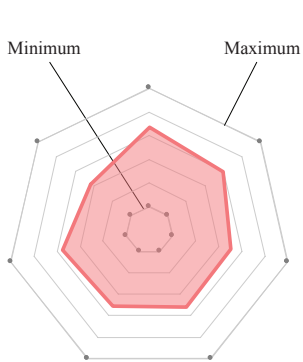

$1.41 \mathrm{E}+03$

$1.77 \mathrm{E}+00$

$9.23 \mathrm{E}+03$

5.89E-03

2.99E-05

5.63E-01

$-1 \%$

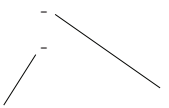

verage percentage difference of environmental

impacts from Building Code

21.3 Minimum

$8.96 \mathrm{E}+00$

$1.62 \mathrm{E}+03$

$1.99 \mathrm{E}+00$

$1.07 \mathrm{E}+04$

6.35E-03

3.41E-05

6.62E-01

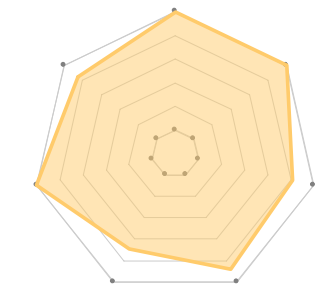

$1.61 \mathrm{E}+03$

$1.97 \mathrm{E}+00$

$1.06 \mathrm{E}+04$

6.30E-03

3.38E-05

$6.58 \mathrm{E}-0$

$12 \%$

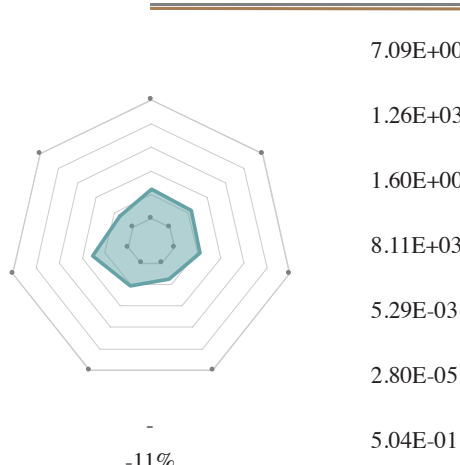

$.26 \mathrm{E}+03$

$1.60 \mathrm{E}+00$

8.11E+03

E-03

$5.04 \mathrm{E}-01$

$-1 \%$

$-10 \%$

Figure 68 Environmental impact for each environmental indicator - Christchurch 
Findings

\begin{tabular}{|c|c|c|c|c|c|}
\hline \multicolumn{2}{|c|}{$\begin{array}{c}\text { BRANZ } \\
\text { Best }\end{array}$} & \multicolumn{2}{|c|}{ Passivhaus } & \multicolumn{2}{|c|}{$\begin{array}{l}\text { Voluntary } \\
\text { Standard }\end{array}$} \\
\hline & $\mathrm{R}$-value & & $\mathrm{R}$-value & & R-value \\
\hline Roof & 3.7 & Roof & 3.3 & Roof & \\
\hline Walls & 4.2 & Walls & 3.3 & Walls & 5 \\
\hline Floor & 3.1 & Floor & 3.3 & Floor & 4.5 \\
\hline Glazing & 0.6 & Glazing & 0.81 & Glazing & 0.81 \\
\hline
\end{tabular}
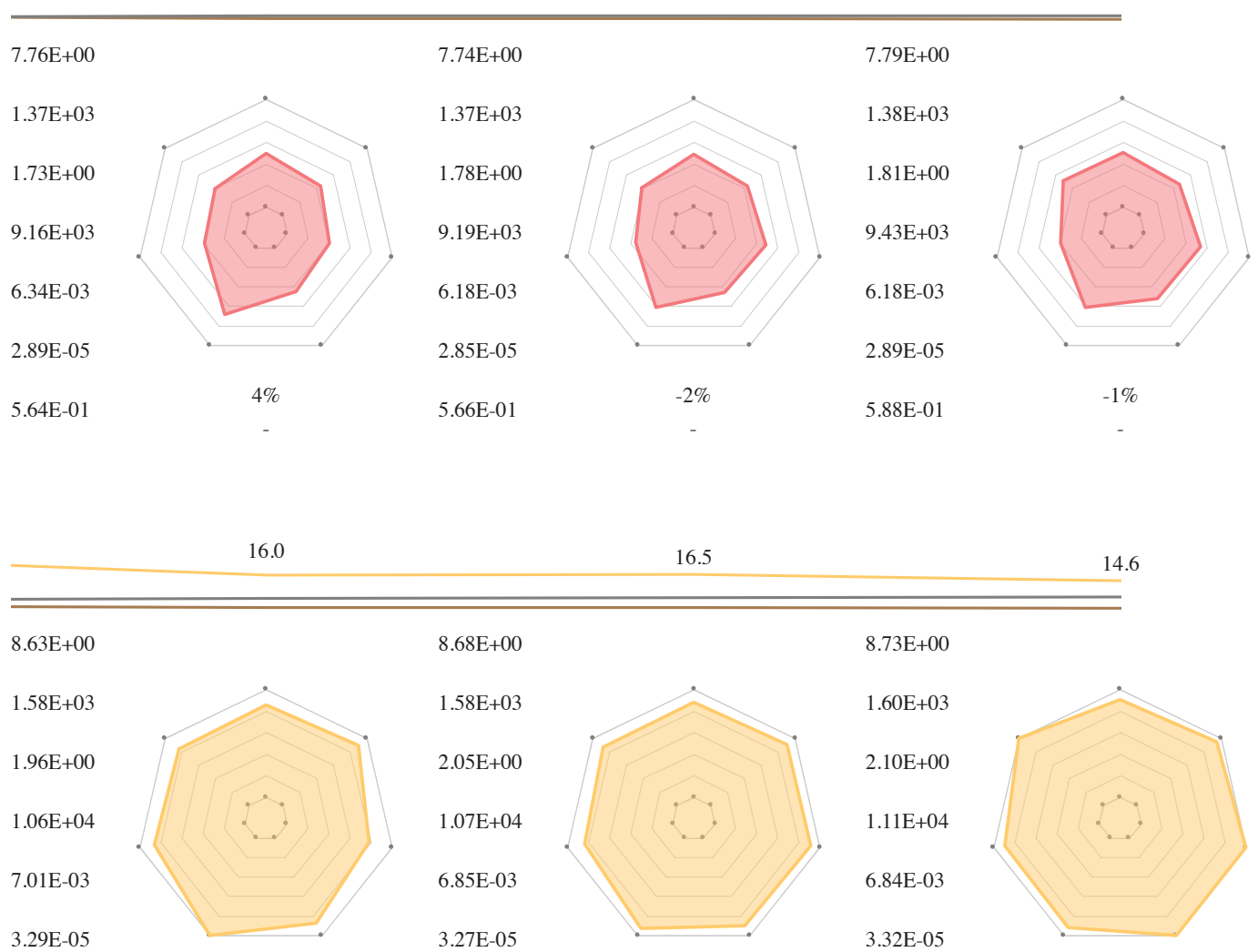

$8.68 \mathrm{E}+00$

$8.73 \mathrm{E}+00$

$6.60 \mathrm{E}-01$

$\begin{array}{cc}7 \% & 6.67 \mathrm{E}-01 \\ 15 \% & \end{array}$

$1.58 \mathrm{E}+03$
$2.05 \mathrm{E}+00$
$1.07 \mathrm{E}+04$
$6.85 \mathrm{E}-03$
$3.27 \mathrm{E}-05$
$6.67 \mathrm{E}-01$

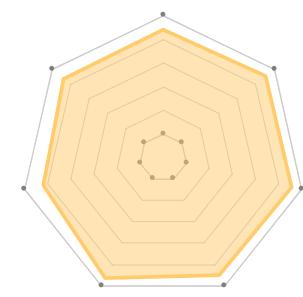

$1.60 \mathrm{E}+03$

$2.10 \mathrm{E}+00$

$1.11 \mathrm{E}+04$

6.84E-03

3.32E-05

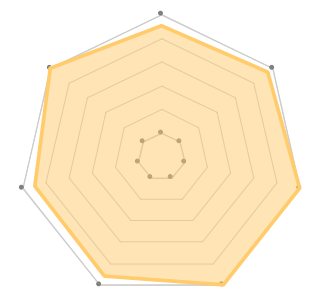

$0 \%$

6.95E-01

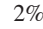

$15 \%$

\begin{tabular}{|c|c|c|c|c|c|}
\hline & 8.6 & & 8.7 & & 6.8 \\
\hline $7.03 \mathrm{E}+00$ & & $7.02 \mathrm{E}+00$ & & $7.04 \mathrm{E}+00$ & \\
\hline $1.26 \mathrm{E}+03$ & & $1.25 \mathrm{E}+03$ & & $1.26 \mathrm{E}+03$ & \\
\hline $1.58 \mathrm{E}+00$ & & $1.62 \mathrm{E}+00$ & & $1.65 \mathrm{E}+00$ & \\
\hline $8.25 \mathrm{E}+03$ & & $8.23 \mathrm{E}+03$ & & $8.50 \mathrm{E}+03$ & \\
\hline $5.67 \mathrm{E}-03$ & & $5.56 \mathrm{E}-03$ & & $5.53 \mathrm{E}-03$ & \\
\hline $2.82 \mathrm{E}-05$ & & $2.79 \mathrm{E}-05$ & & $2.82 \mathrm{E}-05$ & \\
\hline \multirow[t]{2}{*}{$5.10 \mathrm{E}-01$} & $5 \%$ & \multirow{2}{*}{$5.11 \mathrm{E}-01$} & $0 \%$ & \multirow{2}{*}{ 5.33E-01 } & $2 \%$ \\
\hline & $-9 \%$ & & $-8 \%$ & & $-8 \%$ \\
\hline
\end{tabular}


Table 61 Environmental impact of construction changes for each environmental indicator and house per m2 of GFA - Christchurch (Percentage increase/decrease in comparison to Building Code minimum)

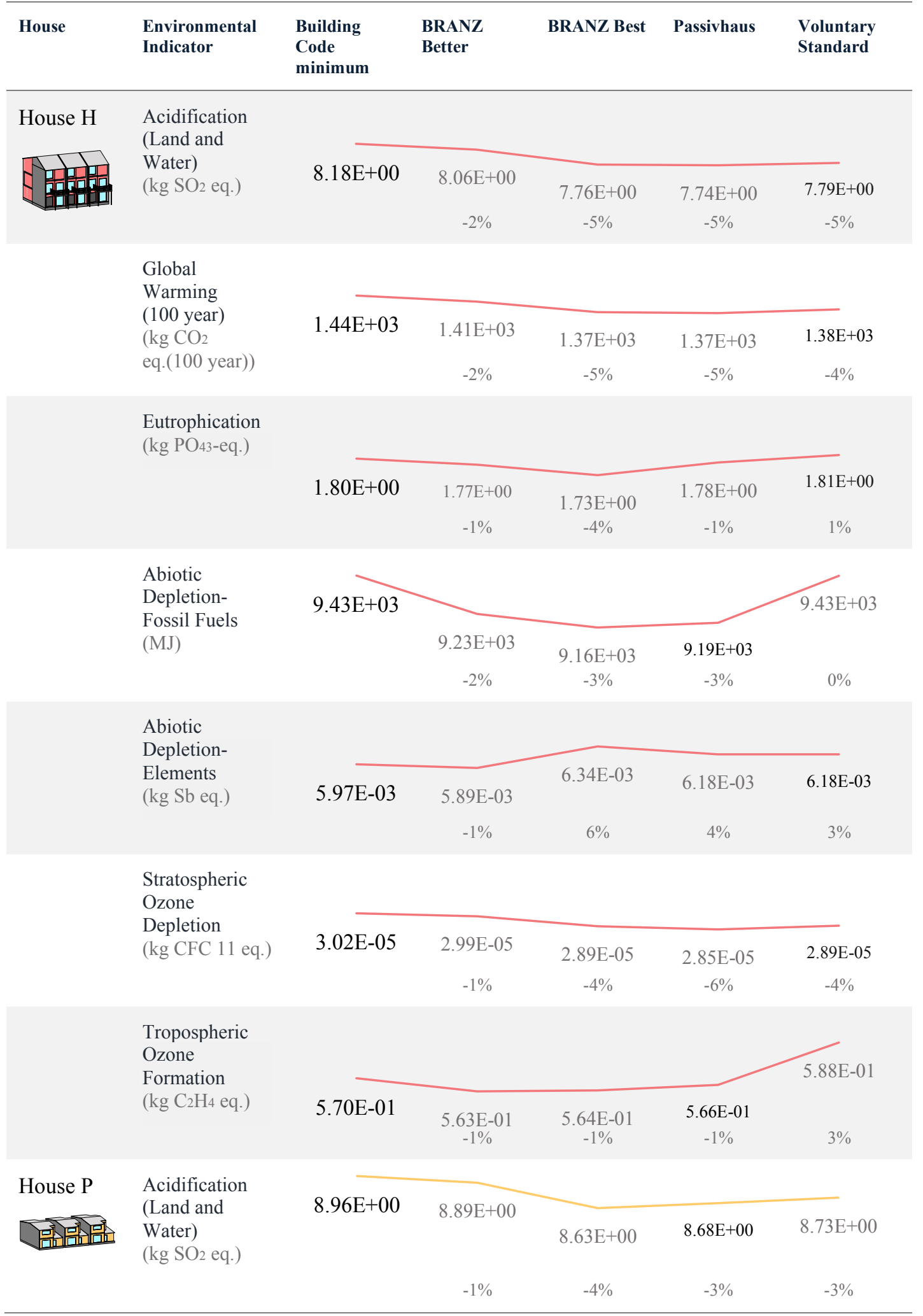




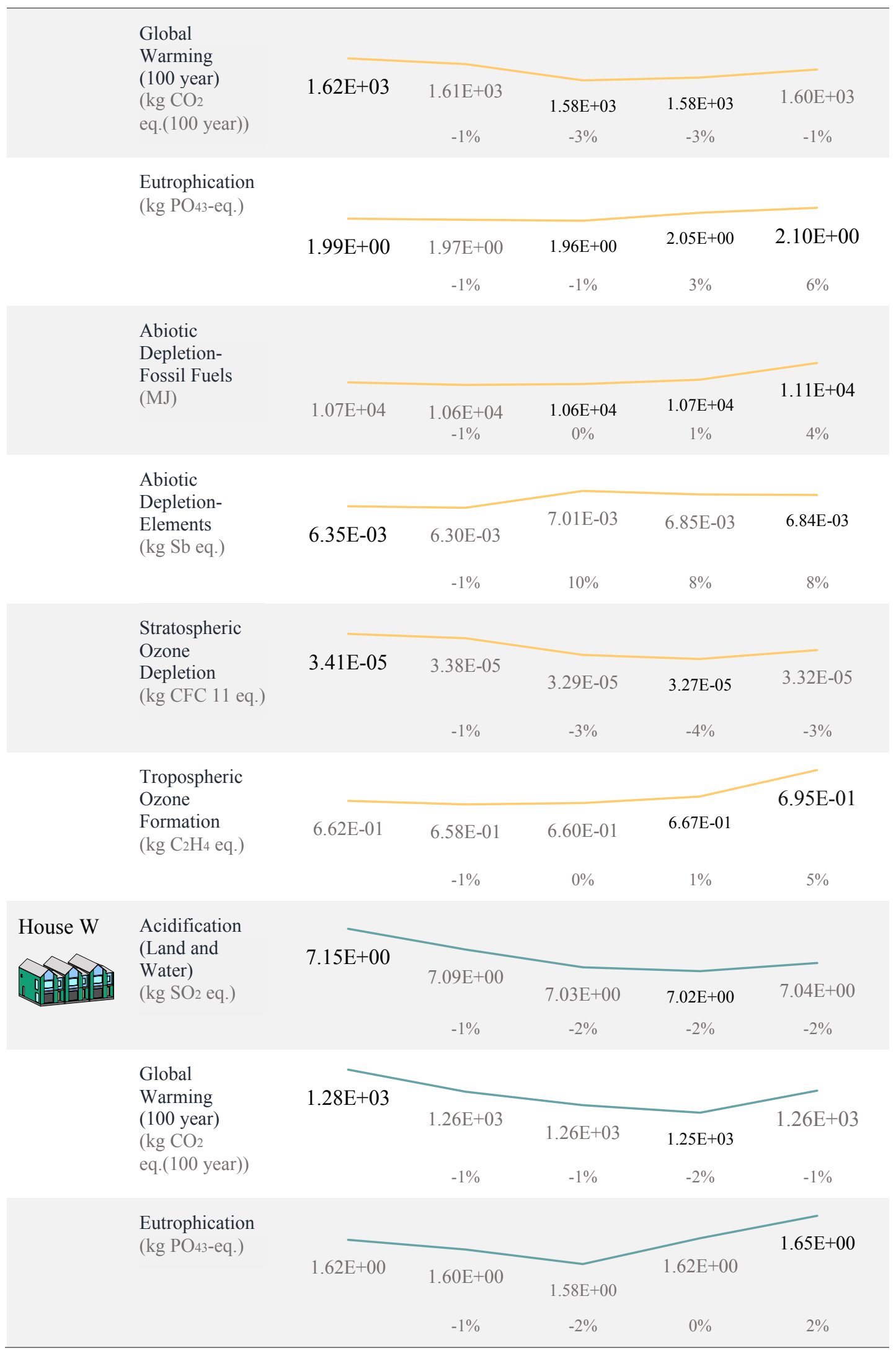




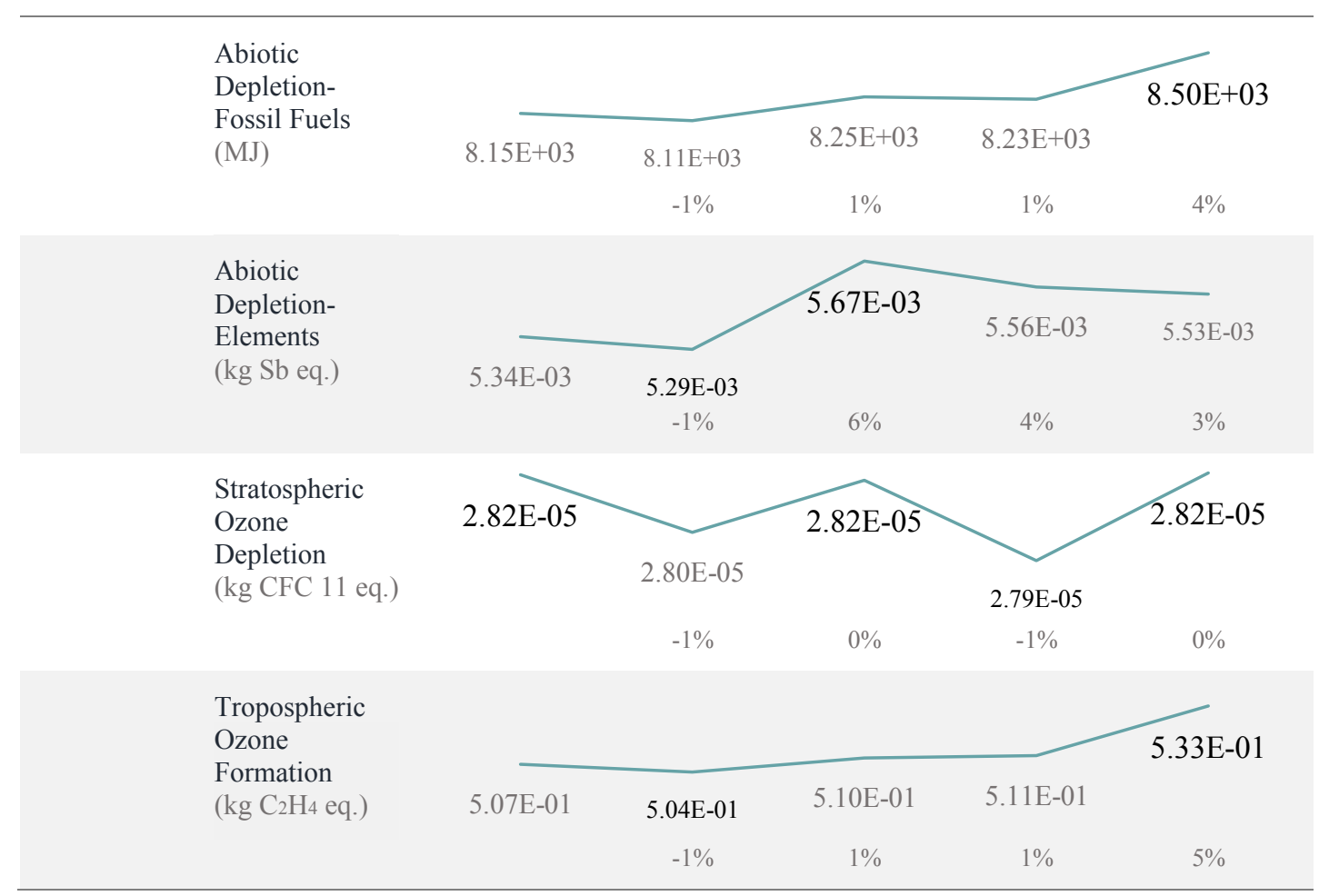

\subsection{Green Star innovation challenge}

New Zealand Green Building Council (NZGBC) Green Star innovation challenge, material life cycle impact assessment, provides an alternative method of analysis to the above methods. Applying the NZGBC method to the selected houses, the houses total cumulative percentage reduction (sum of all environmental indicator reductions and increases) was calculated compared to a reference building.

This method calculates the number of points that can be contributed to a building's Green Star rating. One point out of a maximum of five is awarded per $20 \%$ cumulative reduction. A total of five points are awarded when the cumulative buildings reduction is $100 \%$ or higher. If one of the environmental indicators increases by more than $10 \%$, then no points are awarded (BRANZ, 2019a).

Applying this method to all three houses in Auckland across each construction change using Building Code minimum as the reference building in Table 62 shows BRANZ Better is the only construction change to have a reduction in environmental impact, but this impact is small ranging from 1 to $5 \%$. The other construction changes all have an increase in environmental impact. The increase aligns to the findings from previous sections with Voluntary Standard having the largest environmental increase ranging from 39 to $49 \%$. In Christchurch, changes in environmental impact are not the 
same as in Auckland. For House $\mathrm{H}$ in Table 63, all designs have a reduction in impact compared to Building Code minimum with BRANZ Better having the largest reduction and Passivhaus the largest increase in environmental impact.

Table 62 Point awarded using NZGBC compared to Building Code minimum Auckland (points awarded (cumulative reduction \% - a negative percentage shows an environmental increase))

\begin{tabular}{llllll}
\hline & $\begin{array}{l}\text { Building Code } \\
\text { minimum (As } \\
\text { reference) }\end{array}$ & $\begin{array}{l}\text { BRANZ } \\
\text { Better }\end{array}$ & BRANZ Best & Passivhaus & $\begin{array}{l}\text { Voluntary } \\
\text { Standard }\end{array}$ \\
\hline House H & - & $0.25(5 \%)$ & $0(-17 \%)$ & $0(-18 \%)$ & $0(-39 \%)$ \\
House P & - & $0.06(1 \%)$ & $0(-25 \%)$ & $0(-27 \%)$ & $0(-49 \%)$ \\
House W & - & $0.05(1 \%)$ & $0(-27 \%)$ & $0(-26 \%)$ & $0(-48 \%)$ \\
\hline
\end{tabular}

Table 63 Point awarded using NZGBC compared to Building Code minimum Christchurch (points awarded (cumulative reduction \% - a negative percentage shows an environmental increase))

\begin{tabular}{llllll}
\hline & $\begin{array}{l}\text { Building Code } \\
\text { minimum (As } \\
\text { reference) }\end{array}$ & $\begin{array}{l}\text { BRANZ } \\
\text { Better }\end{array}$ & BRANZ Best & Passivhaus & $\begin{array}{l}\text { Voluntary } \\
\text { Standard }\end{array}$ \\
\hline House H & - & $0.52(10 \%)$ & $0.80(16 \%)$ & $0.83(17 \%)$ & $0(5 \%)$ \\
House P & - & $0.24(5 \%)$ & $0(1 \%)$ & $0(-3 \%)$ & $0(-16 \%)$ \\
House W & - & $0.28(6 \%)$ & $0(-2 \%)$ & $0(-1 \%)$ & $0(-13 \%)$
\end{tabular}

Using House $\mathrm{H}$ as a reference building for the other two houses shows that House W has the largest environmental decrease and House $\mathrm{P}$ the largest increase across all construction changes for both Auckland and Christchurch in Table 64 and Table 65.

Table 64 Point awarded using NZGBC compared to House H - Auckland (points awarded (cumulative reduction \% - a negative percentage shows an environmental increase))

\begin{tabular}{llllll}
\hline & $\begin{array}{l}\text { Building Code } \\
\text { minimum }\end{array}$ & $\begin{array}{l}\text { BRANZ } \\
\text { Better }\end{array}$ & BRANZ Best & Passivhaus & $\begin{array}{l}\text { Voluntary } \\
\text { Standard }\end{array}$ \\
\hline $\begin{array}{l}\text { House H (As } \\
\text { reference) }\end{array}$ & - & - & - & - & - \\
House P & $0(-93 \%)$ & $0(-98 \%)$ & $0(-102 \%)$ & $0(-103 \%)$ & $0(-104 \%)$ \\
\hline
\end{tabular}




\begin{tabular}{llllll}
\hline House W & $2.76(55 \%)$ & $2.58(52 \%)$ & $2.27(45 \%)$ & $2.40(48 \%)$ & $2.37(47 \%)$ \\
\hline $\begin{array}{l}\text { Table } 65 \text { Point awarded using NZGBC compared to House H - Christchurch } \\
\text { (points awarded (cumulative reduction } \% \text { - a negative percentage shows an } \\
\text { environmental increase)) }\end{array}$ \\
$\begin{array}{llllll}\text { Building Code } \\
\text { minimum }\end{array}$ & $\begin{array}{l}\text { BRANZ } \\
\text { Better }\end{array}$ & BRANZ Best & Passivhaus & $\begin{array}{l}\text { Voluntary } \\
\text { Standard }\end{array}$ \\
\hline $\begin{array}{l}\text { House H (As } \\
\text { reference) }\end{array}$ & - & - & - & - & - \\
$\begin{array}{l}\text { House P } \\
\text { House W }\end{array}$ & $0(-81 \%)$ & $0(-87 \%)$ & $0(-97 \%)$ & $0(-103 \%)$ & $0(-105 \%)$ \\
\hline
\end{tabular}

An issue with this analysis is that it uses the cumulative reduction which means it does not consider each environmental indicator individually which increases the likelihood of a building design reducing its impact in one environmental indicator but inadvertently increasing in another. This issue is what this study was aimed at avoiding. The potential for hiding these counter-influencing impacts is a flaw in any method of assessment like the NZGBC method.

\subsection{Summary of results}

This analysis of three houses with four construction changes in two locations shows three key points:

1. The design of the house has a more significant impact on reducing environmental impact compared to changes to the thermal envelope. Changes to the buildings' insulation levels resulted in an average change in environmental impact across the seven indicators ranging from -1 to $7 \%$ in Auckland and -2 to $2 \%$ in Christchurch whereas differences in the design resulted in a decrease of 21 to $22 \%$ in Auckland and 22 to $23 \%$. The change in environmental impact indicates that regardless of what level of insulation is used in the building at the levels simulated, changing the design of the building will have a more significant effect on the environmental impact. The three cases selected for their wide variation in design, but a similar 
provision of accommodation, have been sufficient to demonstrate this trend. As for space heating end energy use, the figures are different with an average decrease at Voluntary Standard levels of insulation of $7 \%$ in Auckland and $40 \%$ in Christchurch whereas differences in the house designs resulted in an average energy decrease of $8 \%$ and $11 \%$ in Auckland and Christchurch. The differences show that energy can be significantly decreased through different insulation levels and house design. From an energy cost perspective, this leads to lower heating/cooling bills but an increase in environmental impact.

2. Increasing the thermal resistance of the thermal envelope decreases space heating energy as expected, but the additional materials cause an increase in environmental impact. For both locations, exceeding the New Zealand Building Code minimum R-value requirements causes a reduction in environmental impact. For Auckland, BRANZ Better, which is a slight increase to the Building Code minimum R-values causes the least environmental impact for each house. Whereas in Christchurch, the optimum ranges from insulation levels in between BRANZ Best and Voluntary Standard depending on house design. The change in optimum insulation is because Christchurch is a cooler climate requiring more heating energy than Auckland. Increasing the $\mathrm{R}$-values above these levels mentioned causes environmental impacts to increase due to the additional material impact versus the change in impact from a reduction of energy use.

3. The process created and presented in this study can be used to show the environmental differences between different design choices. When comparing multiple designs with multiple environmental indicators, this data created is immense. The testing of this process shows that it is possible to assess the difference in the environmental impact of multiple designs and buildings with a range of environmental indicators. This process can show small differences in environmental impact between designs allowing designers to make a judgement on which design is best suited for their context. 
A Life Cycle Assessment of Medium Density Houses in New Zealand 


\section{Chapter 6}

\section{Discussion and Conclusions}

The main aim of this study was to test the methodology of taking designer's 3D CAD models and conducting an LCA on these and the process of analysis. The study has demonstrated that this can be done and provide useful information for design issues that designers are currently facing. This research has investigated the basis of all the information available to the author and discussed the rationale behind each process to show why each decision was made. The next time this process is completed, it should be far quicker as this study can act as a guide for each step and help reduce the necessary quality assurance steps.

The systematic literature review identified 20 studies, but no study documented all the following data that is essential to the analysis being replicated:

- material impacts,

- resultant operational energy use,

- change in materials,

- multiple environmental indicators,

- the rationale behind the selected building,

- quality assurance of the results,

- presentation of model inputs and all results.

This study is unique because it includes all these aspects in sufficient detail for the process to be tested and replicated. The placement of the models, the cross-references to the input data, and the raw output data in an online Open Science Framework repository should encourage the wider examination of more than just the insulation levels tested here. For example, the analysis of MDH to define a range of typical buildings for evidence-based policy analysis can begin with the analysis in Chapter 3 of this study. 


\subsection{Building Information Modelling process}

Designers' issues with conducting LCAs are partly due to lack of knowledge and time. This study presents input data with references and rationale related to the energy model for a New Zealand context, which can be used by designers as a database for their own energy models to resolve these issues. There is still an issue of having to create a separate energy model and not have this integrated into the BIM modelling process, which is due to limitations of the process of exporting from Revit to Grasshopper. If this were possible, together with the database of values, this would remove a barrier to implementation of LCA into a designers' workflow. If this issue was resolved, this would allow designers to make changes to the BIM model and have the energy model update in real-time, eliminating the need to create a unique energy model in other software. This automation would be quicker and allow consistency between LCA and energy models as they are using the same data. The problem of learning new software for energy modelling is a disincentive for designers' implementation of LCA in their workflow, so this issue needs to be resolved in future.

The LCA BIM model is created using a common 3D CAD software which allows for improved LCA integration. However, multiple designs cannot easily be simulated as each design needs to be manually created both in Revit and Energyplus, adding to the overall time of the process

Assessment of the results is a significant barrier to implementation of LCA for designers due to a lack of knowledge on how to assess a building's environmental impact and assess multiple designs. Together with multiple environmental indicators, this creates a large amount of data which can be overwhelming for designers. Designers do not wish to read extensive reports on LCA data for each building. This process resolves this by showing the results of each building visually allowing designers to understand the impact each building has. This visual analysis using radar diagrams allows designers to compare different designs of buildings with one another quickly but also allows for an in-depth evaluation of each environmental indicator if the designer chooses to do so. Visual identification of problem areas in the building was outside the scope of this study. Assessment and development of the graphic presentation beyond the level shown in this study requires feedback from a range of 
practitioners but is more a development question for the next phase of this project than future research.

The process created resolves a number of the issues that designers identify as a barrier to implementation of LCA in their workflow identified in Zabalza Bribián et al. (2009), but several issues remain, in particular, the manual process of creating and running an energy simulation in a third party software. If this issue is resolved and integrated into the process created, this will allow for the implementation of LCA by designers.

\subsection{Medium Density Housing}

MDH was selected as a housing type to test this process because of predictions of its rise over the next ten years due to an increase in demand for housing. Selecting MDH case study houses was a problem; however, as there are no datasets available to assist with defining typical examples of these types of buildings. This study has developed and tested a method to select case study houses which can be applied to any housing type. The method involves determining common qualities from a sample of randomly selected MDH. It is the first step towards a more systematic development of a prototypical MDH exemplar for benchmarking and policy development. As this study has demonstrated, the development of a range of prototypes should enable a far more robust analysis than a single exemplar.

\subsection{Life Cycle Assessment findings}

The critical difference in the environmental analysis between this study and others is that it uses multiple environmental indicators, more than one house, conducts construction changes and changes the material quantities in these changes. Because of all these factors, this results in a lot of data to be interpreted, assessed and presented. If the results were interpreted differently without a discussion on why this was presented, then this could lead to different and possibly incorrect findings. Decisions that were made in the analysis of the results were presented in full to minimise bias in the results.

The findings from the results can be summarised into three key points: 
1. The design of the house has a more significant impact on reducing environmental impact compared to changes to the thermal envelope. Changes to the buildings insulation levels resulted in an average change in environmental impact across the seven indicators ranging from -1 to $7 \%$ in Auckland and -2 to $2 \%$ in Christchurch. Whereas differences in the design resulted in a decrease of 21 to $22 \%$ in Auckland and 22 to $23 \%$. Energy use decreased with more insulation added to the building (7\% in Auckland and 40\% in Christchurch). Changing the design of the building resulted in a reduction of $8 \%$ in Auckland and $11 \%$ in Christchurch.

2. Increasing the thermal resistance of the thermal envelope decreases space heating end energy use as expected, but the additional materials cause an increase in environmental impact when there is an excessive increase over the Building Code minimum. For both locations, exceeding the Building Code minimum R-value requirements causes a reduction in environmental impact. In Auckland, this is BRANZ Better and Christchurch BRANZ Best to Voluntary Standard insulation levels.

3. The process created and tested in this study can show differences in designs using a range of environmental indicators allowing designers to make a judgement of which design is best suited in their context.

\subsection{Further research}

This study has shown the process of conducting an LCA on a set of buildings and the analysis of the results. However, there are several aspects as a result of this study that requires further research.

Firstly, the process of creating a BIM model to generate an SoQ for LCAQuick and energy simulations is time and resource-intensive. This study spent a large portion of time ( $25 \%$ of the study period), creating these models and conducting quality assurance to ensure both models were consistent with one another (dimensions and materials). If the process were adjusted so only a single model for an SoQ and an 
energy simulation was needed to perform the LCA, this would allow for not only a quicker process but allow designers to implement LCA into their workflow.

Regarding modelling, there are differences in what is required for an architectural, energy and LCA model. Which raises the question of how to make this method routine in architectural practice?

The methodology developed was created for housing and tested on $\mathrm{MDH}$, a stage of further research for the methodology is to test this on a different type of housing like stand-alone dwellings or apartments to determine whether it can be used outside of this study.

In addition to this, the results of this study are only representative of the buildings included in this study. A further study could use the methodology developed with a larger dataset of buildings.

Finally, end-energy use of the houses is based on literature assumptions of occupant behaviour as there are no industry standards on simulating occupant behaviour. There is a need for a dataset of occupant behaviour that reflects typical behaviour rather than an ideal. 
A Life Cycle Assessment of Medium Density Houses in New Zealand 


\section{Reference List}

ASHRAE. (2005). 2005 ASHRAE Handbook Fundamentals SI Edition. Atlanta: American Society of Heating, Refrigerating, and Air-Conditioning Engineers.

Autodesk. (2018). Revit 2018.

Berg, B. (2019, 10 June).

Boland, A., Dickson, R., \& Gemma, C. (2014). Doing a systematic review: a students guide. London: SAGE.

BRANZ. (2009). Standard Window R-value Calculation Procedure (SCP). Judgeford: Building Research Association of New Zealand.

BRANZ. (2016). Bulletin Issue 596. Judgeford: Building Research Association of New Zealand.

BRANZ. (2019a). LCAQuick. Judgeford: Building Research Association of New Zealand.

BRANZ. (2019b). BRANZ CO 2 NSTRUCT. Judgeford: Building Research Association of New Zealand.

Brunsdon, N., \& Morgan, C. (2018). Physical Characteristics of New Houses 2017 SR396. Retrieved from Judgeford:

Bryson, K., \& Allen, N. (2017). Defining Medium Density Housing SR376. Judgeford: Building Research Association of New Zealand.

Burgess, J. (2007). EC1353 Accurate modification for New Zealand. Judgeford: Building Research Association of New Zealand.

Cuce, E., Cuce, P. M., Wood, C. J., \& Riffat, S. B. (2014). Optimizing insulation thickness and analysing environmental impacts of aerogel-based thermal superinsulation in buildings. Energy and Buildings, 77, 28-39. doi:10.1016/j.enbuild.2014.03.034.

Čuláková, M., \& Vilčeková, S. (2013). Comparison of material compositions of structures in terms of environmental and energy performance. Paper presented at the CESB 2013 PRAGUE - Central Europe Towards Sustainable 
Building 2013: Sustainable Building and Refurbishment for Next Generations.

D'Alessandro, F., Bianchi, F., Baldinelli, G., Rotili, A., \& Schiavoni, S. (2017).

Straw bale constructions: Laboratory, in field and numerical assessment of energy and environmental performance. Journal of Building Engineering, 11, 56-68. doi:10.1016/j.jobe.2017.03.012.

Donn, M. (2019, 7 May).

Donn, M., Elzine, B., Marc, W., Evzen, N., \& Andrew, B. (2015). Design Research: Optimising Row-House Orientation. Paper presented at the 14th Conference of International Building Performance Simulation Association, Hyderabad.

Dowdell, D. (2014). New Zealand Whole Building Whole of Life Framework: Life Cycle Assessment-based Indicators SR 293. Retrieved from Judgeford:

Dowdell, D., \& Berg, B. (2016). New Zealand whole-building whole-of-life framework: An overview SR349. Retrieved from Judgeford:

Erlandsson, M., Levin, P., \& Myhre, L. (1997). Energy and environmental consequences of an additional wall insulation of a dwelling. Building and Environment, 32(2), 129-136. doi:10.1016/S0360-1323(96)00041-8.

Estokova, A., Vilcekova, S., \& Porhincak, M. (2017). Analyzing Embodied Energy, Global Warming and Acidification Potentials of Materials in Residential Buildings. Paper presented at the Procedia Engineering.

Firedman, A. (2012). Town and Terraced Housing for Affordability and Sustainability (1st ed.). Abingdon: Routledge.

Frenette, C. D., Beauregard, R., Salenikovich, A., \& Derome, D. (2008). Multicriteria evaluation of the compositions of walls of light frame wood construction. Paper presented at the Proceedings, Annual Conference Canadian Society for Civil Engineering.

Galán-Marín, C., Rivera-Gómez, C., \& García-Martínez, A. (2015). Embodied energy of conventional load-bearing walls versus natural stabilized earth blocks. Energy and Buildings, 97, 146-154.

doi:https://doi.org/10.1016/j.enbuild.2015.03.054 
Gorshkov, A., Vatin, N., Nemova, D., Shabaldin, A., Melnikova, L., \& Kirill, P. (2015). Using life-cycle analysis to assess energy savings delivered by building insulation. Paper presented at the Procedia Engineering.

Hollberg, A., \& Ruth, J. (2016). LCA in architectural design — a parametric approach (Vol. 21).

International Organization for Standardization. (2011). ISO 21929-1:2011 Sustainability in building construction - Sustainability indicators - Part 1: Framework for the development of indicators and a core set of indicators for buildings. In. Switzerland: International Organization for Standardization.

Islam, H., Jollands, M., Setunge, S., \& Bhuiyan, M. A. (2015). Optimization approach of balancing life cycle cost and environmental impacts on residential building design. Energy \& Buildings, 87, 282-292. doi:10.1016/j.enbuild.2014.11.048.

Karami, P., Al-Ayish, N., \& Gudmundsson, K. (2015). A comparative study of the environmental impact of Swedish residential buildings with vacuum insulation panels. Energy and Buildings, 109, 183-194. doi:10.1016/j.enbuild.2015.10.031.

Kunič, R., \& Kutnar, A. (2013). Accelerated ageing and global warming potential of VIP thermal insulation. 11th International Vacuum Insulation.

Kylili, A., Ilic, M., \& Fokaides, P. A. (2017). Whole-building Life Cycle Assessment (LCA) of a passive house of the sub-tropical climatic zone. Resources, Conservation \& Recycling, 116, 169-177. doi:10.1016/j.resconrec.2016.10.010.

Laboratory, L. B. N. (Producer). (2017). WINDOW.

Liddament, M. (1996). A Guide to Energy Efficient Ventilation. Coventry: Air Infiltration and Ventilation Centre.

Liley, B., Hisako, S., Sturman, J., \& Wratt, D. (2008). Typical Meteorological Years for the New Zealand Home Energy Rating Scheme. Prepared for the Energy Efficiency and Conservation Authority. NIWA Client Report: LAU2008-01JBL. Retrieved from Omakau, New Zealand.

M Dovjak, M., M Košir, M., L Pajek, L., N Iglič, N., Božiček, D., \& Kunič, R. (2017). Environmental impact of thermal insulations: How do natural 
insulation products differ from synthetic ones? Series: Earth and Environmental Science.

MBIE. (2017). National Construction Pipeline Report 2017. A forecast of Building and Construction Activity. Retrieved from Wellington.

McNeil, S., Plagmann, M., McDowall, P., \& Bassett, M. (2015). Study Report 341. The role of ventilation in managing moisture inside New Zealand homes. Judgeford: Building Research Association of New Zealand.

Meex, E., Hollberg, A., Knapen, E., Hildebrand, L., \& Verbeeck, G. (2018). Requirements for applying LCA-based environmental impact assessment tools in the early stages of building design. Building and Environment, 133, 228-236. doi:https://doi.org/10.1016/j.buildenv.2018.02.016.

Mikulic, D., Milovanovic, B., Kolic, D., Sokacic, A., \& Simunovic, T. (2010). Environmental impact of improving energy efficiency of buildings. Paper presented at the 2nd International Conference on Sustainable Construction Materials and Technologies.

Monteiro, H. I., \& Freire, F. M. (2011). Environmental life-cycle impacts of a singlefamily house in Portugal: assessing alternative exterior walls with two methods. Gazi University Journal of Science.

Morbitzer, C. (2003). Towards the integration of simulation into the building design process. University of Strathclyde, Glasgow, UK.

Nemry, F., Uihlein, A., Colodel, C. M., Wetzel, C., Braune, A., Wittstock, B., Frech, Y. (2010). Options to reduce the environmental impacts of residential buildings in the European Union - Potential and costs. Energy and Buildings, 42(7), 976-984. doi:http://dx.doi.org/10.1016/j.enbuild.2010.01.009.

P. R. Chappell. (2013). The Climate and Weather of Auckland. Retrieved from Auckland.

Page, I. (2017). Medium Density Housing Supply and Demand Analysis SR379. Judgeford: Building Research Association of New Zealand.

Passive House Institute. (2016). Criteria for the Passive House, Enerphit and PHI Low Energy Building Standard. Retrieved from Darmstadt. 
Pathway, B. (2008). What is the Waitakere NOW Home® project? Retrieved from http://www.beaconpathway.co.nz/newhomes/article/what_is_the_waitakere_now_home_project.

Pringle, T. (2014). House Insulation Guide (Vol. 5). Judgeford: Building Research Association of New Zealand.

Proietti, S., Sdringola, P., Desideri, U., Zepparelli, F., Masciarelli, F., \& Castellani, F. (2013). LIFE CYCLE ASSESSMENT OF A PASSIVE HOUSE IN A SEISMIC TEMPERATE ZONE. Energy and Buildings, 64, 463-472.

Sherman, M. (1986). Estimation of Infiltration from Leakage and Climate Indicators. Energy and Buildings, 10, 81 - 86.

Standards New Zealand. (2006). NZS 4214:2006 Methods of Determining the Total Thermal Resistance of Parts of Buildings. Wellington: Standards New Zealand.

Standards New Zealand. (2009). NZS 4218:2009 Thermal Insulation - Housing and Small Buildings. Wellington: Standards New Zealand.

Statistics NZ. (2018). Building Consents Issued from March 2015 onwards.

US Department of Energy (Producer). (2013). EnergyPlus Energy Simulation Software.

US Department of Energy. (2017). ENERGYPLUS TM VERSION 8.8.0

DOCUMENTATION Input Output Reference. U.S. Department of Energy. U.S. Department of Energy.

Vilčeková, S., Čuláková, M., Burdová, E. K., \& Katunská, J. (2015). Energy and environmental evaluation of non-transparent constructions of building envelope for wooden houses. Energies, 8(10), 11047-11075. doi:10.3390/en81011047.

Vilćeková, S., Sedláková, A., Burdová, E. K., Čuláková, M., Geletka, V., \& Kapalo, P. (2013). Analysis of environmental aspects in high energy performance family house - Case study. Chemical Engineering Transactions, 35, 385-390. doi:10.3303/CET1335064.

Westphal, F., \& Lamberts, R. (2005). Building Simulation Calibration Using Sensitivity Analysis. Paper presented at the IBPSA, Montreal. 
White, V., \& Jones, M. (2017). Warm, dry, healthy? Insights from the 2015 House Condition Survey on insulation, ventilation, heating and mould in New Zealand houses. SR372. Judgeford: Building Research Association of New Zealand.

Zabalza Bribián, I., Aranda Usón, A., \& Scarpellini, S. (2009). Life cycle assessment in buildings: State-of-the-art and simplified LCA methodology as a complement for building certification. Building and Environment, 44(12), 2510-2520. doi:https://doi.org/10.1016/j.buildenv.2009.05.001. 
Online repository

\section{Online repository}

Data in an online Open Science Framework repository can be accessed at https://osf.io/caq3g/

This repository includes BIM and energy models of Building Code minimum houses and raw results of all scenarios. 
A Life Cycle Assessment of Medium Density Houses in New Zealand 


\section{Appendix A Literature Review}

\section{A.1 Quality assessment questions}

Table A-1 Quality assessment questions answer criteria

\begin{tabular}{|c|c|c|c|}
\hline Question & Yes (Y) & No (N) & Not Applicable (NA) \\
\hline $\begin{array}{l}\text { Was the study purpose } \\
\text { clearly stated? }\end{array}$ & $\begin{array}{l}\text { If in the introduction } \\
\text { and clear }\end{array}$ & $\begin{array}{l}\text { If the purpose is not } \\
\text { clearly stated }\end{array}$ & - \\
\hline $\begin{array}{l}\text { Was relevant } \\
\text { background literature } \\
\text { reviewed? }\end{array}$ & $\begin{array}{l}\text { If in-depth about the } \\
\text { aim }\end{array}$ & $\begin{array}{l}\text { If literature reviewed } \\
\text { but not in-depth } \\
\text { around the aim }\end{array}$ & - \\
\hline $\begin{array}{l}\text { Was the intervention } \\
\text { described in detail? }\end{array}$ & $\begin{array}{l}\text { If materials, size, } \\
\text { quantity are stated }\end{array}$ & $\begin{array}{l}\text { If not enough detail is } \\
\text { given }\end{array}$ & $\begin{array}{l}\text { No intervention is } \\
\text { used }\end{array}$ \\
\hline $\begin{array}{l}\text { Did they quality } \\
\text { assure the quantities } \\
\text { of materials for the } \\
\text { buildings? }\end{array}$ & $\begin{array}{l}\text { If material quantities } \\
\text { are presented }\end{array}$ & $\begin{array}{l}\text { If materials are not } \\
\text { presented }\end{array}$ & - \\
\hline $\begin{array}{l}\text { Did they quality } \\
\text { assure life cycle } \\
\text { indicator/environment } \\
\text { al impact data? }\end{array}$ & $\begin{array}{l}\text { If a database or } \\
\text { manufactures EPDs } \\
\text { are stated }\end{array}$ & If source not stated & - \\
\hline $\begin{array}{l}\text { Did they quality } \\
\text { assure building } \\
\text { heating and cooling } \\
\text { energy? }\end{array}$ & $\begin{array}{l}\text { If energy calculations } \\
\text { are presented }\end{array}$ & $\begin{array}{l}\text { If calculations not } \\
\text { presented }\end{array}$ & $\begin{array}{l}\text { If energy use is not } \\
\text { calculated }\end{array}$ \\
\hline $\begin{array}{l}\text { Were appropriate } \\
\text { criteria used to assess } \\
\text { environmental } \\
\text { impacts? }\end{array}$ & $\begin{array}{l}\text { If more than one } \\
\text { environmental } \\
\text { indicator is used }\end{array}$ & $\begin{array}{l}\text { If one or no indicators } \\
\text { are used }\end{array}$ & - \\
\hline $\begin{array}{l}\text { Did they present the } \\
\text { results of all the } \\
\text { simulations/calculatio } \\
\text { ns? }\end{array}$ & $\begin{array}{l}\text { If all results are } \\
\text { presented in graphs or } \\
\text { numerical form }\end{array}$ & $\begin{array}{l}\text { If not all data is } \\
\text { presented }\end{array}$ & - \\
\hline $\begin{array}{l}\text { Were they critical of } \\
\text { the environmental } \\
\text { results? }\end{array}$ & $\begin{array}{l}\text { If positives and } \\
\text { negatives are stated }\end{array}$ & $\begin{array}{l}\text { If only positives or } \\
\text { negatives are stated }\end{array}$ & $\begin{array}{l}\text { If environmental } \\
\text { impact is not assessed }\end{array}$ \\
\hline
\end{tabular}




\begin{tabular}{lll}
\hline $\begin{array}{l}\text { Were conclusions } \\
\begin{array}{l}\text { appropriate, given } \\
\text { study methods and } \\
\text { results? }\end{array}\end{array}$ & $\begin{array}{l}\text { If the conclusion } \\
\text { relates back to the } \\
\text { purpose }\end{array}$ & $\begin{array}{l}\text { If the conclusion does } \\
\text { not relate to the } \\
\text { purpose }\end{array}$ \\
$\begin{array}{l}\text { Could the study be } \\
\text { replicated with data } \\
\text { provided? }\end{array}$ & $\begin{array}{l}\text { If the schedule of } \\
\text { quantities, materials, } \\
\text { environmental data } \\
\text { and energy data are } \\
\text { presented }\end{array}$ & $\begin{array}{l}\text { If all the above are not } \\
\text { stated }\end{array}$ \\
\hline
\end{tabular}

Table A-2 Quality assessment questions answers

\begin{tabular}{|c|c|c|c|}
\hline Question & Yes & No & Not Applicable \\
\hline $\begin{array}{l}\text { Was the study purpose } \\
\text { clearly stated? }\end{array}$ & $100 \%$ & $0 \%$ & $0 \%$ \\
\hline $\begin{array}{l}\text { Was relevant background } \\
\text { literature reviewed? }\end{array}$ & $55 \%$ & $45 \%$ & $0 \%$ \\
\hline $\begin{array}{l}\text { Was the intervention } \\
\text { described in detail? }\end{array}$ & $75 \%$ & $5 \%$ & $20 \%$ \\
\hline $\begin{array}{l}\text { Did they quality assure the } \\
\text { quantities of materials for } \\
\text { the buildings? }\end{array}$ & $20 \%$ & $80 \%$ & $0 \%$ \\
\hline $\begin{array}{l}\text { Did they quality assure life } \\
\text { cycle } \\
\text { indicator/environmental } \\
\text { impact data? }\end{array}$ & $70 \%$ & $30 \%$ & $0 \%$ \\
\hline $\begin{array}{l}\text { Did they quality assure } \\
\text { building heating and } \\
\text { cooling energy? }\end{array}$ & $25 \%$ & $60 \%$ & $15 \%$ \\
\hline $\begin{array}{l}\text { Were appropriate criteria } \\
\text { used to assess } \\
\text { environmental impacts? }\end{array}$ & $80 \%$ & $20 \%$ & $0 \%$ \\
\hline $\begin{array}{l}\text { Did they present the results } \\
\text { of all the } \\
\text { simulations/calculations? }\end{array}$ & $95 \%$ & $5 \%$ & $0 \%$ \\
\hline $\begin{array}{l}\text { Were they critical of the } \\
\text { environmental results? }\end{array}$ & $70 \%$ & $25 \%$ & $5 \%$ \\
\hline $\begin{array}{l}\text { Were conclusions } \\
\text { appropriate, given study } \\
\text { methods and results? }\end{array}$ & $80 \%$ & $20 \%$ & $0 \%$ \\
\hline $\begin{array}{l}\text { Could the study be } \\
\text { replicated with data } \\
\text { provided? }\end{array}$ & $45 \%$ & $55 \%$ & $0 \%$ \\
\hline
\end{tabular}




\section{Appendix B House Drawings}

\section{B.1 House H}

$\uparrow$
$\mathrm{N}$

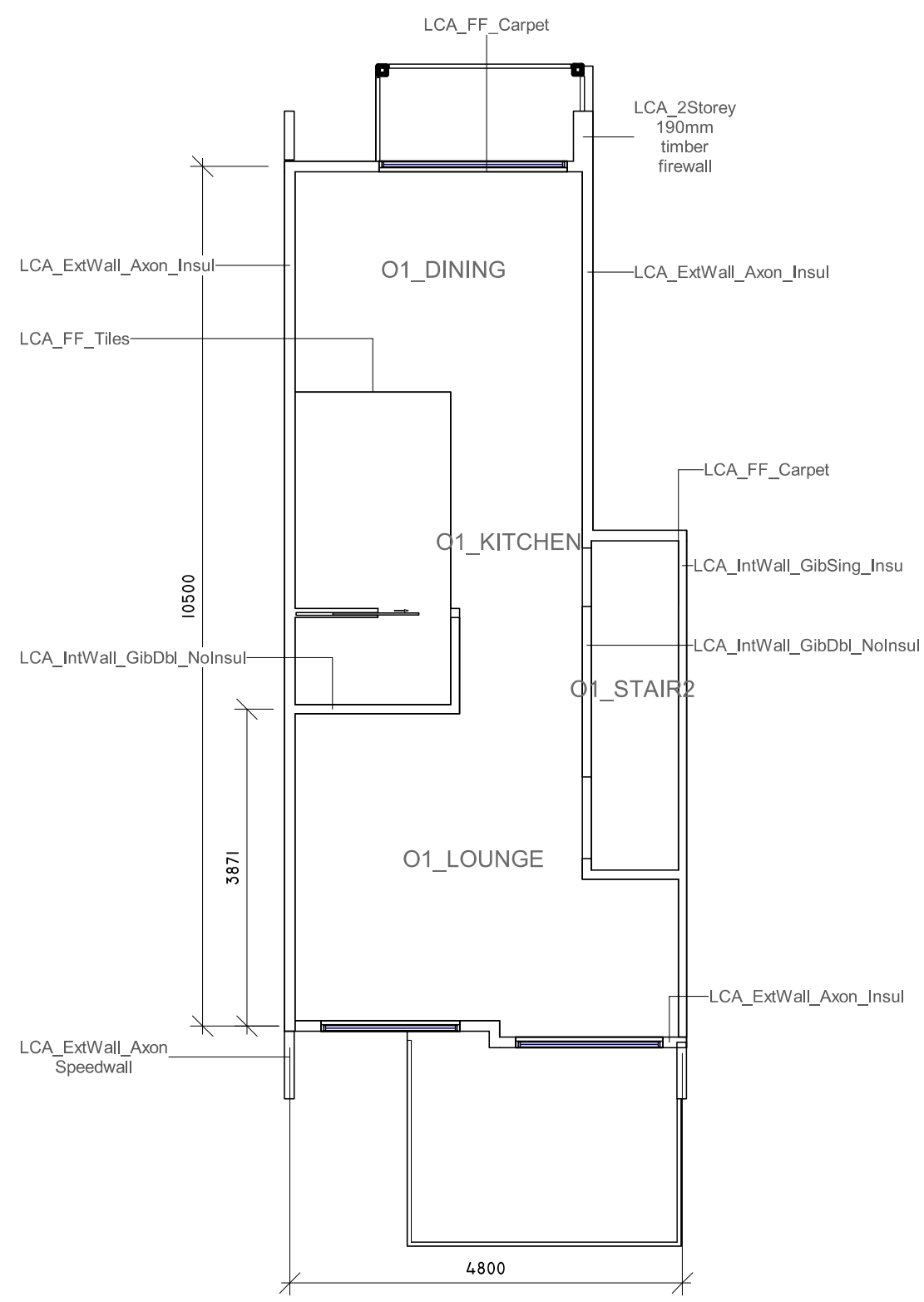

Figure B-1 House $H$ first floor plan 1:100 


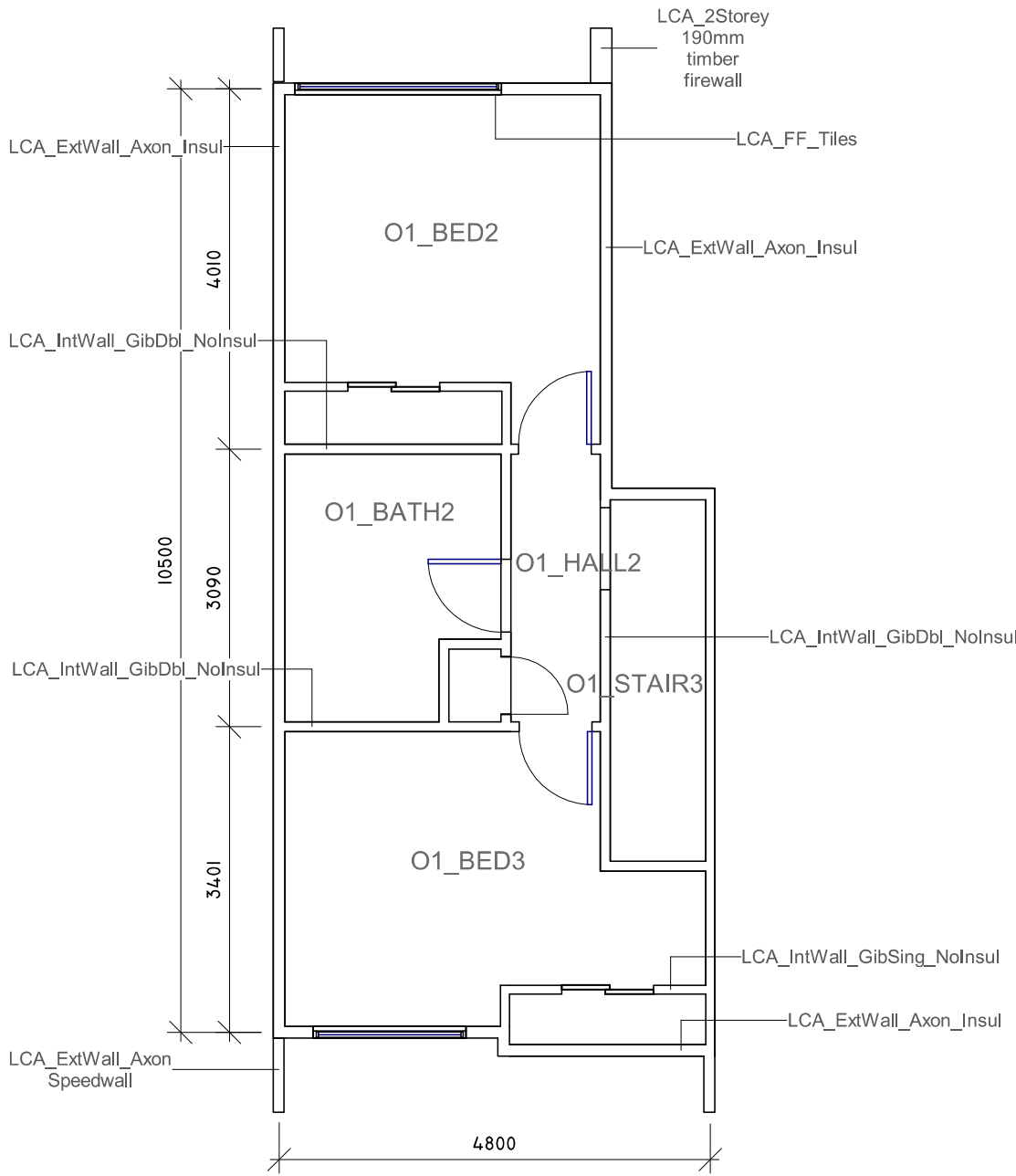

Figure B-2 House H second floor plan 1:100 
Appendix B House Drawings

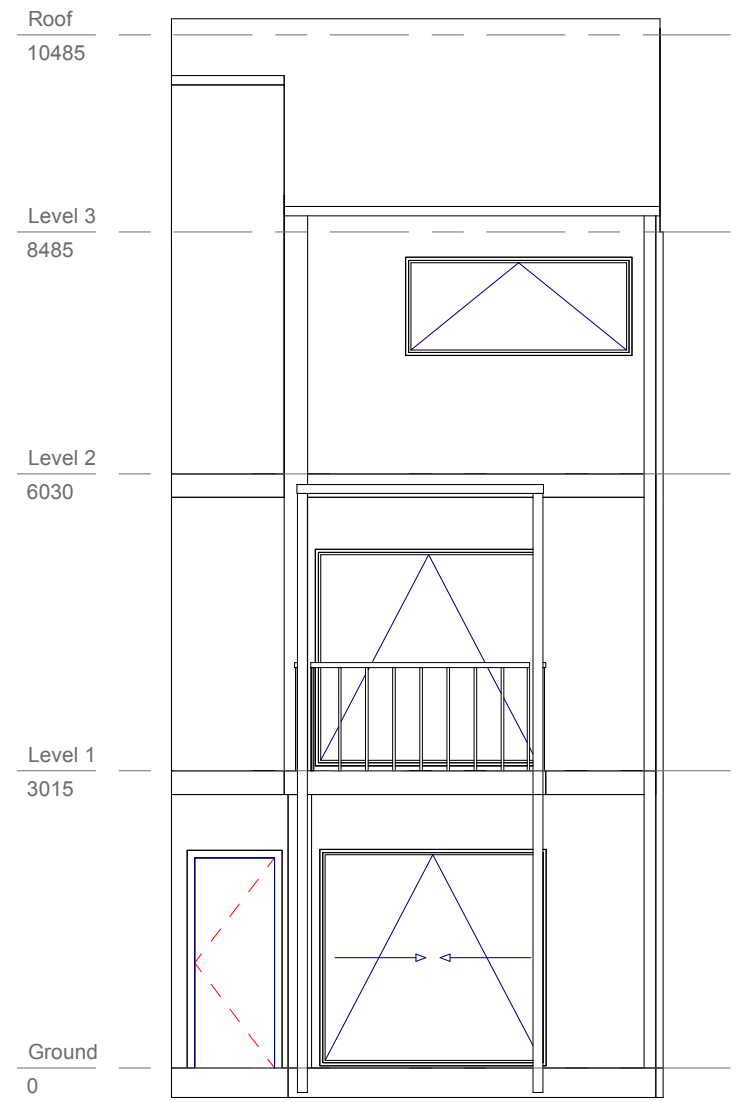

Figure B-3 House H north elevation 1:100

B-3 
A Life Cycle Assessment of Medium Density Houses in New Zealand

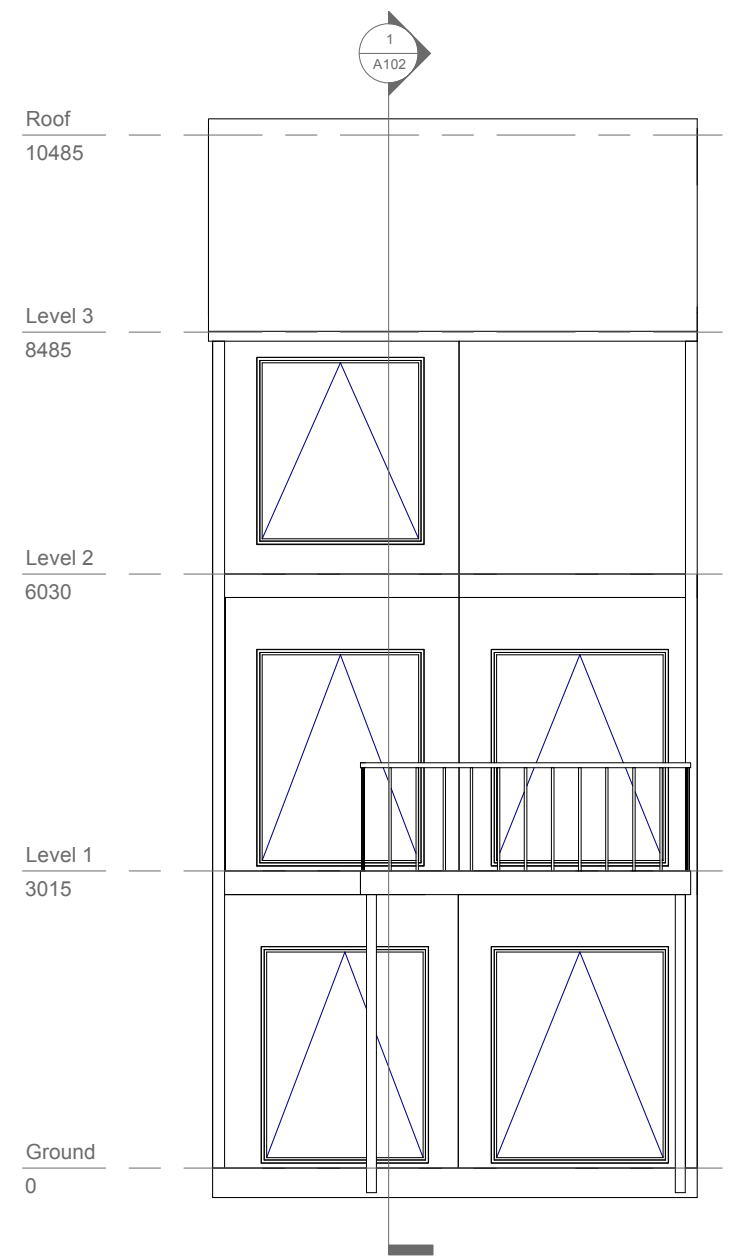

Figure B-4 House $H$ south elevation 1:100 


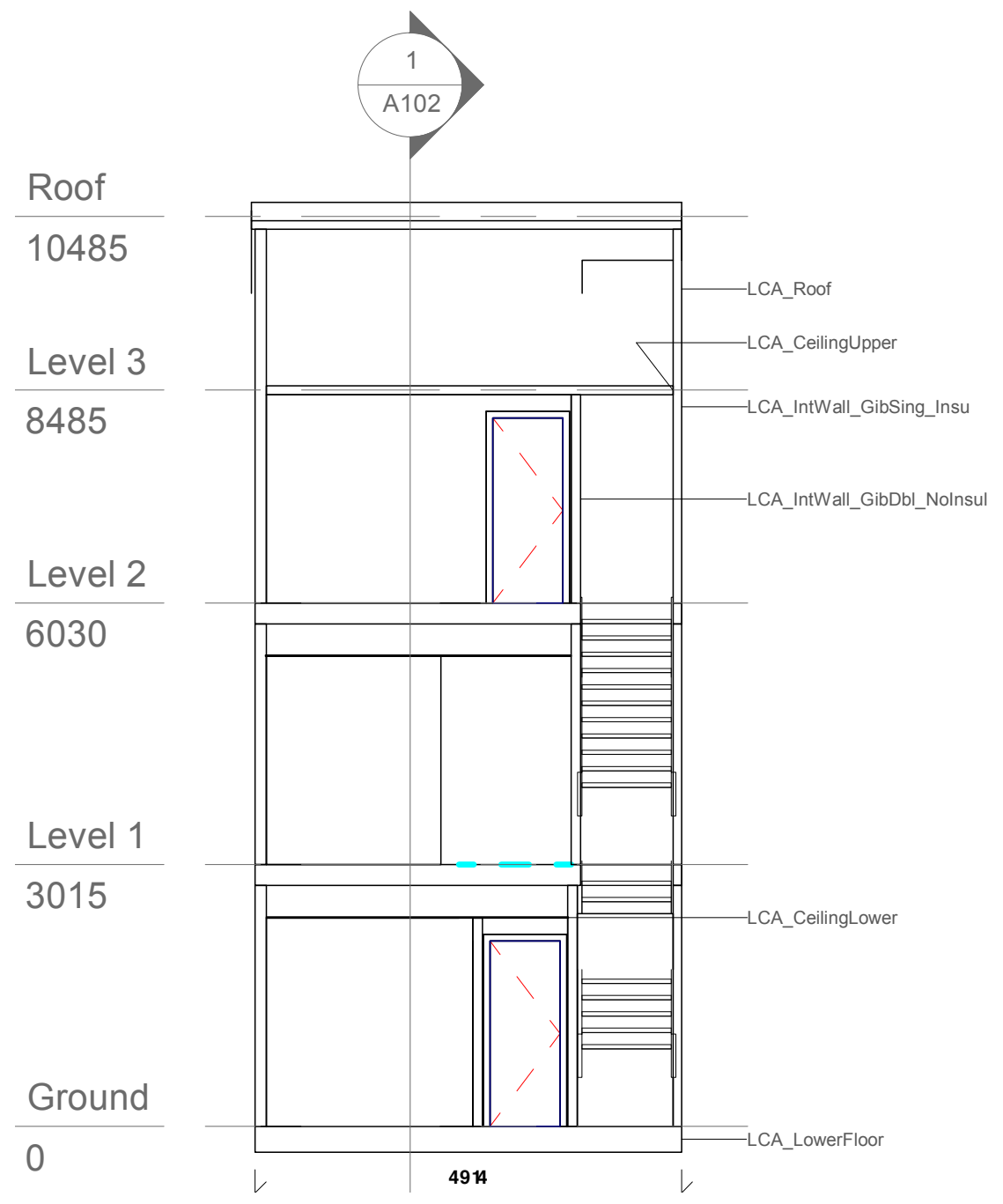


A Life Cycle Assessment of Medium Density Houses in New Zealand

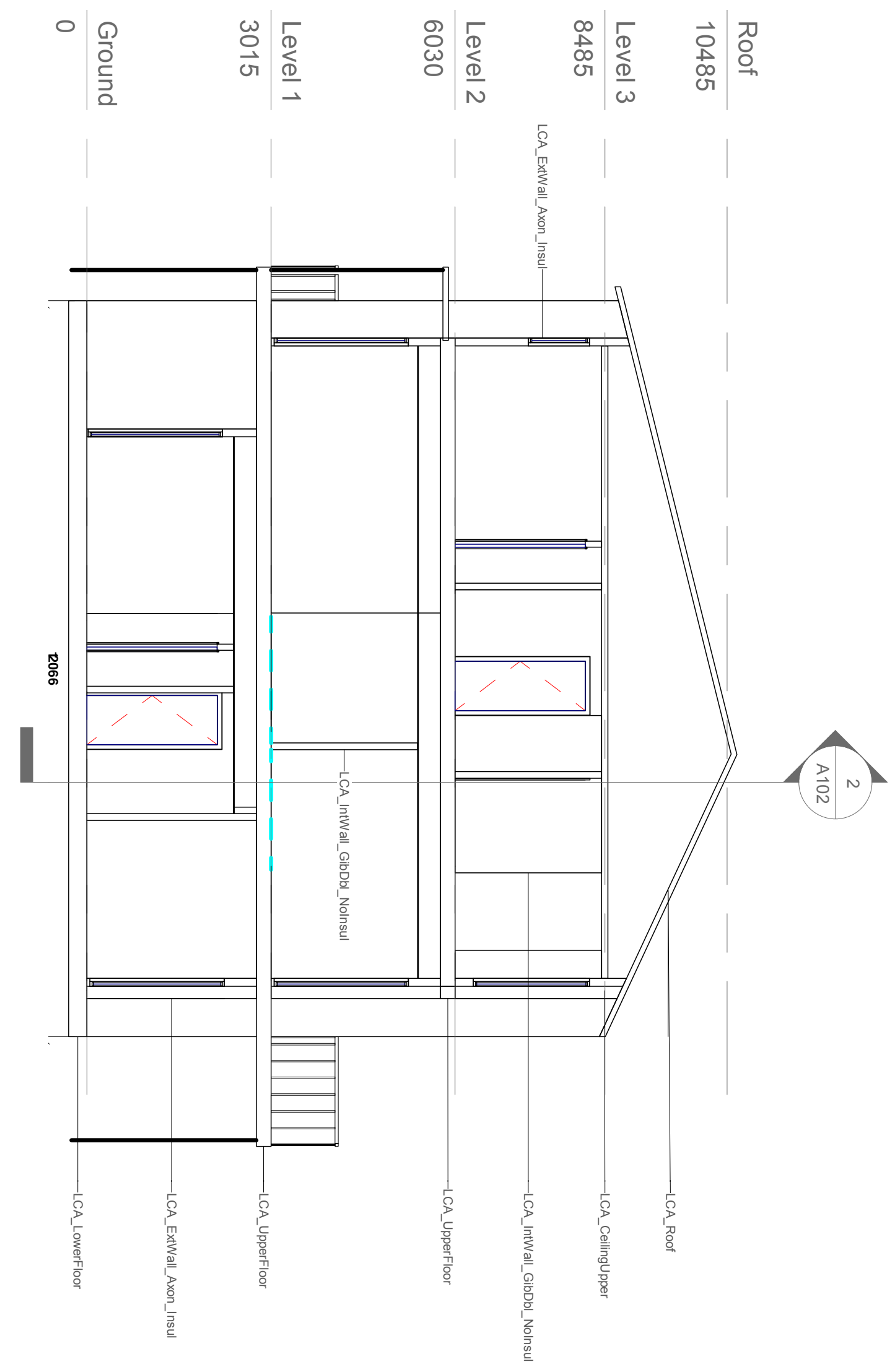

Figure B-6 House H long section 1:100 


\section{B.2 House P}

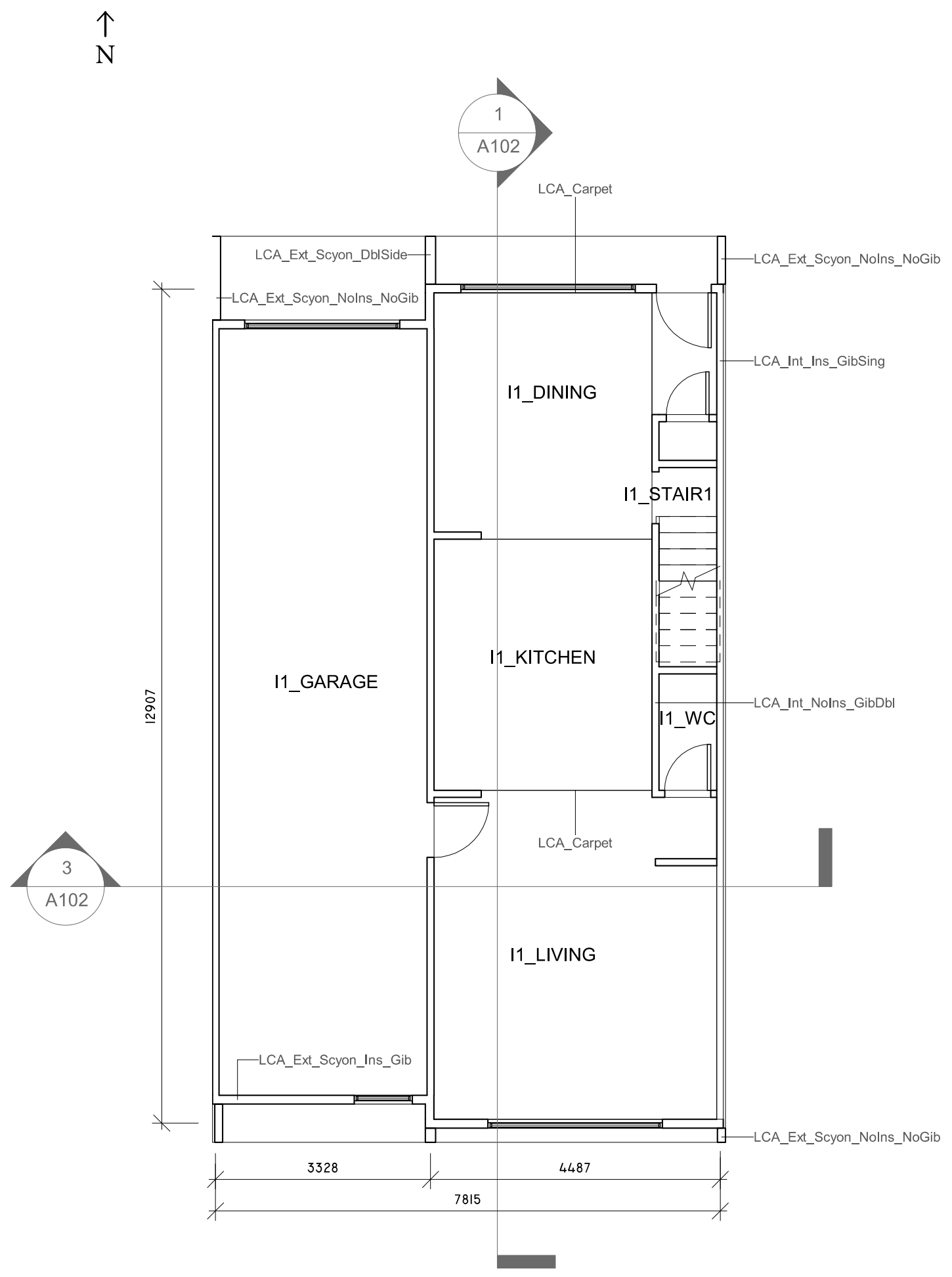

Figure B-7 House P ground floor plan 1:100 
A Life Cycle Assessment of Medium Density Houses in New Zealand

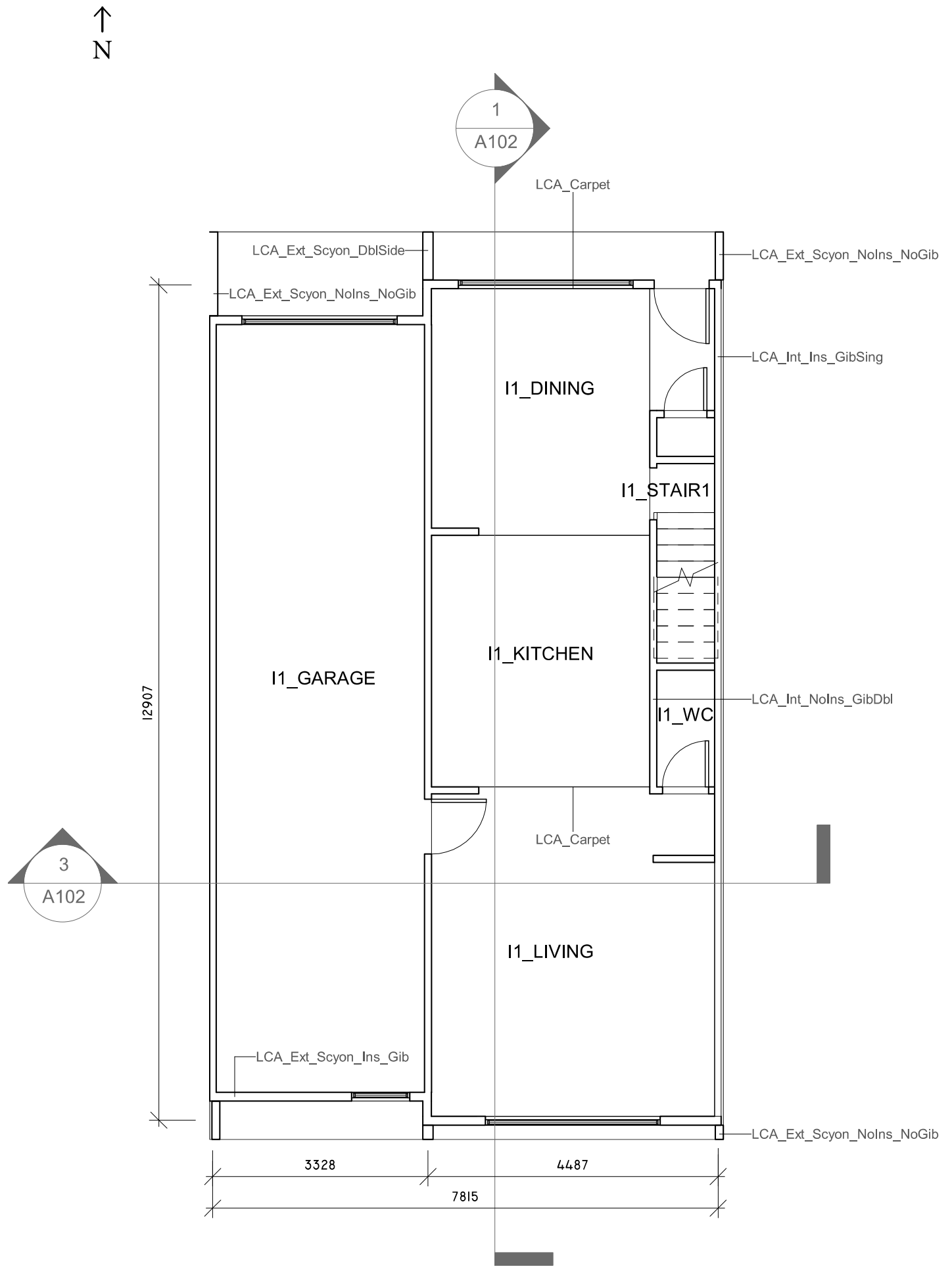

Figure B-8 House P first floor plan 1:100 
Appendix B House Drawings

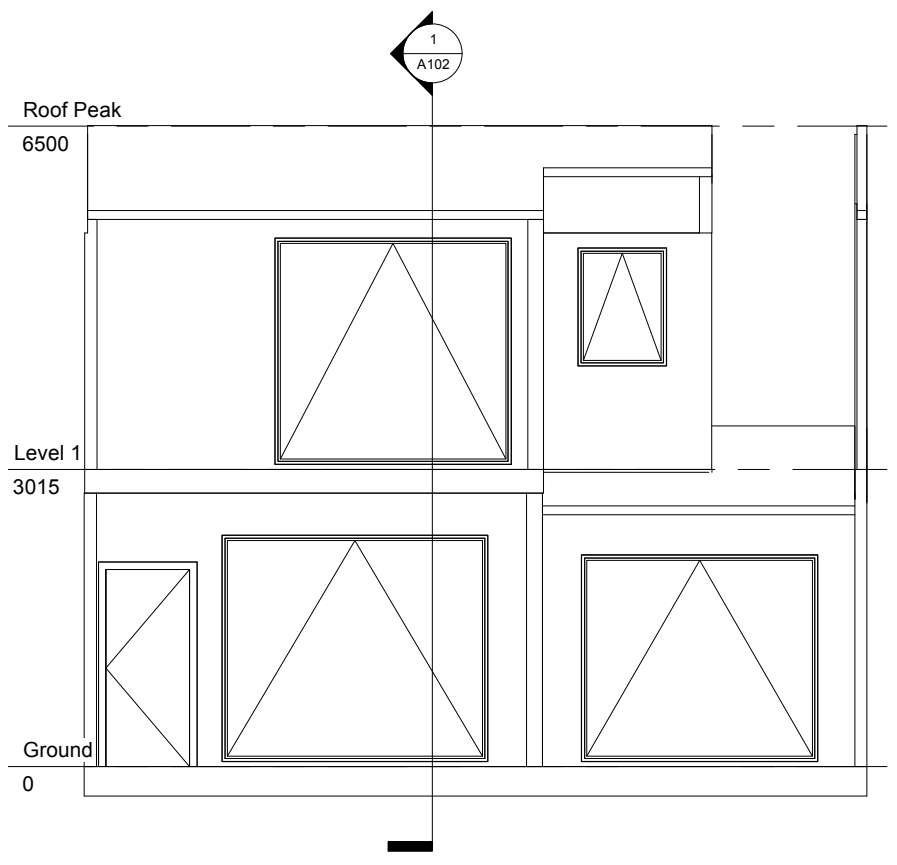

Figure B-9 House P north elevation 1:100 
A Life Cycle Assessment of Medium Density Houses in New Zealand

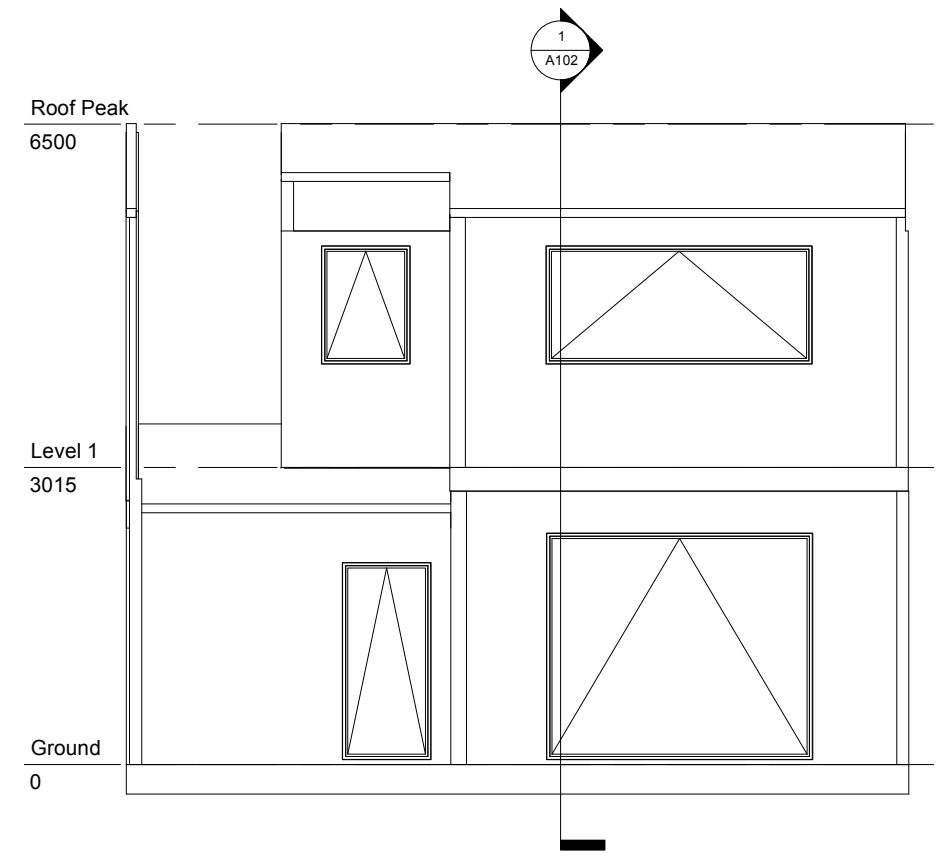

Figure B-10 House P south elevation 1:100 


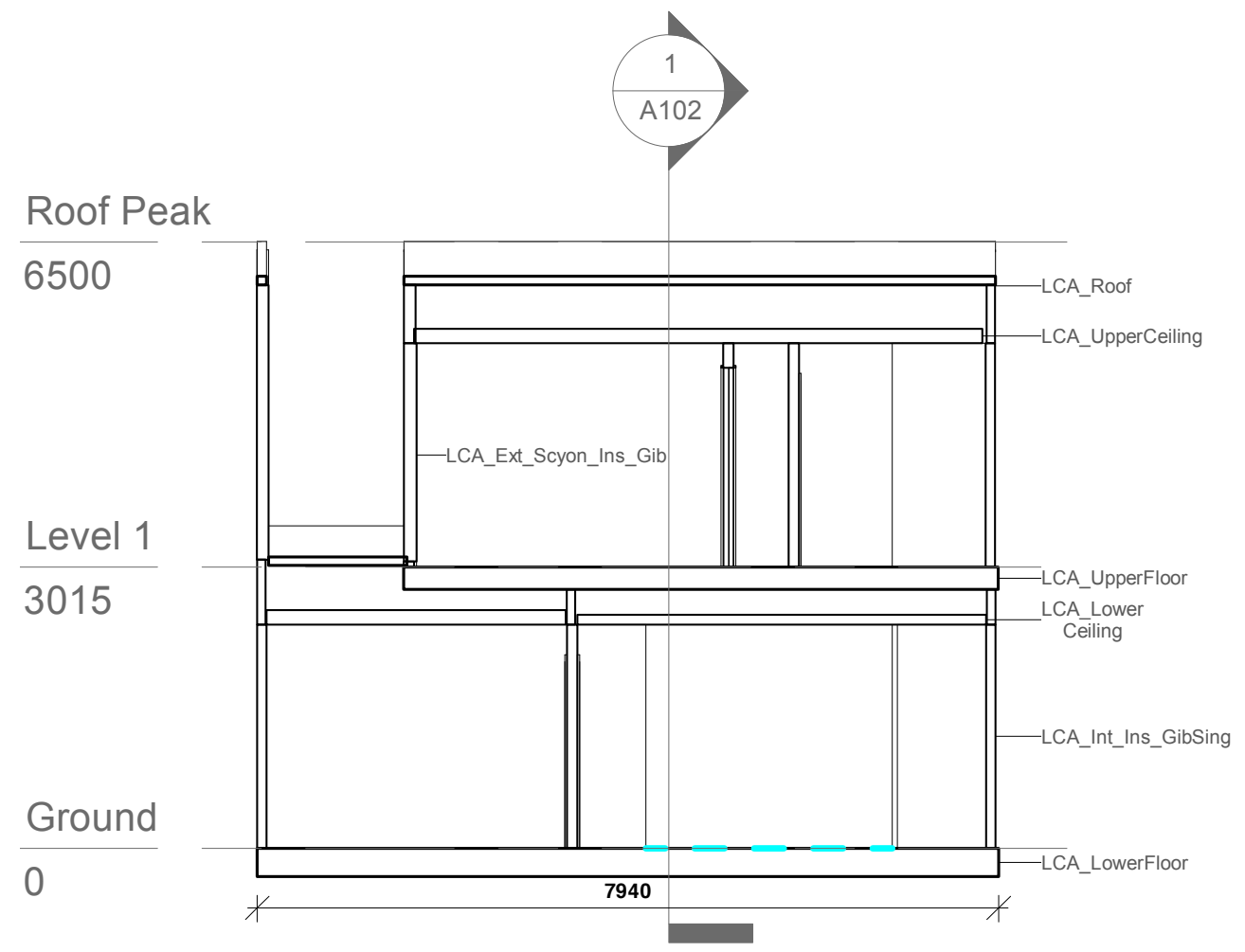




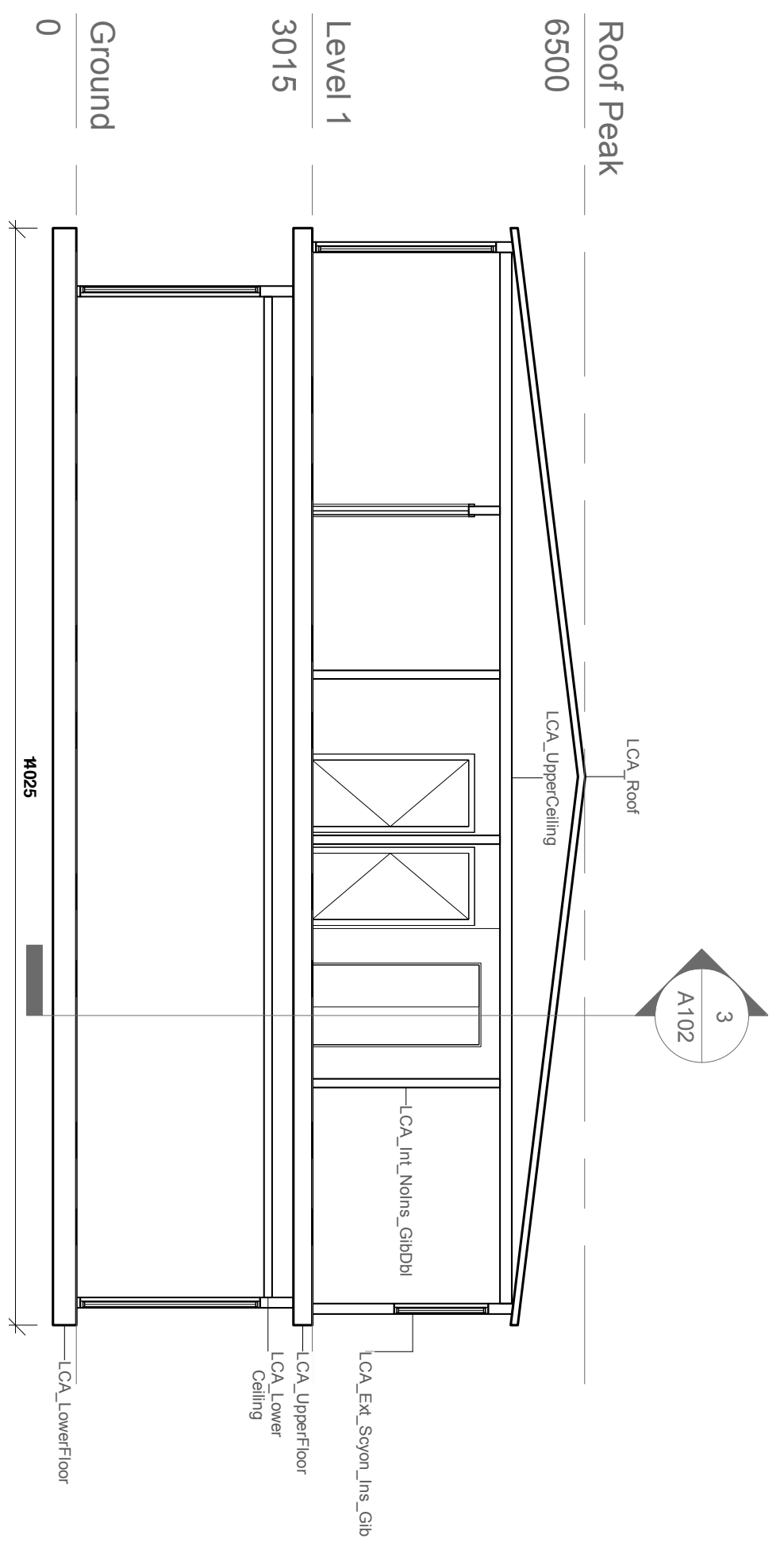




\section{B.3 House W}

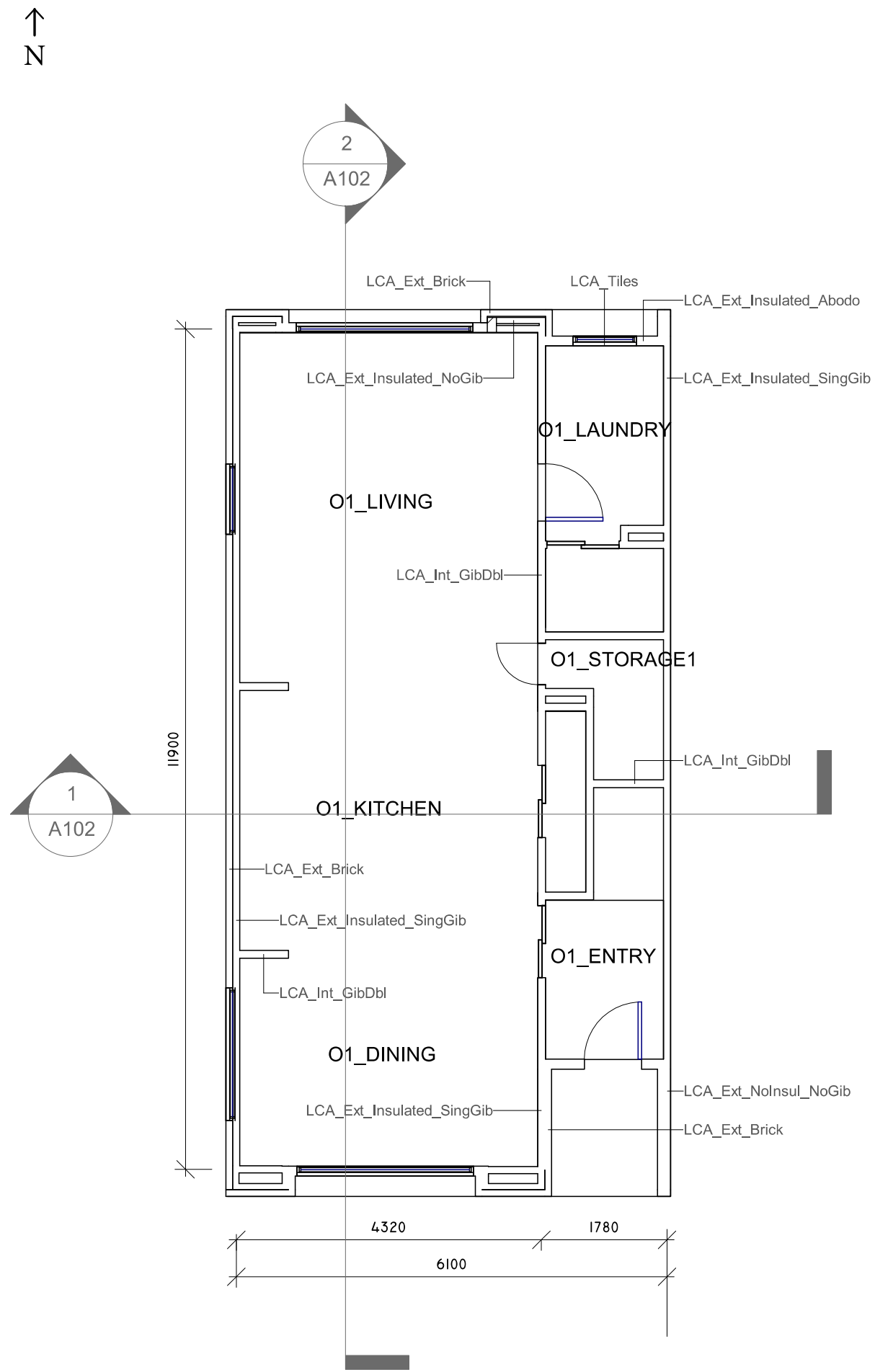

Figure B-13 House W ground floor plan 1:100 


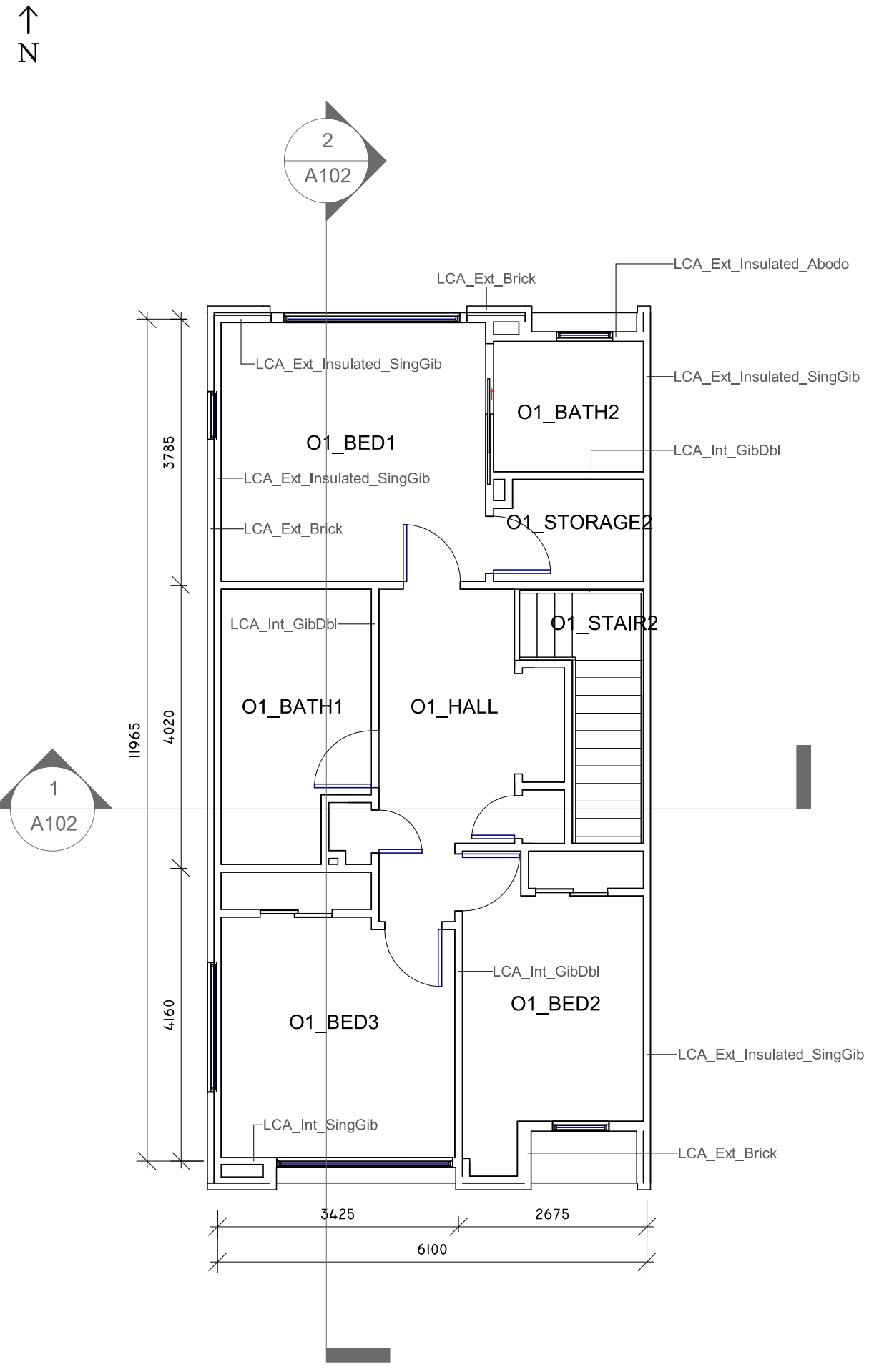


Appendix B House Drawings

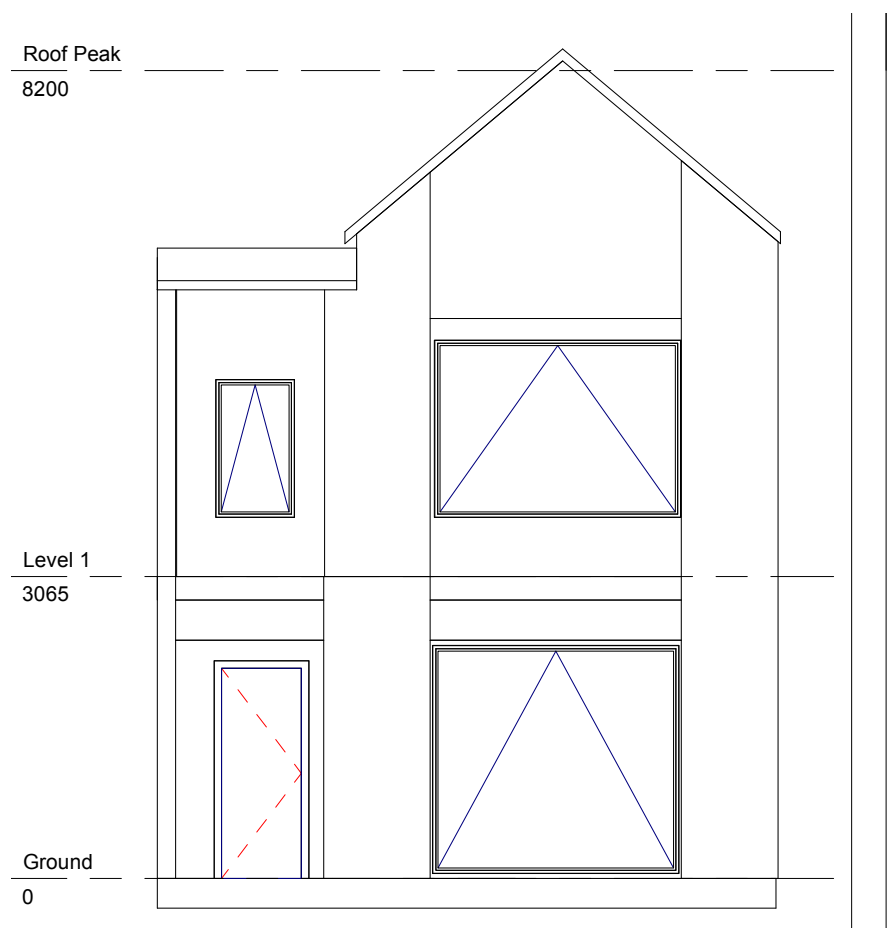

Figure B-15 House W north elevation 1:100 
A Life Cycle Assessment of Medium Density Houses in New Zealand

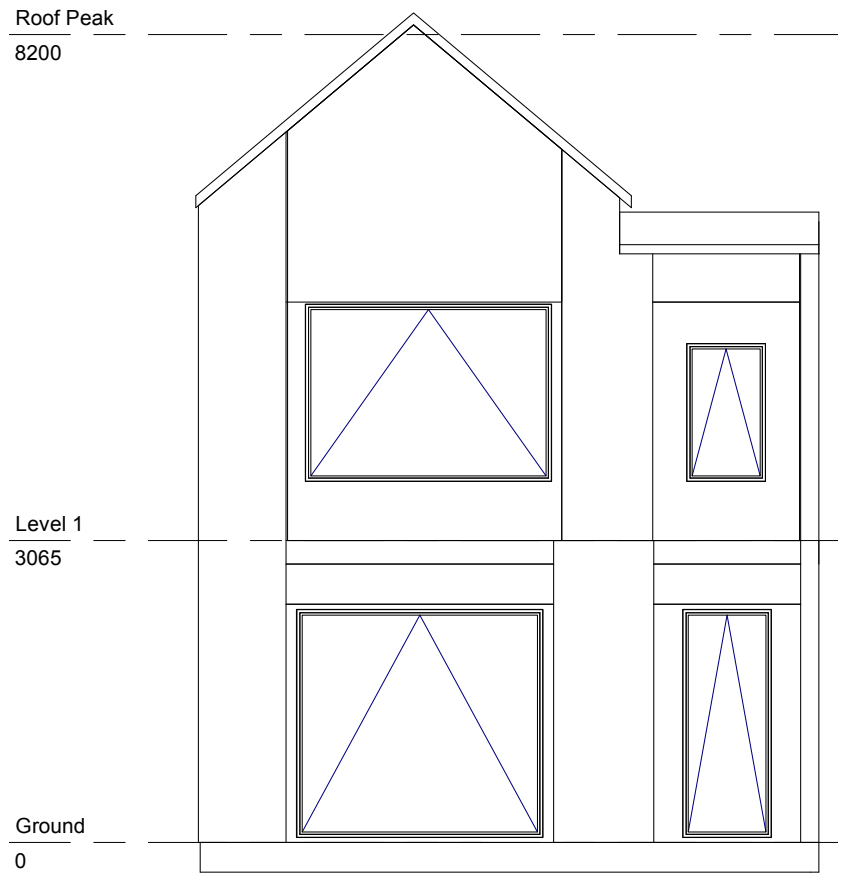

Figure B-16 House W south elevation 1:100 


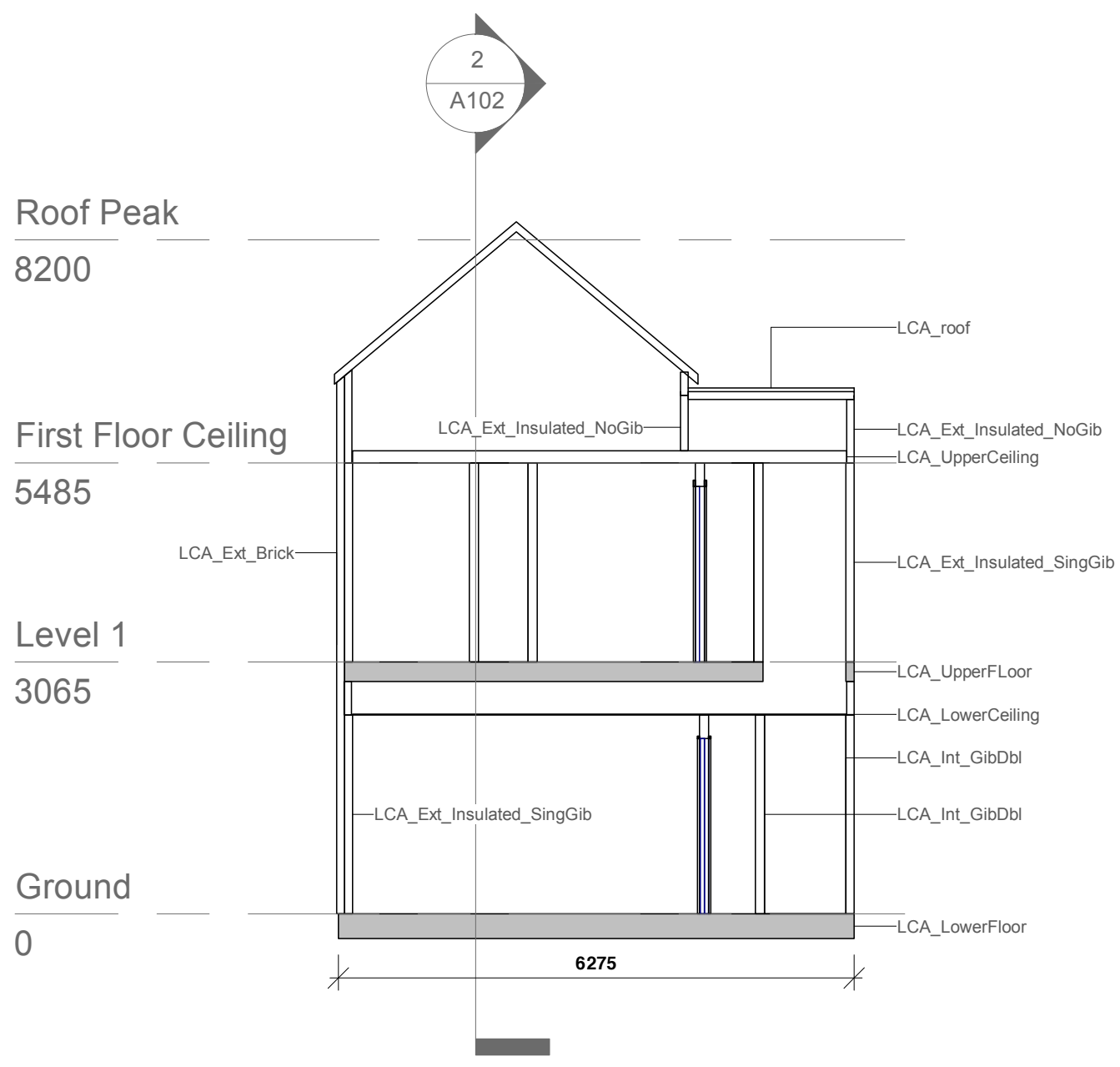


A Life Cycle Assessment of Medium Density Houses in New Zealand

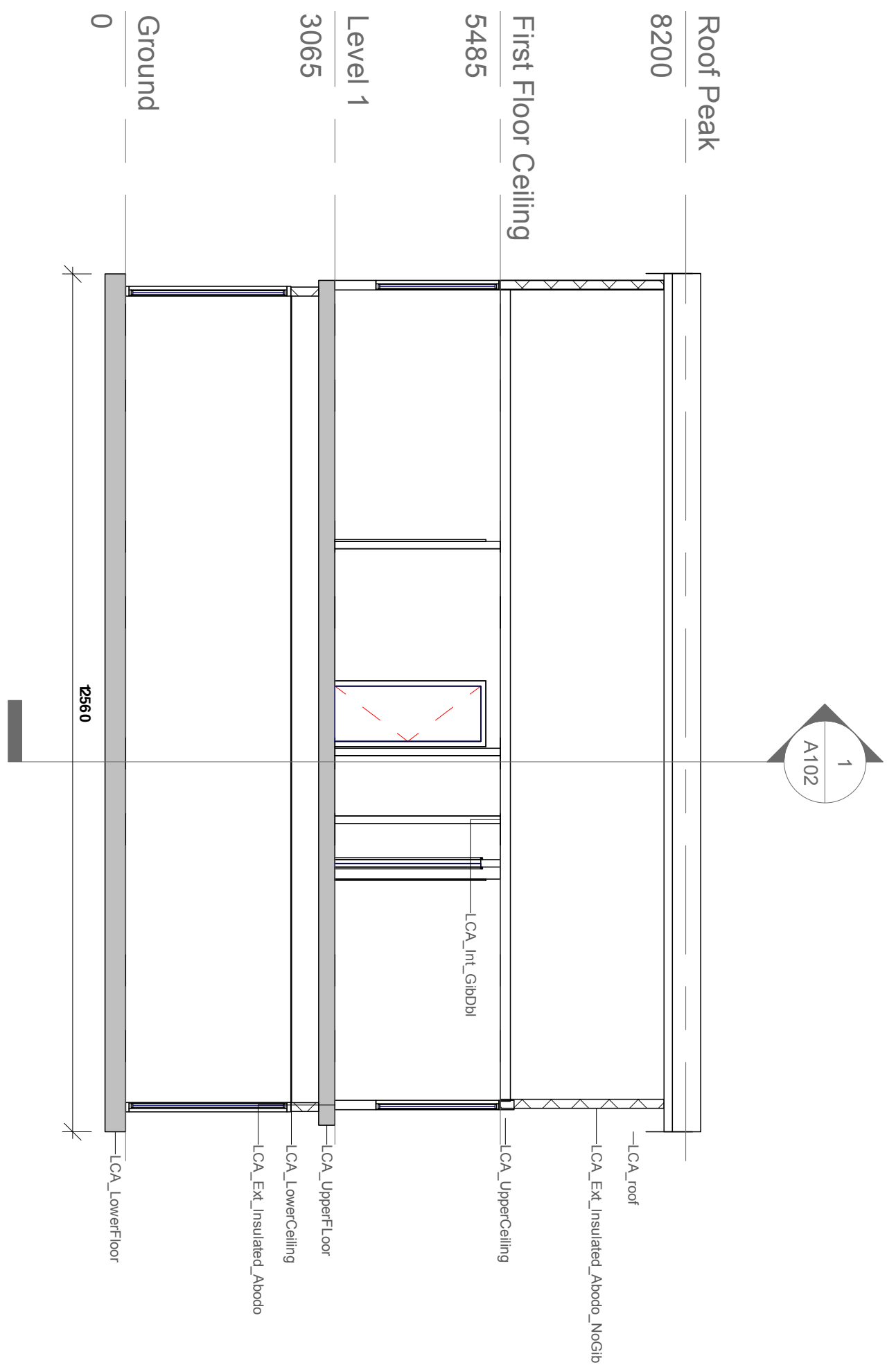

Figure B-18 House W long section 1:100

B-18 


\section{Appendix C Energy model conventions}

\section{C.1 Naming convention}

Thermal zones were renamed based on the houses' location in the row of units, this being either the outer or middle units. An example of this is "O1_Bath2 Thermal Zone”.

' $\mathrm{O}$ ' identifies the zone is part of the outer units, ' 1 ' identifies the zone is in the $1_{\mathrm{st}}$ outer unit.

'Bath2' means the zone is a bathroom and is the 2nd bathroom in the unit. 'Thermal Zone' identifies that it is a thermal zone.

This convention shown in Table C-1 is not only useful to identify what the use of the zone is but also its location within the model.

Table C-1 Thermal zone naming convention

\begin{tabular}{lll}
\hline Outer Unit 01 (West) & Inner Unit 01 (Middle) & Outer Unit 02 (East) \\
\hline $\begin{array}{l}\text { O1_BATH1 THERMAL } \\
\text { ZONE }\end{array}$ & $\begin{array}{l}\text { I1_BATH1 THERMAL } \\
\text { ZONE }\end{array}$ & $\begin{array}{l}\text { O2_BATH1 THERMAL } \\
\text { ZONE }\end{array}$ \\
$\begin{array}{l}\text { O1_BATH2 THERMAL } \\
\text { ZONE }\end{array}$ & $\begin{array}{l}\text { I1_BATH2 THERMAL } \\
\text { ZONE }\end{array}$ & $\begin{array}{l}\text { O2_BATH2 THERMAL } \\
\text { ZONE }\end{array}$ \\
$\begin{array}{l}\text { O1_KITCHEN THERMAL } \\
\text { ZONE }\end{array}$ & $\begin{array}{l}\text { I1_KITCHEN THERMAL } \\
\text { ZONE }\end{array}$ & $\begin{array}{l}\text { O2_KITCHEN THERMAL } \\
\text { ZONE }\end{array}$ \\
O1_LAUNDRY THERMAL & I1_LAUNDRY THERMAL & $\begin{array}{l}\text { O2_LAUNDRY THERMAL } \\
\text { ZONE }\end{array}$ \\
\hline
\end{tabular}

Naming conventions were applied to geometry surfaces which first identifies the zone the surfaces are associated with, followed by the orientation and a surface number shown in Table C-2.

Sub-surfaces are windows and doors that are hosted by surfaces. Sub-surfaces are named in a similar fashion but begin with whether the window is openable or not (OP) followed by the surface name and sub-surface number. 
A Life Cycle Assessment of Medium Density Houses in New Zealand

Table C-2 Surface naming convention

\begin{tabular}{lll}
\hline Surfaces & Surface 1 sub surfaces & Surface 2 sub surfaces \\
\hline $\begin{array}{l}\text { O1_LOUNGE } \\
\text { Thermal Zone_E-1 }\end{array}$ & $\begin{array}{l}\text { OP_WIND_O1_LOUNGE } \\
\text { THERMAL ZONE_S-1_1 }\end{array}$ & $\begin{array}{l}\text { OP_Wind_O1_LOUNGE Thermal } \\
\text { Zone_S-2_1 }\end{array}$ \\
$\begin{array}{l}\text { O1_LOUNGE } \\
\text { Thermal Zone_S-1 }\end{array}$ & $\begin{array}{l}\text { OP_WIND_O1_LOUNGE } \\
\text { THERMAL ZONE_S-1_2 }\end{array}$ & $\begin{array}{l}\text { Wind_O1_LOUNGE Thermal } \\
\text { Zone_S-2_1 }\end{array}$ \\
$\begin{array}{l}\text { O1_LOUNGE } \\
\text { Thermal Zone_S-2 }\end{array}$ & WIND_O1_LOUNGE THERMAL & Wind_O1_LOUNGE Thermal \\
\end{tabular}




\section{Appendix D BIM Model Inputs}

Table D-1 Standard BIM modelling inputs for all houses

\begin{tabular}{|c|c|c|c|}
\hline Family & Material & PR Code & $\begin{array}{l}\text { Thickness } \\
(\mathrm{mm})\end{array}$ \\
\hline \multirow[t]{6}{*}{ Roof } & $\begin{array}{l}\text { Steel, primary }(150 \mathrm{~g} / \mathrm{m} 2 \text { zinc/aluminium alloy } \\
\text { finish both sides, coating class AZ150), profile } \\
\text { metal sheet, generic all profiles, } 0.55 \mathrm{~mm} \text { BMT, } \\
\text { exposure zone C }\end{array}$ & PR_25_71_51_97_1_- & 1 \\
\hline & Airgap & & 18 \\
\hline & $\begin{array}{l}\text { Softwood (dressed, kiln dried) floor [from } \\
\text { unsustainable forest management practices, } \\
\text { don't know or won't ensure from sustainable } \\
\text { forestry], with galvanised fixings }\end{array}$ & $\begin{array}{l}\text { PR_25_71_97_83_1_- } \\
\text { B }\end{array}$ & 5 \\
\hline & Membrane, building wrap, polyethylene (PE) & PR_15_57_30_47_1 & 0 \\
\hline & Airgap & & 46 \\
\hline & $\begin{array}{l}\text { Softwood (dressed, kiln dried) floor [from } \\
\text { unsustainable forest management practices, } \\
\text { don't know or won't ensure from sustainable } \\
\text { forestry], with galvanised fixings }\end{array}$ & $\begin{array}{l}\text { PR_25_71_97_83_1_- } \\
\text { B }\end{array}$ & 24 \\
\hline \multirow[t]{2}{*}{$\begin{array}{l}\text { CeilingL } \\
\text { ower }\end{array}$} & Plasterboard $(\mathrm{GIB} \circledast$ standard $13 \mathrm{~mm})$ & PR_25_71_52_37_1_ & 13 \\
\hline & $\begin{array}{l}\text { Paint, water-borne, walls (Dulux Wash\&Wear@ } \\
\text { low sheen - vivid white) ( } 2 \text { coats / m2) }\end{array}$ & PR_35_31_22_94_2 - & 0 \\
\hline
\end{tabular}

CeilingU Softwood (dressed, kiln dried) floor [from pper unsustainable forest management practices, don't know or won't ensure from sustainable forestry], with galvanised fixings

Insulation (roof), Pink ${ }^{\circledR}$ Batts ${ }^{\circledR}$ Classic R2.6 Ceiling (glass wool)

Plasterboard (GIB ${ }^{\circledR}$ standard $\left.13 \mathrm{~mm}\right)$
PR_25_71_97_83_1_ 49

$\mathrm{B}$

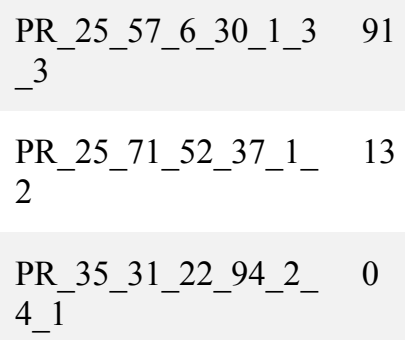

Paint, water-borne, walls (Dulux Wash\&Wear ${ }^{\circledR}$ low sheen - vivid white) ( 2 coats $/ \mathrm{m} 2$ ) 
UpperFlo Flooring, underlay (fibre cement, $6 \mathrm{~mm}$

or thickness)

Softwood (dressed, kiln dried) floor [from unsustainable forest management practices, don't know or won't ensure from sustainable forestry], with galvanised fixings

AirGap

LowerFl Reinforced concrete, $20 \mathrm{MPa}$, in-situ, inc. 50

oor $\mathrm{kg} / \mathrm{m} 3$ steel reinforcing, (OPC)

PR_20_31_16_2_2_1 200

Insulation, polyester

PR_25_57_6_29

100

Membrane, building wrap, polyethylene (PE)

PR_15_57_30_47_1 0

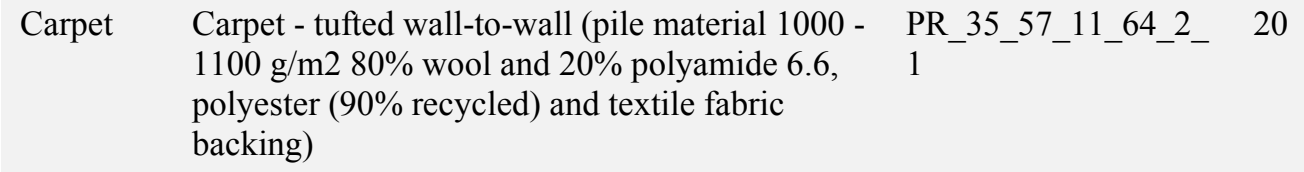

Tiles Tiles (ceramic)

PR_35_93_96_19

15

Intertena Airgap

ncy Wall

Plasterboard (generic)

PR_25_71_52_37

25

Airgap

25

\section{D.1 House H}

Table D-2 House H unique BIM modelling inputs

\begin{tabular}{llll}
\hline Family & Material & PR Code & $\begin{array}{l}\text { Thickness } \\
(\mathbf{m m})\end{array}$ \\
\hline $\begin{array}{l}\text { ExtWall_- } \\
\begin{array}{l}\text { Axon_In } \\
\text { sul }\end{array}\end{array}$ & $\begin{array}{l}\text { Paint } \\
\text { (exterior) }\end{array}$ & $\begin{array}{l}\text { PR_35_31_22_94_2_- } \\
1 \_1\end{array}$ & 0 \\
\hline
\end{tabular}




\begin{tabular}{|c|c|c|c|}
\hline & $\begin{array}{l}\text { Paint (exterior), water-borne, primer/sealer ( } 1 \\
\text { coat / m2) }\end{array}$ & $\begin{array}{l}\text { PR_35_31_22_94_1_- } \\
1 \_1\end{array}$ & 0 \\
\hline & $\begin{array}{l}\text { Cladding, all profiles (fibre cement, } 9 \mathrm{~mm} \\
\text { thickness) }\end{array}$ & PR_25_71_14_30_9 & 9 \\
\hline & Airgap & & 18 \\
\hline & $\begin{array}{l}\text { Softwood (dressed, kiln dried) floor [from } \\
\text { unsustainable forest management practices, } \\
\text { don't know or won't ensure from sustainable } \\
\text { forestry], with galvanised fixings }\end{array}$ & $\begin{array}{l}\text { PR_25_71_97_83_1- } \\
\text { B }\end{array}$ & 2 \\
\hline & Membrane, building wrap, polyethylene (PE) & PR_15_57_30_47_1 & 0 \\
\hline \multirow{8}{*}{$\begin{array}{l}\text { ExtWall } \\
\text { Axon } \\
\text { Speedwa } \\
\text { ll }\end{array}$} & $\begin{array}{l}\text { Paint (exterior), water-borne, for timber ( } 2 \text { coats } \\
/ \mathrm{m} 2 \text { ) }\end{array}$ & $\begin{array}{l}\text { PR_35_31_22_94_2 - } \\
1 \_1\end{array}$ & 0 \\
\hline & $\begin{array}{l}\text { Paint (exterior), water-borne, primer/sealer (1 } \\
\text { coat / m2) }\end{array}$ & $\begin{array}{l}\text { PR_35_31_22_94_1_- } \\
1 \_1\end{array}$ & 0 \\
\hline & $\begin{array}{l}\text { Cladding, all profiles (fibre cement, } 9 \mathrm{~mm} \\
\text { thickness) }\end{array}$ & PR_25_71_14_30_9 & 9 \\
\hline & Airgap & & 19 \\
\hline & $\begin{array}{l}\text { Softwood (dressed, kiln dried) floor [from } \\
\text { unsustainable forest management practices, } \\
\text { don't know or won't ensure from sustainable } \\
\text { forestry], with galvanised fixings }\end{array}$ & $\begin{array}{l}\text { PR_25_71_97_83_1_- } \\
\text { B }\end{array}$ & 1 \\
\hline & Membrane, building wrap, polyethylene (PE) & PR_15_57_30_47_1 & 0 \\
\hline & $\begin{array}{l}\text { Softwood (dressed, kiln dried) floor [from } \\
\text { unsustainable forest management practices, } \\
\text { don't know or won't ensure from sustainable } \\
\text { forestry], with galvanised fixings }\end{array}$ & $\begin{array}{l}\text { PR_25_71_97_83_1_- } \\
\text { B }\end{array}$ & 31 \\
\hline & Airgap & & 59 \\
\hline \multirow{3}{*}{$\begin{array}{l}\text { IntWall- } \\
\text { GibDbl- } \\
\text { NoInsul }\end{array}$} & $\begin{array}{l}\text { Paint, water-borne, walls (Dulux Wash\&Wear® } \\
\text { low sheen - vivid white) ( } 2 \text { coats / m2) }\end{array}$ & $\begin{array}{l}\text { PR_35_31_22_94_2 } \\
4 \_1\end{array}$ & 0 \\
\hline & Plasterboard (GIB ${ }^{\circledR}$ standard $\left.10 \mathrm{~mm}\right)$ & $\begin{array}{l}\text { PR_25_71_52_37_1_ } \\
1\end{array}$ & 10 \\
\hline & $\begin{array}{l}\text { Softwood (dressed, kiln dried) floor [from } \\
\text { unsustainable forest management practices, }\end{array}$ & $\begin{array}{l}\text { PR_25_71_97_83_1_ } \\
\text { B }\end{array}$ & 31 \\
\hline
\end{tabular}




\begin{tabular}{|c|c|c|c|}
\hline & $\begin{array}{l}\text { don't know or won't ensure from sustainable } \\
\text { forestry], with galvanised fixings }\end{array}$ & & \\
\hline & Airgap & & 59 \\
\hline & Plasterboard (GIB $®$ standard $10 \mathrm{~mm})$ & $\begin{array}{l}\text { PR_25_71_52_37_1 } \\
1\end{array}$ & 10 \\
\hline & $\begin{array}{l}\text { Paint, water-borne, walls (Dulux Wash\&Wear }{ }^{\circledR} \\
\text { low sheen - vivid white) }(2 \text { coats } / \mathrm{m} 2)\end{array}$ & $\begin{array}{l}\text { PR_35_31_22_94_2_- } \\
4 \_1\end{array}$ & 0 \\
\hline \multirow[t]{4}{*}{$\begin{array}{l}\text { IntWall_ } \\
\text { GibSing_- } \\
\text { NoInsul }\end{array}$} & $\begin{array}{l}\text { Softwood (dressed, kiln dried) floor [from } \\
\text { unsustainable forest management practices, } \\
\text { don't know or won't ensure from sustainable } \\
\text { forestry], with galvanised fixings }\end{array}$ & $\begin{array}{l}\text { PR_25_71_97_83_1_ } \\
\text { B }\end{array}$ & 31 \\
\hline & Airgap & & 59 \\
\hline & Plasterboard (GIB® standard $10 \mathrm{~mm}$ ) & $\begin{array}{l}\text { PR_25_71_52_37_1_- } \\
1\end{array}$ & 10 \\
\hline & $\begin{array}{l}\text { Paint, water-borne, walls (Dulux Wash\&Wear }{ }^{\circledR} \\
\text { low sheen - vivid white) }(2 \text { coats / m2) }\end{array}$ & $\begin{array}{l}\text { PR_35_31_22_94_2 } \\
4 \_1\end{array}$ & 0 \\
\hline \multirow[t]{4}{*}{$\begin{array}{l}\text { IntWall_- } \\
\text { GibSing } \\
\text { Insu }\end{array}$} & $\begin{array}{l}\text { Steel }(150 \mathrm{~g} / \mathrm{m} 2 \text { zinc/aluminium alloy finish } \\
\text { both sides), profile metal sheet, generic all } \\
\text { profiles, } 0.55 \mathrm{~mm} \text { BMT }\end{array}$ & $\begin{array}{l}\text { PR_25_71_51_97_1_- } \\
1 \_1\end{array}$ & 31 \\
\hline & $\begin{array}{l}\text { Insulation ( } 90 \mathrm{~mm} \text { wall), Pink }{ }^{\circledR} \text { Batts }{ }^{\circledR} \text { Classic } \\
\text { R1.8 Wall (glass wool) }\end{array}$ & $\begin{array}{l}\text { PR_25_57_6_30_1_2 } \\
-1 \_1\end{array}$ & 59 \\
\hline & Plasterboard (GIB ${ }^{\circledR}$ standard $\left.10 \mathrm{~mm}\right)$ & $\begin{array}{l}\text { PR_25_71_52_37_1_- } \\
1\end{array}$ & 10 \\
\hline & $\begin{array}{l}\text { Paint, water-borne, walls (Dulux Wash\&Wear }{ }^{\circledR} \\
\text { low sheen - vivid white) }(2 \text { coats } / \mathrm{m} 2)\end{array}$ & $\begin{array}{l}\text { PR_35_31_22_94_2 } \\
4 \_1\end{array}$ & 0 \\
\hline \multirow{4}{*}{$\begin{array}{l}2 \text { Storey } \\
190 \mathrm{~mm} \\
\text { timber } \\
\text { firewall }\end{array}$} & $\begin{array}{l}\text { Paint (exterior), water-borne, primer/sealer (1 } \\
\text { coat / m2) }\end{array}$ & $\begin{array}{l}\text { PR_35_31_22_94_1_ } \\
1 \_1\end{array}$ & 0 \\
\hline & $\begin{array}{l}\text { Cladding, all profiles (fibre cement, } 9 \mathrm{~mm} \\
\text { thickness) }\end{array}$ & PR_25_71_14_30_9 & 9 \\
\hline & Airgap & & 18 \\
\hline & $\begin{array}{l}\text { Softwood (dressed, kiln dried) floor [from } \\
\text { unsustainable forest management practices, } \\
\text { don't know or won't ensure from sustainable } \\
\text { forestry], with galvanised fixings }\end{array}$ & $\begin{array}{l}\text { PR_25_71_97_83_1_ } \\
\text { B }\end{array}$ & 2 \\
\hline
\end{tabular}




\begin{tabular}{|c|c|c|}
\hline Membrane, building wrap, polyethylene (PE) & PR_15_57_30_47_1 & 0 \\
\hline $\begin{array}{l}\text { Softwood (dressed, kiln dried) floor [from } \\
\text { unsustainable forest management practices, } \\
\text { don't know or won't ensure from sustainable } \\
\text { forestry], with galvanised fixings }\end{array}$ & $\begin{array}{l}\text { PR_25_71_97_83_1_- } \\
\text { B }\end{array}$ & 63 \\
\hline Airgap & & 117 \\
\hline Membrane, building wrap, polyethylene (PE) & PR_15_57_30_47_1 & 0 \\
\hline $\begin{array}{l}\text { Softwood (dressed, kiln dried) floor [from } \\
\text { unsustainable forest management practices, } \\
\text { don't know or won't ensure from sustainable } \\
\text { forestry], with galvanised fixings }\end{array}$ & $\begin{array}{l}\text { PR } 25 \_71 \_97 \_83 \_1- \\
\text { B }\end{array}$ & 2 \\
\hline Airgap & & 18 \\
\hline $\begin{array}{l}\text { Cladding, all profiles (fibre cement, } 9 \mathrm{~mm} \\
\text { thickness) }\end{array}$ & PR_25_71_14_30_9 & 9 \\
\hline $\begin{array}{l}\text { Paint (exterior), water-borne, primer/sealer ( } 1 \\
\text { coat } / \mathrm{m} 2 \text { ) }\end{array}$ & PR_35_31_22_94_1_- & 0 \\
\hline $\begin{array}{l}\text { Paint (exterior), water-borne, for timber ( } 2 \text { coats } \\
\text { / m2) }\end{array}$ & $\begin{array}{l}\text { PR_35_31_22_94_2_- } \\
1 \_1\end{array}$ & 0 \\
\hline
\end{tabular}

\section{D.2 House P}

Table D-3 House P unique BIM modelling inputs

\begin{tabular}{|c|c|c|c|}
\hline Family & Material & PR Code & $\begin{array}{l}\text { Thickness } \\
(\mathrm{mm})\end{array}$ \\
\hline \multirow{6}{*}{$\begin{array}{l}\text { Ext_Scy } \\
\text { on_NoIn } \\
\text { s_NoGib }\end{array}$} & $\begin{array}{l}\text { Paint (exterior), water-borne, for timber ( } 2 \text { coats } \\
\text { / } \mathrm{m} 2 \text { ) }\end{array}$ & PR_35_31_22_94_2_- & 0 \\
\hline & $\begin{array}{l}\text { Paint (exterior), water-borne, primer/sealer ( } 1 \\
\text { coat } / \mathrm{m} 2 \text { ) }\end{array}$ & PR_35_31_22_94_1_- & 0 \\
\hline & $\begin{array}{l}\text { Cladding, all profiles (fibre cement, } 9 \mathrm{~mm} \\
\text { thickness) }\end{array}$ & PR_25_71_14_30_9 & 10 \\
\hline & AirGap & & 18 \\
\hline & $\begin{array}{l}\text { Softwood (dressed, kiln dried) floor [from } \\
\text { unsustainable forest management practices, } \\
\text { don't know or won't ensure from sustainable } \\
\text { forestry], with galvanised fixings }\end{array}$ & $\begin{array}{l}\text { PR_25_71_97_83_1_- } \\
\text { B }\end{array}$ & 2 \\
\hline & $\begin{array}{l}\text { Rigid air barrier (fibre cement, } 4.5 \mathrm{~mm} \\
\text { thickness) }\end{array}$ & PR_25_71_14_30_3 & 4.5 \\
\hline
\end{tabular}




\begin{tabular}{|c|c|c|c|}
\hline & AirGap & & 59 \\
\hline & $\begin{array}{l}\text { Softwood (dressed, kiln dried) floor [from } \\
\text { unsustainable forest management practices, } \\
\text { don't know or won't ensure from sustainable } \\
\text { forestry], with galvanised fixings }\end{array}$ & $\begin{array}{l}\text { PR_25_71_97_83_1_- } \\
\text { B }\end{array}$ & 31 \\
\hline \multirow{10}{*}{$\begin{array}{l}\text { Ext_Scy } \\
\text { on_Ins_ } \\
\text { Gib }\end{array}$} & $\begin{array}{l}\text { Paint (exterior), water-borne, for timber ( } 2 \text { coats } \\
/ \mathrm{m} 2 \text { ) }\end{array}$ & $\begin{array}{l}\text { PR_35_31_22_94_2 } \\
1 \_1\end{array}$ & 0 \\
\hline & $\begin{array}{l}\text { Paint (exterior), water-borne, primer/sealer (1 } \\
\text { coat / m2) }\end{array}$ & $\begin{array}{l}\text { PR_35_31_22_94_1_ } \\
1 \_1\end{array}$ & 0 \\
\hline & $\begin{array}{l}\text { Cladding, all profiles (fibre cement, } 9 \mathrm{~mm} \\
\text { thickness) }\end{array}$ & PR_25_71_14_30_9 & 10 \\
\hline & AirGap & & 2 \\
\hline & $\begin{array}{l}\text { Softwood (dressed, kiln dried) floor [from } \\
\text { unsustainable forest management practices, } \\
\text { don't know or won't ensure from sustainable } \\
\text { forestry], with galvanised fixings }\end{array}$ & $\begin{array}{l}\text { PR_25_71_97_83_1_- } \\
\text { B }\end{array}$ & 18 \\
\hline & $\begin{array}{l}\text { Rigid air barrier (fibre cement, } 4.5 \mathrm{~mm} \\
\text { thickness) }\end{array}$ & PR_25_71_14_30_3 & 4.5 \\
\hline & $\begin{array}{l}\text { Insulation ( } 90 \mathrm{~mm} \text { wall), Pink }{ }^{\circledR} \text { Batts }{ }^{\circledR} \text { Classic } \\
\text { R1.8 Wall (glass wool) }\end{array}$ & $\begin{array}{l}\text { PR_25_57_6_30_1_2 } \\
-1 \_1\end{array}$ & 59 \\
\hline & $\begin{array}{l}\text { Softwood (dressed, kiln dried) floor [from } \\
\text { unsustainable forest management practices, } \\
\text { don't know or won't ensure from sustainable } \\
\text { forestry], with galvanised fixings }\end{array}$ & $\begin{array}{l}\text { PR_25_71_97_83_1_- } \\
\text { B }\end{array}$ & 31 \\
\hline & Plasterboard $(\mathrm{GIB} \otimes$ standard $10 \mathrm{~mm})$ & $\begin{array}{l}\text { PR_25_71_52_37_1_- } \\
1\end{array}$ & 10 \\
\hline & $\begin{array}{l}\text { Paint, water-borne, walls (Dulux Wash\&Wear }{ }^{\circledR} \\
\text { low sheen - vivid white) }(2 \text { coats } / \mathrm{m} 2)\end{array}$ & PR_35_31_22_94_2 & 0 \\
\hline \multirow{4}{*}{$\begin{array}{l}\text { Ext_Scy } \\
\text { on_DblSi } \\
\text { de }\end{array}$} & $\begin{array}{l}\text { Paint (exterior), water-borne, for timber ( } 2 \text { coats } \\
/ \mathrm{m} 2)\end{array}$ & $\begin{array}{l}\text { PR_35_31_22_94_2 } \\
1 \_1\end{array}$ & 0 \\
\hline & $\begin{array}{l}\text { Paint (exterior), water-borne, primer/sealer (1 } \\
\text { coat } / \mathrm{m} 2 \text { ) }\end{array}$ & $\begin{array}{l}\text { PR_35_31_22_94_1_ } \\
1 \_1\end{array}$ & 0 \\
\hline & $\begin{array}{l}\text { Cladding, all profiles (fibre cement, } 9 \mathrm{~mm} \\
\text { thickness) }\end{array}$ & PR_25_71_14_30_9 & 10 \\
\hline & AirGap & & 18 \\
\hline
\end{tabular}




\begin{tabular}{|c|c|c|c|}
\hline & $\begin{array}{l}\text { Softwood (dressed, kiln dried) floor [from } \\
\text { unsustainable forest management practices, } \\
\text { don't know or won't ensure from sustainable } \\
\text { forestry], with galvanised fixings }\end{array}$ & $\begin{array}{l}\text { PR_25_71_97_83_1_- } \\
\text { B }\end{array}$ & 2 \\
\hline & $\begin{array}{l}\text { Rigid air barrier (fibre cement, } 4.5 \mathrm{~mm} \\
\text { thickness) }\end{array}$ & PR_25_71_14_30_3 & 4.5 \\
\hline & $\begin{array}{l}\text { Insulation ( } 90 \text { mm wall), Pink }{ }^{\circledR} \text { Batts }{ }^{\circledR} \text { Classic } \\
\text { R1.8 Wall (glass wool) }\end{array}$ & $\begin{array}{l}\text { PR_25_57_6_30_1_2 } \\
-1 \_1\end{array}$ & 59 \\
\hline & $\begin{array}{l}\text { Softwood (dressed, kiln dried) floor [from } \\
\text { unsustainable forest management practices, } \\
\text { don't know or won't ensure from sustainable } \\
\text { forestry], with galvanised fixings }\end{array}$ & $\begin{array}{l}\text { PR_25_71_97_83_1_- } \\
\text { B }\end{array}$ & 31 \\
\hline & $\begin{array}{l}\text { Rigid air barrier (fibre cement, } 4.5 \mathrm{~mm} \\
\text { thickness) }\end{array}$ & PR_25_71_14_30_3 & 4.5 \\
\hline & $\begin{array}{l}\text { Softwood (dressed, kiln dried) floor [from } \\
\text { unsustainable forest management practices, } \\
\text { don't know or won't ensure from sustainable } \\
\text { forestry], with galvanised fixings }\end{array}$ & $\begin{array}{l}\text { PR_25_71_97_83_1_- } \\
\text { B }\end{array}$ & 2 \\
\hline & AirGap & & 18 \\
\hline & $\begin{array}{l}\text { Cladding, all profiles (fibre cement, } 9 \mathrm{~mm} \\
\text { thickness) }\end{array}$ & PR_25_71_14_30_9 & 10 \\
\hline & $\begin{array}{l}\text { Paint (exterior), water-borne, primer/sealer (1 } \\
\text { coat / m2) }\end{array}$ & $\begin{array}{l}\text { PR_35_31_22_94_1_- } \\
1 \_1\end{array}$ & 0 \\
\hline & $\begin{array}{l}\text { Paint (exterior), water-borne, for timber ( } 2 \text { coats } \\
/ \mathrm{m} 2)\end{array}$ & $\begin{array}{l}\text { PR_35_31_22_94_2 - } \\
1 \_1\end{array}$ & 0 \\
\hline \multirow{6}{*}{$\begin{array}{l}\text { Ext_Scy } \\
\text { on_Ins } \\
\text { Nogib }\end{array}$} & $\begin{array}{l}\text { Paint (exterior), water-borne, for timber ( } 2 \text { coats } \\
/ \mathrm{m} 2 \text { ) }\end{array}$ & $\begin{array}{l}\text { PR_35_31_22_94_2 - } \\
1 \_1\end{array}$ & 0 \\
\hline & $\begin{array}{l}\text { Paint (exterior), water-borne, primer/sealer (1 } \\
\text { coat } / \mathrm{m} 2 \text { ) }\end{array}$ & PR_35_31_22_94_1_ & 0 \\
\hline & $\begin{array}{l}\text { Cladding, all profiles (fibre cement, } 9 \mathrm{~mm} \\
\text { thickness) }\end{array}$ & PR_25_71_14_30_9 & 10 \\
\hline & AirGap & & 1 \\
\hline & $\begin{array}{l}\text { Softwood (dressed, kiln dried) floor [from } \\
\text { unsustainable forest management practices, } \\
\text { don't know or won't ensure from sustainable } \\
\text { forestry], with galvanised fixings }\end{array}$ & $\begin{array}{l}\text { PR_25_71_97_83_1_- } \\
\text { B }\end{array}$ & 20 \\
\hline & $\begin{array}{l}\text { Rigid air barrier (fibre cement, } 4.5 \mathrm{~mm} \\
\text { thickness) }\end{array}$ & PR_25_71_14_30_3 & 4.5 \\
\hline
\end{tabular}


Insulation (90 mm wall), Pink ${ }^{\circledR}$ Batts ${ }^{\circledR}$ Classic R1.8 Wall (glass wool)

PR_25_57_6_30_1_2 59 $-1{ }_{-} 1$

Softwood (dressed, kiln dried) floor [from unsustainable forest management practices, PR_25_71_97_83_1_ 31 don't know or won't ensure from sustainable $\mathrm{B}$ forestry], with galvanised fixings

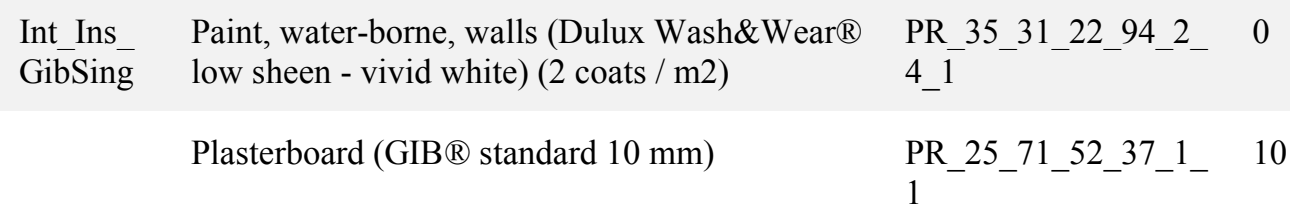

Softwood (dressed, kiln dried) floor [from unsustainable forest management practices, PR_25_71_97_83_1_ 31 don't know or won't ensure from sustainable $\mathrm{B}$ forestry], with galvanised fixings

Int_NoIn Paint, water-borne, walls (Dulux Wash\&Wear ${ }^{\circledR}$ s_GibDb low sheen - vivid white) $(2$ coats $/ \mathrm{m} 2)$

PR_35_31_22_94_2_ 0 1

Plasterboard $(\mathrm{GIB} \AA$ standard $10 \mathrm{~mm})$

PR_25_71_52_37_1_ 10

1

AirGap

Softwood (dressed, kiln dried) floor [from unsustainable forest management practices, PR_25_71_97_83_1_ 31 don't know or won't ensure from sustainable $\mathrm{B}$ forestry], with galvanised fixings

Plasterboard $(G I B \circledR$ standard $10 \mathrm{~mm})$ PR_25_71_52_37_1_ 10 1

Paint, water-borne, walls (Dulux Wash\&Wear ${ }^{\circledR}$ low sheen - vivid white) ( 2 coats $/ \mathrm{m} 2$ )

PR_35_31_22_94_2_ 0 $4 \_1$

Int_NoIn Paint, water-borne, walls (Dulux Wash\&Wear® s_GibSin low sheen - vivid white) $(2$ coats $/ \mathrm{m} 2)$ g

PR_35_31_22_94_2_ 0 4_1

Plasterboard (GIB ${ }^{\circledR}$ standard $\left.10 \mathrm{~mm}\right)$ PR_25_71_52_37_1_ 10 


\begin{tabular}{|c|c|c|c|}
\hline & $\begin{array}{l}\text { Softwood (dressed, kiln dried) floor [from } \\
\text { unsustainable forest management practices, } \\
\text { don't know or won't ensure from sustainable } \\
\text { forestry], with galvanised fixings }\end{array}$ & $\begin{array}{l}\text { PR_25_71_97_83_1_- } \\
\text { B }\end{array}$ & 31 \\
\hline & Plasterboard (GIB $®$ standard $10 \mathrm{~mm})$ & $\begin{array}{l}\text { PR_25_71_52_37_1 } \\
1\end{array}$ & 10 \\
\hline & $\begin{array}{l}\text { Paint, water-borne, walls (Dulux Wash\&Wear® } \\
\text { low sheen - vivid white) ( } 2 \text { coats / m2) }\end{array}$ & $\begin{array}{l}\text { PR_35_31_22_94_2 - } \\
4 \_1\end{array}$ & 0 \\
\hline \multirow[t]{6}{*}{$\begin{array}{l}\text { Int Ins } \\
\text { GibDbl }\end{array}$} & $\begin{array}{l}\text { Paint, water-borne, walls (Dulux Wash\&Wear® } \\
\text { low sheen - vivid white) ( } 2 \text { coats / m2) }\end{array}$ & PR_35_31_22_94_2 - & 0 \\
\hline & Plasterboard (GIB $®$ standard $10 \mathrm{~mm})$ & $\begin{array}{l}\text { PR_25_71_52_37_1_ } \\
1\end{array}$ & 10 \\
\hline & $\begin{array}{l}\text { Insulation ( } 90 \text { mm wall), Pink }{ }^{\circledR} \text { Batts }{ }^{\circledR} \text { Classic } \\
\text { R1.8 Wall (glass wool) }\end{array}$ & PR_25_57_6_30_1_2 & 59 \\
\hline & $\begin{array}{l}\text { Softwood (dressed, kiln dried) floor [from } \\
\text { unsustainable forest management practices, } \\
\text { don't know or won't ensure from sustainable } \\
\text { forestry], with galvanised fixings }\end{array}$ & $\begin{array}{l}\text { PR_25_71_97_83_1_- } \\
\text { B }\end{array}$ & 31 \\
\hline & Plasterboard $(\mathrm{GIB} \circledast$ standard $10 \mathrm{~mm})$ & PR_25_71_52_37_1_ & 10 \\
\hline & $\begin{array}{l}\text { Paint, water-borne, walls (Dulux Wash\&Wear® } \\
\text { low sheen - vivid white) ( } 2 \text { coats / m2) }\end{array}$ & PR_35_31_22_94_2 - & 0 \\
\hline \multirow{2}{*}{$\begin{array}{l}\text { Int_Ins } \\
\text { NoGib }\end{array}$} & AirGap & & 59 \\
\hline & $\begin{array}{l}\text { Softwood (dressed, kiln dried) floor [from } \\
\text { unsustainable forest management practices, } \\
\text { don't know or won't ensure from sustainable } \\
\text { forestry], with galvanised fixings }\end{array}$ & $\begin{array}{l}\text { PR_25_71_97_83_1_- } \\
\text { B }\end{array}$ & 31 \\
\hline \multirow[t]{3}{*}{$\begin{array}{l}\text { GarageC } \\
\text { eiling_In } \\
\text { sulated }\end{array}$} & $\begin{array}{l}\text { Softwood (dressed, kiln dried) floor [from } \\
\text { unsustainable forest management practices, } \\
\text { don't know or won't ensure from sustainable } \\
\text { forestry], with galvanised fixings }\end{array}$ & $\begin{array}{l}\text { PR_25_71_97_83_1_- } \\
\text { B }\end{array}$ & 49 \\
\hline & $\begin{array}{l}\text { Insulation (roof), Pink }{ }^{\circledR} \text { Batts }{ }^{\circledR} \text { Classic R2.6 } \\
\text { Ceiling (glass wool) }\end{array}$ & $\underset{3}{\text { PR_25_57_6_30_1_3 }}$ & 91 \\
\hline & Plasterboard (GIB ${ }^{\circledR}$ standard $\left.13 \mathrm{~mm}\right)$ & $\begin{array}{l}\text { PR_25_71_52_37_1_ } \\
2\end{array}$ & 13 \\
\hline
\end{tabular}




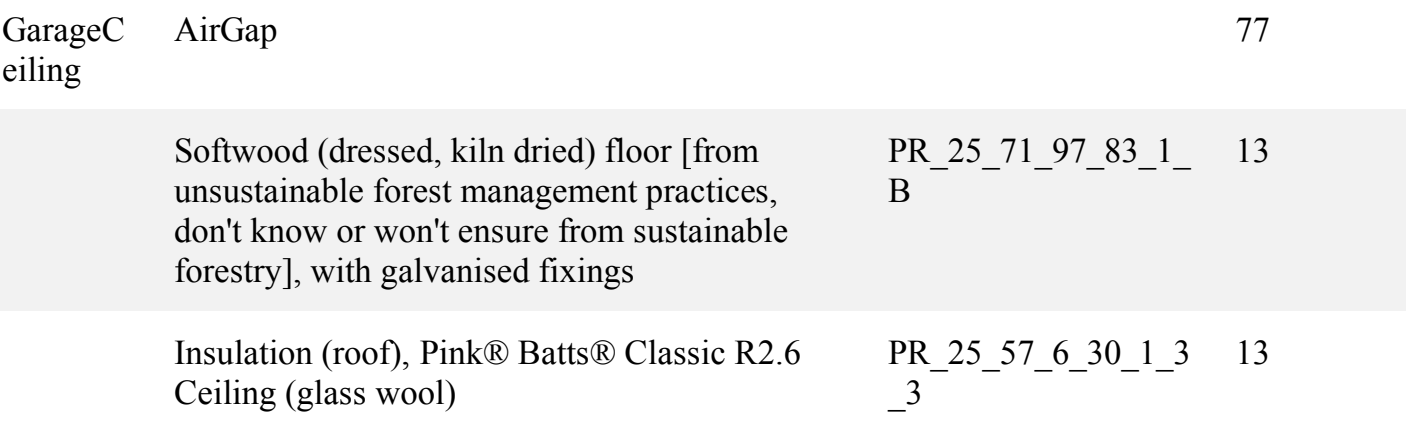

\section{D.3 House W}

\section{Table D-4 House W unique BIM modelling inputs}

\begin{tabular}{|c|c|c|c|}
\hline Family & Material & PR Code & $\begin{array}{l}\text { Thickness } \\
(\mathrm{mm})\end{array}$ \\
\hline \multirow[t]{2}{*}{$\begin{array}{l}\text { Ext_NoI } \\
\text { nsul_No } \\
\text { Gib }\end{array}$} & $\begin{array}{l}\text { Softwood (dressed, kiln dried) floor [from } \\
\text { unsustainable forest management practices, } \\
\text { don't know or won't ensure from sustainable } \\
\text { forestry], with galvanised fixings }\end{array}$ & $\begin{array}{l}\text { PR_25_71_97_83_1_- } \\
\text { B }\end{array}$ & 31 \\
\hline & Airgap & & 59 \\
\hline \multirow{7}{*}{$\begin{array}{l}\text { Ext_Insu } \\
\text { lated_Ab } \\
\text { odo_No } \\
\text { Gib }\end{array}$} & $\begin{array}{l}\text { Paint (exterior), water-borne, for timber ( } 2 \text { coats } \\
\text { / m2) }\end{array}$ & $\begin{array}{l}\text { PR } 35 \_31 \_22 \_94 \_2- \\
1 \_1\end{array}$ & 0 \\
\hline & $\begin{array}{l}\text { Paint (exterior), water-borne, primer/sealer (1 } \\
\text { coat / m2) }\end{array}$ & $\begin{array}{l}\text { PR } 35 \_31 \_22 \_94 \_1- \\
1 \_1\end{array}$ & 0 \\
\hline & $\begin{array}{l}\text { Cladding, weatherboard, all profiles (fibre } \\
\text { cement, } 16 \mathrm{~mm} \text { thickness) }\end{array}$ & PR_25_71_14_30_7 & 20 \\
\hline & Airgap & & 18 \\
\hline & $\begin{array}{l}\text { Softwood (dressed, kiln dried) floor [from } \\
\text { unsustainable forest management practices, } \\
\text { don't know or won't ensure from sustainable } \\
\text { forestry], with galvanised fixings }\end{array}$ & $\begin{array}{l}\text { PR_25_71_97_83_1_- } \\
\text { B }\end{array}$ & 2 \\
\hline & Membrane, building wrap, polyethylene (PE) & PR_15_57_30_47_1 & 0 \\
\hline & $\begin{array}{l}\text { Softwood (dressed, kiln dried) floor [from } \\
\text { unsustainable forest management practices, } \\
\text { don't know or won't ensure from sustainable } \\
\text { forestry], with galvanised fixings }\end{array}$ & $\begin{array}{l}\text { PR_25_71_97_83_1_- } \\
\text { B }\end{array}$ & 31 \\
\hline
\end{tabular}


Insulation (90 mm wall), Pink ${ }^{\circledR}$ Batts ${ }^{\circledR}$ Classic R1.8 Wall (glass wool)

PR_25_57_6_30_1_2 59 $-1-1$

Ext_Bric Brick, clay

PR_20_93_52_15

$\mathrm{k}$

Airgap

25

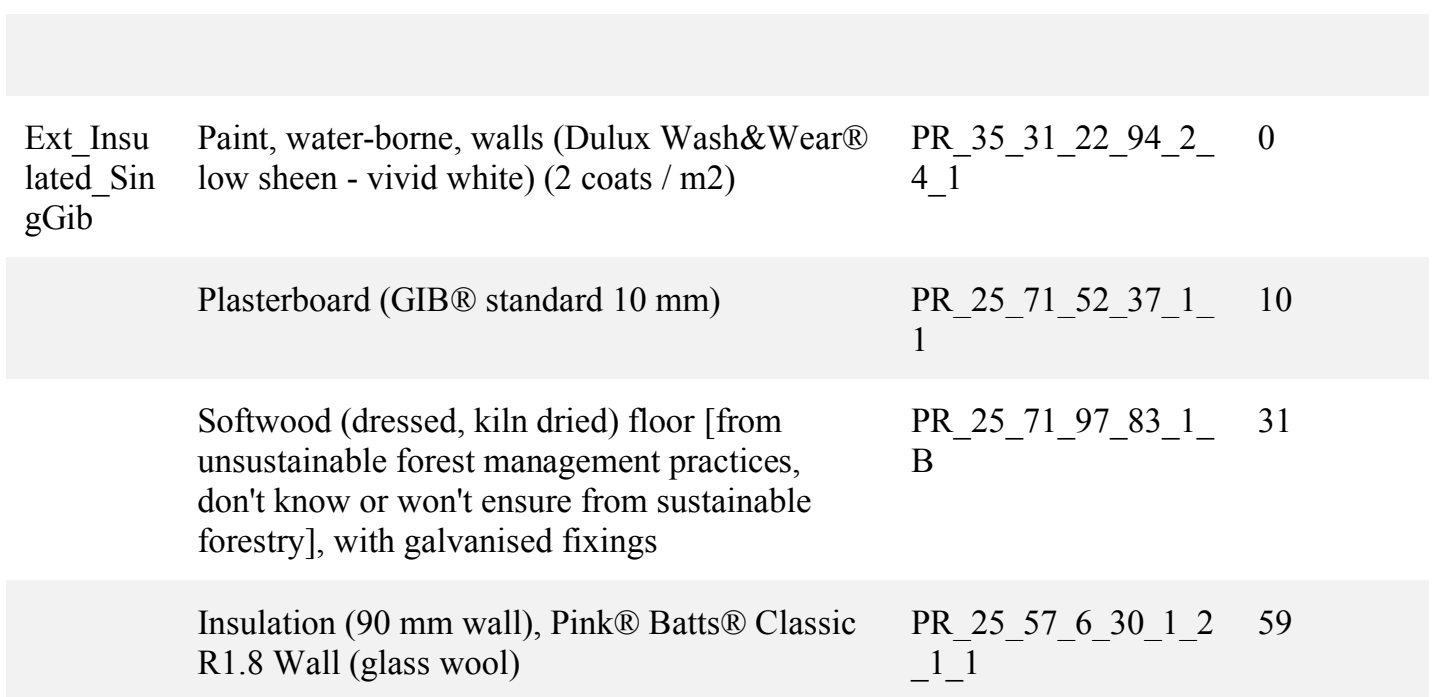

Ext_Insu Paint (exterior), water-borne, for timber (2 coats lated_Ab / m2

odo

PR_35_31_22_94_2_ 0

1 1

Paint (exterior), water-borne, primer/sealer (1

PR_35_31_22_94_1_ 0 coat $/ \mathrm{m} 2$ )

$1 \_1$

Cladding, weatherboard, all profiles (fibre

PR_25_71_14_30_7 20 cement, $16 \mathrm{~mm}$ thickness)

Airgap

18

Softwood (dressed, kiln dried) floor [from unsustainable forest management practices, don't know or won't ensure from sustainable PR_25_71_97_83_1_ 2 forestry], with galvanised fixings

Membrane, building wrap, polyethylene (PE) PR_15_57_30_47_1 0

Softwood (dressed, kiln dried) floor [from unsustainable forest management practices, PR_25_71_97_83_1_ 31 don't know or won't ensure from sustainable $\mathrm{B}$ forestry], with galvanised fixings

Insulation (90 mm wall), Pink ${ }^{\circledR}$ Batts ${ }^{\circledR}$ Classic PR_25_57_6_30_1_2 59 R1.8 Wall (glass wool) 


\begin{tabular}{|c|c|c|c|}
\hline & Plasterboard (GIB $®$ standard $10 \mathrm{~mm})$ & $\begin{array}{l}\text { PR_25_71_52_37_1_ } \\
1\end{array}$ & 10 \\
\hline & $\begin{array}{l}\text { Paint, water-borne, walls (Dulux Wash\&Wear }{ }^{\circledR} \\
\text { low sheen - vivid white) ( } 2 \text { coats / m2) }\end{array}$ & $\begin{array}{l}\text { PR_35_31_22_94_2 } \\
4 \_1\end{array}$ & 0 \\
\hline \multirow[t]{2}{*}{$\begin{array}{l}\text { Ext_Insu } \\
\text { lated_No } \\
\text { Gib_}\end{array}$} & $\begin{array}{l}\text { Softwood (dressed, kiln dried) floor [from } \\
\text { unsustainable forest management practices, } \\
\text { don't know or won't ensure from sustainable } \\
\text { forestry], with galvanised fixings }\end{array}$ & $\begin{array}{l}\text { PR_25_71_97_83_1_ } \\
\text { B }\end{array}$ & 31 \\
\hline & $\begin{array}{l}\text { Insulation ( } 90 \mathrm{~mm} \text { wall), Pink }{ }^{\circledR} \text { Batts }{ }^{\circledR} \text { Classic } \\
\text { R1.8 Wall (glass wool) }\end{array}$ & $\begin{array}{l}\text { PR_25_57_6_30_1_2 } \\
-1 \_1\end{array}$ & 59 \\
\hline \multirow[t]{5}{*}{$\begin{array}{l}\text { Int_GibD } \\
\text { bl }\end{array}$} & $\begin{array}{l}\text { Paint, water-borne, walls (Dulux Wash\&Wear }{ }^{\circledR} \\
\text { low sheen - vivid white) }(2 \text { coats } / \mathrm{m} 2)\end{array}$ & $\begin{array}{l}\text { PR_35_31_22_94_2 }- \\
4 \_1\end{array}$ & 0 \\
\hline & Plasterboard (GIB ${ }^{\circledR}$ standard $\left.10 \mathrm{~mm}\right)$ & $\begin{array}{l}\text { PR_25_71_52_37_1_- } \\
1\end{array}$ & 10 \\
\hline & $\begin{array}{l}\text { Softwood (dressed, kiln dried) floor [from } \\
\text { unsustainable forest management practices, } \\
\text { don't know or won't ensure from sustainable } \\
\text { forestry], with galvanised fixings }\end{array}$ & $\begin{array}{l}\text { PR_25_71_97_83_1_ } \\
\text { B }\end{array}$ & 31 \\
\hline & Airgap & & 59 \\
\hline & Plasterboard $(\mathrm{GIB} \otimes$ standard $10 \mathrm{~mm})$ & $\begin{array}{l}\text { PR_25_71_52_37_1_ } \\
1\end{array}$ & 10 \\
\hline \multirow[t]{3}{*}{$\begin{array}{l}\text { Int_Sing } \\
\text { Gib }\end{array}$} & Plasterboard $(\mathrm{GIB} \otimes$ standard $10 \mathrm{~mm})$ & $\begin{array}{l}\text { PR_25_71_52_37_1_ } \\
1\end{array}$ & 10 \\
\hline & $\begin{array}{l}\text { Softwood (dressed, kiln dried) floor [from } \\
\text { unsustainable forest management practices, } \\
\text { don't know or won't ensure from sustainable } \\
\text { forestry], with galvanised fixings }\end{array}$ & $\begin{array}{l}\text { PR_25_71_97_83_1_ } \\
\text { B }\end{array}$ & 31 \\
\hline & Airgap & & 59 \\
\hline \multirow[t]{2}{*}{$\begin{array}{l}\text { Int_NoGi } \\
\mathrm{b}\end{array}$} & $\begin{array}{l}\text { Softwood (dressed, kiln dried) floor [from } \\
\text { unsustainable forest management practices, } \\
\text { don't know or won't ensure from sustainable } \\
\text { forestry], with galvanised fixings }\end{array}$ & $\begin{array}{l}\text { PR_25_71_97_83_1_- } \\
\text { B }\end{array}$ & 59 \\
\hline & Airgap & & 31 \\
\hline
\end{tabular}




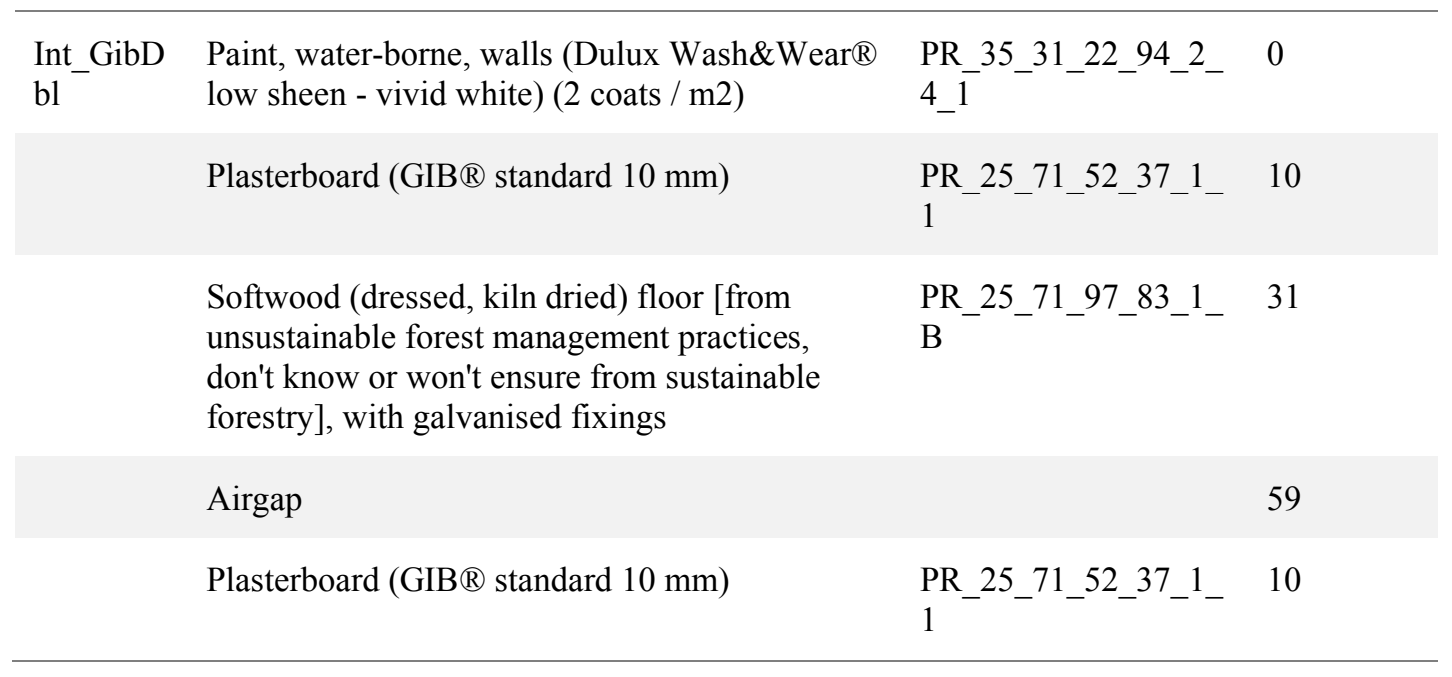

\section{D.4 Construction changes}

Table D-5 Construction changes BIM modelling inputs - ceiling

\begin{tabular}{|c|c|c|c|}
\hline Change & Material & PR Code & $\begin{array}{l}\text { Thickness } \\
\text { (mm) }\end{array}$ \\
\hline $\begin{array}{l}\text { Building } \\
\text { Code } \\
\text { minimum }\end{array}$ & $\begin{array}{l}\text { Insulation (roof), Pink }{ }^{\circledR} \text { Batts }{ }^{\circledR} \text { Classic R2.6 } \\
\text { Ceiling (glass wool) }\end{array}$ & $\underset{-}{\text { PR }}$ 25_57_6_30_1_3 & 74.75 \\
\hline $\begin{array}{l}\text { BRANZ } \\
\text { Better }\end{array}$ & $\begin{array}{l}\text { Insulation (roof), Pink }{ }^{\circledR} \text { Batts }{ }^{\circledR} \text { Classic R3.2 } \\
\text { Ceiling (glass wool) }\end{array}$ & PR_25_57_6_30_1_3 & 74.75 \\
\hline $\begin{array}{l}\text { BRANZ } \\
\text { Best }\end{array}$ & $\begin{array}{l}\text { Insulation (roof), Pink }{ }^{\circledR} \text { Batts }{ }^{\circledR} \text { Classic R3.6 } \\
\text { Ceiling (glass wool) }\end{array}$ & PR 6 -25_57_6_30_1_3 & 107.25 \\
\hline Passivhaus & $\begin{array}{l}\text { Insulation (roof), Pink }{ }^{\circledR} \text { Batts }{ }^{\circledR} \text { Classic R3.2 } \\
\text { Ceiling (glass wool) }\end{array}$ & PR $\_$25_57_6_30_1_3 & 74.75 \\
\hline $\begin{array}{l}\text { Voluntary } \\
\text { standard }\end{array}$ & $\begin{array}{l}\text { Insulation (roof), Pink }{ }^{\circledR} \text { Batts }{ }^{\circledR} \text { Classic R7.0 } \\
\text { Ceiling (glass wool) }\end{array}$ & PR 25 - 25 & 195 \\
\hline
\end{tabular}

Table D-6 Construction changes BIM modelling inputs - wall

\begin{tabular}{|c|c|c|c|}
\hline Change & Material & PR Code & $\begin{array}{l}\text { Thickness } \\
(\mathbf{m m})\end{array}$ \\
\hline $\begin{array}{l}\text { Building } \\
\text { Code } \\
\text { minimum }\end{array}$ & $\begin{array}{l}\text { Insulation }\left(90 \text { mm wall), Pink }{ }^{\circledR} \text { Batts }{ }^{\circledR}\right. \\
\text { Classic R1.8 Wall (glass wool) }\end{array}$ & $\begin{array}{l}\text { PR_25_57_6_30_1_2 } \\
-1 \_1\end{array}$ & 58.5 \\
\hline $\begin{array}{l}\text { BRANZ } \\
\text { Better }\end{array}$ & $\begin{array}{l}\text { Insulation }\left(90 \text { mm wall), Pink }{ }^{\circledR} \text { Batts }{ }^{\circledR}\right. \\
\text { Classic R2.2 Wall (glass wool) }\end{array}$ & PR $1 \_25 \_57 \_6 \_30 \_1 \_2$ & 58.5 \\
\hline $\begin{array}{l}\text { BRANZ } \\
\text { Best }\end{array}$ & $\begin{array}{l}\text { Insulation (140 mm wall), Pink }{ }^{\circledR} \text { Batts }{ }^{\circledR} \\
\text { Ultra }{ }^{\circledR} \text { R4.0 } 140 \mathrm{~mm} \text { Wall (glass wool) }\end{array}$ & $\begin{array}{l}\text { PR } 25 \_57 \_6 \_30 \_1 \_2 \\
2 \_4\end{array}$ & 91 \\
\hline
\end{tabular}


A Life Cycle Assessment of Medium Density Houses in New Zealand

\begin{tabular}{|c|c|c|c|}
\hline Passivhaus & $\begin{array}{l}\text { Insulation ( } 140 \mathrm{~mm} \text { wall), Pink }{ }^{\circledR} \text { Batts }{ }^{\circledR} \\
\text { Ultra }{ }^{\circledR} \text { R3.2 } 140 \mathrm{~mm} \text { Wall (glass wool) }\end{array}$ & $\begin{array}{l}\text { PR_25_57_6_30_1_2 } \\
\text { 2_- } 1\end{array}$ & 91 \\
\hline $\begin{array}{l}\text { Voluntary } \\
\text { standard }\end{array}$ & $\begin{array}{l}\text { Insulation ( } 140 \mathrm{~mm} \text { wall), Pink }{ }^{\circledR} \text { Batts }{ }^{\circledR} \\
\text { Ultra }{ }^{\circledR} \text { R4.0 } 140 \mathrm{~mm} \text { Narrow Wall (glass } \\
\text { wool) }\end{array}$ & $\begin{array}{l}\text { PR } 25557 \_6 \_30 \_1 \_2 \\
-2 \_5\end{array}$ & 117 \\
\hline
\end{tabular}

